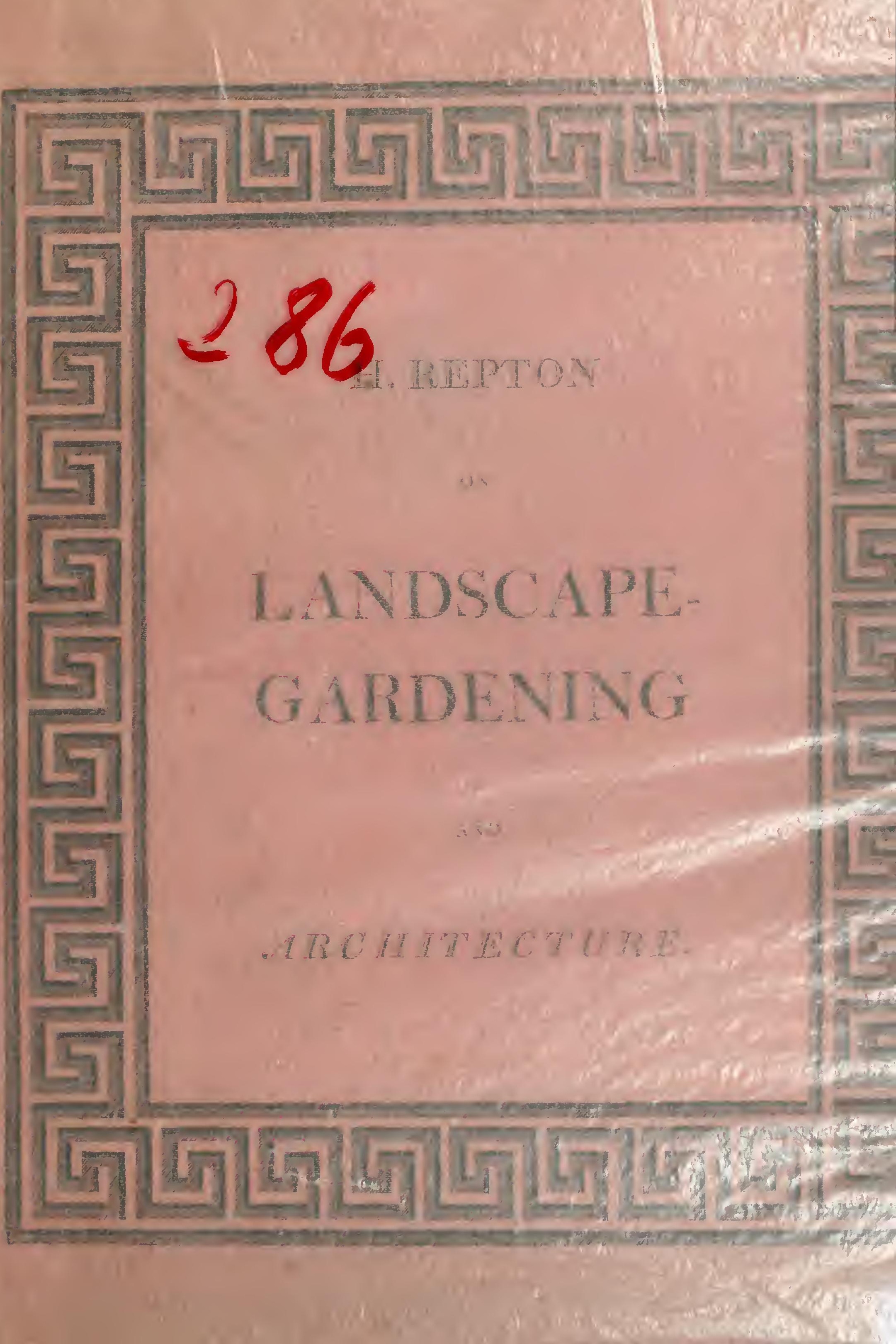


Digitized by the Internet Archive in 2010 with funding from

Research Library, The Getty Research Institute 



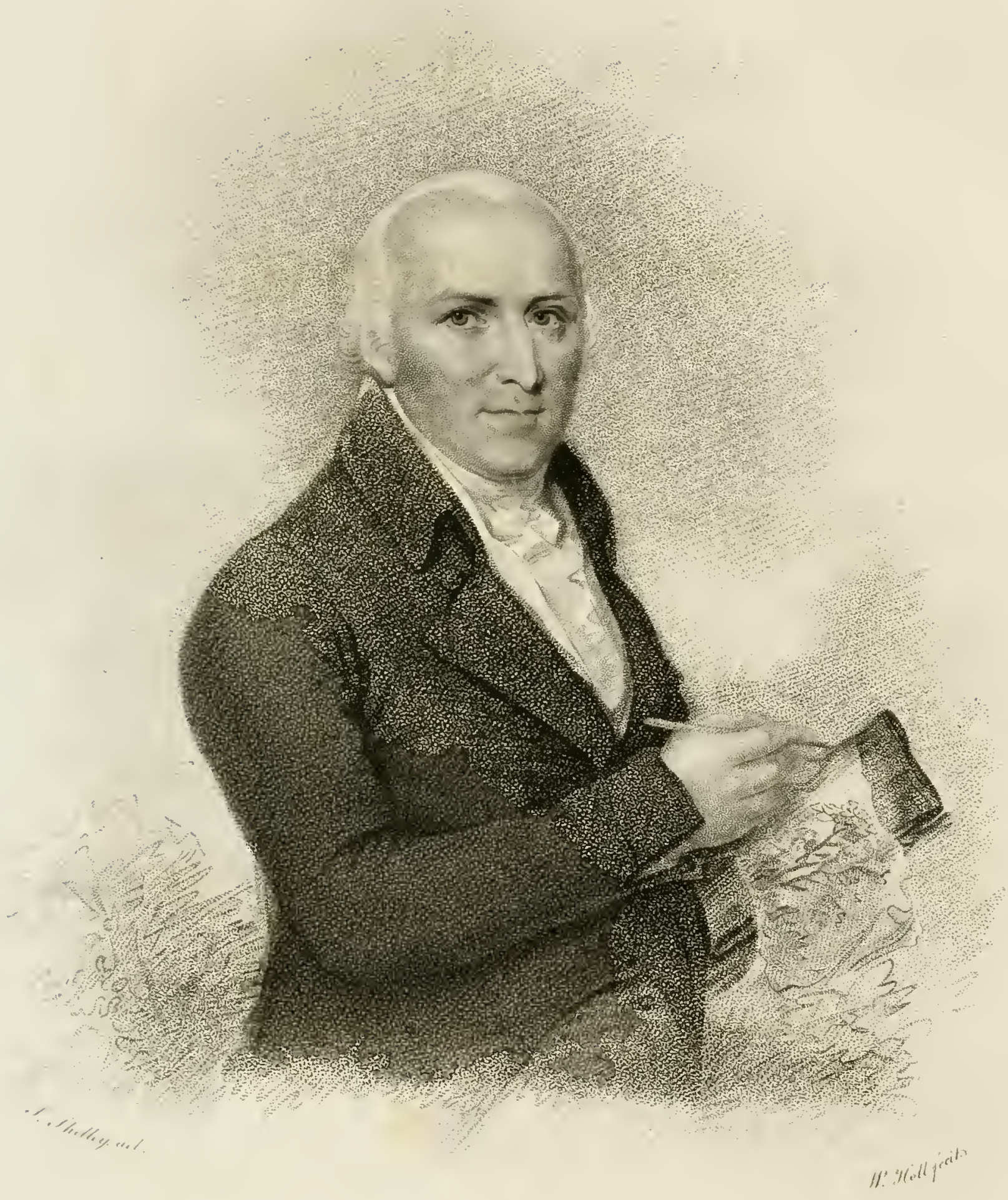

HOYTHRY RPP'POY

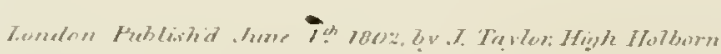




\section{OBSERVATIONS}

ON

\section{THE THEORY AND PRACTICE}

oF

\section{ILandscape Gardening.}

I N CLU DING

SOME REMARKS

ON

\section{GRECIAN AND GOTHIC ARCHITECTURE,}

COLLECTED FROM

VARIOUS MANUSCRIPTS,

IN THE POSSESSION OF

THE DIFFERENT NOBLEMEN AND GENTLEMEN, FOR WHOSE USE THEY WERE ORIGINALLY WRITTEN;

THE WHOLE TENDING TO ESTABLISH FIXED PRINCIPLES IN THE RESPECTIVE ARTS.

By H. REPTON, Eso.

LONDON:

PRINTED BY T. BENSLEY, BOLT COURT,

FOIR J. TAYLOR, AT THE ARCHITECTURAL LIBRARY, HIGH HOIBORN.

1805. 



\title{
THE KING,
}

WITH

\author{
HIS MAJESTY'S \\ MOST GRACIOUS PERMISSION,
}

\section{THIS WORK}

IS HUMBLY INSCRIBED BY

\section{HIS MAJESTY'S}

MOST FAITHFUL, OBEDIEN'T,

AND HUMBLE SUBJECT,

HUMPHRY REPTON.

Hare Street, near Romford, Dec. 31, 1802. 



\section{ADVERTISEMENT}

EXPLAINING THE NATURE OF THIS WORK.

SEVEN years have now elapsed since the publication of my "Sketches and Hints on Landscape Gardening," during which, by the continued duties of my profession, it is reasonable to suppose much experience has been gained and many principles established. Yet so difficult is the application of any rules of $\mathrm{ART}_{\mathrm{RT}}$ to the works of $\mathrm{N}_{\mathrm{ATU}} \mathrm{RE}$, that I do not presume to give this Book any higher title, than "Observations tending to establish faxed Principles in the Ait of Landscape Gardening."

After various attempts to arrange systematically the matter of this volume, I found the difficulties increase with the number of the subjects; and although each was originally treated with order and method in a separate state, yet in combining many of these subjects, the same order and method could not easily be preserved. I have, however, with as much attention to arrangement as my professional duties would admit, collected such observations as may best vindi- 
cate the Art of Landscape Gardening from the imputation of being founded on caprice and fashion: occasionally adding such matter as I thought might suit the various taste or inclinations of various readers. Some delight in speculative opinions, some in experimental facts; others prefer description, others look for novelty, and some, perhaps, for what I hope will not be found in this Work, impracticable theories.

The present volume neither supersedes, nor contradicts my former work, neither is it a repetition nor a continuation; but to avoid the oblong and inconvenient shape of that book the present volume is printed under a different form and title, because I am less ambitious of publishing a book of beautiful prints, than a book of precepts: I must therefore intreat that the plates be rather considered as necessary than ornamental; they are introduced to illustrate the arguments, rather than to attract the attention. I wish to make my appeal less to the eye, than to the understanding.

In excuse for the frequent use of the first personal pronoun, it should be remembered, that when an author relates his own theory, and records his own practice, it is hardly possible to avoid the language of egotism.

When called upon for my opinion concerning the improvement of a place, I have generally delivered it in writing, bound in a small book, containing maps and sketches to explain the alterations proposed: this is called the Red Book of the place; and thus my opinions have been diffused over the kingdom in nearly two hundred such manuscript volumes. 


\section{7}

From many of these, with the permission of their respective proprietors, this volume has been composed; sometimes adopting the substance, and sometimes quoting the words of the Red Book.

The severity of criticism is seldom abated in consideration of the circumstances under which a work is produced; yet should it be objected that some parts of this volume are unequal, the author can plead in excuse, that the whole has been written in a carriage during his professional journeys from one place to another, and being seldom more than three days together in the same place, the difficulty of producing this volume, such as it is, can hardly be conceived by those who enjoy the blessings of stationary retirement, or a permanent home.

The Plates are fac similes of my sketches in the original Red Books, and have been executed by various artists, whose names are affixed to each; to whom I thus publickly express my acknowledgments, and when tempted to complain of delay, disappointment, and want of punctuality in artists, I am checked by the consideration that works of genius cannot be restricted by time like the productions of daily labour. ${ }^{2}$

The necessity of blending Architecture with Landscape Gardening, mentioned in my former work, induced me to

a The art of colouring plates in imitation of drawings has been so far improved of late, that I have pleasure in recording my obligations to $\mathrm{Mr}$. Clarke, under whose directions a number of children have been employed to eurich this rolume. 
turn the studies of one of my sons to that auxiliary part of my profession; it is therefore to the assistance of Mr. John Adey Repton that I am indebted for many valuable ornaments to this volume. His name has hitherto been little known as an architect, because it was suppressed in many works begun in that of another person, to whom I freely, unreservedly, and confidentially gave my advice and assistance, while my son aided with his architectural knowledge and his pencil to form plans and designs from which we have derived neither fame nor profit; but amongst the melancholy evils to which human life is subject, the most excruciating to a man of sensibility is the remembrance of disappointed hope from misplaced confidence.

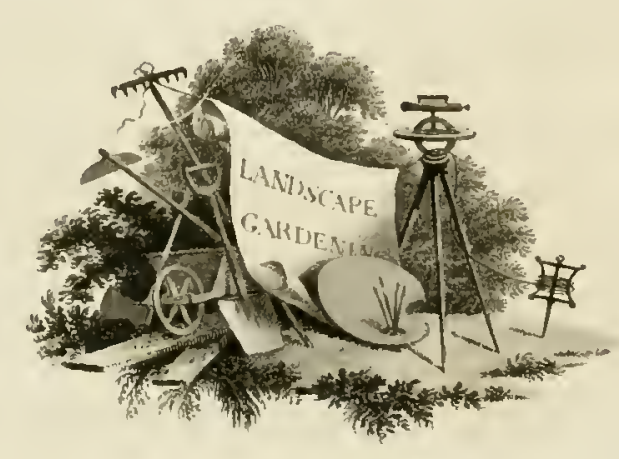




\section{P R E F A C E,}

CONTAINING

\section{SOME OBSERVATIONS ON TASTE.}

Is every other polite Art, there are certain established rules or general principles, to which the professor may appeal in support of his opinions; but in Landscape Gardening erery one delivers his scntiments, or displays his taste, as whim or caprice may dictate, without having studied the subject, or even thought it capable of being reduced to any fixed rules. Hence it has been doubted, whether each proprietor of his own estate, may not be the most proper person to plan its improrcment.

Had the art still continued under'the direction of working gardeners, or nurserymen, the proprictor might supersede the necessity of such landscape gardeners, provided he had previously made this art his study; but not, (as it is frequently asserted) because the gentleman who constantly resides at his place, must be a better judge of the means of improving it, than the professor whose visits are only occasional: for if this reason for a preference were granted, we might with equal truth assert, that the constant companion of a sick man lias an advantage orer his physician.

Improrements may be suggested by any one, but the professor only acquires a knowledge of effects before they are produced, and a facility in producing them by various methods, expedients, and resources, the result of study, obserration, and experience. He knows what can, and what can not be accomplished within certain limits. He ought to know what to adopt, 
and what to reject; he must endearour to accommodate his plans to the wishes of the person who consults him, ${ }^{a}$ although, in some cases, they may not strictly accord with his own taste.

Good sense may exist without good taste, ${ }^{\text {b }} \mathrm{yel}$, from their intimate connexion, many persons are as much offended at having their taste, as their understanding, disputed; benee the most ignorant being generally the most obstinate, I have occasionally found that as " a little learning is a dangerous thing," a little taste is a troublesome one.

Both taste and understanding require cultiration and improvement. Natural taste, like natural genius, may exist to a certain degree, but wilhout study, observation, and experience, they lead to error: there is, perhaps, no circumstance which so strongly manks the decline of public taste, as the cxtraragant applause bestowed on early efiorts of unlettered and uncultivated genius: extraordinary instances of prematurity deserve to be patronised, fostered, and enconraged, provided they excite admiration from excellence, independent of peculiar circumstances; but the public taste is endangered by the circulation of such crude productions as are curious only from the youth or ignorance of their authors. Such an apology to the learned will not compensate for the defects of granmar in Poetry, nor to the scientific artist for the defects of proportion and design in Arehitecture; while the inconechess of such efforts is hardly visible to the bulk of mankind, incapable of comparing their excellence with works of established reputation. 'Thus in poetry, in painting, and in architecture, false taste is propagated by the sanction gizen to mediocrity.

a Thus before a louse is planned, the proprietor must describe the kind of house he wishes to build. The architect is to consider what must be had, and what may be dispensed with. He ouglat to keep his plan as scrupulously within the expence proposed, as within the linits of the ground he is to build upons: he is, in short, to enter into the riews, the wishes, and the ideas of the gentleman who wilt inhabit the house proposed.

b The requisites of laste are weit described by Dr. Beattic, muler five distinct heads. 1. "A lively and corred imagination; $\mathcal{O}$. lle power of distinct apprehension: 3. the capacity "of heing easily, strongly, and agreeably affected with sublimily, beanty, harmony, correct " imitation, \&cc.; 4. sympathy, or sensibility of heart; and 5. judgment or good sense, which "6 is the principal thing, and may not rery improperly be said to comprehend all the rest." 
Its dangerous tendency, added to its frequency, must plead my excuse for taking notice of the following rulgar mode of expression: "I do not pro"fess to understand these matters, but I know what pleases me." This may be the standard of perfection with those who are content to gratify their own taste without inquiring how it may affect others; but the man of good taste endeavours to investigate the causes of the pleasure he receives, and to inquire whether others receire pleasure also. He knows that the same principles which direct taste in the polite arts, direct the judgment in morality; in short, that a knowledge of what is good, what is bad, and what is indifferent, whether in actions, in manners, in language, in arts, or science, constitutes the basis of good taste, and marks the distinction between the higher ranks of polished society, and the inferior orders of mankind, whose daily labours allow no leisure for other enjoyments than those of mere sensual, individual, and personal gratification.

"In most countries novelty, in every form of extravagance, broad humour, " and caricatures, aftord the greatest delight to the populace. This preference " is congenial with their love of coarse pleasures, and distinguishes the mul"titude from the more polite classes of every nation. The inferior orders of "society are therefore disqualificd from deciding upon the merits of the fine " arts; and the department of taste is consequently confined to persons en"lightened by education and conversant with the world, whose views of na" ture, of art, and of mankind, are enlarged and elevated by an extensive "range of observation." Kett's Elements of General Knožledge.

Those who delight in depreciating the present by comparisons with former times, may, perhaps, observe a decline of taste in many of the polite arts; but surely in architecture and gardening, the present rera furnishes more examples of attention to comfort and convenience than are to be found in the plans of Palladio, Vitruvius Britannicus, or Le Nôtre, where, in the display of useless symmetry, the requisites of habitation are often forgot. The leading feature in the good taste of modern times, is the just sense of GENERAL UTILITI". 
So difficult is the task of giving general satisfaction, that I am aware I shall cause offence to some by mentioning their places; to others, by not mentioning them: to some, by having said too much, to others, by having said too little. Yet to establish principles from experience, and theory from practice, it was necessary to quote examples; I have therefore prefixed a list of those places only to which I refer in the course of the work.

It will, perhaps, be observed, that some of these places are of great extent and importance, whilst others are so inconsiderable that they might have been omitted. But to the proprietor his own place is always important; and to the professor a small place may serve to illustrate the principles of his art: and his whole attention and abilities should be exerted, whether he is to build a palace or a cottage, to improve a forest or a single field. Well knowing that every situation has its facilities and its difficulties, I have never considered how many acres I was called upon to improve, but how much I could improve the subject before me, and have occasionally experienced more pleasure and more dificulties in a small flower garden, than amidst the wildest scenery of rocks and mountains.

Some of the places here enumerated are subjects which I have visited only once: others from the death of the proprietors, the change of property, the difference of opinions, or a variety of other causes, may not, perhaps, have been finished according to my suggestions. It would be endless to point out the circumstances in each place where my plans have been partially adopted or partially rejected. To claim as my own, and to arrogate to myself all that I approve at each place, would be doing injustice to the taste of the several proprietors who may have suggested improvements. On the other hand, I should be sorry, that to my taste should be attributed all the absurdities which fashion, or custom, or whim, may have occasionally introduced in some of these places. I can only advise, I do not pretend to dictate, and, in many cases, must rather conform to what has been ill begun, than attempt to pull to pieces and re-model the whole Work.

" Non mili res sed me rebus subjungere conor:"

To aroid the imputation of having fully approved, where I have found it necessary mcrely to assent, I shall here beg leave to subjoin my opinion negalirely, as the only means of doing so without giving offence to those from whom I may differ; at the same time, with the humility of experience, I am 
conscious my opinion may, in some cases, be deemed wrong. The same motives which induce me to mention what I recommend, will also justify me in mentioning what I disapprove; a few observations, therefore, are subjoined to mark those errors, or absurdities in modern gardening and architecture, to which I have nerer willingly subscribed, and from which it will easily be ascertained how much of what is called the improvement of any place in the list, may properly be attributed to my advice. It is rather upon my opinions in writing, than on the partial and imperfect manner in which my plans have sometimes been executed, that I wish my Fame to be established.

\section{OBJECTION No. 1.}

There is no error more prevalent in modern gardening, or more frequently carried to excess, than taking away hedges to unite many small fields into one extensive and naked lawn, before plantations are made to give it the appearance of a park; and where ground is subdivided by sunk fences, imaginary freedom is dearly purchased at the expence of actual confinement.

No. 2.

'The baldness and nakedness round a house is part of the same mistaken system, of concealing fences to gain extent. A palace, or even an elcgant villa, in a grass field, appears to me incongruous; yet I have seldom had sufficient influence to correct this common error.

No. 3.

An approach which does not evidently lead to the house, or which does not take the shortest course, cannot be right.

$$
\text { No. } 4 .
$$

A poor man's cottage, divided into what is called a pair of lodges, is a mistaken expedient to mark importance in the entrance to a Park.

$$
\text { No. } 5 .
$$

'The entrance gate should not be visible from the mansion, unless it opens into a court yard. 
No. 6.

The plantation surrounding a place, called a Belt, I have never advised; nor have I ever willingly marked a drive, or walk, completely round the verge of a park, except in small villas where a dry path round a person's own field, is always more interesting to him than any other walk.

\section{No. 7.}

Small plantations of trees, surrounded by a fence, are the best expedients to form groupes, because trees planted singly seldom grow well; neglect of thinning and of removing the fence, has produced that ugly deformity called al Clump.

\section{No. 8.}

Water on an eminence, or on the side of a hill, is among the most common crrors of Mr. Brown's followers: in numerous instances I have been allowed to remove such pieces of water from the hills to the valleys; but in many my advice has not prevailed.

No. 9.

Deception may be allowable in imitating the works of NATURE; thus artificial rivers, lakes, and rock scenery, can only be great by deception, and the mind acquiesces in the fraud after it is detected: but in works of ART every trick ought to be avoided. Sham churches, sham ruins, sham bridges, and every thing which appears what it is not, disgusts when the trick is discovered.

\section{No. 10.}

In buildings of erery kind the character should be strictly observad. No ineongruous mixture can be justified. 'T'o add Grecian to Gothic, or Gothic to Grecian, is cqually absurd; and a sharp pointed arch to a garden gate, or a dairy window, however frequently it occurs, is not less offensive than Grecian architecture, in which the standard rules of relative proportion are neglected or violated.

The perfection of landscape gardening consists in the fullest attention to these principles, Utility, Proportion, and Unity, or harmony of paris to the whole. 


\section{LIST OF THE PLACES}

REFERRED TO AS EXAMPLLS.

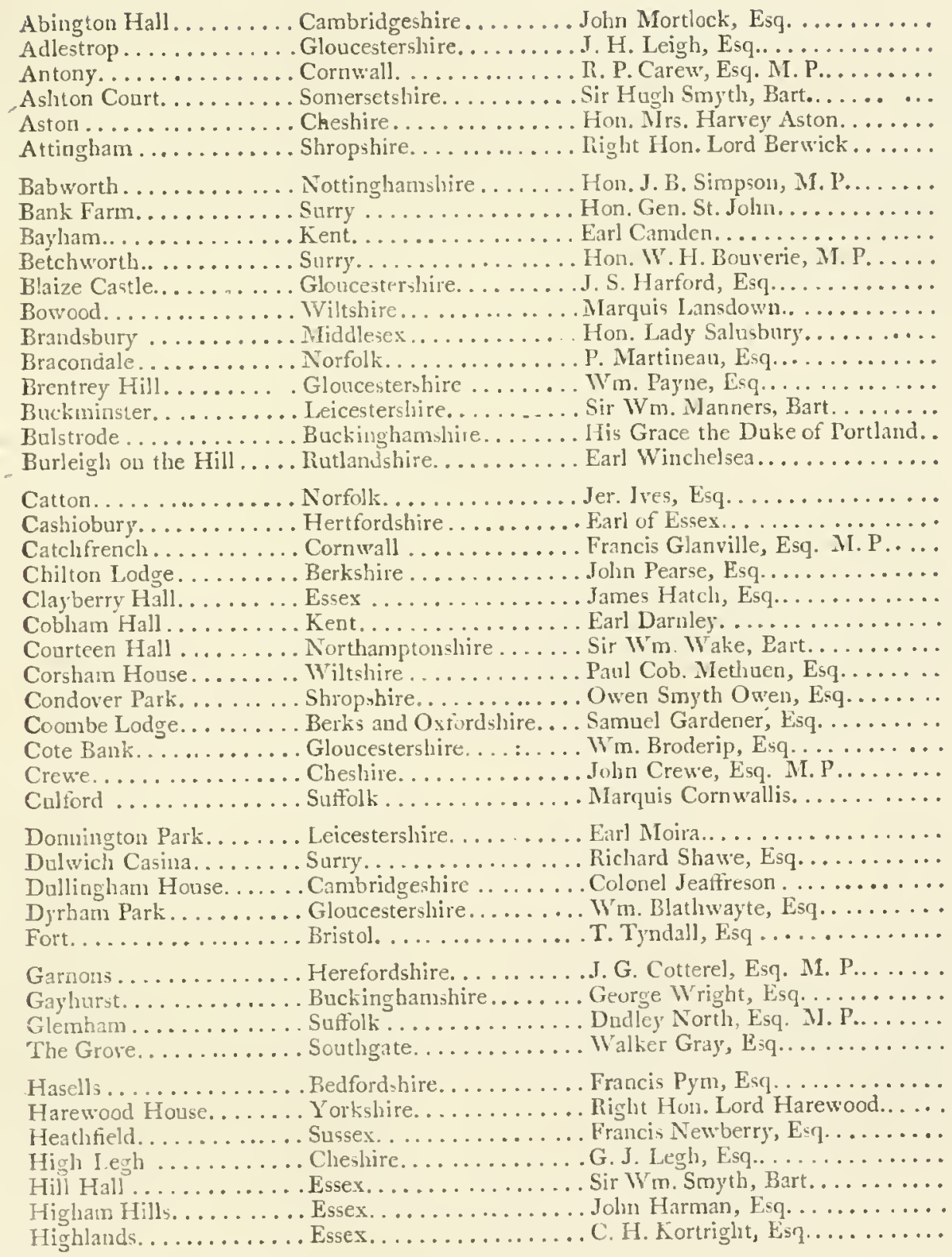




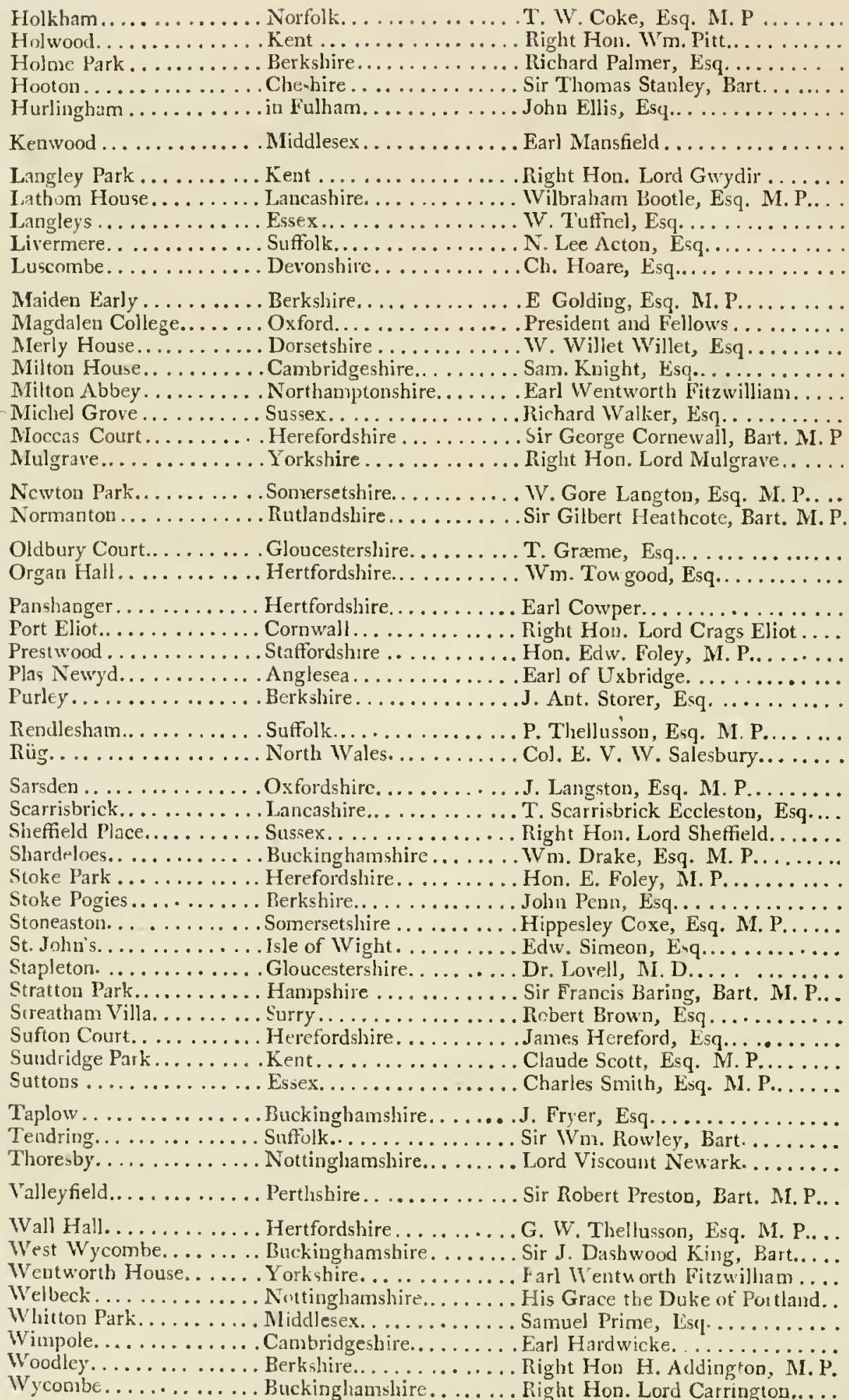




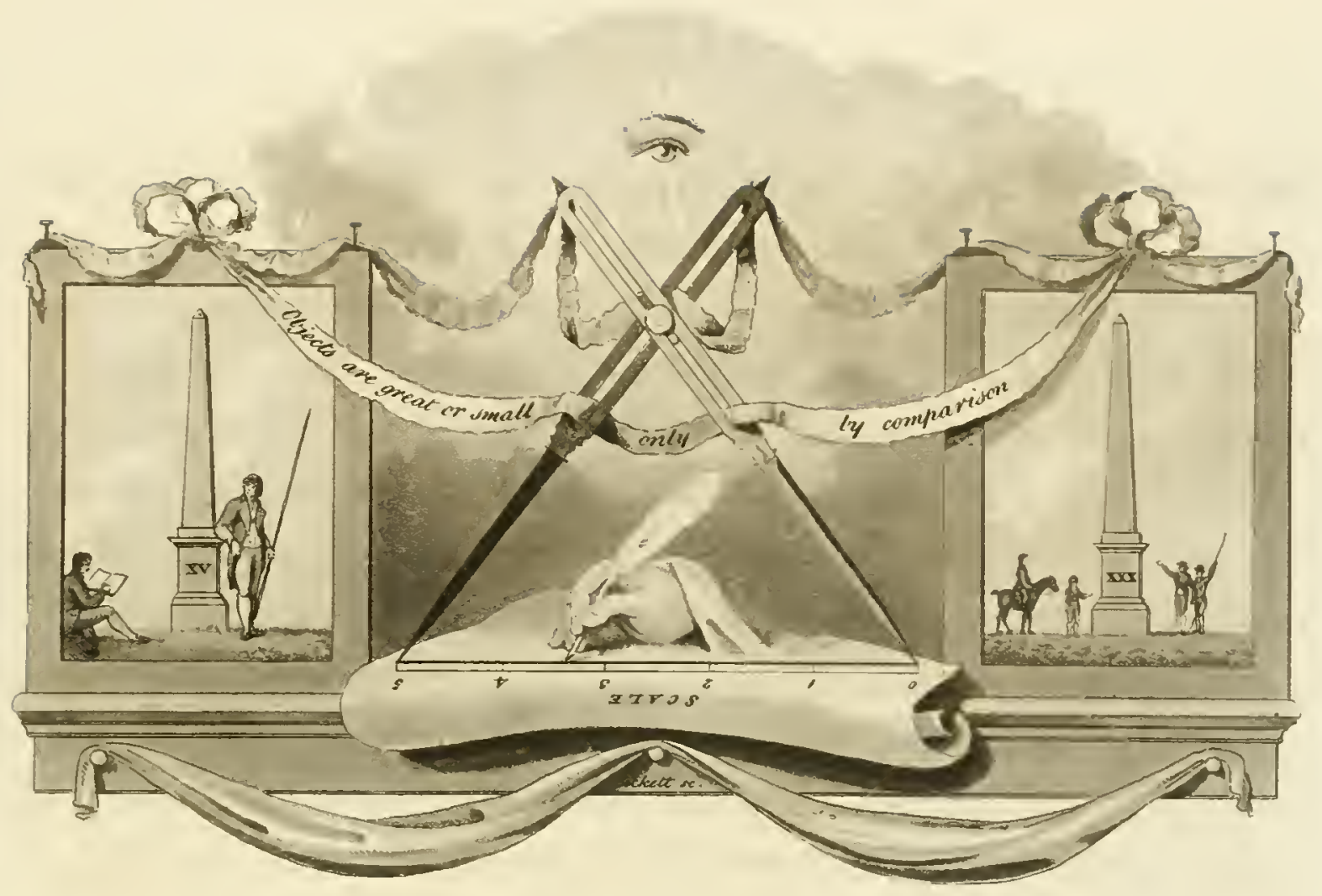

CHAPTER I.

Introduction-General Principles-Utility-Scale-Various Examples of comparative Proportion-Use of Perspective-Example from $\mathrm{THE}$ For T-Ground-Several Examples of removing Earth - The great Hill at Wentworth.

The Theory and Practice of Landscape Gardening have seldom fallen under the consideration of the same author; because those who have delivered their opinions in writing on this art have had little practical experience, and few of its professors have been able to deduce their rules from theoretical principles. To such persons indeed had its practice been committed, that it required no common degree of fortitude and perseverance to elevate the art of landscape gardening to its proper rank 
and amongst those which distinguish the pleasures of civilized society from the pursuits of savage and barbarous nations.

Not deterred by the sneer of ignorance, ${ }^{2}$ the contradiction of obstinacy, the nonsense of vanity, or the prevalence of false taste, I made the attempt; and with the counsels and advice of men of science, and the countenance of some of the first characters in the kingdom, a very large portion of its scenery has been committed to my care for improvement. Hence it might be expected that with some degree of confidence I now should deliver the result of my observations; yet from the difficulties continually increasing with my knowledge of the subject, I submit this work to the public with far more diffidence than I did my former volume: because in this, as in every other study, reflection and observation on those things which we do know, teach us to regret our circumscribed knowledge, and the difficulty of reducing to fixed principles the boundless variety of the works of Nature.

If any general principles could be established in this art, I think they might be deduced from the joint consideration of relative fitness or UTILITY, and comparative proportion or SCALE; the former may be referred to the mind, the latter to the eye, yet these two must be inseparable.

Under relative fitness I include the comfort, the convenience, the character, and every circumstance of a place, that renders it the desirable habitation of man, and adapts it to the uses of each individual proprietor; for it has occasionally happened to me to have been consulted on the same sulject by two diffe-

2 The ignorance aud obstinacy here alluded to, relate to the frequent opposition I have experienced from gardeners, bailiffs, and land stewards, who either wilfully mar my plans, or ignorantly mistake my instructions. 
rent proprietors, when my advice has been materially varied, 10 accord with the respective circumstances or intentions of each.

The second is that leading principle which depends on sight, and which I call comparative proportion; because all objects appear great or small by comparison only, or as they have. a reference to other objects with which they are liable to be compared.

As this will be more clearly explained by an example, the vignette $^{b}$ at the beginning of the chapter presents two obelisks, of exactly the same size, yet by the figures placed near each, they appear to be of very different dimensions. The height of a man we know to be generally from five to six feet, but an obelisk may be from ten to an hundred feet high; we therefore compare the unknown with the known object, and immediately pronounce one of these obelisks to be twice the size of the other. Yet without some such scale to assist the eye, it would be equally difficult either in nature, or in a picture, to form a correct judgment concerning oljjects of uncertain dimensions.

At Holk нa m, about twenty years ago, the lofty obelisk seen from the portico, appeared to be surrounded by shrubbery, but

b Beside the obelisks in the vignette, are several otlser emblems relating to landscape gardeniug: the proportional compasses are often necessary to fix the exact comparative dimensions on paper, to reduce or enlarge the scale, and the flowing lines of ribbon or linen cloth are frequently necessary to mark the outline of a piece of water, when its effect is to be judged of at a distance; but above all, the eye to observe and the hand to delineate, are always necessary, and will often supersede the use of every instrument, because the judlicious artist must rather consider things as they appear than as they really exist, by which he may unite distant objects, and separate those in contact; his effects must be studied with the eye of the painter, and reduced to proper scale with the measurement of the land surveyor. 
on a nearer approach, I found that these apparent shrubs were really large trees, and only depressed by the greater height of the obelisk. A similar instance occurs at Wéвеск; the large grove of oaks seen from the house across the water, consists of trees most remarkable for their straight and lofty stems; yet, to a stranger, their magnitude is apparently lessened by an enormous large and flourishing ash, which rises like a single tree out of a bank of brushwood. When I was first consulted respecting Wentworth House, the lawn behind it appeared circumscribed, and the large trees which surrounded that lawn appeared depressed by four tall obelisks: these have since been removed, the stately trees have assumed their true magnitude, and the effect of confinement is done away.

I have illustrated these observations by the example of an obelisk, because its height being indeterminate, it may mislead the eye as a scale; since according to its size and situation the very same design may serve for a lamp-post, a mile-stone in the market-place of a city, an ornament to a public square, or it may be raised on the summit of a hill, a monument to a nation's glory.

The necessity of observing scale or comparative proportion, may be further elucidated by a reference to $W_{\text {EST }} W_{\text {Y compe, }}$ a place generally known from its vicinity to the road to Oxford. Anongst the profusion of buildings and ornament which the false taste of the last age lavished upon this spot, many were correct in design, and, considered separately, in proportion; but even many of the designs, although perfect in themselves, were rendered absurd, from inattention either to the: scale or situation of the surrounding objects. The summit of a hill is 
covered by a large mass of Grecian architecture, out of which apparently rises a small square projection, with a ball at the top, not unlike the kind of cupolas misplaced over stables; but in reality this building is the tower of a church, and the ball a room sufficiently large to contain eight or ten people.

This comparative proportion, or, in other words, this attention to scale or measurement, is not only necessary with regard to objects near each other, but it forms the basis of all improvement depending on perspective, by the laws of which it is well known, that objects diminish in apparent size in proportion to their distance: yet the application of this principle may not perhaps have been so universally considered. I shall therefore mention a few instances in which I have availed myself of its effects.

At Hunlingram on the banks of the Thames, the lawn in front of the house was necessarily contracted by the vicinity of the river, yet being too large to be kept under the scythe and

' On the summit of another building, viz. a saw-mill in the park, was a figure of a man in a brown coat and a broad brimmed hat, representing the great Pem of Pensilvania, which being much larger than the natural proportion of a man, yet having the appearance of a man upon the roof of the building, diminished the size of every other object by which it was surrounded. It has since been remored, and is now in the possession of Mr. Penn at Stoke Pogies, where, placed in a ruom, it seens a colossal figure. Another instance of false scale at this place, was the diminutive building with a spire at the end of the park, which, perhaps, when the neighbouring trees were small, might have been placed there with a view of extending the perspective. This artifice may be allowable in certain cases, and to a certain degree, yet a cathedral in miniature must in itself be absurd; and when we know that it was ouly the residence of a shoemaker, and actually dedicated to St. Crispin, it becomes truly ridiculous.

I have drawn these examples of defects from West Wycombe, because they are obvious to every passenger on a very public road, and because I shall, in the course of this volume, have occasion to mention the many beaties of this place. 
rolled, and too small to be fed by a flock of sheep, I recommended the introduction of Alderney cows only; and the effect is that of giving imaginary extent to the place, which is thus measured below a true standard; because if distance will make a large animal appear small, so the distance will be apparently extended by the smallness of the animal.

The same reasoning induced me to prefer at Stoke Pogres a bridge of more arches than one over a river which is the work of art, whilst in natural rivers a single arch is often preferalble, because in the latter we wish to increase the magnitude of the bridge, whilst in the former we endeavour to give importance to the artificial river.

Another instance of the necessity of attending to comparative scale, occurred near the metropolis, where a gentleman wished to purchase a distant field for the purpose of planting out a tile-kiln, but I convinced him, that during the life of man the nuisance could never be hid from his windows by planting near the kiln, whilst a few trees judiciously placed within his own ground, would effect the purpose the year after they were planted.

The Art of Landscape Gardening is in no instance more intimately connected with that of painting than in whatever relates to perspective, or the difference between the real and apparent magnitude of the oljects, arising from their relative situations; for without some attention to perspective; both the dimensions and the distances of objects will be changed and confounded. 
Few instances having occurred to me where this can be more forcibly elucidated than in the ground at тне ғовт near Bristol; I shall avail myself of the following observations to shew what can, and what can not be done by a judicious application of the laws of perspective.

When I first visited тне fort, I found it surrounded by vast chasms in the ground, and immense heaps of earth and broken rock; these had been made to form the cellars and foundations of certain additions to the city of Bristol, which were afterwards relinquished. The first idea that presented itself was to restore the ground to its original shape; but a little reflection on the charaeter and situation of the place, naturally led me to enquire whether some considerable advantage might not be derived from the mischief which had thus been already done.

Few situations command so varied, so rich, and so extensive a view as тне ғоRт; situated on the summit of a hill which looks over the vast city of Bristol, it formerly surveyed the river, and the beautiful country surrounding it, without being incommoded by too much view of the city itself: but the late prodigious increase of buildings had so injured the prospect from this house, that its original advantages of situation were almost destroyed, and there was some reason to doubt whether it could ever be made desirable either as a villa or as a country residence; because it was not only exposed to the unsightly rows of houses in Park Street and Berkley Square, but it was liable to be overlooked by the numerous crowds of people who claimed a right of footpath through the park immediately before the windows. It was therefore as public as any house in any square or street of Bristol. If the carth had been simply put back to the places from 
whence it had been taken, the expence of its removal would have been greater than the method which occurred to me as more advisable; viz. to fill up the chasms partly by levelling the sides into them, and raising a bank with a wall to exclude the foot-path, as shewn in the annexed section, where the dotted line shews the original shape of the ground; the zig-zag line, holes from fifteen to twenty feet deep; the shaded line, the shape of the ground as altered.

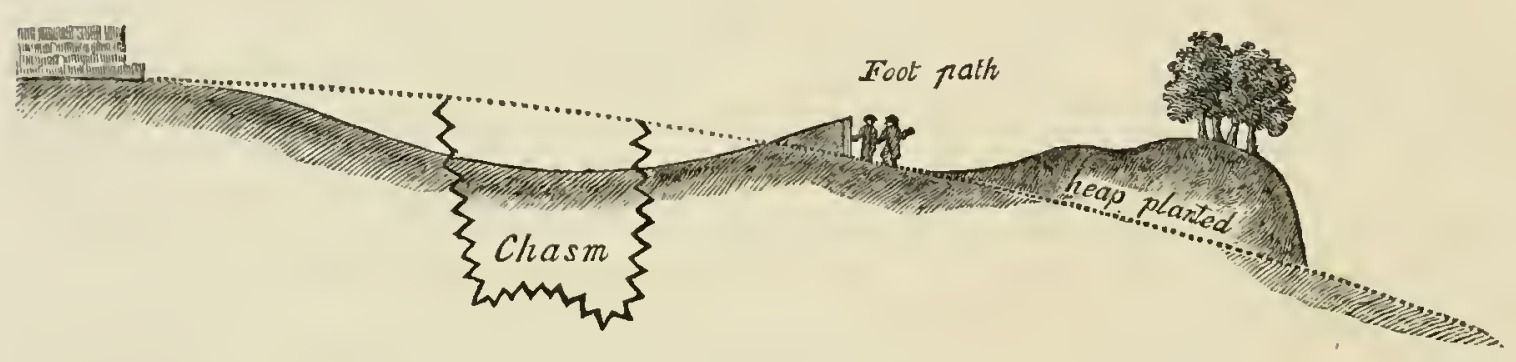

By this expedient we hide the objectionable part of the view, and by planting the raised heap of earth we produce a degree of privacy and seclusion in this newly created valley within the pleasure grounds, which was never before known or expected in this open situation. The pleasure ground, immediately near the house, is separated from the park by a wall, against which the earth is every where laid as before described, so as to carry the eye over the heads of persons who may be walking in the adjoining foot-path. This wall not only hides them from the house, but also prevents their overlooking the pleasure ground. Yet notwithstanding this great utility, this absolute necessity, the appearance of such a wall from the park gives an air of confinement, and the only expedient by which this might be well remedied, would be a total change in the character of the place, 



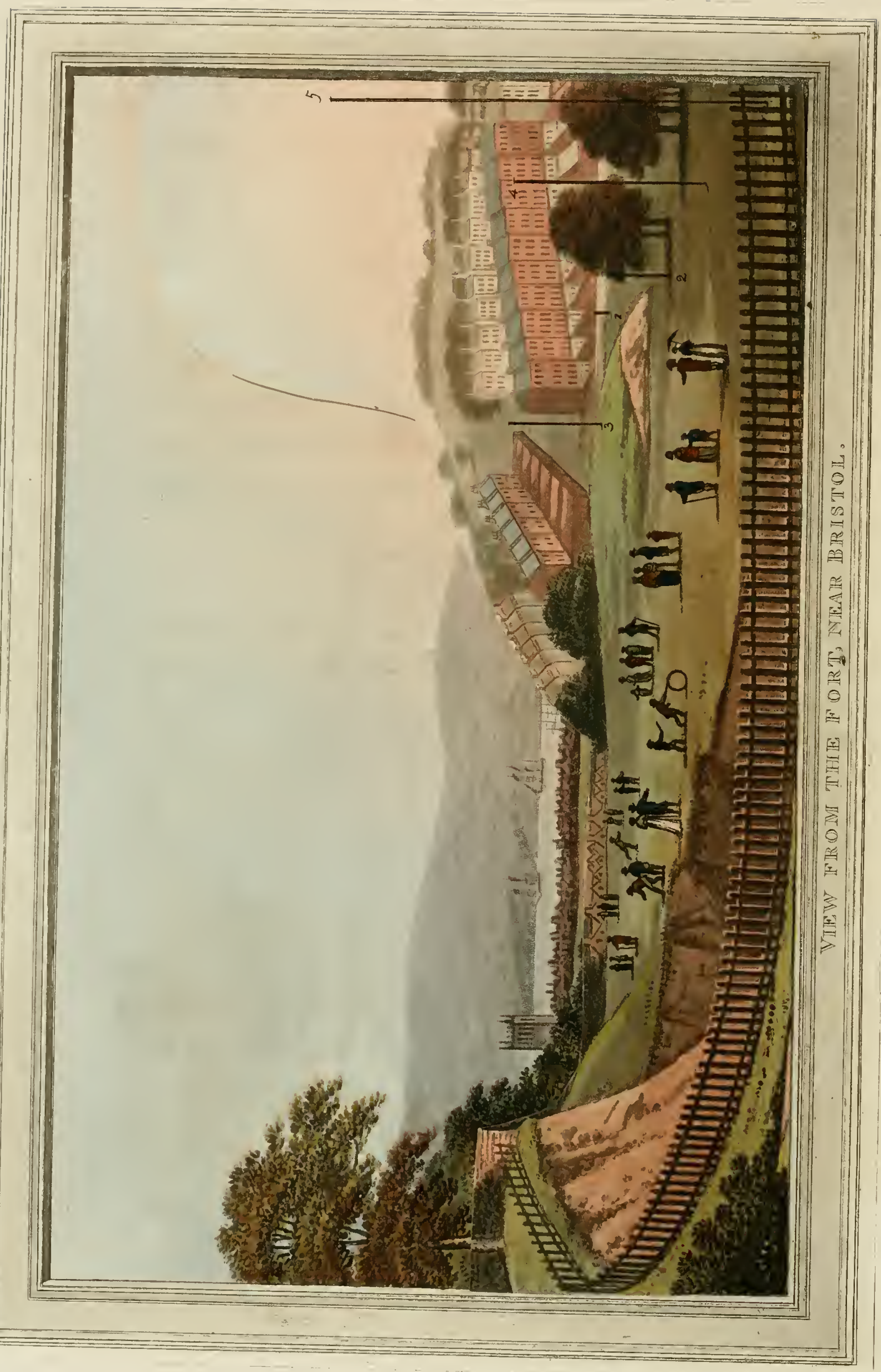





or rather by altering the house to make it what its name and situation denote: for if THE FORT were restored to its original character of a castle or fortress, this wall, instead of being objectionable, would then act as a terrace, and contribute to the general effect of extent, and the magnificence of the whole. ${ }^{d}$

The drawing represents the view from the house, as it appeared before and after the improvement; upon the slide are shewn five rods or poles, each of which are supposed to be ten feet high, and placed at different distances from the eye; these shew the difference in the apparent height of the same object in the different situations, and of course what may be expected from trees planted of any given size at each place: from hence it is evident that a young tree at No. 1. will hide nothing for many years except the park wall. A tree of the same size at No. 2. will do little more; this is confirmed also by the large trees already growing there; but at No. 3. where a heap of earth has been thrown up to a considerable height, a tree of twenty feet would hide most of the louses, and in like manner at No.4. and No.5; immediate effects may be produced by judiciously planting to shew the distant objects over or under the branches of trees in the foreground.

Although from the nature of this work it is difficult to preserve any connecting series of arrangement, yet it may not be

A A drawing is inserted in the red book to shew the manner of thus altering the house; but the plate in this work is sufficient to explain the process used in ascertaining the possibility of so planting out the view of the neighbouring houses as to exclude what ought to be hid, without hiding what ought to be seen. 
improper in this place to mention a few remarkable instances of removing earth and altering the shape of the surface of ground, especially as there is no part of my profession attended with so much expence, or more frequently objected to, because so often mismanaged.

Where a ridge of ground very near the eye intercepts the view of a valley below, it is wonderful how great an effect may be produced by a very trifling removal of the ridge only; thus at Moccas Court a very small quantity of earth concealed from the house the view of that beautiful reach of the river Wye which has since been opened. At Oldaury Court the view is opened into a romantic glen by the same kind of operation. At Catchfrence the same thing is advised to shew the opposite hills; and in this instance it may appear surprising, that the removal of a few yards of earth was sufficient to display a vast extent of distant prospect.

But this effect must depend on the natural shape of the surface near the eye; for example, if the shape be that of the upper line $\mathrm{A}$.

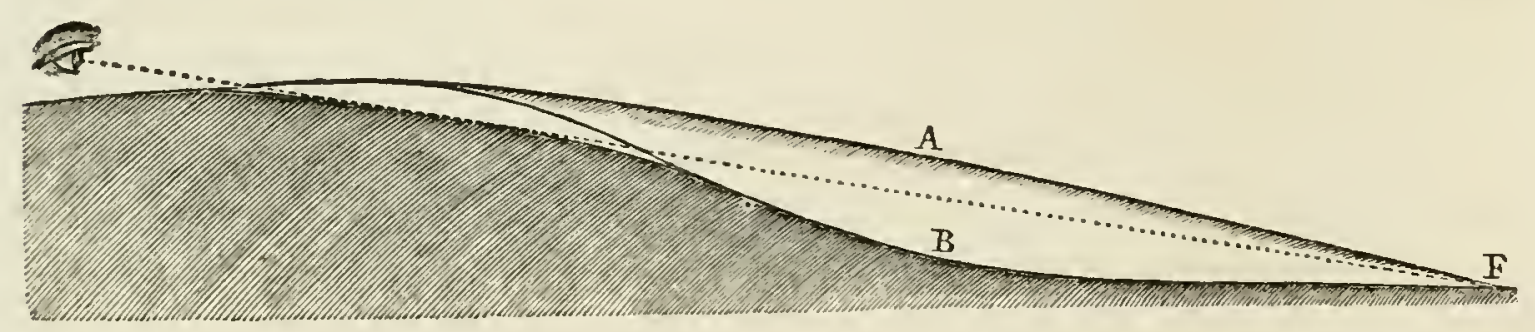

the object at $F$. cannot be seen without the removal of all the earth between the dotted line and the surface; but if the shape be that of $B$. the removal of the part not shaded will be suffi- 
cient to shew the valley; and it is not always desirable to see the whole surface, on the contrary, it is better that a part should be concealed, than that the whole should be shewn foreshortened, which is always the case in looking down or up an inclined plane. ${ }^{\circ}$

The most arduous operations of removing ground are generally those where the geometric taste of gardening had distorted the natural surface, and where it would now be attended with much greater trouble and expence to restore the ground to its original shape, than had been formerly dedicated to make those slopes and regular forms, which are more like the works of a military engineer than of a painter or a gardener.

Few instances have occurred to me where great expence in moving ground was requisite to produce pleasing effects, and it is always with reluctance that $I$.advise much alteration in the surface of ground, because however great the labour or expensive the process, it is a part of the art from which the professor can derive but little credit, since his greatest praise must be, that the ground looks when finished, as if art had never interfered. "Ars est celare artem."

- Having often seen great expence incurred by removing ground to shew the whole surface of a valley from the top of a hill, it may not be improper to explain that such an effort is seldom useful or desirable. To the painter it is impossible to represent ground thus fore-shortened, and the first source of beauty in the composition of a landscape, is the separation of distinct distances; the imagination delights in filling up those parts of the picture which the eye cannot see; and thus in a landscape while we do not see the bottom of a deep glen, we suppose it deeper than it really is; but when its whole shape is once laid open, the magic of fancied rocks and rattling torrents, is reduced perhaps to the mortifying discovery of a dry valley or a swampy meadow. 
When I was first consulted at Sundridge Park by Mr. Lind the former possessor, the house, which has since been pulled down, stood on the south side of the valley; and those who knew the spot despaired of finding a situation for a house on the opposite side of the valley that the rooms might have a southern aspect, as the bank was too steep to admit of any building. My much respected friend, the present possessor, was aware of this circumstance, and by art we have produced a situation which nature denied. The earth was lowered thirty feet perpendicularly at the spot on which the house was built, and so disposed at the foot of the hill, that no trace of artificial management is now to be discovered. ${ }^{f}$

Among the greatest examples of removing ground may be mentioned the work going on at Bucstrode under the direction of his Grace the Duke of Portland himself; whose good taste will not suffer any part of that beautiful park to be disguised by the misjudging taste of former times, and who, by opening the valleys and taking away a great depth of earth from the stems of the largest trees, which had been formerly buried, is

' The house, and the hill on which it stands, are exactly in due proportion to each other; and the former is so fitted to the situation and views which it commands, that I regret having shared with another the reputation of designing and adapting this very singular house to circumstances which cannot well be explained but upon the spot: having given a drawing and description of the scene to Mr. Angus, in justice to his work, I will not insert any view of this house; but its distance is so slort from the capital, that, like many others, my best reference will be to the place itself.

In thus referring to places improved under my dircction, it is not to be supposed that they are at all times accessible to idle curiosity; but the same good taste, and the same liberality of sentiment which induces a proprietor to consult the professor of an art, will naturally operate in favour of scientific inquiry. 
by degrees restoring the surface of the ground to its original and natural shape. ${ }^{\mathrm{g}}$

As connected with the subject of moving ground, I shall extract from my Red Book of Wentwonth the following observations concerning the great work at that place which lad so long been carrying on under the direction of the late Marquis of Rockingham.

Of the view from the portico at Wentworti House, my opinion is so contrary to that of many others who have advised a farther removal of the hill, that I hope it will not be improper to state very fully the reasons on which. I ground this opinion, viz. that so far from such an operation being equivalent to the trouble by which it must be executed, I would not advise its removal, if it could be much more easily effected, because

1. The outline of the horizon beyond this hill is almost at straight line, and would be very offensive when shewn over another straight line parallel to it.

2. The view of the valley beyond, however rich in itself, is too motley to form a part of the proper landscape from such a palace as Wentworth House, although from many situations in the park it is a very interesting feature.

3. The vast plain, which has with so much difficulty been obtained in front of the house, is exactly proportionate to the extent of the edifice, and tends to impress the ideas of magni-

${ }^{g}$ In this great work are occasionally employcd among the more efficient labourers, an hundred children from ten to fifteen years old, who are thus early trained to habits of wholesome industry, far different from the foul air and confinement of spinning in a cotton nill; to the benevolent observer no objcct can be more delightful than park scenery thus animated. 
ficence which so great a work of art is calculated to inspire. Such a plain forms an ample base for the noble structure which graces its extremity; the building and the plain are evidently made for each other, and consequently to increase the dimensions of either seems unnecessary.

The foregoing reasons relate to the hill as considered from the house only, I shall now consider it in other points of view.

Wentworth park consists of parts in themselves truly great and magnificent. The Woods, the Lawns, the Water, and the Buildings, are all separately striking; but considered as a whole, there is a want of connexion and harmony in the composition: because parts in themselves large, if disjoined, lose their importance. This I am convinced is the effect of too great an expanse of unclothed lawn, but when the young trees shall have thrown a mantle over this extensive knowl, all the distant parts will assume one general harmony, and the scattered masses of this splendid scenery will be connected and brought together into one vast and magnificent whole.

The use of a plantation on this hill in the approach from Rotherham is evident from the effect of a small clump which will form a part of this great mass, and which now hides the house, till by the judicious bend round that angle, the whole building bursts at once upon the view.

It can readily be conceived, that before the old stables were removed there might appear some reason for not planting this hill; not because it was too near the front, but because the view thus bounded by a wood on one side, and the large pile of old stables on the other, would be too confined. That objection is removed with the stables, and norv a wood on this hill will form 


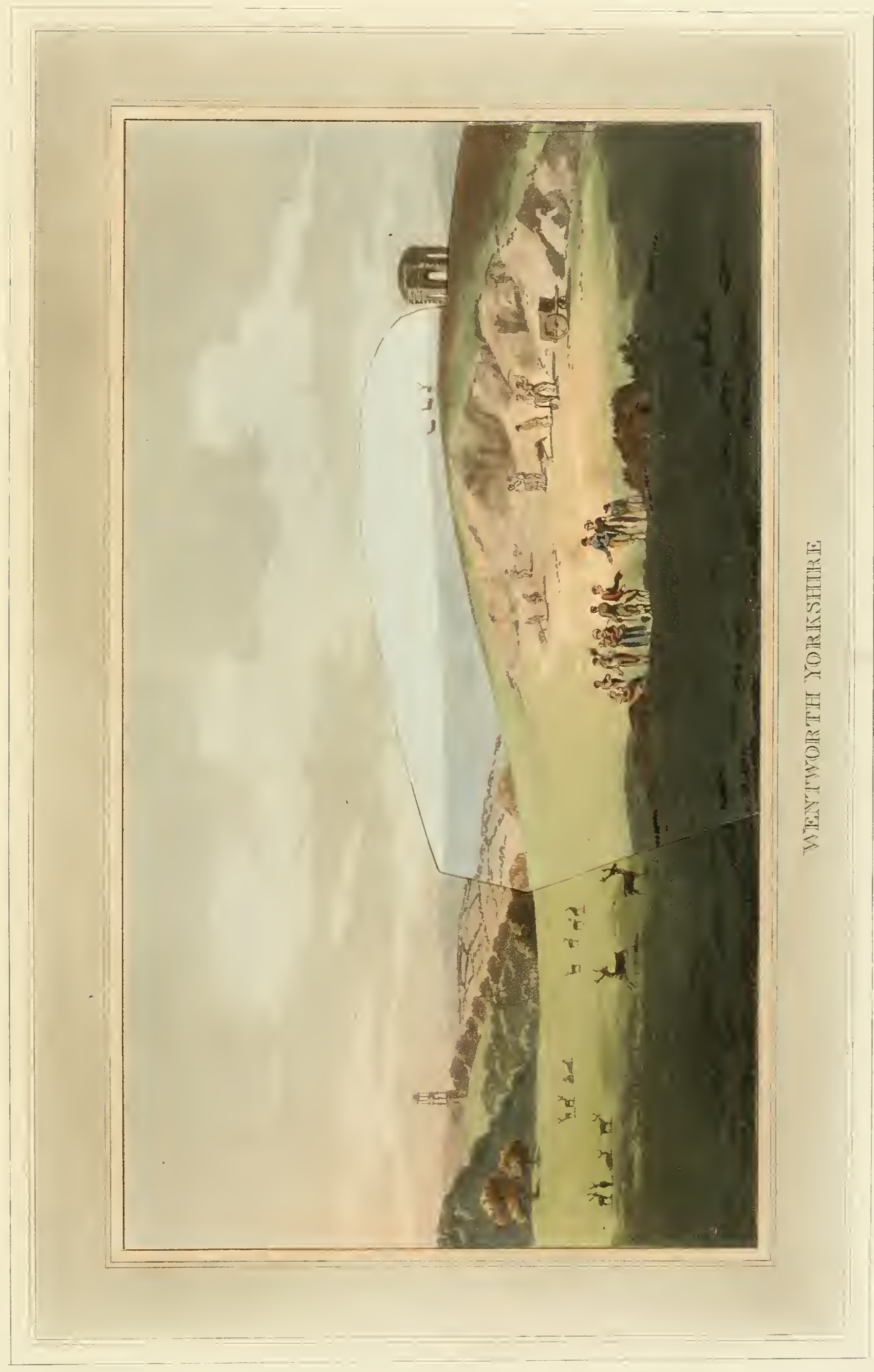





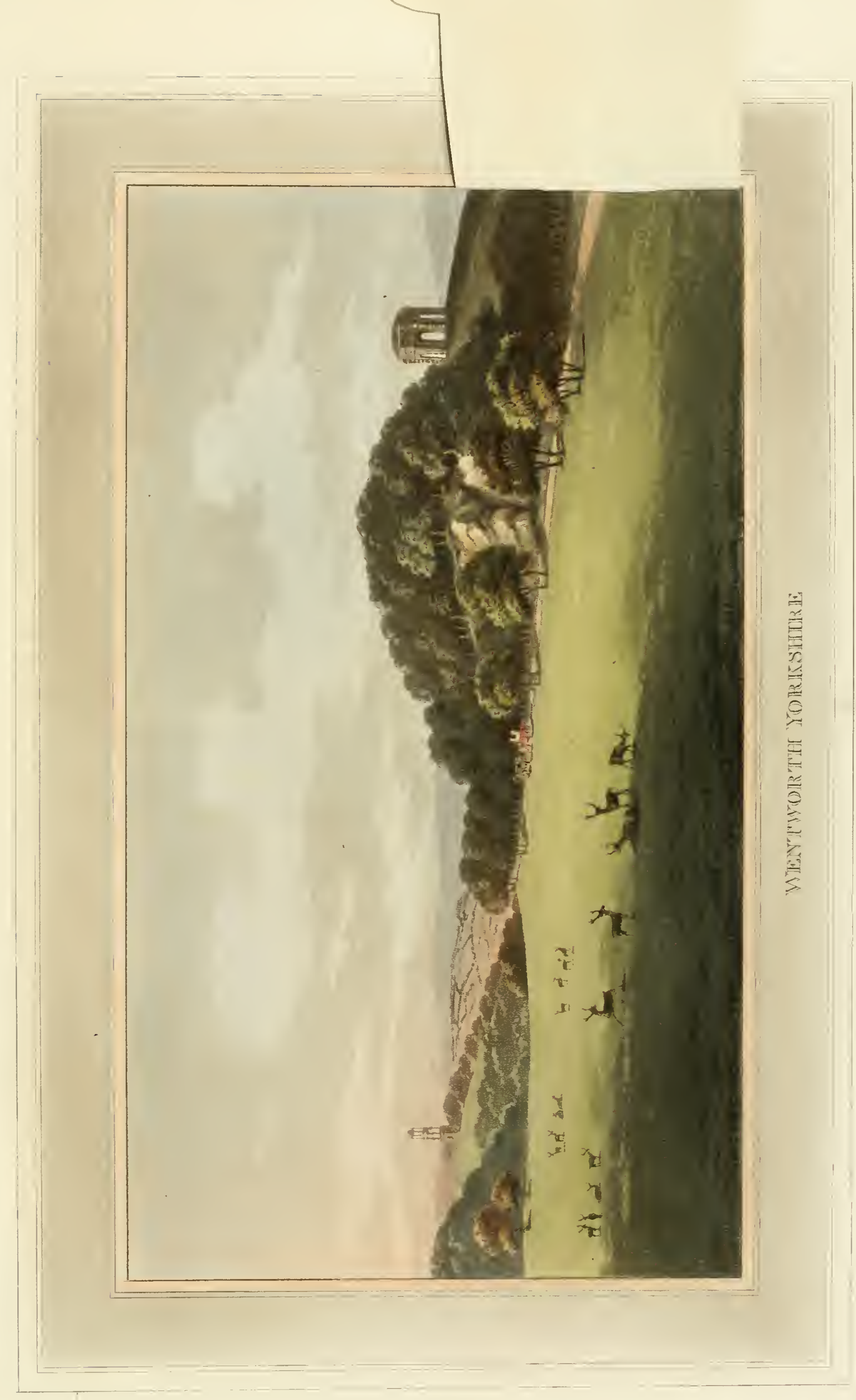



a foreground, and lead the eye to each of those scenes, which are too wide apart ever to be considered as one landscape. In the adjoining sketch $I$ have endeavoured to shew the effect of planting this hill, leaving part of the rock to break out among the trees. In a line of such extent, and where the angle nearest the house will be rather acute, it may be necessary to hide part, and to soften off the corner of the plantation by a few scattered single trees in the manner I. have attempted to represent.

Among the future uses of the hill plantation it may be mentioned, that the shape which the ground most naturally seems to direct for the outline of this wood is such as will hereafter give opportunity to form the most interesting walk that imagination can suggest; because from a large crescent of wood on a knowl the views must be continually varying, while by a judicious management of the small openings, and the proper direction of the walks, the scenery in the park will be shewn under different circumstances of foreground with increased beauty. 
Optics or vision - At what Distance Objects appear largest - Axis of Vision - Quantity or Field of Vision - Ground apparently altered by Situation of the Spectator-Reflections from the Surface of Water explained and applied-Different Effects of Light on different Objects - Example.

Landscape Gardening being connected with oplics or vision, or rather with the application of their rules to practical improvement, it may not be improper to devote a chapter to the following observations.

There is a certain point of distance from whence every object appears at its greatest magnitude. This subject was originally discussed in consequence of observing that a particular rock at Pon т Eцот appeared higher or lower, at different distances. The inquiry into the cause of this difference led me to propose a question to several ingenious friends.

Query, At what distance does any object appear at its greatest licight?

' The general optical distinction of the magnitude of objects is into real and apparent; the real being what its name imports, and the apparent not that which may ultimately result to the mind, but that which is immediately impressed on the eye. This is measured by a plain and certain rule, namely, the angle which is formed at the eye by lines drawn from the extremities 
of the object. 'The apparent height of a man therefore at a quarter of a mile distance, is not the conception which we form of his height, but the opening or angle of the two lines above mentioned, viz. of the two drawn from the extremities of the object to our eye. This apparent height therefore of any object, will be measured always upon the simplest principles; and will vary according to, first, the distance of the object; secondly, the inclination it makes with the horizon; and thirdly, our relative elevation or depression. Any two of the above three things continuing the same, the apparent magnitude will decrease with the third, though not in exact proportion to it.

'Thus the object being perpendicular to the horizon, and our elevation remaining the same, its apparent height will decrease with the distance. Our elevation and the distance remaining the same, the apparent height of the object will decrease with its inclination to the horizon. The inclination and distance being the same, the angle, or apparent height, will decrease with our elevation or depression, supposing our height was at first the middle point of the object. This last heing liable to some exceplions, the general rule is, that the distance from the object, measured by a perpendicular to it, being the same, the point at which its apparent height will be greatest, is, where the perpendicular from the eye falls upon the centre.

' The apparent height of a body, as upon the same principles any other of its dimensions, is a matter of easy consideration; its inclination, its distance, and the relative position of the observer being known. The difficulty is to know what the conception is that we shall form of the height and magnitude of an object; according to different circumstances, its apparent height, 
as well as its real height, remaining the same. This you will see belongs to wholly different principles, and such as cannot be reduced to certain rules; it appears too from hence, that the question has little or nothing to do wilh mathematical principles, at least beyond those simple ones which I have just stated. Of other principles, the consideration is more diversified: much may be ascribed to the habit, which we probably have, of estimating the height of objects, not by the angle formed by lines to the summit and the base, when the base is below us, but by that formed between a line from the summit and a line parallel to the horizon; in this way our conception of the magnitude may be less, while the apparent magnitude may be greater. A thousand other canses may likewise operate, amongst which will be some that belong to what is called aerial perspective, or those rules by which we judge of the distance or dimensions of objects, not by their ontline on the retina, but by their colour and distinctness. The existence and operation of these can hardly be found, but by a careful examination and comparison of particular instances.'

The concluding paragraph in this letter, from one of the most able men of the age, encouraged me to examine and compare particular instances as they fell under my observation, and from a variety of these $I$ am led to conclude, that among those numerous causes here said to operate independent of mathematical principles, one may proceed from the position of the eye itself; which is so placed as to view a certain portion of the hemisphere without any motion of the head. This portion has been differently stated by different authors, varying from sixty to ninely degrees. 
The question before us relates to the height, and not to the general magnitude of the oljject, these being separate considerations; because the eye is capable of surveying more in breadth than in height; but it is also capable of seeing much farther below its axis than above it, as shewn by the following profile. From hence it appears that the projection of the forehead and eyebrow causes great difference betwixt the angle A. B. and the angle $A$. C. and that the line parallel to the horizon A. which I shall call the axis of rision, does not fall in the centre of the opening betwixt the extreme rays $\mathrm{B}$. and $\mathrm{C}$.

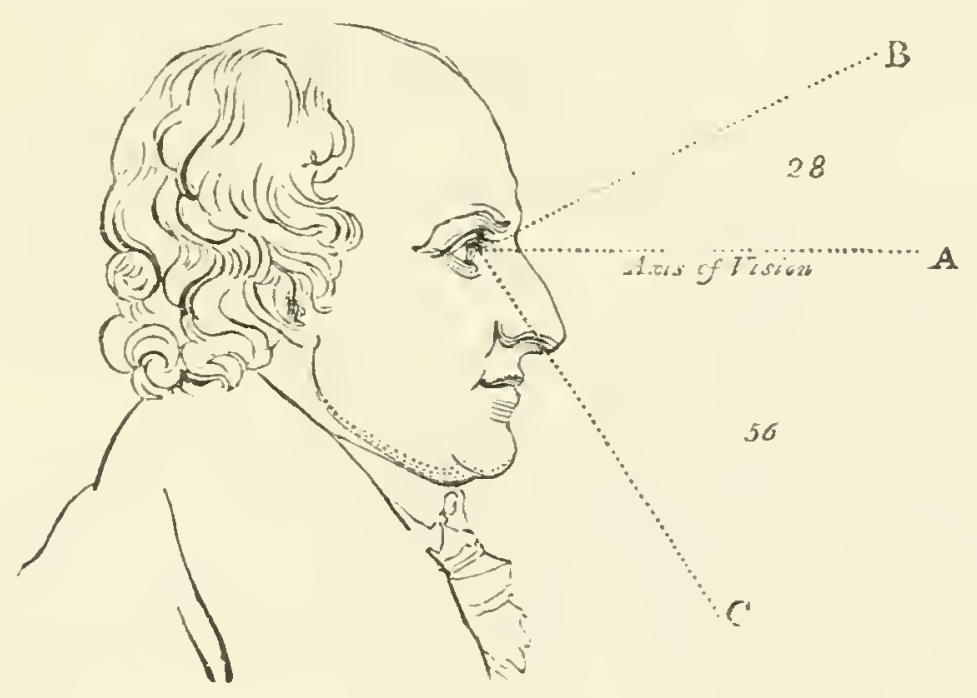

Doubtless these angles may vary in different individuals from various causes, such as, the prominency of the eye, the habit or usual position of the head, \&c. yet the upper angle A. B. will seldom be greater than one half of the lower angle A. C. and I have ascertained, with some precision, that I could not distinguish objects more than twenty-eight degrees above my axis of vision, although I can distinctly see them fifty-seven degrees 
below it. From hence I conclude that the distance at which an object appears at its greatest height, is, when the axis of vision and the summit of the object form an angle of aljout thirty degrees; because, under this angle, the eye perceives its full extent without moving the head, yet not withont some effort of the eye itself to comprehend the whole of the object.

To this theory it may, perhaps, be objected. that in the act of seeing, the motion of the head is too rapid to effect any material difference; but it will be found, on examining this subject attentively, that the olject is seen in a new point of view, from the instant the head is moved, because the rays no longer meet at the same centre; and therefore the effect of such vision on the mind, is rather a renewal in succession of similar ideas, than the same single idea simultaneously excited: and this difference may be compared to that between seeing a landscape reflected in a mirror at rest, and the same landscape when the mirror has been removed from its original position. ${ }^{\mathrm{g}}$

From frequent observation of the difference between seeing an object with and without moving the head, I am inclined to believe, that by the latter the mind grasps the whole idea at once, but liy the former it is rather led to observe the parts separately: hence are derived many of those ideas of apparent magnitude or proportion which induce us to pronounce at the first glance, whether objects are great or small. I should there-

${ }^{\mathrm{B}}$ Perhaps this difference may be more familiarly explained by observing, that when a lark ascends in the air we have no difficulty in keeping the bird in sight so long as we continue our head in the first position; but from the moment the head is moved, we have to search for the object again, and often in vain, through the vast expanse of sky. 
fore answer the question, "at what distance does any object appear at its greatest height?" by saying, when the spectator is at such a distance that the line drawn from his eye to the top of the object forms an angle of not less than twenty-eight degrees with the axis of vision; and thus supposing the eye to be fire feet six inches from the ground, the distance will be according to the following table.

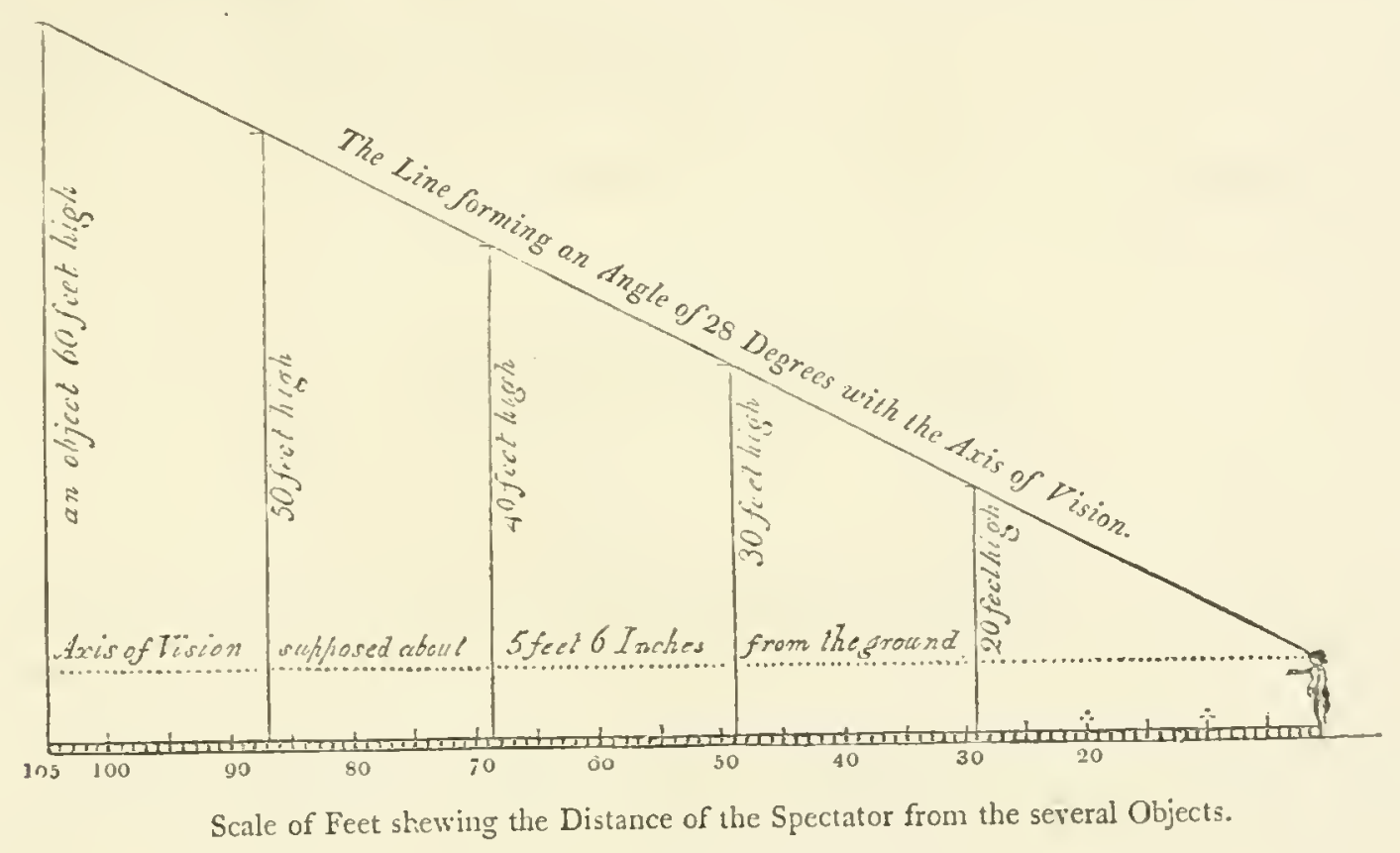

The scientific observer will always rejoice at discorering any law of Nature by which the judgment is unconscionsly directed. At a certain distance from the front of any building, we admire the general proportions of the whole: but if the building can only be viewed within those angles of vision already described, it is the several parts which first attract our notice, and we generally pronounce that object large, the whole of which the eye can not at once comprehend. 
Hence it is commonly observed by those who have seen both St. Peter's at Rome, and St. Paul's at London, that the latter appeared the largest at the first glance, till they became aware of the relative proportion of the surrounding space; and I doubt whether the dignity of St. Paul's would not suffer if the area round the building were increased, since the great west portico is in exact proportion to the distance from whence it can now be viewed according to the preceding table of heights and distances: but if the whole church could be viewed at once like St. Peter's, the dome would overpower the portico, as it does in a geometrical view of the west front. ${ }^{\mathrm{h}}$

The field of vision, or the portion of landscape which the eye will comprehend, is a circumstance frequently mistaken in fixing the situation for a house; since a view seen from the windows of an apartment will materially differ from the same view seen in the open air. In one case, without moving the head, we see from sixty to ninety degrees; or by a single motion of the head, without moving the body, we may see.every object within one hundred and eighty degrees of vision. In the other case the portion of landscape will be much less, and must de-

"I have sometimes thought that this same rule of optics may account for the pleasure felt at first entering a room of just proportions, such as twenty by thirty, and fiftcen feet high; or twenty-four by thirty-six, and eighteen feet high; or the double cube when it exceeds twenty-four fect. 
pend on the size of the window, the thickness of the walls, and the distance of the spectator from the aperture. Hence it arises that persons are frequently disappointed after building a house to find, that those objects, which they expected would form the leading features of their landscape, are scarcely seen except from such a situation in the room as may be inconvenient to the spectator; or otherwise the object is shewn in an oblique and unfavourable point of view. This will be more clearly explained by the following diagram.

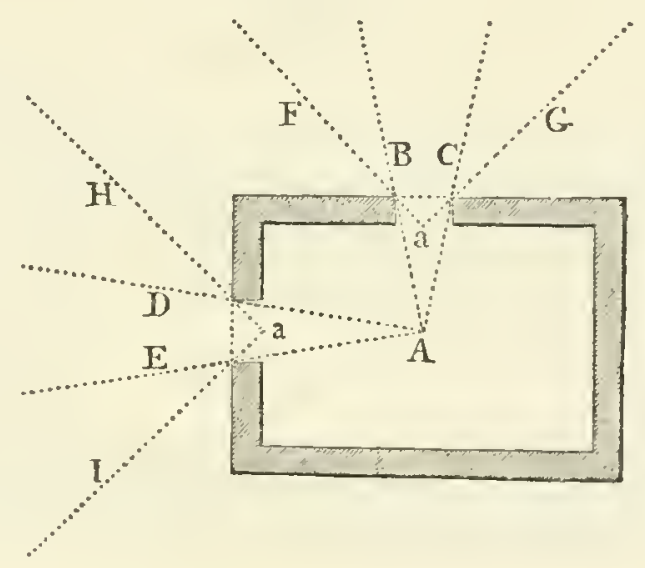

It is evident that a spectator at $A$. can only see through an aperture of four feet those objects which fall within the opening B. C. in one direction, and D. E. in the other, neither comprehending more than twenty or thirty degrees. But if he removes to $a$ near the windows, he will then see all the objects within the angle F. G. in one direction, or H. I. in the other; yet it is obvious that even from these spots, that part of the landscape which lies betwixt the extreme lines of vision $\mathrm{F}$. and $\mathrm{H}$. will be invisible, or at least seen with difficulty, by placing the eye much nearer to the window than is always convenient.

From hence it follows, that to obtain so much of a view as 
may be expected, ${ }^{\mathrm{i}}$ it is not sufficient to have a cross light or windows in two sides of the room at right angles with each other; but there must be one in an oblique direction, which can only be obtained by a bow-window: and although there may be some advantage in making the different views from a house distinct landscapes, yet as the villa requires a more extensive prospect than a constant residence, so the bow-window is peculiarly applicable to the villa. I mus.t acknowledge that its external appearance is not always ornamental, especially as it is often forced upon obscure buildings where no view is presented near great towns, and oftener is placed like an uncouth excrescence upon the blcak and exposed lodging houses at a watering-place; but in the large projecting windows of old gothic mansions beauty and grandeur may be united to utility.

The apparent shape of the ground will be altered by the situation of the spectator. 'This is a subject of much importance to the Landscape Gardener, although not generally studied.

In hilly countries where the banks are bold, a road in a valley is always pleasing, because it seems natural, and carries

'Of this I observed a curions instance at Hootox House, from whence a distant view of Liverpool, and its busy scenery of shipping, is not easily seen without opening the windows, while the difference of a few yards in the original position of the house would liave obviated the defect while it improvel its general situation. 
with it the idea of ease and safety; but in a country that is not hilly, we ought rather to shew the little ${ }^{k}$ inequalities of ground to advantage. The difference betwixt viewing ground from the bottom of a valley, or the side of a hill, will be best explained by the following diagram, where the rules of perspective again assist the scientific improver.

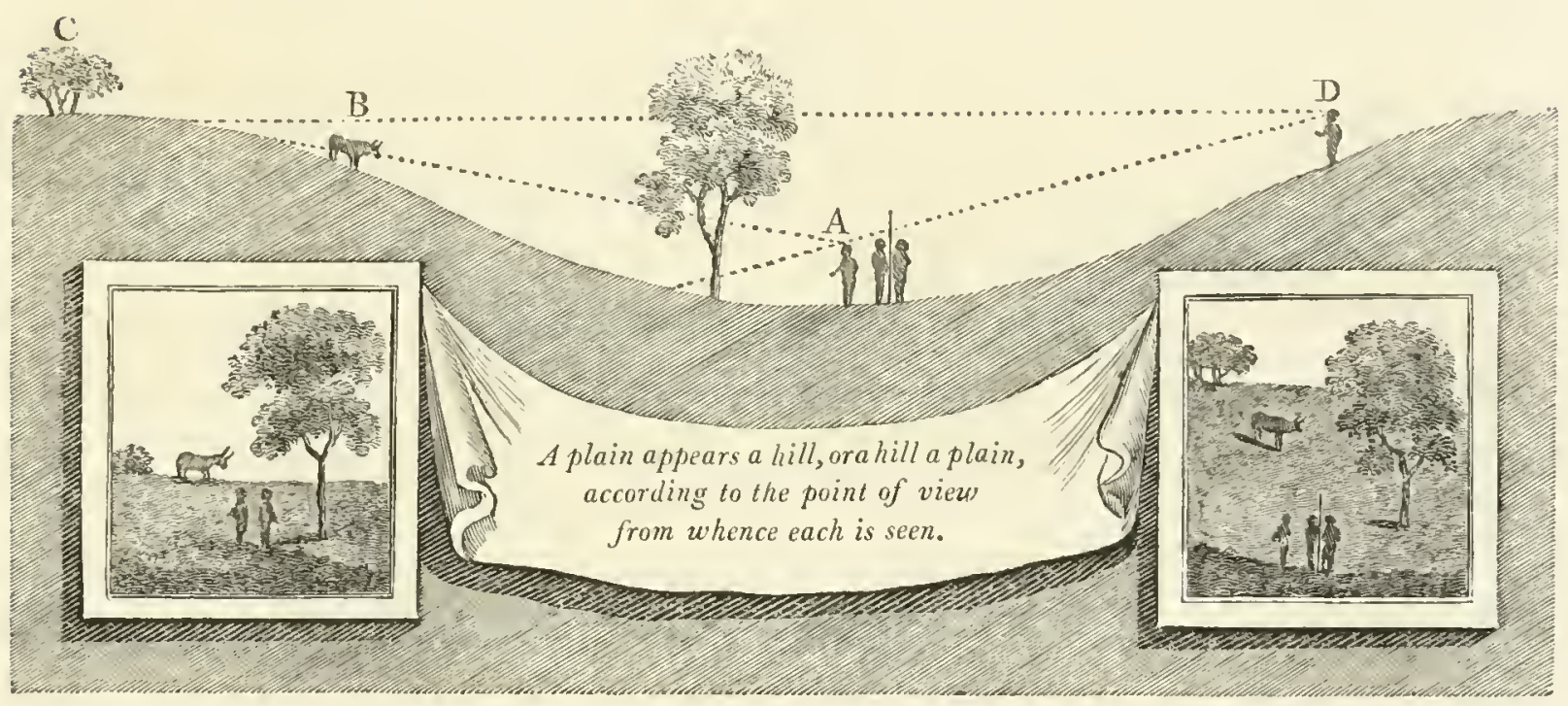

The spectator at $A$. in looking up the hill towards $C$. will lose all the ground that is fore-shortened; and every object which rises higher than five feet (i. e. the height of his eye) will present itself above his horizon if the slope is exactly an inclined plane or hanging level; but as the shape of ground here delineated more frequently occurs, he will actually see the shy, and

${ }^{k}$ That I may not be misunderstond as recommending a road orer hill and dale to shew the extent or beauty of a place, I must here observe, that nothing can justify a visible deriation from the shortest line in an approach to a house, but such obstacles as evidently point out the reason for the deviation. 
consequently the utmost pitch of the hill beneath the body of the animal placed at $B$. and part of the thorn at $C$. becomes invisible.

This accounts for the highest mountains losing their importance when seen only from the base; while, on the contrary, a plain or level surface (for instance the sea) appears to rise considerably when viewed from an eminence. Let us suppose another spectator to be placed at D. it is evident that this person will see no ground fore-shortened but that below him, while the opposite hill will appear to him far above the head of the man at $A$. and above the cow at $B$. In the section the dotted lines are the respective horizons of the two spectators, and the sketches shew the landscape seen by each, in which the forked tree may serve as a scale to measure the height of each horizon.

The reflections of objects in water are no less dependent on the laws of perspective, or of vision, than the instances already enumerated.

If the water be raised to the level of the ground beyond it, we lose all advantage of reflection from the distant ground or trees: this is the ease with pieces of water near the house in many places, for all ponds on high ground present a constant glare of light from the sky; but the trees beyond can never be 
reflected on the surface, hecause the angle of incidence and the angle of reflection are always equal: and the surface of the water will always be a perfect horizontal plane. This I shall farther explain by the following lines.

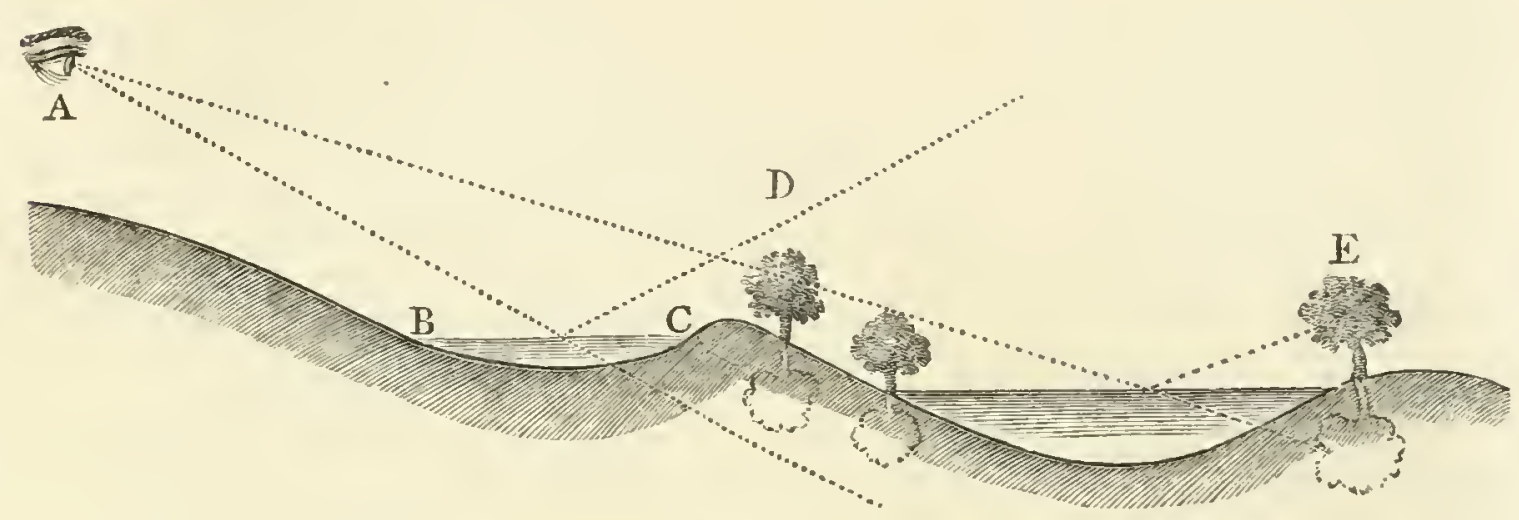

The spectator at A. in looking on the upper water will see only sky; because the angle of incidence $B$. and that of reflection $\mathrm{C}$. being equal, the latter passes over the top of the trees $D$. on lower ground: but the same spectator A. in looking on the lower water, will see the trees E. reflected on its surface, because the line of reflection passes through them, and not over them, as in the first instance.

There are other circumstances belonging to reflection on the surface of water, which deserve attention, and of which the landscape gardener should avail himself in the exercise of his art. Water in motion, whether agitated by wind or by its natural current, produces little or no reflection; but in artificial rivers the quiet surface doubles every object on its shores, and for this reason I have frequently found that the surface could be increased in appearance by sloping its banks: not only that which actually concealed part of the water, but also the oppo- 
site bank; because it increased the quantity of sky reflected on the surface.

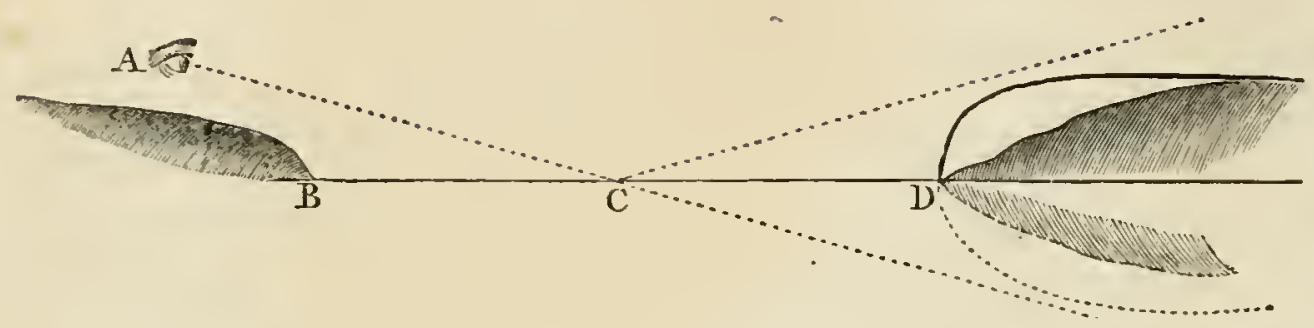

Example. The spectator at $A$. sees the sky reflected only from B. to C. while the opposite bank is round; but if sloped to the shaded line, less of the bank will be reflected in the water, and the quantity of sky seen in the water will be from $B$. to $D$. and as the brilliancy of still water depends on the sky reflected on its surface, the quantity of water will be apparently increased.

As properly belonging to this chapter, may be mentioned a curious observation which occurred in the view of the Thames from Punley. In the morning, when the sun was in the east, the landscape appeared to consist of wood, water, and distant country, with few artificial accompaniments; but in the evening, when the sun was in the west, objects presented themselves, which were in the morning scarcely visible. In the first instance, the Wood was in a solemn repose of shade, the Water reflecting a clear sky was so brilliantly illuminated, that I could trace the whole course of the river, the dark Trees were strongly 


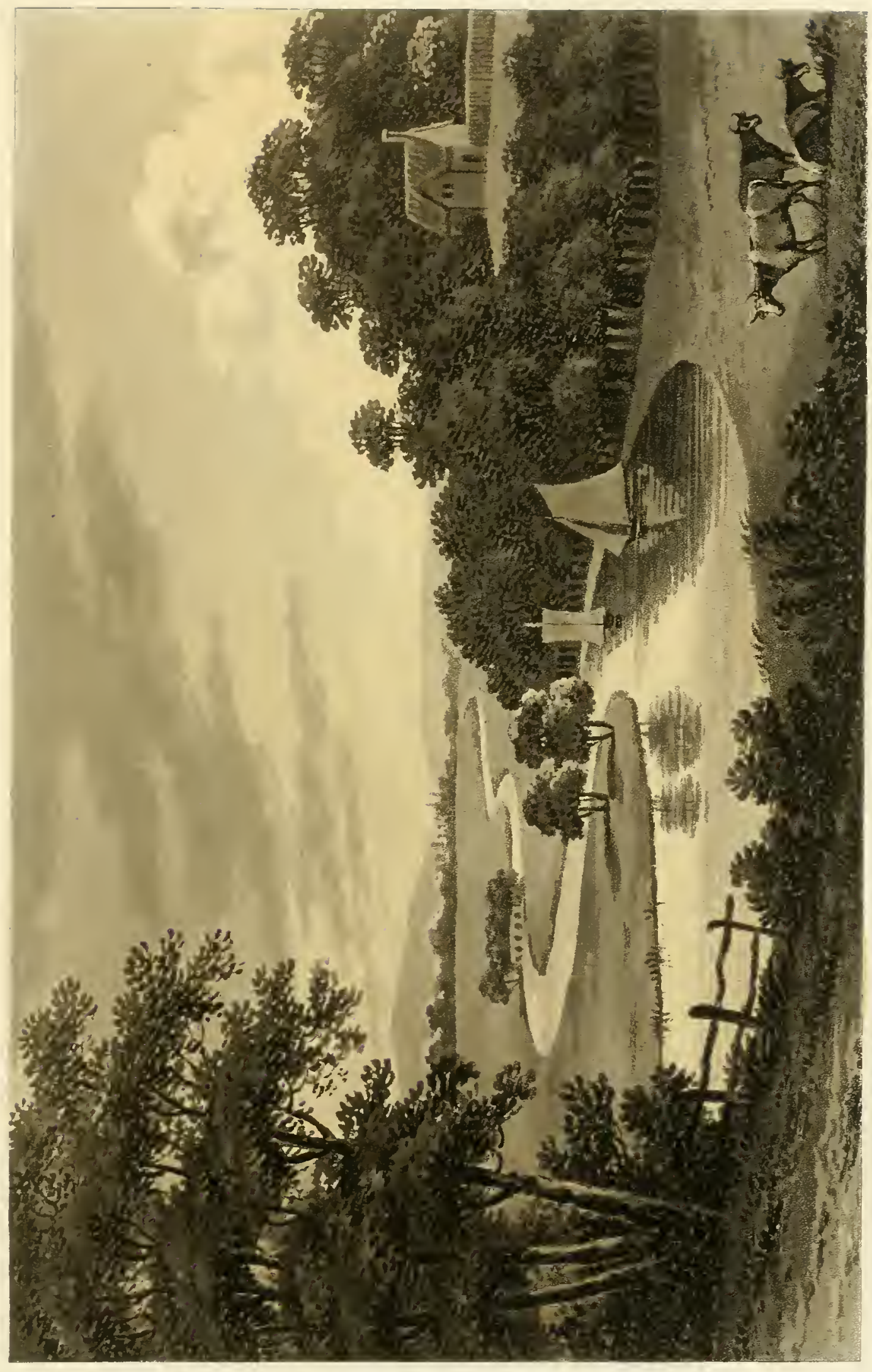






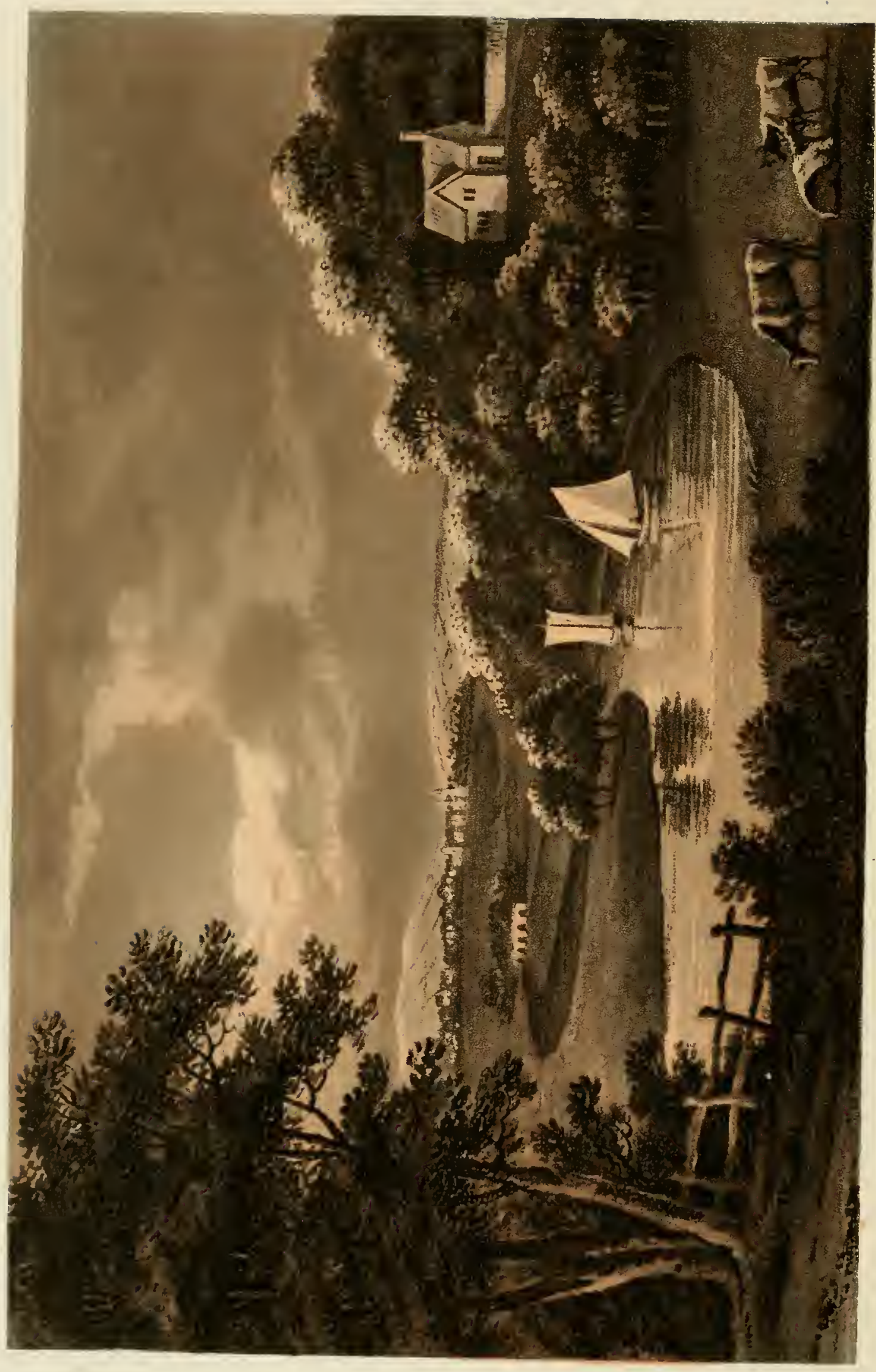


contrasted by the vivid green of the meadows, and the outline of distant Hills was distinctly marked by the brightness of the atmosphere. I could scarcely distinguish any other objects; but these formed a pleasing landscape from the breadth or contrast of light and shade.

In the evening the scene was changed; dark clouds reflected in the water rendered it almost invisible, the opposite hanging wood presented one glare of rich foliage; not so beautiful in the painter's eye, as when the top of each tree was relieved by small catching lights: but the most prominent features were the Buildings, the Boat, the Path, the Pales, and even the distant town of Reading, now strongly gilded by the opposite sun.

On comparing this effect with others which I have frequently since observed, I draw this conclusion: that certain objects appear best with the sun behind them, and others with the sun full upon them; and it is rather singular, that to the former belong all natural objects, such as Woods, Trees, Lawn, Water, and distant Mountains; while to the latter belong all artificial objects, such as Houses, Bridges, Roads, Boats, Arable-fields, and distant Towns or Villages.

In the progress of this work I shall have occasion to call the reader's attention to the principles here assumed, and which, in certain situations, are of great importance, and require to be well considered. 


\section{CHAPTER III.}

Water-it may be too naked or too much clothed-Example from West Wy Motion of Water-Eacumple at An LEst Rop-Art must deceive to imitate Nature-Cascade at Thовеsвy-The RivuletWater at Wentwonth described-A River easier to imitate than a Lake-A bubbling Spring may be imitated-A Ferry Boat at Holk inam-A rocky Channel at Harewood.

The observations in the preceding chapter concerning the reflection of sky on the surface of water, will account for that brilliant and cheerful effect produced by a small pool, frequently placed near a house, although in direct violation of nature: for since the ground ought to slope, and generally does slope from a house, the water very near it must be on the side of a hill, and of course artificial. Although I have never proposed a piece of water to be made in such a situation, I have frequently advised that small pools so umaturally placed should be retained. in compliance with that general satisfaction which the eye derives from the glitter of water, however absurd its situation.

It requires a degree of refinement in taste bordering on fastidionsness, to remove what is cheerful and pleasing to the eye, merely because it cannot be accounted for by the common laws of nature; I was, however, not sorry to discover some plea for my compliance, by considering, that although water on a hill 
is generally deemed unnatural, yet all rivers derive their sources from hills, and the highest mountains are known to have lakes or pools of water near their summits.

We object, therefore, not so much to the actual situation, as to the artificial management of such water. We long to break down the mound of earth by which the water is confined; although we might afterwards regret the loss of its cheerful glitter; and hence, perhaps, arises that baldness in artificial pools, so disgusting to the painter, and yet so pleasing to the less accurate observer. The latter delights in a broad expanse of light on the smooth surface, reflecting a brilliant sky; the former expects to find that surface ruffled by the winds, or the glare of light in parts obscured by the reflection of trees from the banks of the water; and thus while the painter requires a picture, the less scientific observer will be satisfied with a mirror.

During great part of last century West Wycombe was deemed a garden of such finished beauty, that to those who formerly remembered the place, it will seem absurd to suggest any improvement. But time will equally extend-its changing influence to the works of nature and to those of art, since the PLANTER has to contend with a power-

\footnotetext{
"A hidden power! at once his friend and foc!

'Tis Vegetatiox! Gradual to his groves She gives their wished effects, and that displayed, O! that her power would pause! but active still, She swells each stem, prolongs each vagrant bough, And darts, with unremitting vigour bold, From grace to wild luxuriance"
} 
'Thus at West Wrconbe, those trees and shrubs which were once its greatest ormament, have now so far outgrown their situation, that the whole character of the place is altered; and instead of that gaiety and cheerfulness inspired by flowering shrubs and young trees, gloom and melancholy seem to have reared their standard in the branches of the tallest elms, and to shed their influence on every surrounding object: on the House, by lessening its importance; on the Water, by darkening its surface; and on the Lawn, by lengthened shadows.

The prodigious height of the trees near the house has not merely affected the character, but also the very situation of the house. Instead of appearing to stand on a dry bank, considerably above the water (as it actually does) the house, oppressed by the neighbouring trees, became damp, and appeared to have been placed in. a gloomy bottom, while the water was hardly visible, from the dirk reflection of the trees on its surface, and the views of the distant hills were totally concealed from the house.

It is a fortunate circumstance for the possessor where improvement can be made rather by cutting down than by planting trees. The effect is instantly produced, and as the change in the scenery at this place has actually been realized before I could make a sketch to explain its necessity, the following drawing serves to record my reason for so boldly advising the use of the axe. I am well aware that my advice may subject me to the criticism of some, who will regret the loss of old trees, which, like old acquaintances, excite a degree of veneration, even when their age and infirmity have rendered them uscless, perhaps offensive, to all but their youthful associates. 
The tedious process of planting and rearing woods, and the dreadful havock too often made by injudiciously falling large trees, ought certainly to inspire caution and diffidence; but there is in reality no more temerity in marking the trees to be taken down than those to be planted, and I trust there has not. been a single tree displaced at $W_{\text {Est }} W_{\text {у сом ве, which has not }}$ tended to improve the healthfulness, the magnificence, and the beauty of the place.

Most of the principal rooms having a north aspect, the landscape requires peculiar management not generally understood ${ }^{1}$. Lawn, wood, and water, are always seen to the greatest advantage with the sun behind them, because the full glare of light between opposite trees destroys the contrast of wood and lawn; while water never looks so brilliant and cheerful when reflecting the northern, as the southern sky: a view therefore to the north would be dull and uninteresting without some artificial. objects, such as boats or buildings, or distant corn fields, to receive the opposite beams of the sun.

A sketch (in the Red Book) ${ }^{\mathrm{m}}$ shewed the effect of taking down trees to admit the distant woods, and by removing those on the island, and of course their reflection, the water becomes more conspicuous; in addition to this, the proposed new road of approach, with carriages occasionally passing near the banks of the lake, will give animation to the view from the saloon.

' This subject has been explained in the preceding Chapter.

" $\Lambda$ view of the house across the water, not here inserted, being exactly the reverse of that which represents the view towards the house, which is inserted. 


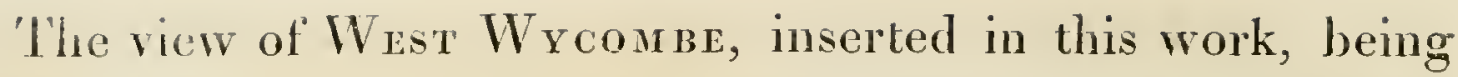
taken from the proposed approach, I shall here beg leave to make a short digression, explaining my reasons for that line, founded on some general principles respecting an approach, although it has no other reference to the water than as it justifies its course in passing the house to arrive at its object.

If the display of magnificent or of picturesque scenery in a park be made without ostentation, it can be no more at variance with good taste than the display of superior affluence in the houses, the equipage, the furniture, or the habiliment of wealthy individuals. It will, therefore, I trust, sufficiently justify the line of approach here proposed, to say, that it passes through the most interesting part of the grounds, and will display the scenery of the place to the greatest advantage, without making any violent or unnecessary circuit, to include objects that do not naturally come within its reach. This I deem to be a just and sufficient motive, and an allowable display of property without ostentation.

The former approach to the house was on the south side of the valley, and objectionable for two reasons; 1 st, it ascended the hill, and after passing round the whole of the buildings, it descended to the house, making it appear to stand low: gnd, by going along the side of the hill, little of the park was shewn, although the road actually passed through it; because, on an inclined plane, ${ }^{\mathrm{n}}$ the ground which either rises on one side or falls on the other, becomes fore-shortened and little observed, while the eye is directed to the opposite side of the

\footnotetext{
n This is explained in Chap. II.
} 


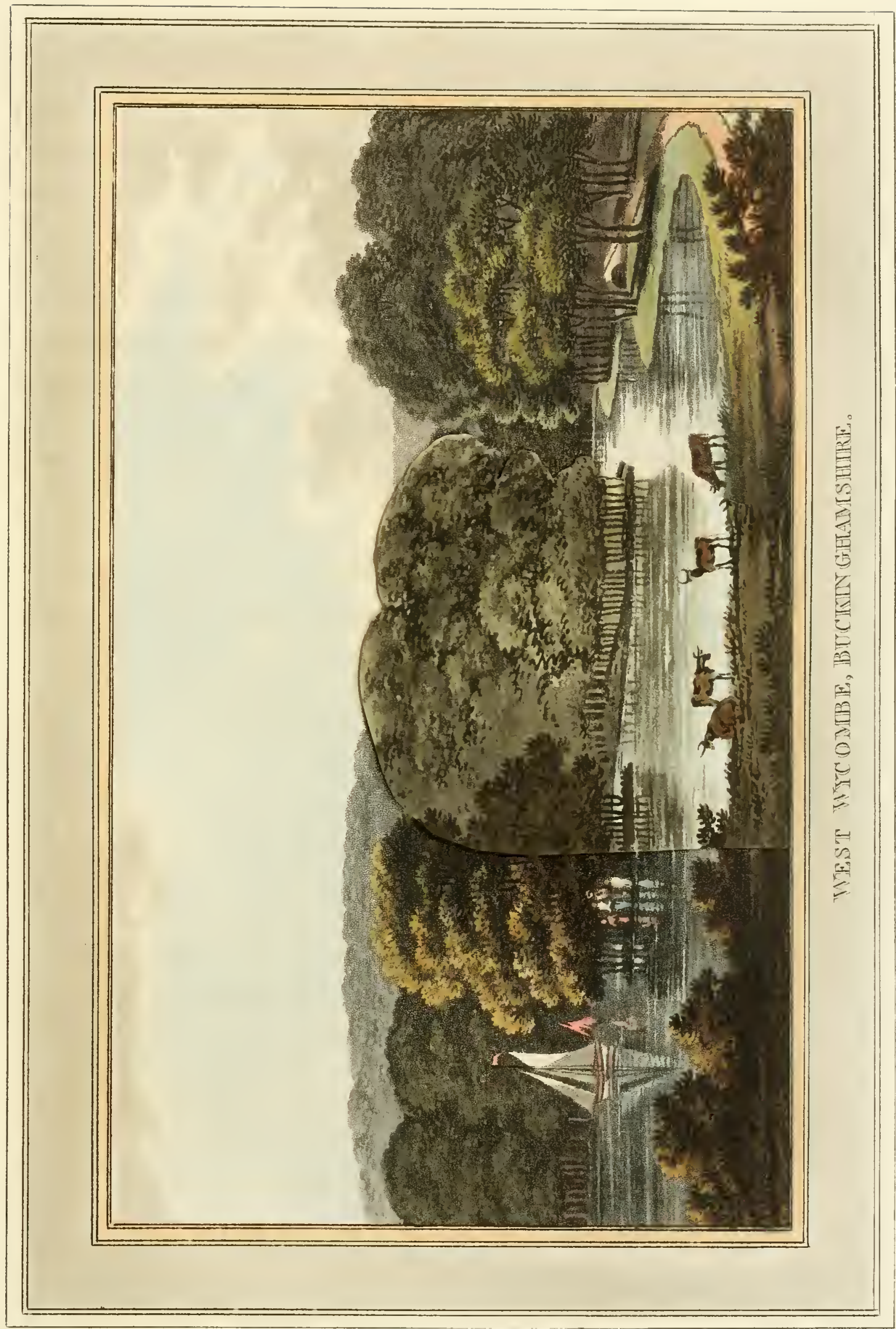





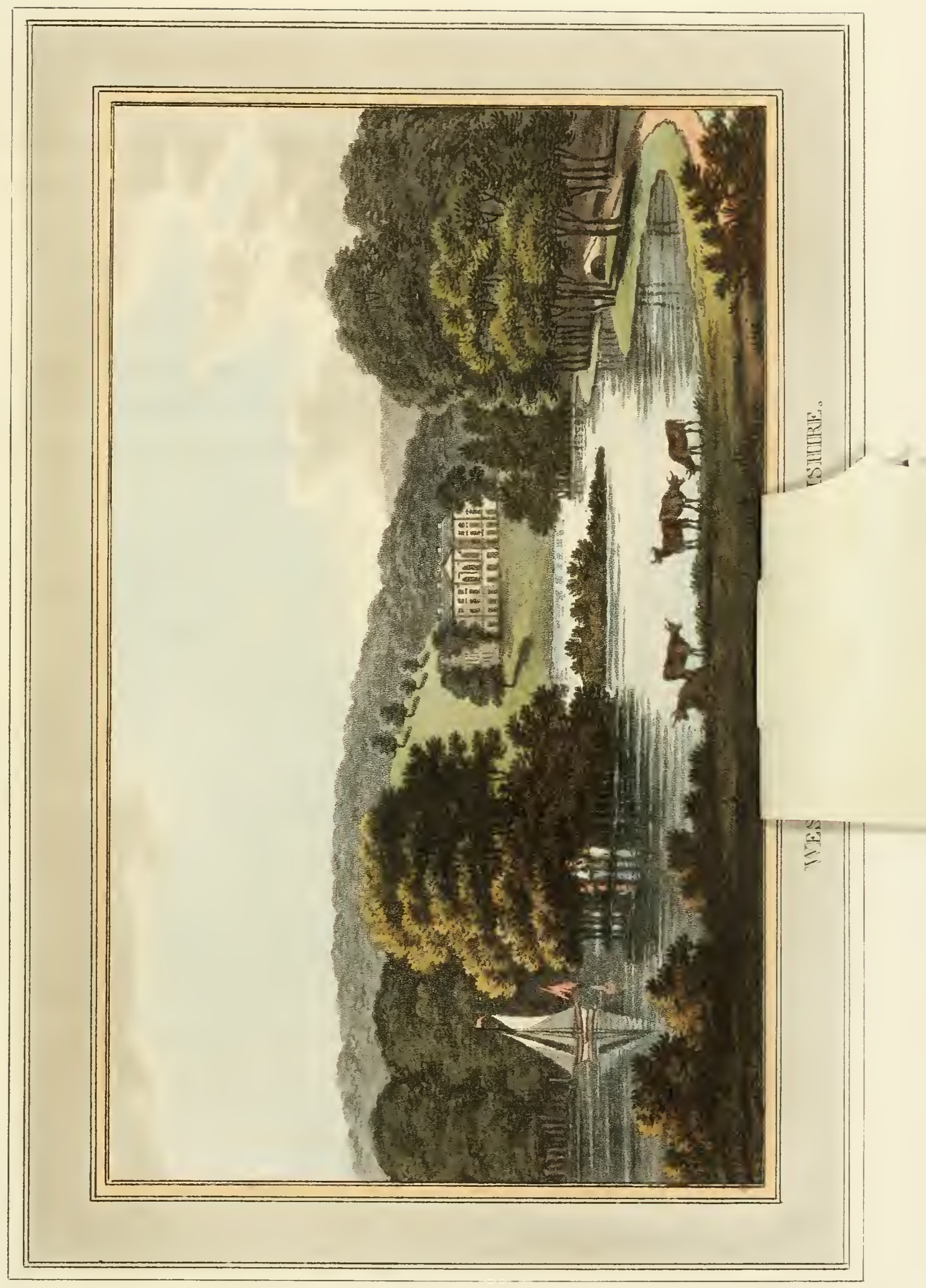



valley, which, in this instance, consisted of enclosmes beyond the park. On the contrary, the proposed new approach, being on the north side of the valley, will shew the park on the opposite bank to advantage, and, by ascending to the house, it will appear in its true and desirable situation upon a suficient eminence above the water; yet backed by still higher ground, richly clothed with wood, this view of the house will also serve to explain, and I hope to justify, the sacrifice of those large trees which have been ${ }^{\circ}$ cut down upon the island, and whose dark shadows being reflected on the water, excluded all cheerfulness.

The water at Wrst Wycombe, from the brilliancy of its colour, the variety of its shores, the different courses of its channel, and the number of its wooded islands, possessed a degree of pleasing intricacy which I have rarely seen in artificial pools or rivers; there appears to be only one improvement necessary to give it all the variety of which it is capable. The glassy surface of a still calm lake, however delightful, is not more interesting than the lively brook rippling over a rocky bed; but when the latter is compared with a narrow stagnant creek, it must have a decided preference; and as this advantage might

- Mr. Brown has been accused of cutting down large old trees, and afterwards planting small ones on the same spot; the annexed plate may serve to vindicate the propriety of his advice. 
easily be obtained in view of the house, I think it ought not to be neglected.

It may perhaps be objected, that to introduce rock scenery in this place would be unnatural; but if this artifice be properly executed, no eye can discover the illusion; and it is only by such deceptions that art can imitate the most pleasing works of nature. By the help of such illusion we may see the interesting struggles of the babbling brook, which soon after

This idea has been realized in the scenery at AdLestrop, where a small pool, very near the house, was supplied by a copious spring of clear water. The cheerful glitter of this little mirror, although on the top of the hill, gave pleasure to those who had never considered how much it lessened the place, by attracting the eye and preventing its range over the lawn and falling ground beyond. This pool has now been removed; a lively stream of water has been led through a flower garden, where its progress down the hill is occasionally obstructed by ledges of rock, and after a variety of interesting circumstances it falls into a lake at a considerable distance, but in full view both of the mansion and the parsonage, to each of which it makes a delightful, because a natural, feature in the landscape.

Few persons have seen the formal cascade at Troressy in front of the house, and heard its solemn roar, without wishing to retain a feature which would be one of the most interesting scenes in nature, if it could be divested of its disgusting and 
artificial formality; but this can only be effected by an equally violent, though less apparent, interference of art; because without absolutely copying any particular scene in Nature, we must endeavour to imitate the causes by which she produces her effects, and the effects will be natural.

The general cause of a natural lake, or expanse of water, is an obstruction to the current of a stream by some ledge or stratum of rock which it cannot penetrate; but as soon as the water has risen to the surface of this rock, it tumbles over with great fury, wearing itself a channel among the craggy fragments, and generally forming an ample bason at its foot. Such is the scenery we must attempt to imitate at 'Thoresbr. ${ }^{p}$

Having condemned the ill-judged interference of art in the disposition of the ground and water at Thoressy, it may perhaps be objected that I now recommend an artificial management not less extravagant; because I presume to introduce some appearance of rock scenery in a soil where no rock naturally exists; but the same objection might be made with equal propriety to the introduction of an artificial lake in a scene where no lake before existed. When under the guidance of Le Nôtre and his disciples, the taste for geometric gardening prevailed, nature was totally banished or concealed by the works of art.

- No drawing is inserted of this cascade, because the whole has been so weli executed, that the best reference is to the spot itself, which will, I trust, long continue to prove my art "above the pencil's power to imitate."

In forming this cascade huge masses of rock were brought from the craigs of Creswell, one in particular of many tons weight, with a large tree growing in its fissures; the water has been so conclucted by concealed leaden pipes, that in some places it appears to have forced its way through the lerlges of the rocks. 
Now in defining the shape of land or water, we take nature for our model; and the highest perfection of landscape gardening is, to imitate nature so judiciously, that the interference of art shall never be detected.

\section{L'Arte che tutto fa nulla se scopre.}

A rapid stream, violently agitated, is one of the most interesting objects in nature. Yet this can seldom be enjoyed except in a rocky country; since the more impetuous the stream, the sooner will it be buried within its banks, unless they are of such materials as can resist its fury. To imitate this natural effect, therefore, in a soil like that of Thoresвy, we must either force the stream aloove its level and deprive it of natural motion, or introduce a foundation of stones disposed in such a manner as to appear the rocky channel of the mountain stream. The former has been already done in forming the lake, and the latter has been attempted according to the fashion of geometric gardening in the regular cascade; where a great body of water was led under ground from the lake to move down stairs, into a scolloped bason, between two bridges immediately in front of the house.

The violence done to nature by the introduction of rock scenery at Thoresiy is the more allowable, since it is within a short distance of Derbyshire, the most romantic county in England; while from the awful and picturesque scenery of Creswell Craigs such strata and ledges of stone, covered with their natural vegetation, may be transported thither, that no eye can discover the fraud.

It is scarcely possible for any admirer of nature to be more 
enthusiastically fond of her romantic scenery than myself; but her wildest features are seldom within the common range of man's habitation. The rugged paths of alpine regions will not be duily trodden by the foot of affuence, nor will the thundering cataracts of Niagara seduce the votaries of pleasure fiequently to visit their wonders; it is only by a pleasing illusion that we can avail ourselves of those means which nature herself furnishes even in tame scenery to imitate her bolder effects; and to this illusion, if well conducted, the eye of gemuine taste will not refuse its assent.

"La nature fuit les lieux frequentés, c'est au sommet des montagnes, au fond des forèts, dans les isles desertes, qu'elle etale ses charmes les plus touchants, ceux qui l'aiment et ne peuvent l'aller chereher si loin, sont reduits à lui faire violence, et à la forcer en quelque sorte à venir habiter parmi eux, et tout cela ne pcut se faire sans un pen d'illusion."-J. J. Rousseav.

One of the views from the house at Thoressy looked towards

___ " the long line

Deep delr.d of flat canal, and all that toil

Misled by tasteless fashion could atchieve

To mar fair nature's lineaments divine." Mason.

As in this instance I shall have occasion to propose a different idea to that suggested by Mr. Brown, I must beg leave to explain the reasons on which I ground my opinion. 
Amidst the numerous proofs of taste and judgment which that celebrated landscape gardener has left for our admiration, he frequently mistook the character of rumning water; he was too apt to check its progress by converting a lively river into a stagnant pool, nay, he even dared to check the progress of the furious Derwent at Chatsworth, and transform it into a tame and sleepy river unworthy the majesty of that palace of the mountains. Such was his intention with respect to the stream of water which flows through Thon еsв presents a magnificent expanse of water, the river below the cascade should be restored to its natural character: a vivulet in motion.

At Wentworth, although the quantity of water is very considerable, yet it is so disposed as to be little seen from the present approach, and when it is crossed in the drive on the head between two pools, the artificial management destroys much of its effect: they appear to be several distinct ponds, and not the series of lakes which nature produces in a mountainous country. But the character of this water should rather imitate one large river than several small lakes; especially as it is much easier to produce the appearance of continuity, than of such vast expanse as a lake requires. The following sketch is a view of the scenery presenting itself under the branches of trees, which act as a frame to the landscape.

To preserve the idea of a river nothing is so effectual as a 


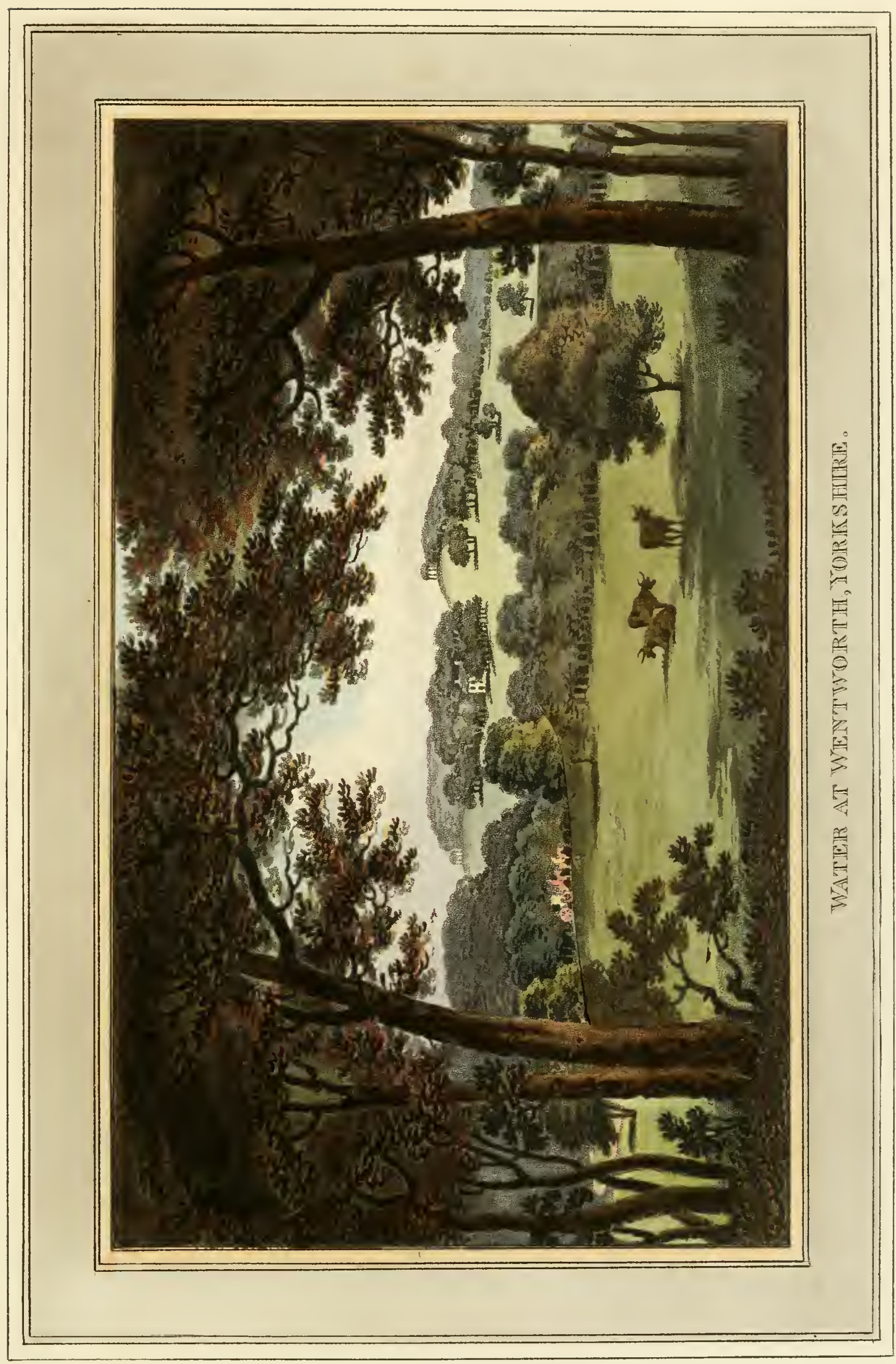





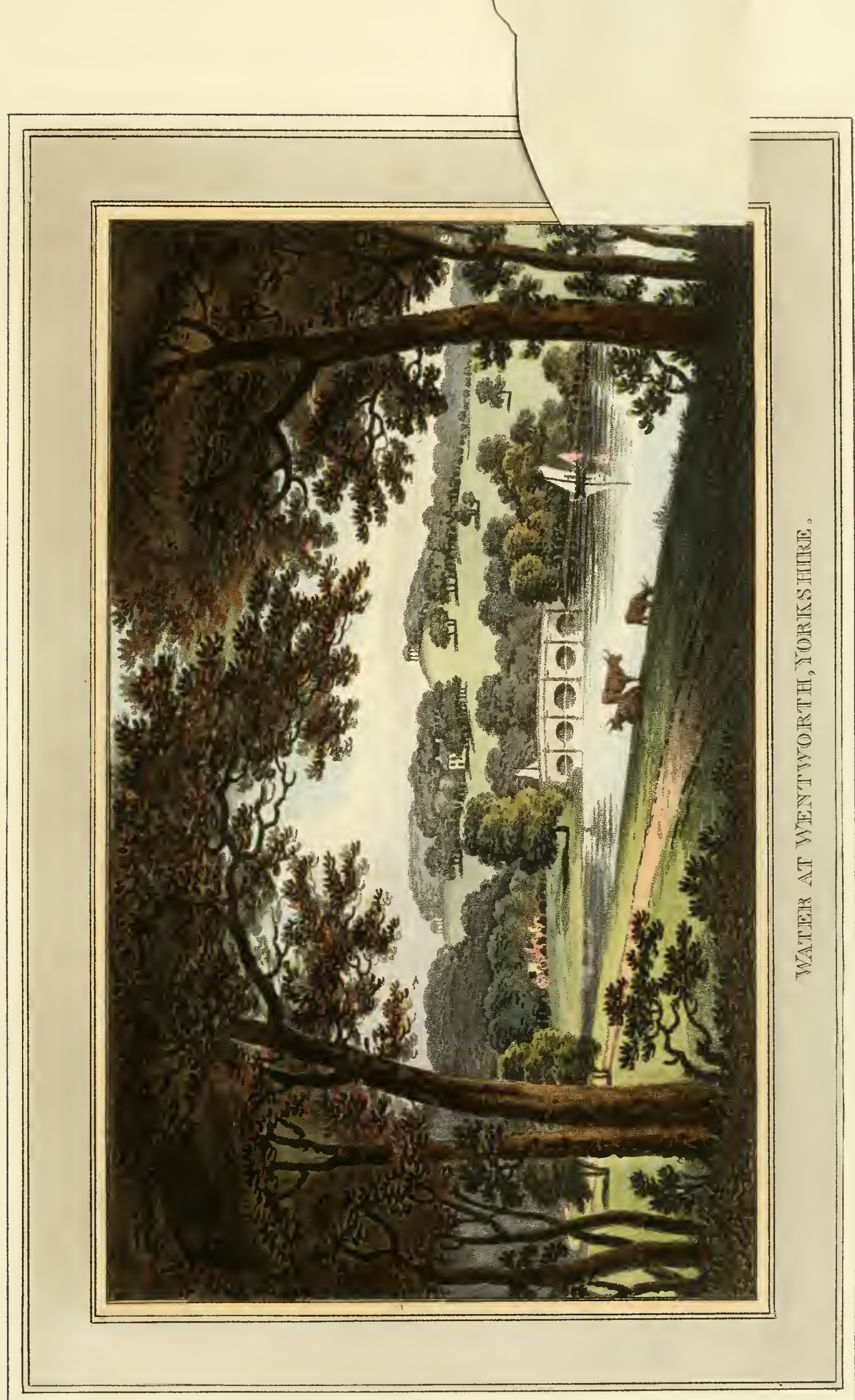



bridge; instead of dividing the water on each side, it always tends to lengthen its continuity by shewing the impossibility of crossing it by any other means, provided the ends are well concealed, which is fortunately the case with respect to this water. Although the upper side of the bridge would be very little seen because the banks are every where planted; yet as the bridge would not be more than fifty yards long, it would be more in character with the greatness of the place to have such a bridge as would no where appear a deception, and in this case the different levels of the water (being only five feet) would never be discovered.

The rippling motion of water is a circumstance to which Improvers have seldom paid sufficient attention. They generally aim at a broad expanse and depth, not considering that a narrow shallow brook in motion over a gravelly bottom is not less an object of beauty and worthy of imitation; the deep dell betwixt the boat-house and the bridge, might be rendered very interesting by bringing a lively brook along the valley; the embouchure of this brook should be laid with gravel, to induce cattle to form themselves in groups at the edge of the water, which is one of the most pleasing circumstances of natural landscape. It sometimes happens near large rivers that a clear spring bubbles from a fountain, and pours its waters rapidly into the neighbouring stream; this is always considered a delightful object in nature, yet I do not recollect it has ever been imitated by art; it would be very easy to produce it in this instance by leading water in a channel from the upper pool, and after passing under ground by tubes for a few yards, let it suddenly burst through a bed of sand and stones, and being 
thus filtered by ascent, it would ripple along the valley till it joined the great water. Milton was aware of this contrast between the river and the rill, where he mentions amongst the scenery of his Allegro,

"Shallow brooks and rivers wide."

As applicable to the suljject of this chapter, I shall insert the following extract from the Red Book of Hour ma m.

"The opposite banks in the middle part of the lake being the most beautiful ground in HoLk нам park, it is a desirable object to unite them without the long circuit which must be made by land round either end of the lake.

A bridge, however elegant for the sake of magnificence, or however simple for the sake of convenience, would be improper; because it would destroy the effect of the lake, and give it the character of a river, which its round and abrupt terminations render improbable. I therefore propose to unite these opposite shores by a ferry-boat of a novel construction, so contrived as to be navigated with the greatest safety and ease, as explained by the following sketch.

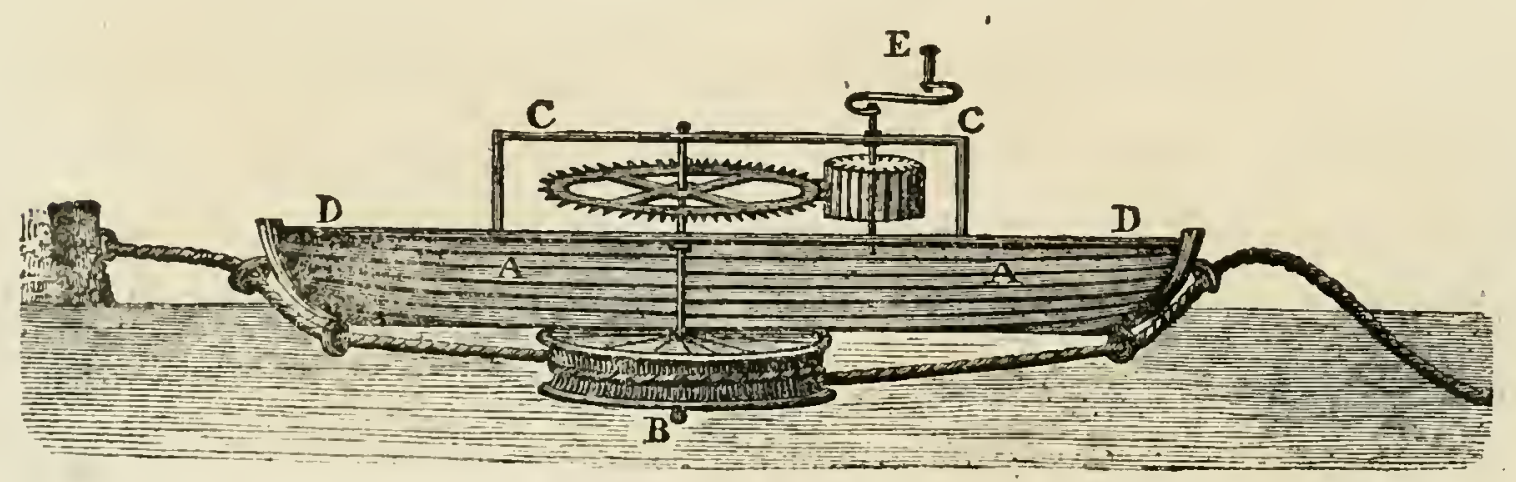




\section{EXPLANATION.}

The ferry-boat to be a broad flat-bottomed punt A. at the bottom is a pulley-shaped wheel and axis B. about a yard in diameter, carrying a rope fastened to the two opposite sides of the lake, which will sink to admit the passing of other boats; this wheel is put in motion by the correspondent one above it, which has five times as many teeth as the pinion C. consequently at every five turns of the winch $\mathrm{E}$. the wheel makes one revolution, and the boat advances three yards, or three times the diameter of the wheel; at each end of the boat the rope must pass through rings of brass smoothly polished, which will always guide it to one certain spot. The whole machinery, which is very simple, and not likely to be out of order, may be covered by a box C. C. to form a convenient seat in the centre of the ferry-boat, and the surface or deck of this boat D. may be covered with gravel and cement, having a hand-rail on each side; thus it will in a manner become a moveable part of the gravel walk."

Where two pieces of water are at some distance from each other, and of such different levels that they cannot easily be made to unite in one sheet: if there be a sufficient supply to furnish a continual stream, or only an occasional redundance in winter, the most picturesque mode of uniting the two, is by imitating a common process of nature in mountainous countries, 
where we often see the water in its progress from one lake to another, dashing among broken fragments, or gently gliding over ledges of rock, which form the bottom of the channel: this may be accomplished at $H_{A R E w O O D}$, where the most beautiful stone is easily procured; but in disposing the ledges of rock, they should not be laid horizontally, but with the same slanting inclination that is observed more or less in the bed of the neighbouring river. A hint of such management is shewn under this bridge, the design of which may serve as a specimen of architecture, neither too much nor too little ornamented for rock scenery, in the neighbourhood of a palace.

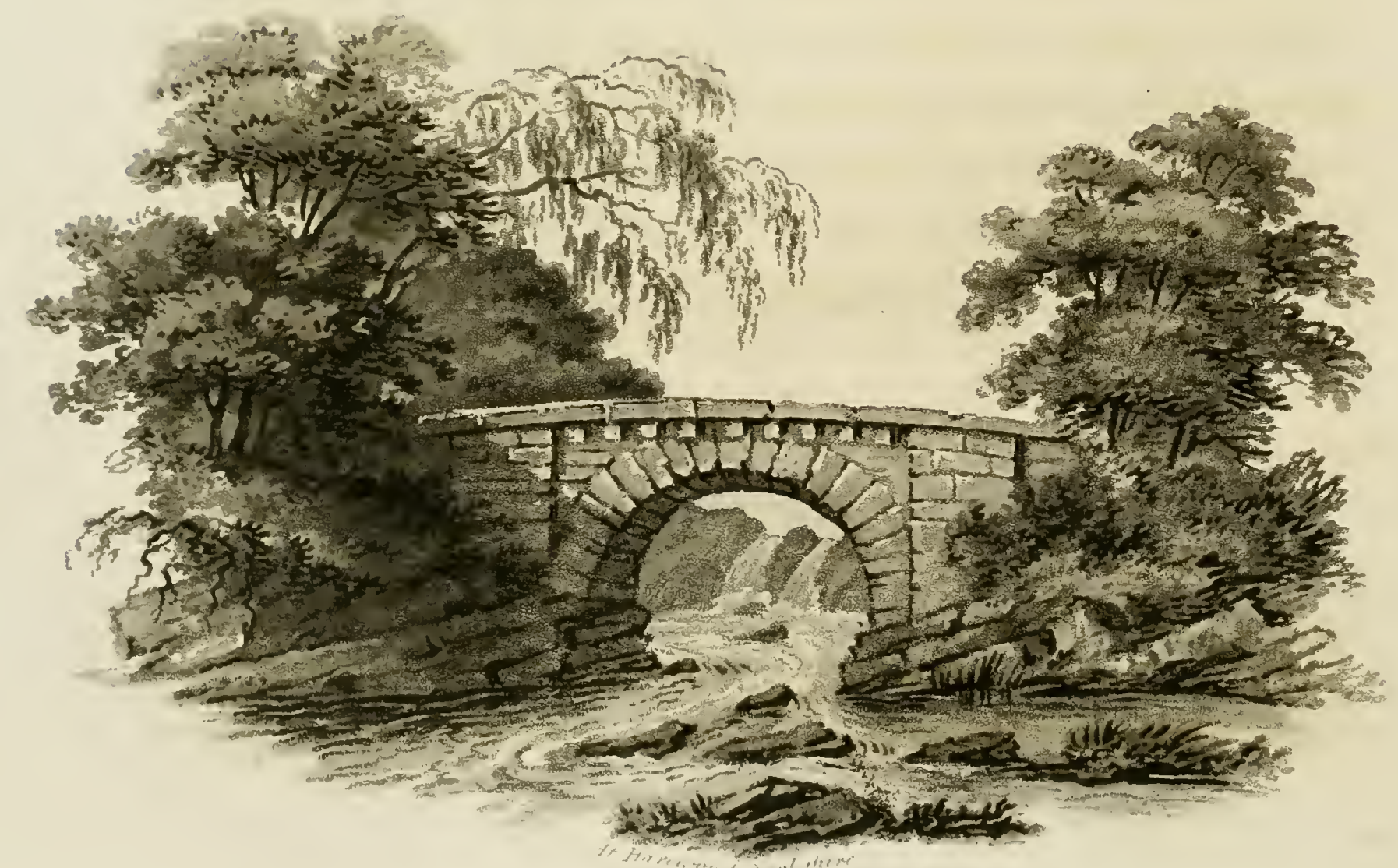




\section{CHAPTER IV.}

of PLANTING for immediate and for future Effect-ClumpsGroups-Masses - New Mode of planting Wastes and Commons -the browsing Line described-Example Milton AввеуCombination of Masses to produce great Woods-Example Coоnв Lodge-Character and Shape of Ground to be studied -Outline of new Plantations.

THE following observations on planting are not intended to pursue the minute detail so copiously and scientifically described in Evelyn's Sylva, and so frequently quoted, or rather repeated from him, in modern publications; I shall merely consider it as a relative subject: and being one of the chief ornaments in landscape gardening when skilfully appropriated, I shall divide it into two distinct heads: the first including those single trees or groups which may be planted of a larger size to produce present effect; the second comprehending those masses of plantation clestined to become woods or groves for future generutions.

Since few of the practical followers of Mr. Brown possessed that force of genius which rendered him, according to MAson,

Ghe living leader of thy powers,

Great Nature"

it is no wonder that they should have occasionally copied the means he used, without considering the effect which he intended 
to produce. Thus Brown has been treated with ridicule by the contemptuous observation, that all his improvements consisted in belting, chumping, and dotting; but I conceive the two latter onght rather to be considered as cause and effect, than as two distinct ideas of improvement; for the disagreeable and artificial appearance of young trees, when protected by what is called a cradle fence, together with the difficulty of making them grow thus exposed to the wind, induced Mr. Brown to form small clumps fenced round, containing a number of trees calculated to shelter each other, and to promote the growth of those ferv which might be ultimately destined to remain and form a group.

This I apprehend was the origin and intention of those clumps, and that they never were designed as ornaments in themselves, but as the most efficacious and least disgusting manner of producing single trees and groups to vary the surface of a lawn, and break its uniformity by light and shadow.

In some situations where great masses of wood, and a large expanse of open lawn prevail, the contrast is too violent, and the mind becomes dissatisfied by the want of unity; we are never well pleased with a composition in natural landscape, unless the wood and the lawn are so blended that the eye cannot trace the precise limits of either; yet it is necessary that each should preserve its original character in broad masses of light and shadow; for although a large wood may be occasionally relieved by clearing small openings to break the heaviness of the mass, or vary the formality of its outline, yet the general character of sharle must not be destroyed.

In like manner the too great expanse of light on a lawn must 
be broken and diversified by occasional shadow, but if too many trees be introduced for this purpose, the effect becomes fritter'd, and the eye is offended by a deficiency of composition, or, as the painter would express it, of a due breadth of light and shade. Now it is obvious, that in newly formed places, such a redundance of trees will generally remain from former hedgerows, that there can seldom be occasion to increase the number of single trees, though it will often be advisable to combine them into proper groups.

It is a mistaken idea scarcely worthy of notice, that the beauty of a group of trees consists in odd numbers, such as five, seven, or nine; a conceit which I have known to be seriously asserted.' I should rather pronounce that no group of trees can be natural in which the plants are studiously placed at equal distances, however irregular in their forms. Those pleasing combinations of trees which we admire in forest scenery, will often be found to consist of forked trees, or at least of trees placed so near each other that the branches intermix, and by a natural effort of vegetation the stems of the trees themselves are forced from that perpendicular direction, which is always observable in trees planted at regular distances from each other. No groups will therefore appear natural unless two or more trees are planted very near each other, ${ }^{p}$ whilst the perfection of a group consists in the combination of trees of different age, size, and character.

Po produce this effect $t$ wo or more trees should sometimes be planted in the same hole, cutting their roots so as to bring them nearer together; and we sometimes observe great beauty in a tree and a bush thus growing together, or even in trees of different characters, as the great oak and ash at Welbeck, and the oak and beech in Windsor Forest. Yet it will generally be more consonant to nature if the groups be tormed of the same species of trees. 
The two sketches in the annexed plate exemplify this remark; the first represents a few young trees protected by cradles, and though some of them appear nearer together than others, it arises from their being seen in perspective, for I suppose them to be planted (as they usually are) at nearly equal distances. In the same landscape I have supposed the same trees grown to a considerable size, but from their equi-distance, the stems are all parallel to each other, and not like the group below, where being planted much nearer, the trees naturally recede from each other. A few low bushes or thorns produce the kind of group in the lower sketch, consisting of trees and bushes of various growth. It may be observed that the single tree, and every part of the upper sketch is evidently artificial, and that the lower one is natural, and like the groups in a forest.

Another source of variety may be produced by such opake masses of spinous plants as protect themselves from cattle; thus stems of trees seen against lawn or water are comparatively dark, while those contrasted with a back ground of wood appear light. This difference is shewn in both these sketches: the stems of the trees A. A. appear light, and those at B. B. are dark, merely from the power of contrast, although both are exposed to the same degree of light.

Where a large tract of waste heath or common is near the boundary of a park, if it cannot be inclosed, it is usual to dot certain small patches of trees upon it, with an idea of improvement; a few clumps of miserable Scotch firs, surrounded by a mud wall, are scattered over a great plain, which the modern improver calls "clumping the common." It is thus that Hounslow Heath has been clumped; and even the vast range of country 


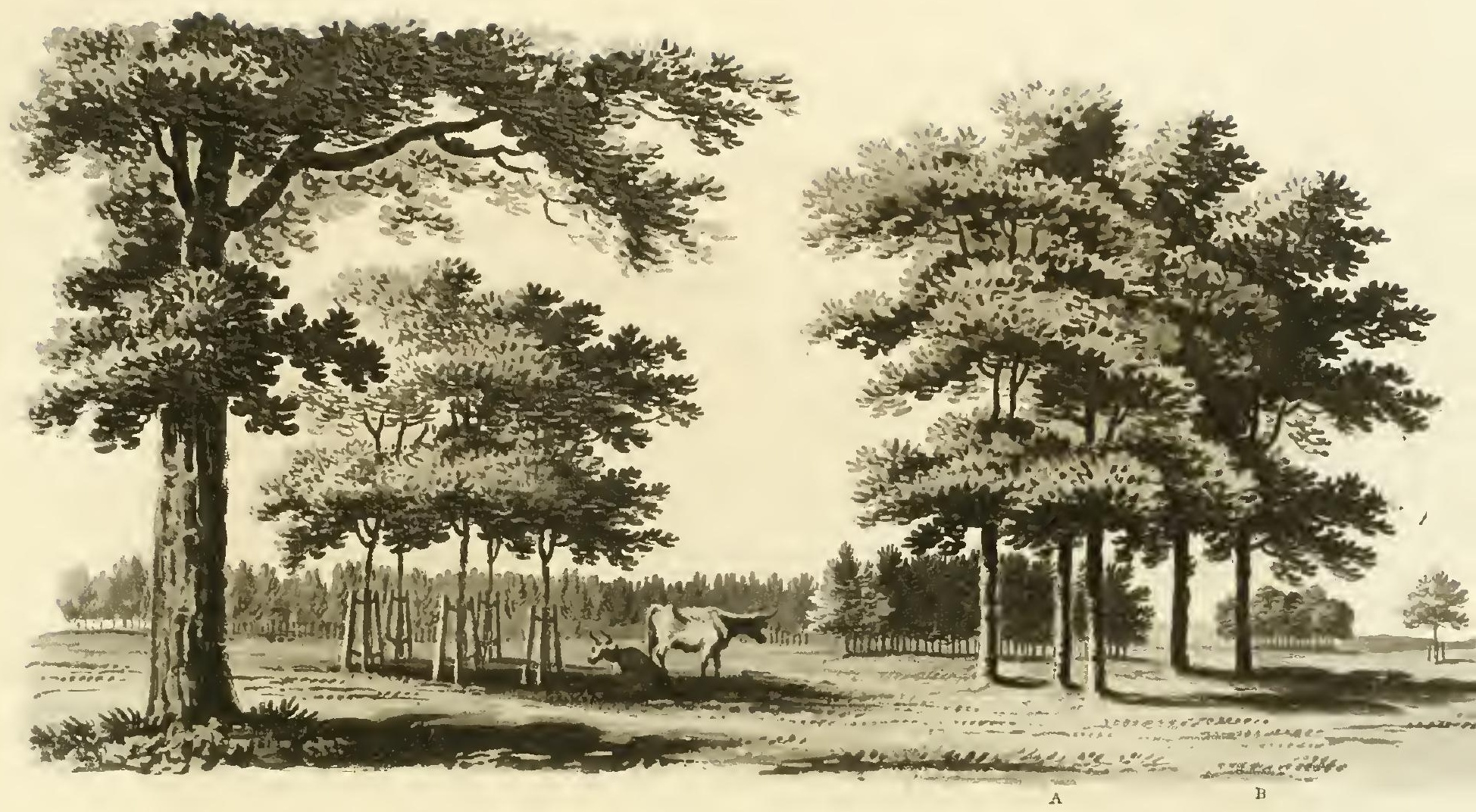

- Xrtificied. Son nery

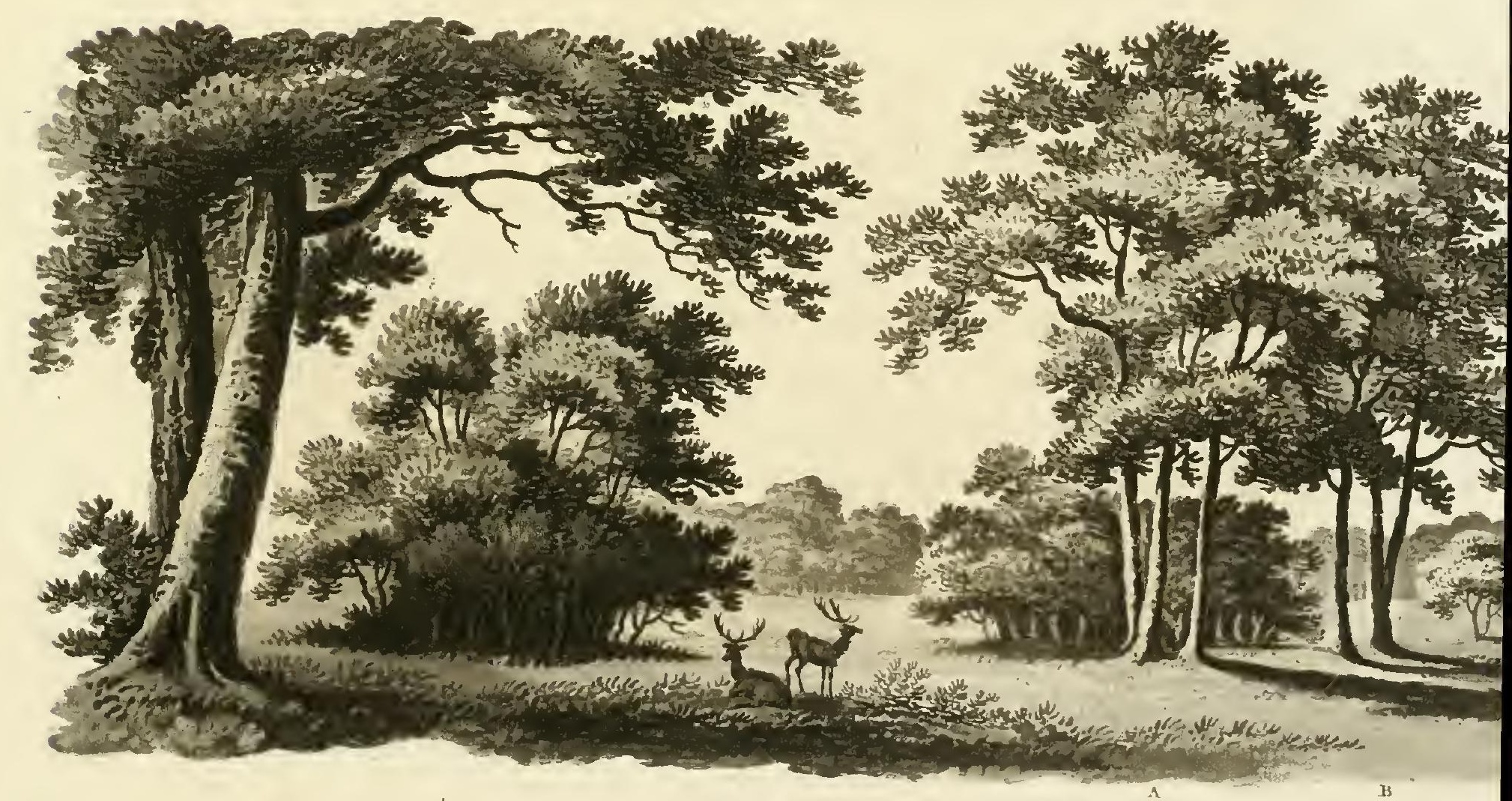



formerly the Forest of Sherwood, has submitted to this meagre kind of misnamed ornament.

It may appear unaccountable that these examples, which have not the least beauty either of nature or art to recommend them, should be so generally followed; but alteration is frequently mistaken for improvement, and two or three clumps of trees, however bad in themselves, will change the plain surface of a flat common. This I suppose has been the cause of planting some spruce firs on MAIDEx EARLY Common, which fortunately do not grow; for if they succeeded, the contrast is so violent between the wild surface of a heath, and the spruce appearance of firs, that they would be misplaced: besides, the spiral firs are seldom beautiful, except when their lower branchès sweep upon the ground, and this could never be the case with those exposed to cattle on a common.

A far better method of planting waste land, where inclosures are not permitted, has been adopted with great success in Norfolk, by my much valued friend the late Robert Marsham, Esq. of Stratton. Instead of firs surrounded by a mud bank, he placed decidnous trees of every kind, but especially birch, intermixed with thorns, crabs, and old hollies, cutting off their heads and all their branches about eight feet from the ground: these are planted in a puddle and the earth laid round their roots in small hillocks, which prevent the cattle from standing very near to rub them; and thus $I$ have seen groups of trees which looked like bare poles the first year, in a very short time become beautiful ornaments to a dreary waste. 


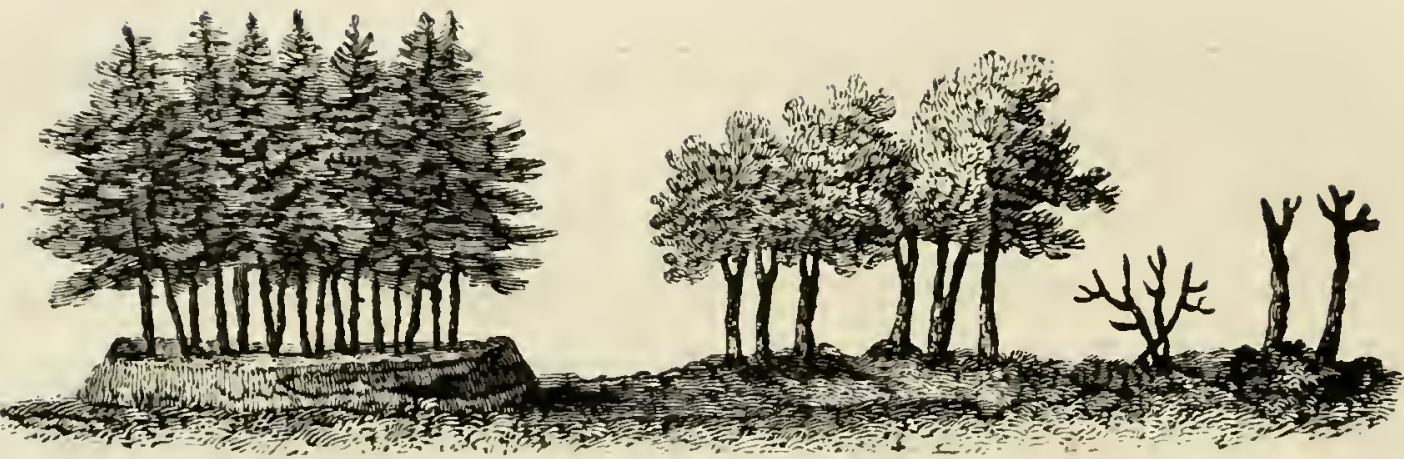

'This sketch shews the difference between the sort of clump so often seen on a common, and that mode of planting stumps of trees and thorns recommended in the foregoing page; the appearance at first is not very promising, but in a few years they will become such irregular groups and natural thickets as are represented below, while the formal clump of firs will for ever remain an artificial object.

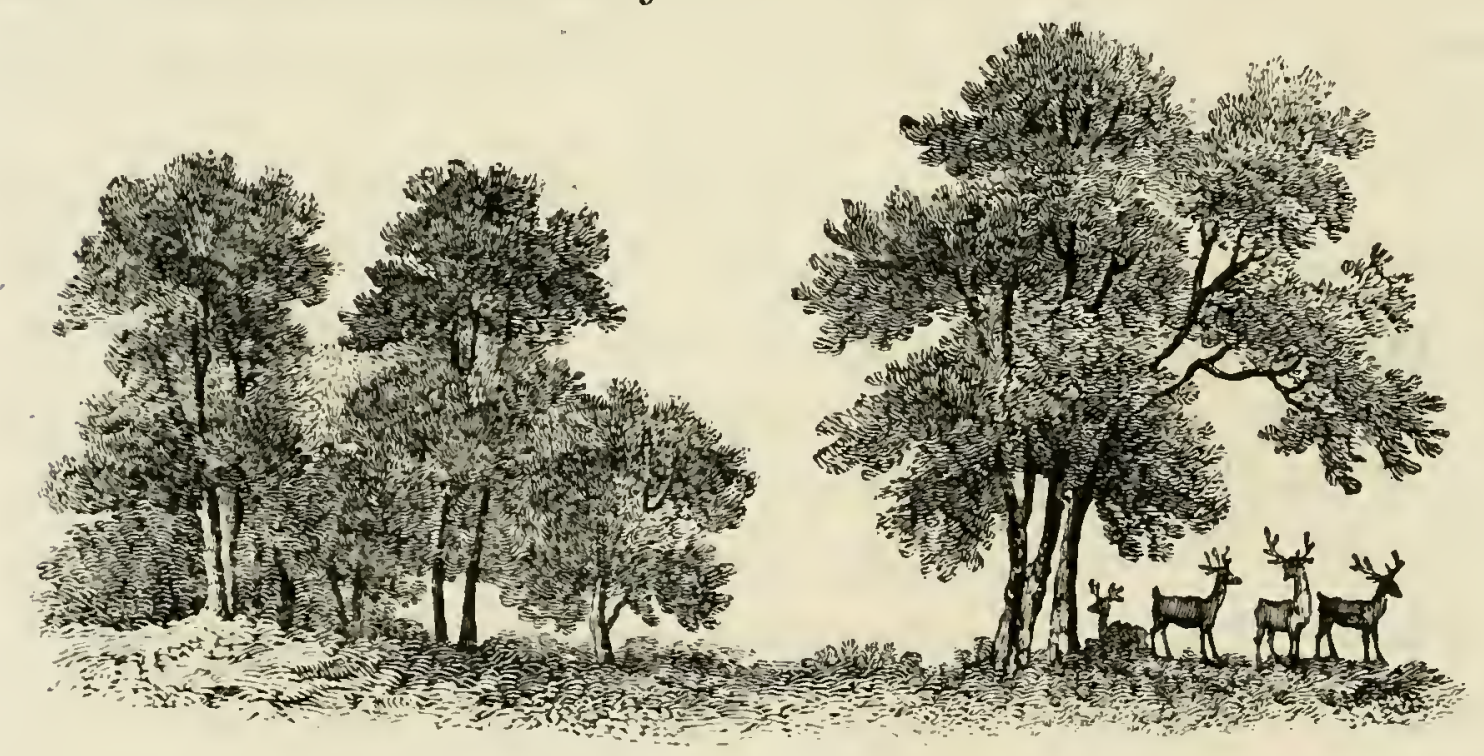

Mr. Gilpin, in his Forest Scenery, has given some specimens of the outlines of a wood, one of which is not unlike that beauliful skreen which bounds the park to the north of Milton ABBEY, and which the first of the two annexed sketches more 


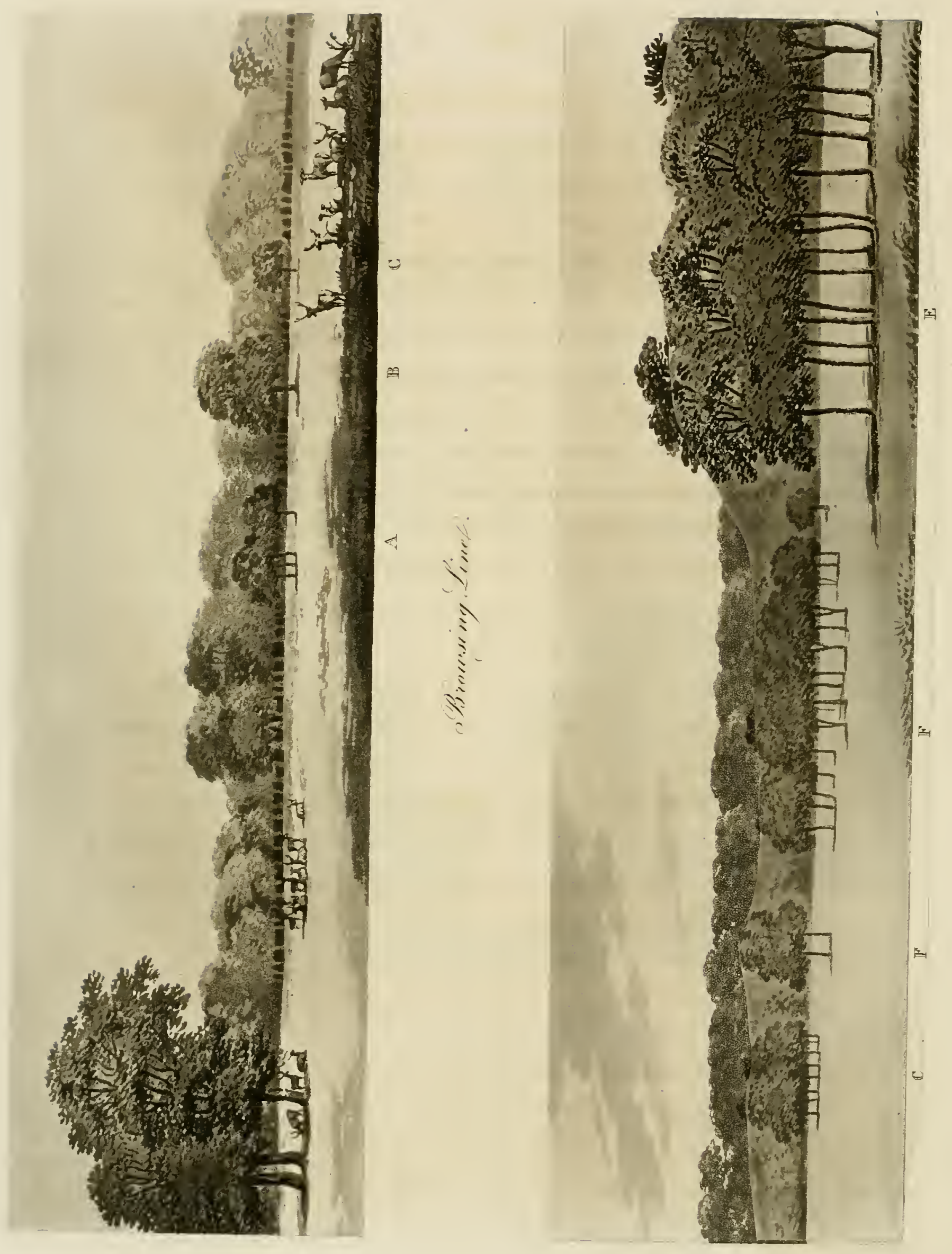
accurately represents. We have here a very pleasing and varied line formed by the tops of trees, but from the distance at which they are viewed, they seem to stand on one straight base line, although many of the trees are separated from the others by a considerable distance: the upper outline of this skreen is so happily varied, that the eye is not offended by the straight line at its base; but there is another line which is apt to ereate disgust in flat situations, and for this reason; all trees unprotected from cattle will be stripped of their foliage to a certain height, and where the surface of the ground is perfectly flat, and forms one straight line, the stems of trees thus brought to view by the browsing of cattle, will present another straight line parallel to the ground, at about six feet high, which I shall call

THE ${ }^{\text {q BROWSING LINE. }}$

Whether trees be planted near the eye or at a distance from it, and whether they be very young plants or of the greatest stature, this browsing line will always be parallel to the surface of the ground, and being just above the eye, if the heads of single trees do not rise above the outline of more distant woods, the stems will appear only like stakes of different sizes scattered about the plain; this is evidently the effect of those single thorns or trees in the upper sketch marked A. B. C.

In the lower sketch I have represented a view of that long

4 All trees exposed to cattle are liable to this browsing line, although thorns, crabs, and other prickly plants, will sometimes defend themselves; the alder, from the bitterness of its leaves, is also an exception; but where sheep only are almitted, the line will be so much below the eye, that it produces a different effect, of which great advantage may sometimes be taken, especially in flat situations. 


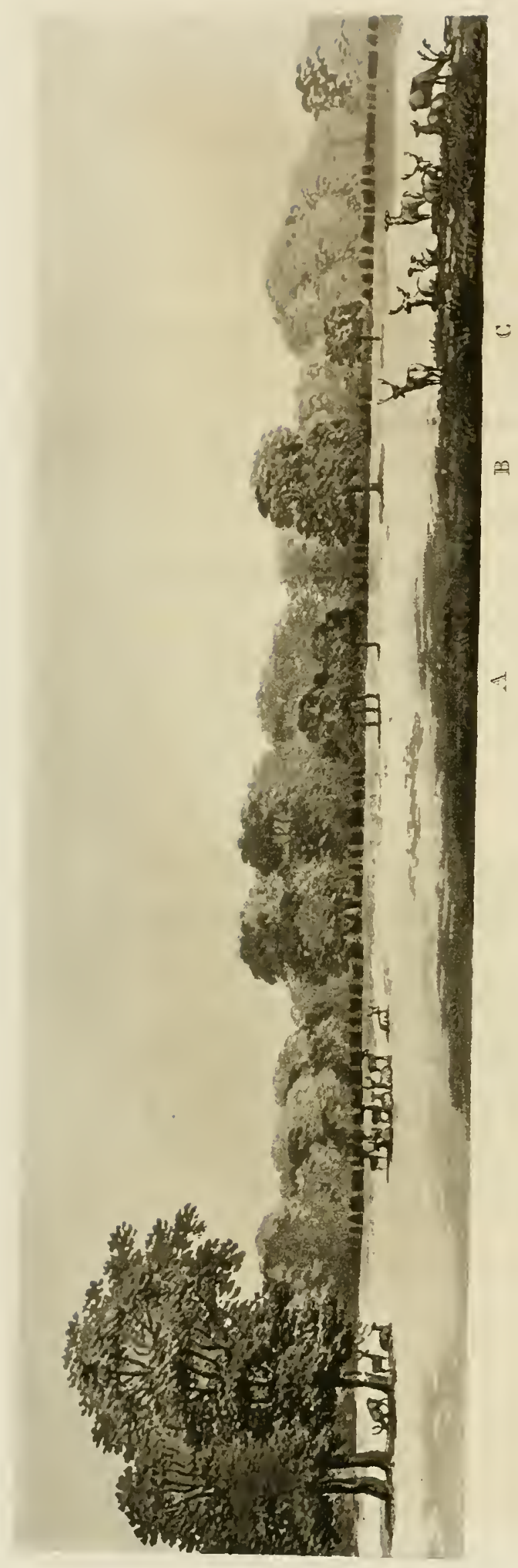

ำ

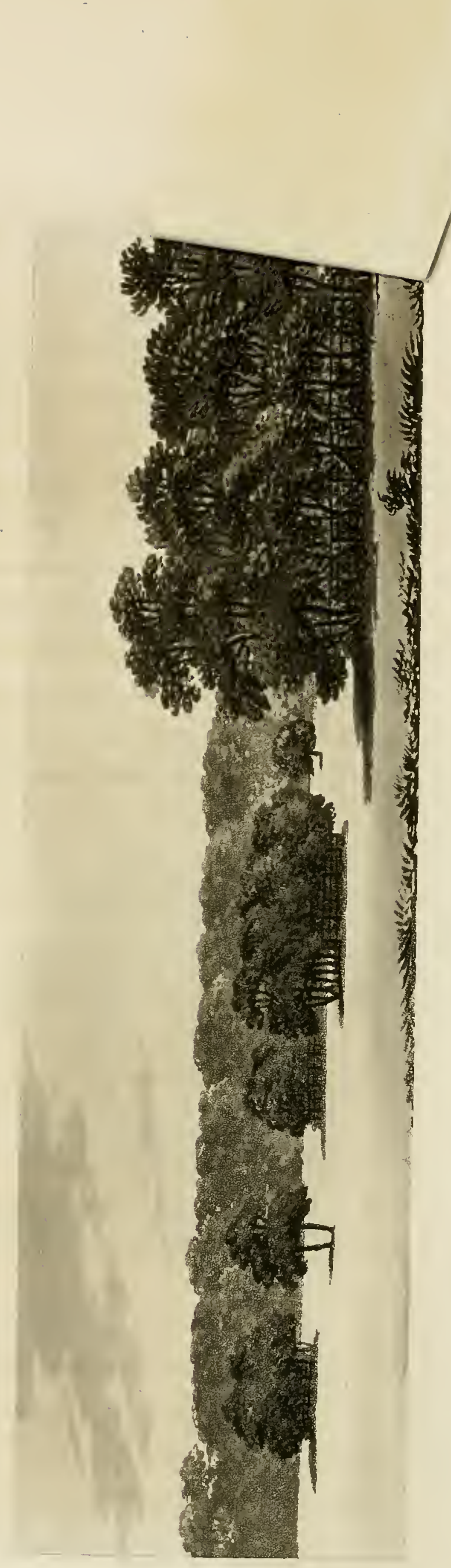



skreen at Milton Aвbey, which shuts out Castor Field, and which is certainly not a pleasing feature, from its presenting not only a straight line at the bottom, but the trees being all of the same age; the top outline is also straight. This skreen forms the back ground of a view taken from the approach, and the slide represents the difference between an attempt to break the uniformity of the plain by open or by close plantations.

The trees of this skreen are of such a height that we can hardly expect in the life of man to break the upper outline by any young trees, except they are planted very near the eye as at $\mathrm{E}$. because those planted at F. or G. will, by the laws of perspective, sink beneath the outline of the skreen; it is therefore not in our power to vary the upper line, and if the plantations be open, the browsing line will make a disagreeable parallel with the even surface of the ground; this can only be remedied by preventing cattle from browsing the underwood, which should always be encouraged in such situations; thus, although we cannot vary the upper line of this skreen, we may give such variety to its base as will, in some measure, counteract the flatness of its appearance.

The browsing line being always at nearly the same distance of about six feet from the ground, it acts as a scale, by which the eye measures the comparative height of trees at any distance; for this reason the importance of a large tree may be injured by cutting the lower branches above this usual standard. It is obvious that the following trees are of different ages, characters, and heights, yet the browsing line is the same in all, and furnishes a natural scale by which we at once decide on their relative height at various distances. 


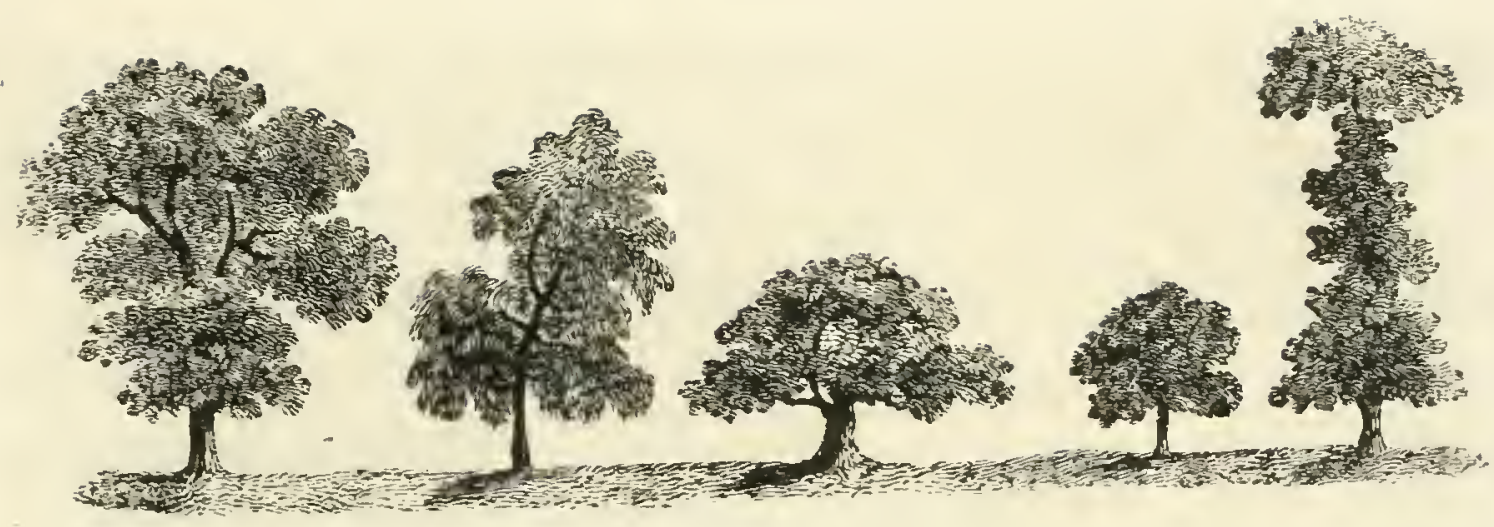

Let us suppose the same trees pruned or trimmed by man, and not by cattle, and this scale will be destroyed; thus a full grown oak may be made to look like an orchard tree, or by encouraging the under branches to grow lower than the usual standard, a thorn or a crab tree may be mistaken for an oak at a distance.

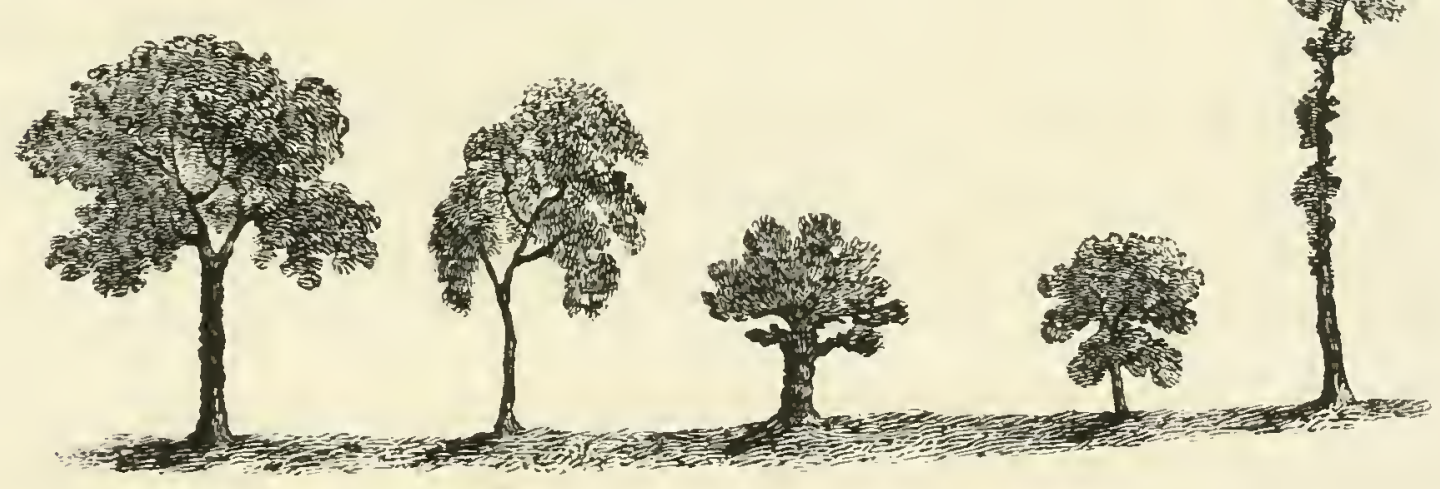

The last tree in the foregoing example is supposed to be one of those tall elms which, in particular counties, so much disfgure the landscape; it is here introduced for the sake of the following remark. I am sorry to have observed, that when trees have long been used to this unsightly mode of pruning, it is difficult, or indeed impossible, to restore their natural shapes, 
because if the lower branches be suffered to grow, the tops will soon decay; and therefore they must either be continued tall by occasionally cutting off the lateral branches, or they must be converted into pollards by cutting off their tops.

Single trees, or open groups, are objects of great beauty when scattered on the side of a steep hill, because they may be made to mark the degree of its declivity, and the shadows of the trees are very conspicuous; but on a plain the shadows are little seen, and therefore single trees are of less use.

I am now to speak of plantations for future, rather than for immediate effect, and instead of mentioning large tracts of land which have been planted under my directions, where a naked, or a barren country, has been clothed without difficulty or contrivance, I shall rather instance a subject requiring peculiar management, especially as from its vicinity to a high road, I cannot perhaps produce a better example than the following extract furnishes.

"Coom be Lodge, seen from the turnpike road, does not at present give a favourable impression; for though the view from the house, consisting of the opposite banks of Basildon, is richly wooded, the place itself is naked; and it is difficult to remove this objection without sacrificing more land to the purposes of beauty, than would be advisable, or even justifiable.

Both the situation and the outline of the house at Coombe LODGE have been determined with judgment: the situation 
derives great advantage from its southern aspect, and from the views which it commands; and the house derives importance from its extended front. Both these circumstances, however, contribute to the bad opinion conceived of the place when viewed from the road, which is the point from whence its defects are most apparent.

The front towards the road faces the south, and is therefore lighted by the sun during the greatest part of the day; but being backed by lawn and arable land, and not relieved by wood, the effect of sunshine is equally strong on the back ground as on the house, because there is not a sufficient opposition of colour to separate these different objects; but if, on the contrary, the house be opposed to wood, it will then appear light and conspicuous, the attention being principally directed to the mansion, while the other parts of the scene will be duly subordinate.

It is also proper that the grounds should accord with the size and stile of the place, and that the mansion be surrounded by its appropriate appendages. At present the character of the house, and that of the place, are at variance: the latter is that of a farm, but the character of the house is that of a gentleman's residence, which should be surrounded by pleasure ground, wood, and lawn; and although great credit is due to those gentlemen who patronize farming by their example, as well as by their influence, it would be a reflection on the good taste of the country to suppose that the habitation of the gentleman ought not to be distinguished from that of the farmer, as well in the character of the place, as by the size of the house.

I shall not on this occasion enter into a discussion of the 
difference between a scene in nature, and a landscape on the paiuter's canvas; nor consider the very different means by which the painter and the landscape gardener produce the same effect: I shall merely endeavour to shew how far the same principles would direct the professors of either art in the improvement of Coon ве Lodge, and more particularly in the form and character of the wood to the north of the house.

Breadth, which is one of the first principles of painting, would prompt the necessity of planting the whole of the hill behind the house; but the improver, who embellishes the scene for the purposes of general utility and real life, must adopt what is convenient as ivell as beautiful. The painter, when he studies the perfection of his art, forms a correct picture, and takes beauty for his guide. The improver consults the genius of the scene, and connects beauty with those useful supporters; economy and convenience; and as Coombe Lodge would not be relieved by one large wood without a great sacrifice of land, the effect must be produced by planting a part only, whilst the judgment must be influenced by two principles belonging to the sister art, breadth and intricacy.

Breadth directs the necessity of large masses or continued lines of plantation, whilst intricacy suggests the shape and direction of the glades of lawn, and teaches how to place loose groups of trees, and separate masses of brushwood, where the outline might otherwise appear hard; and by occasional interruptions to the flowing lines of grass, with suitable recesses and projections of wood, Intricacy contrives to "lead the eye a wanton chase," producing variety without fritter, and continuity without sameness. 
'There is another principle to guide the improver in planting' the hill in question, which may be derived from the art of painting, and belongs to perspective. It is evident, that if the whole bank were planted, its effect would be good from every point of view: it is no less evident, that where it is necessary to regard economy in planting, and, as in the present instance, to produce the effect of clothing by several lines of wood, instead. of one great mass; that effect from some points of sight may be good, from some indifferent, and from others bad; it is therefore necessary to consider how those lines of plantation, which produce a good effect from the house, will appear in perspective from different heights and from different situations, and this question has been determined by various circumstances of the place itself.

This subject was elucidated by as many drawings as there were stations described; but as most of them were taken from the public road between Reading and Wallingford, the effect of these plantations will be seen from thence; and I have availed myself, as much as possible, of those examples which, from their proximity to a public road, are most likely to be generally observed.

If the more common appearances in nature were objects of our imitation, we should certainly plant the valleys and not the hills, since nature generally adopts this rule in her spontaneous plantations; but it is "la belle nature," or those occasional 
effects of extraordinary beauty, which nature furnishes as models to the Landscape Gardener. And although a wood on the summit of a bleak hill may not be so profitable, or grow so fast, as one in the sheltered valley, yet its advantages will be strongly felt on the surrounding soil. The verdure will be improved when defended from winds, and fertilized by the successive fall of leaves, whilst the cattle will more readily frequent the hills when they are sheltered and protected by sufficient skreens of plantation. ${ }^{\mathrm{r}}$

In recommending that the hills should be planted, I do not mean that the summits only should be covered by a patch or clump; the woods of the valleys should, on the contrary, seem to climb the hills by such connecting lines, as may neither appear meagre nor artificial, but following the natural shapes of the ground, produce an apparent continuity of wood falling down the hills in varions directions.

" Rich the robe,

And ample let it flow, that nature wears

On her thron'd eminence! where'er she takes

Her horizontal march, pursue her step

With sweeping train of forest; hill to hill

Unite, with prodigality of shade."

Mason.

During the first few years of large plantations in a naked country, the outline, however graceful, will appear hard and artificial; but when the trees begin to require thinning, a few

" This remark is verified at $A$ sron, where it is found that more cattle are fed in the park from the improved quality of the pasture, since the quantity has been reduced by the ample plantations made within the last ten years. 
single trees or groups may be brought forward. The precise period at which this may be advisable must depend on the nature of the soil; but so rich is the ground in which plantations were made at Astox, about ten years since, that this management has already been adopted with effect. Although it will again be repeated in the chapter treating of fences, I must observe in this place, that instead of protecting large plantations with hedges and ditches, I have generally recommended a temporary fence of posts and rails, or hurdles on the outside, and either advise a hedge of thorns to be planted at eight or ten yards distance from the outline, or rather that the whole plantation be so filled with thorns and spinous plants, that the cattle may not penetrate far when the temporary fences shall be removed, and thus nay be formed that beautiful and irregular outline so much admired in the woods and thickets of a forest. 


\section{CHAPTER V.}

Woods. - Whateley's Remarks exemplified at SHardeloes. - Intricacy-Variety-A Drive at Bu ustro oe traced, with Reasons for its Course-Further Example from Heathaleld ParkA Belt-On thinning Woods-Leaving Groups-Opening a

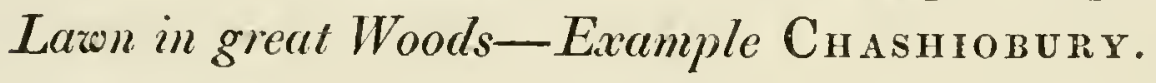

"Observations on Modern Gardening," by the late Mr. Whateley, contain some remarks peculiarly applicable to the improvement of woods, and so clearly expressive of my own sentiments, that I beg to introduce the ample quotation inserted in the note, especially as the annexed drawing conveys a

- "The outline of a wood may sometimes be great, and always be beautiful; the first requisite is irregularity. That a mixture of trees and underwood should form a long straight line, can never be natural, and a succession of easy sweeps and gentle rounds, each a portion of a greater or less circle, composing altogether a line literally serpentine, is, if possible, worse: it is but a number of regularities put together in a disorderly manner, and equally distant from the beautiful, both of art and of nature. The true beauty of an outline consists more in breaks, than in sweeps; rather in angles, than rounds; in variety, not in succession.

"The outline of a wood is a continued line, and small variations do not save it from the insipidity of sameness; one deep recess, one bold prominence, has inore effect than twenty little irregularities: that one divides the line into parts, but no breach is thereby made in its unity; a continuation of woorl always remains, the form of it only is altered, and the extent is increased: the eye, which hurries to the extremity of whatever is uniform, delights to trace a varied line through all its intricacies, to pause from stage to stage, and to lengthen the progress. 
specimen of these rules, which require but little further elucidation.

The beech woods in Buckinghamshire derive more beauty from the unequal and varied surface of the ground on which they are planted, than from the surface of the woots themselves; because they have generally more the appearance of copses, than of woods: and as few of the trees are suffered to arrive to

"The parts must not, however, on that account, be multiplied till they are too minute to be interesting, and so numerous as to create confusion. A few large parts should be strongly distinguished in their forms, their clirections, and their situations; each of these may afterwards be decorated with subordinate varieties, and the mere growth of the plants will occasion some irregularity, on many occasions more will not be required.

"Every variety in the outline of a wood must be a prominence or a recess; breadth in either is not so important as length to the one, and deptl to the other; if the former ends in an angle, or the latter diminishes to a point, they have more force than a shallow dent or a dwarf excrescence, how wide soever: they are greater deviations from the continued line which they are intended to break, and their effect is to enlarge the wood itself.

"An inlet in to a wood seens to have been cut, if the opposite points of the entrance tally, and that shew of art depreciates its merit: but a difference only in the situation of those points, by bringing one more forward than the other, prevents the appearance, though their forms be similar.

"Other points which distinguish the great parts, should in general be strongly marked; a short turn has more spirit in it than a tedious circuity; and a line broken by angles has a precision and firmuess, which in an undulated line are wanting: the angles should indeed be a little softened, the rotundity of the plant, which forms them, is sometimes sufficient for that purpose; but if they are mellowed down too much they lose all meaning.

"Every variety of outline hitherto mentioned, may be traced by the underciood alone; but frequently the same effects may be produced with more ease, and much more beauty, by a few trees standing out from the thicket, and belonging, or seeming to belong to the wood, so as to make a part of its figure." 
great size, there is a deficiency of that venerable dignity which a grove always ought to possess.

These woods are evidently considered rather as objects of profit than of picturesque beanty; and it is a circumstance to be regretted, that pecuniary advantage and ornament are seldom strictly compatible with each other. The underwood cannot be protected from cattle without fences, and if the fence be a live hedge, the trees lose half their beauty, while they appear confined within the unsightly boundary. To remedy this defect, the quick fence at SHARDELoes has, in many places, been removed, and a rail placed at a little distance within the wood; but the distance is so small, that the original outline is nearly as distinct as if the fence were still visible, and the regular undulations of those lines give an artificial appearance to the whole scenery.

A painter's landscape depends upon his management of light and shade: if these be too smoothly blended with each other the picture wants force; if too violently contrasted, it is called herd. The light and shade of natural landscape requires no less to be studied than that of painting. The shade of a landscapegardener is wood, and his lights proceed either from a lawn, from water, or from buildings. If on the lawn too many single trees be scattered, the effect becomes frittered, broken, and diffuse; on the contrary, if the general surface of the lawn be too naked, and the outline of the woods form an uniform heavy boundary between the lawn and the horizon, the eye of taste will discover an unpleasing harshness in the composition, which no degree of beauty, either in the shape of the ground or in the outline of the woods, can entirely counteract. In this state the natural landscape, like an unfinished picture, will appear to 
want the last touches of the master: this wonld be remedied on the canvas in proportion as the picture became more highly finished; but on the ground, it can only be effected by taking away many trees in the front of the wood, leaving some few individually and more distinctly separated from the rest: this will give the finishing touches to the outline where no other defect is apparent.

The eye, or rather the mind, is never long delighted with that which it surveys without effort at a single glance, and therefore sees without exciting curiosity or interest. It is not the vast extent of lawn, the great expanse of water, or the long. range of wood, that yields satisfaction; for these, if shapeless, or, which is the same thing, if their exact shape, however large, be too apparent, only attract our notice by the space they occupy, "to fill that space with objects of beauty, to delight " the eye after it has been struck, to fix the attention where it " has been caught, to prolong astonishment into admiration, are " purposes not unworthy of the greatest designs."

This can only be effected by intricacy, the due medium between uniformity on the one hand, and confusion on the other; which is produced by throwing obstacles in the way to amuse the eye, and to retard that celerity of rision so natural, where no impediments occur to break the uniformity of objects. Yet while the hasty progress of the eye is checked, it ought not to be arrested too abriptly. The mind requires a continuity, though not a sameness; and while it is pleased with succession and variely, it is offended by sudden contrast, which destroys the unity of composition.

There is a small clump at $\mathrm{B}$. which is of great use in breaking 
the outline of the wood beyond it; and there is a dell or scar in the ground at $\mathrm{C}$. that may also be planted for the like purpose. It is a very common expedient to mend an outline by adding new plantation in the front of an old one: but although the improver may plant large woods with a view to future ages, yet something appears due to the present day. If by cutting down a few trees in the front of a large wood, the shape of its outline may immediately be improved in a better manner, than can be expected from a solitary clump a century hence; it is surely a more rational system of improvement than so long to endure a patch surrounded by an unsightly fence, in the distant hope of effects which the life of man is too short to realize.

There is a part of the wood at $D$. so narrow as to admit the light beiween the stems of the trees; this naturally suggests the idea of adding new plantation. But the horizon is already uniformly bounded by wood, and the mind is apt to affix the idea of such boundary being the limit of the park, as strongly as if the pale itself were visible; on the contrary, the ground falling beyond this part, and a range of wood sweeping over the brow of the hill, it is better to clear away some of the trees, to increase the apparent extent of lawn. Instead of destroying the continuity of wood, this will increase its quantity; because the tops of the trees being partly seen over the opening, the imagination will extend the lawn beyond its actual boundary, and represent it as surrounded by the same chain of woods.

I have often heard it asserted as a general maxim in gardening, that hills should be planted and valleys cleared of wood. This idea perhaps originated, and ought only to be implicitly followed in a flat or tame country, where the hills are so low as to require 


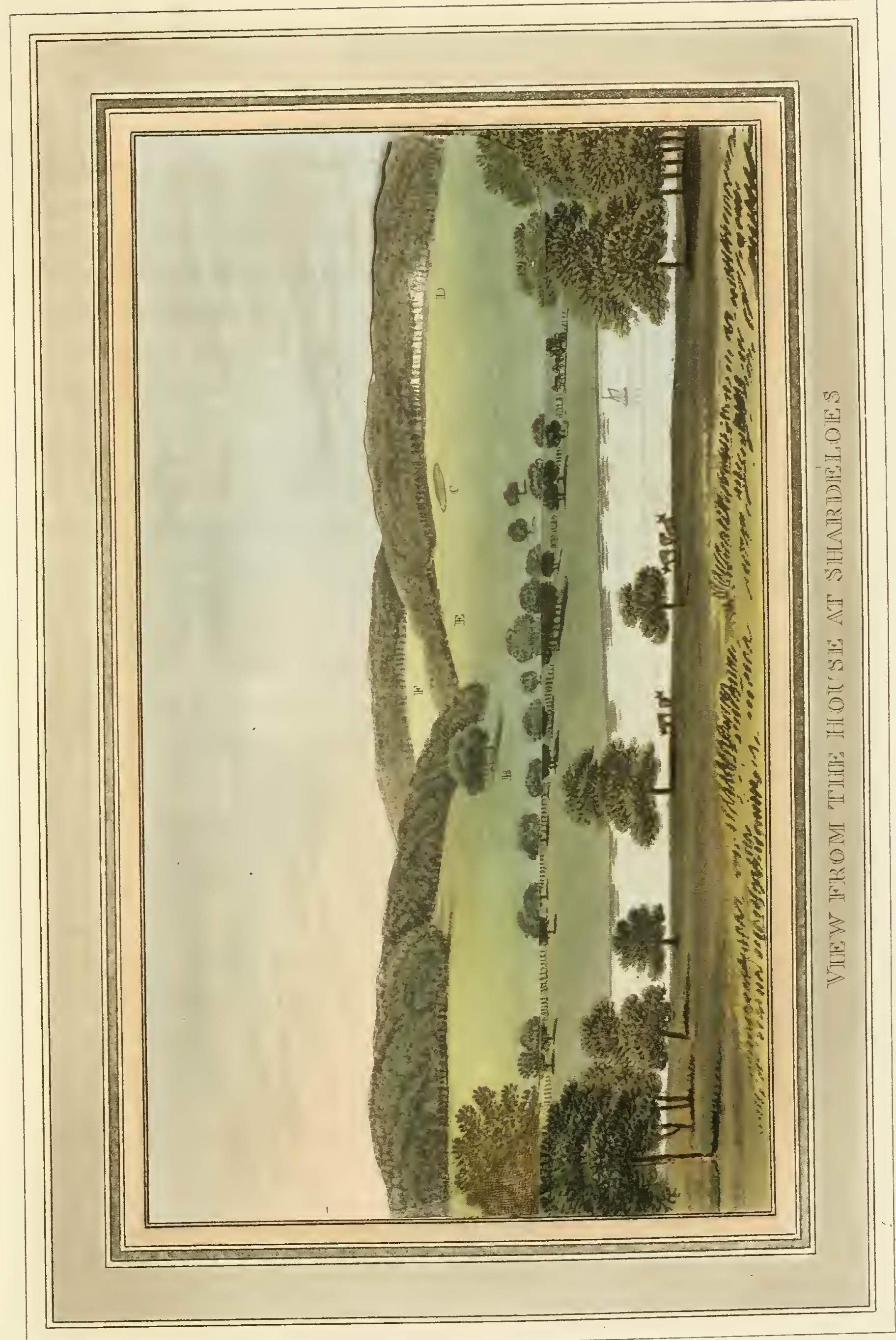



greater height by planting, and the valleys so shallow, that trees would hide the neighbouring hills: but whenever the hills are sufficiently bold to admit of ground being seen between large trees in the valley and those on the brow of the hill, it marks so decided a degree of elevation, that it ought sedulously to be preserved. Instead therefore of removing the trees in the valley at $E, I$ should prefer shewing more of the lawn above them, by clearing away some of the wood on the knoll at $F$. which I have distinguished by the pavilion: such a building would have many uses, besides acting as an ornament to the scenery, which seems to require some artificial objects to appropriate the woods to the magnificence of the place; because wood and lawn may be considered as the natural features of Buckinghamshire.

The Red Book of Sha rofloes contains a minute description of the rides made in the woods, with the reasons for every part of their course; but as this subject is more amply treated in my remarks on Bulstrode, the following extract is accompanied with a map, on which the course of an extensive drive is minutely described. This park must be acknowledged one of the most beautiful in England, yet I doubt whether Claude himself could find in its whole extent a single station from whence a picture could be formed. I mention this as a proof of the little affinity between pictures and scenes in nature.

It is not uncommon to conduct a drive either round a park, or into the adjoining woods, without any other consideration than its length; and I have frequently been carried through a belt of plantation surrounding a place, without one remarkable 
object to call the attention from the trees which are every where mixed in the same unvaried manner.

Although the verdure, the smoothness of the surface, and nature of the soil at Bulstrode, is such as to make every part of the park pleasant to drive over; yet there is a propriety in marking certain lines of communication which may lead from one interesting spot to another, and though a road of approach to a house ought not to be circuitous, the drive is necessarily so; yet this should be under some restraint. By the assistance of the map I shall describe the course of the drive at BuLSTRODE; and however devious it may appear on paper, it will, I trust, be found to possess such variety as few drives can boast; and that no part of it is suggested without sufficient reasons for its course.

I would not here be understood to infer, that every park can boast those advantages which BuLstrode possesses, or that every place offers sufficient extent and variety for such a drive appropriated to pleasure only; but this is introduced as an archetype or example, from whence certain principles are reduced to practice. Some of my observations, in the course of this description, may appear to have been anticipated by Mr. Whately, and if I may occasionally deliver them as my own sentiments, $I$ hope the coincidence in opinion with so respectable a theorist, will not subject me to the imputation of plagiarism. 



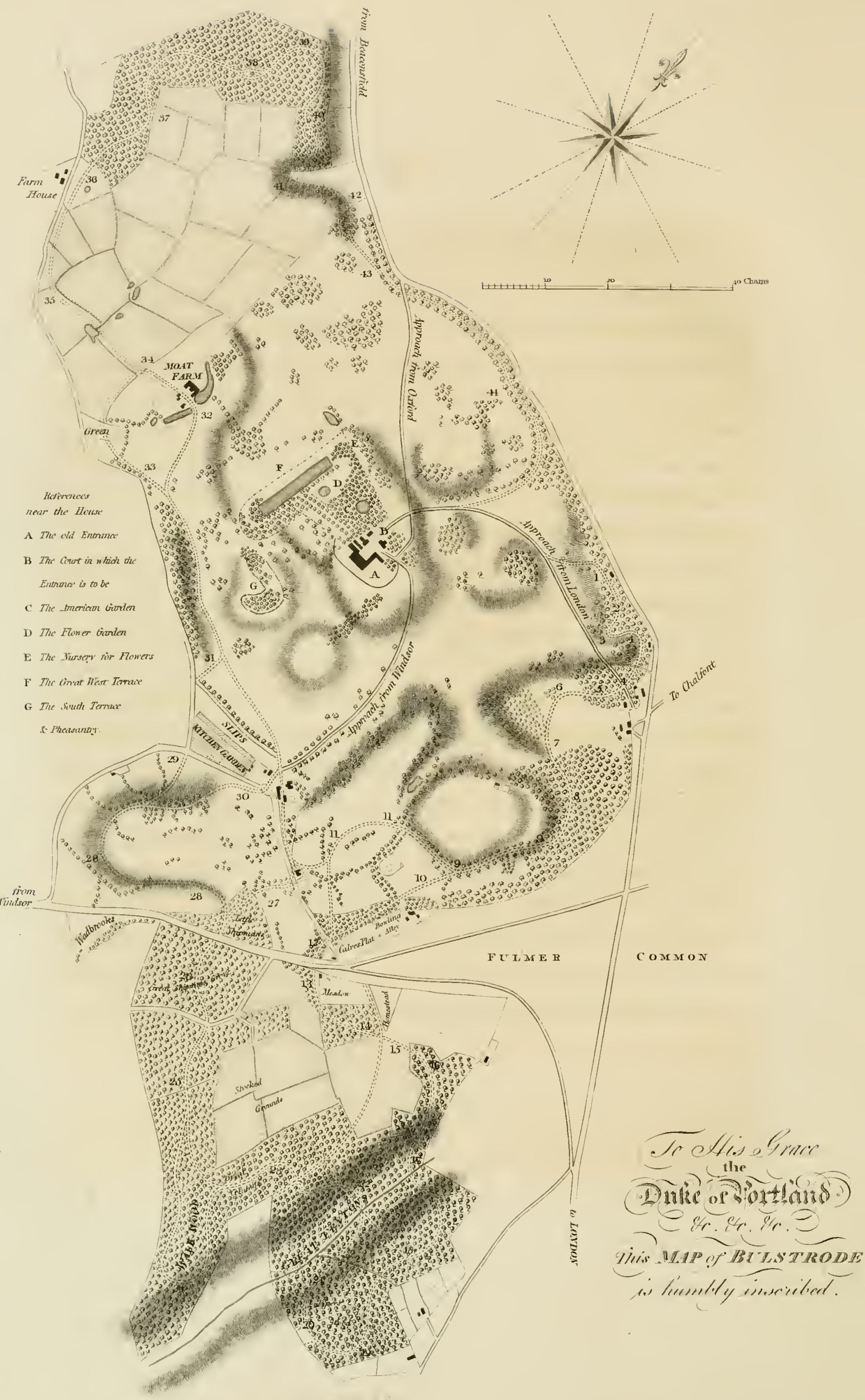




\section{COURSE OF THE DRIVE A'T BULSTRODE.}

Taking the departure from the house along the valley towards the north, it passes the situation proposed for a cottage at No. 1, from thence ascends to the summit of the chalk cliff that overhangs the dell at No. 2, and making a sharp turn at No. 3. to descend with ease, it crosses the head of the valley and enters the rough broken ground, which is curious for the variety of plants, at No.4.

From the several points No. 1, 2, and 3, the view along the great valley is nearly the same, but seen under various circumstances of foreground: at No. 4. it crosses the approach from London, and passes through an open grove No. 5 .

The drive now sweeps round on the knoll at No. 6, along a natural terrace, from which the opposite hill and the house appear to great advantage. From hence crossing the valley No.7, among the finest trees in the park, it passes a deep romantic dell at No. 8 , which might be enlivened by water, as a drinking pool for the deer, and then as it will pass at No. 9, near the side of the Roman camp, I think the ${ }^{t}$ drive should be made on one of the banks of the Vallum; because it is a circumstance of antiquity worthy to be drawn into notice, and by being elevated above the plain, we shall not only see into the intrenchment, but remark the venerable trees which enrich its banks; these trees are the growth of many

'This great work being in a progressive state, the reader will observe that some parts of this drive are mentioned as not yet completed. 
centuries, yet they lead the mind back to the far more ancient date of this encampment, when the ground must have been a naked surface. Another advantage will also be derived from carrying the drive above the level of the plain. The eye being raised above the brousing "line, the park wall will be better hid by the lower branches of intermediate trees. At No. 10. the drive is less interesting, because the surface is flat; but such occasional tameness gives repose, ${ }^{\mathrm{x}}$ and serves to heighten the interest of subsequent scenery; yet at this place, if the drive be made to branch along the Vallum, it will pass over the most beautiful part of the park, on a natural terrace at No. 11, and this will join the inner drive returning down the valley towards the kitchen garden.

I am now to speak of the great woods called Fentum's, Piper's, Column's, Walk Wood, and Shipman's, in which a serpentine drive has been formerly cut, which no one would desire to pass a second time, from its length, added to the total absence of interest or variety of objects; but following the taste which supposes " nature to abhor a straight line," this drive meanders in uniform curves of equal lengths, and the defect is increased by there being only one connexion with the park, while the other end of the drive finishes at a great distance across Fulmer Common. The first object therefore of improvement will be to form such a line of connexion with the park as may make it seem a part of the same domain, and this would be more easily done

"The browsing line is explained in Chap. IV.

x The excess of variety may become painful, and therefore in a long drive some parts should be less interesting, or, if possible, should excite no interest, and be indifferent without exciting disgust. 
if the hollow way road under the park wall, could be removed; because otherwise the drive must cross the road twice at No. 12, as I suppose it to enter a field at No. 13, which might be planted to connect it with the Broomfield copse No. 14, from whence, after crossing several interesting small inclosures, with forest-like borders, it enters and sweeps through the wood Little Fentums No. 16, to join the old drive, or at least such parts of it as can be made subservient to a more interesting line. After crossing a valley and streamlet at No. 17, and another at No. 18, it should ascend the hill of Piper's Wood, in which there are at present no drives, and at No. 19. a branch may lead on to the common, as a green way to London. The drive sweeping round to $\mathrm{N}_{0}$. 20 . opens on a view of the village and valley of Fulmer, with a series of small ponds, which; in this point of view, appear to be one large and beautiful piece of water: this scene may be considered the most pleasing subject for a picture, during the whole course of the drive. This would be a proper place for a covered seat, with a shed behind it for horses or open carriages; ${ }^{y}$ but it should be set so far back as to command the view under the branches of trees, which are very happily situated for the purpose at No. 20.

From hence the drive descends the hill in one bold line No. 21, with a view towards the opposite wood across the valley. Having again ascended the hill in wood, there are some parts of the present drive which might be made interesting by various

In long drives such attention to convenience is advisable; a thatched hovel of Doric proportions, may not only be made an ornament to the scenery, but it will often serve for a shelter from sudden storms in our uncertain climate; for this reason it should be large enough to contain several open carriages. 
expedients. At No. 22. one side of the drive might be opened to shew the opposite hanging wood in glades along the course of the drive. At No. 23. a shorter branch might be made to avoid the too great detour, though there is a view into the valley of Fulmer at No. 24. worthy to be preserved." In some parts the width of the drive might be varied, and some of the violent curvatures corrected; in others the best trees might be singled out and little openings made to be fed by sheep occasionally; and another mode of producing variety would be to take away certain trees, and leave others, where any particular species abound: thus in some places, the birches only might be left, and all the oaks and beech and other plants removed, to make in time a specimen of Birkland forest, while there are some places where the holley and hawothom might be encouraged, and all taller growth give place to these low shrubs with irregular shapes of grass flowing anong them. This would create a degree of variety that it is necdless to enlarge upon.

The course of the drive through Shipman's Wood No. 26, may be brought lower down the hill to keep the two lines as far distant from each other as possible, and also to make the line easier round the knoll at No. 28, though an intermediate or shorter branch may also diverge at No. 27, towards the valley. There is some difficulty in joining this drive with the park without going round the gardener's house; but as the

z I have distinguished, by Italics, some peculiar circumstances of variety, from having observed great sameness in the usual mode of conducting a drive through a belt of young plantation, where trees of every species are mixed together. There is actually more variety in passing from a grove of oaks to a grove of firs, or a scene of brushwood, than in passing through a wood composed of a liundred different species of trees as they are usually mixed together. 
kitchen garden must be seen from this part of the drive, and ats it forms a leading feature in the establishment of Bulstrode, it will sometimes become part of the circuit to walk through it, and the carriages may enter the drive again at No.31, I have therefore described two ways, No. 29, and No.30, as I suppose the bottom of this valley to be an orchard, through which the drive may pass, or make the shorter line along the garden wall to No. 31 .

The course along the valley is extremely interesting, and as some consider the farm yard and premises a part of the beauty, as well as the comfort, of a residence in the country, I have supposed one branch of the drive No. 3Q , to pass near a large tree, and the other to go on the bank at No.33, and cross the corner of Hedgerly Green, which I suppose might be planted round the gravel pit; but when the drive enters the furm enclosures, it ought, if possible, to follow the course of the hedges, and not to cross a field diagonally. From No. 34. to No. 35, is perfectly flat, and follows the line of the hedges to the corner at No. 35, where a new scene presents itself, viz. a view tow ards the village of Hedgerley, in a valley, surrounded with woody banks. The drive now skirts along the hedge and passes at No. 36. a farm house, which might be opened to the field, and then enters Wapsey's Wood, in which the first bold feature will present itself at No. 37, where the drive may come so near the edge as to shew the view along the valley, and the amphitheatre of wood surrounding these small enclosures: it then passes through the wood to a very large oak at No. 38, which may be brought into notice by letting the drive go on each side of it, and afterwards following the shape of the ground it sweeps round the knoll at 
No. 39, with a rich view of the opposite bank across the high road, seen under large trees; it then ascends the hill by the side of a deep dell at No. 40, and makes a double at No. 41, to cross the valley, that it may skirt round the knoll on the furze hill at No. 42, from whence it descends into the valley at No.43, and either returns to the house by the approach from Oxford, or is continued under the double line of elms at No.44, to ascend by the valley from whence the drive began.

To some persons this description may appear tedious, to others it will perhaps furnish amusement to trace the course of such a line on the map; but I have purposely distinguished by Italics, some observations containing principles which have not before been reduced to practical improvement.

Heatufielo Park is one of those subjects from whence my art can derive little credit: the world is too apt to mistake alteration for improvement, and to applaud every change, although no higher beauty is produced. The character of this park is strictly in harmony with its situation; both are splendid and magnificent; yet a degree of elegance and beauty prevails, which are rarely to be found where greatness of character, and loftiness of situation, are the predominant features: because magnificence is not always united with convenience, nor extent of prospects with interesting and beautiful scenery. The power of art can have but little 
influence in increasing the natural advantages of Heathfield Park. It is the duty of the improver to avail himself of those beauties which nature has profusely scattered, and by leading the stranger to the most pleasing stations to call his attention to those objects which from their variety, novelty, contrast, or combination, are most likely to interest and delight the mind. On this foundation ought to be built the future improvement of Heathfield Park; not by doing violence to its native genius, but by sedulously studying its true character and situation: certain roads, walks, or drives, may collect the scattered beauties of the place, and comnect them with each other in lines, easy, natural, and graceful.

A common error by which modern improvers are apt to be misled, arises from the mistake so often made in adopting extent for beauty. Thus the longest circuit is frequently preferred to that which is most interesting; not indeed by the visitors, but by the fancied improver of a place. This I apprehend was the origin, and is always the tedious effect, of what is called a Belt; through which the stranger is conducted that he may enjoy the drive, not by any striking points of view or variety of scenery, but by the number of miles over which he has traced its course, and instead of leading to those objects, which are most worthy our attention, it is too common to find the drive a mere track round the utmost verge of the park; and if any pleasing features excite our notice, they arise rather from chance than design.

To avoid this popular error therefore, I shall endeavour to avail myself of natural beauties in this drive, without any unnecessary circuit calculated to surprise by its extent. I shall rather select those points of view which are best contrasted with each other, 
or which discover new features, or the same under different circumstances of foreground; beguiling the length of the way by a succession of new and pleasing objects.

If the circuitous drive round a place becomes tedious by its monotony, we must equally avoid too great sameness or confinement in any road which is to be made a path of pleasure: a short branch from the principal drive, although it meets it again at a little distance, relieves the mind by its variety, and stimulates by a choice between two different objects; but we must cautiously avoid confusion, lest we cut a wood into a labyrinth. The principal Road at Heathfield leads towards the tower, the other is no less interesting where it bursts out on one of those magnificent landscapes so pleasing in nature, yet so difficult to be represented in painting; because quantity and variety are apt to destroy that unity of composition which is expected in an artificial landscape: for it is hardly possible to convey an adequate and distinct idea of those numerous objects so wonderfully combined in this extensive view; the house, the church, the lawns, the woods, the bold promontory of Beechy Head, and the distant plains bounded by the sea, are all collected in one splendid picture, without being crowded into confusion.

This view is a perfect landscape, while that from the tower is rather a prospect; it is of such a nature as not to be well represented by painting; because its excellence depends upon a state of the atmosphere, which is very hostile to the painter's art. An extensive prospect is most admired when the distant objects are most clear and distinct; but the painter can represent his distances only by a certain haziness and indistinctness which is termed aerial perspective. I cannot dismiss this subject 
without expressing the pleasure which was excited in my mind on finding a lofty tower erected by the present possessor, and consecrated as a tribute of respect and gratitude to that gallant Commander, for his public services, who derived his title of HeathField from this domain, and his military glory from the rock of Gibraltar. Over the door is inscribed in large letters, made of the metal from the gun-boats destroyed,

\section{CALPES DEFENSORI.}

In the woodland counties, such as Hertfordshire, Herefordshire, Hampshire, \&c. it often happens that the most beautiful places may rather be formed by falling, than by planting trees; but the effect will be very different whether the axe be committed to the hand of genius or the porver of avarice. The land steward, or the timber merchant, would mark those trees which have acquired their full growth and are fit for immediate use, or separate those which he deems to stand too near together, but the man of science and of taste will search with scrutinizing care for groups and combinations, such as his memory recalls in the pictures of the best masters; these groups he will studiously leave in such places as will best display their varied or combined forms: he will also discover beauties in a tree which the others would condemn for its decay; he will rejoice when he finds two trees whose stems have long grown so near each other that their branches are become interwoven; 


\section{6}

he will examine the outline formed by the combined foliage of many trees thus collected in groups, and removing others near them he will give ample space for their picturesque effect: sometimes he will discover an aged thom or maple at the foot of a venerable oak, these he will respect not only for their antiquity, being perhaps coeval with the father of the forest; but knowing that the importance of the oak is comparatively increased by the neighbouring situation of these subordiuate objects; this will sometimes happen when young trees grow near old ones, as when a light airy ash appears to rise from the same root with an oak or an elm. These are all circumstances dependent on the sportive accidents of nature, but even where art has interfered, where the long and formal line of a majestic avenue shall be submitted to his decision, the man of taste will pause, and not always break their venerable ranks, for his hand is not guided by the levelling principles or sudden innovations of modem fashion; he will reverence the glory of former ages, while he cherishes and admires the ornannent of the present, nor will he neglect to foster and protect the tender sapling which promises with improving beauty to spread a grateful shade for future "tenants of the soil."

To give however such general rules for thinning woods as might be understood by those who have never attentively and scientifically considered the subject, would be like attempting to direct a man who had never used a pencil to imitate the groups of a Claude or a Poussin. ${ }^{2}$

a It is in the act of removing trees and thinning woods that the landscape gardener must shew his intimate knowledge of pleasing combinations, his genius for painting, and his acute perception of the principles of an art which transfers the imitative, 
On this head I have frequently found my instructions opposed, and my reasons unintelligible to those who look at a wood, as an object of gain; and for this reason I am not sorry to have discovered some arguments in favour of my system, of more weight, perhaps, than those which relate to mere taste and beauty: these I shall beg leave to mention, not as the foundation on which my opinion is built, but as collateral props to satisfy those who require such support.

1st. When two or more trees have long grown very near each other, the branches form themselves into one mass, or head; and if any part be removed, the remaining trees will be more exposed to the power of the wind, by being heavier on one side, having lost their balance. 2d. If trees have long grown very near together, it will be impossible to take up the roots of one without injuring those of another: and lastly, although trees at equal distances may grow more erect, and furnish planks for the use of the navy, yet not less valuable to the ship-builder are those naturally crooked branches, or knees, which support the decks, or form the ribs, and which are always most likely to be produced from the outside trees of woods, or the fantastic forms which arise from two or more trees having grown very near each other in the same wood, or in hedgerows.

It is therefore not inconsistent with the considerations of profit, as well as picturesque effect, to plant or to leave trees very

though permanent beauties of a picture, to the purposes of elegant and comfortable habitation, the ever varying effects of light and shade, and the inimitable circumstances of a natural landscape. 
near each other, and not to thin them in the usual manner without caution.

In some places belonging to ancient noble families, it is not uncommon to see woods of vast extent intersected by vistas and glades in many directions; this is particularly the case at BUR LEY, and at $\mathrm{C}_{\mathrm{Ashionury}}$. It is the property of a straight glade or vista to lead the eye to the extremity of a wood, without attracting the attention to its depth.

I have occasionally been required to fell great quantities of timber, from other motives than merely to improve the landscape; and in some instances this work of necessity has produced the most fortunate improvements. I do not hesitate to say, that some woods might be increased five-fold in apparent quantity, by taking away a prodigions number of trees, which are really lost to view; but unless such necessity existed, there is more difficulty and temerity in suggesting improvement by cutting down, however profitable, and however suddenly the effect is produced, than by planting, though the latter be tedious and expensive.

I have seldom found great opposition to my hints for planting, but to cutting down trees innumerable obstacles present themselves; as if, unmindful of their value, and heedless of their slow growth, I should advise a military abatis, or one general sweep, denuding the face of a whole country. What I should 
advise both at BuRley and at CAshiobury, ${ }^{b}$ would be to open some large areas within the woods, to produce a spacious internal lawn of intricate shape and irregular surface, preserving a sufficient number of detached trees or groups, to continue the general effect of one great mass of wood.

- This advice has been followed at Cashiobury since the above pages were written, and the effect is all that I had promised to myself. 


\section{CHAPTER VI.}

Of Fences - The Boundary - The Separation - Example from Sheffield Place - Fence to Plantations only temporaryThe double Gate-Lines of Fences-of Roads - of Wallisof Rivers-all different.

That the boundary fence of a place should be concealed from the house, is among the few general principles admitted in modern gardening; but even in this instance, want of precision has led to error; the necessary distinction is seldom made between the fence which incloses a park, and those fences which are adapted to separate and protect the subdivisions within such inclosure. For the concealment of the boundary various methods have been adopted, on which I shall make some observations.

1. A plantation is certainly the best expedient for hiding the pales; but in some cases it will also hide more than is required. And in all cases, if a plantation surround a place in the manner commonly practised under the name of a belt, it becomes a boundary scarce less offensive than the pale itself. The mind feels a certain disgust under a sense of confinement in any situation, however beautiful, as Dr. Johnson has forcibly illustrated in describing the feeling of Rasselas, in the happy valley of Abyssinia.

2. A second method of concealing a fence is, by making it 
of such light materials as to render it nearly invisible; such are fences made of slender iron and wire painted green.

3. A third method is, sinking the fence below the surface of the ground, by which means the view is not impeded, and the contimuity of lawn is well preserved. Where this sunk fence or fosse is adopted, the deception ought to be complete; but this cannot be where grass and corn lands are divided by such a fence: if it is used betwixt one lawn and another, the mind acquiesces in the frand even after it is discovered, so long as the fence itself does not obtrude on the sight. We must therefore so dispose a fosse, or ha! ha! that we may look across it and not along it. For this reason a sunk fence must be straight and not curving, and it should be short, else the imaginary freedom is dearly bought by the actual confinement, since nothing is so difficult to pass as a deep sunk fence.

4. A fourth expedient I have occasionally adopted, and which (if I may use the expression) is a more bold deception than a sunk fence, viz. a light hurdle instead of paling; the one we are always used to consider as a fixed and immovable fence at the boundary of a park or lawn; the other only as an occasional division of one part from the other: it is a temporary inconvenience, and not a permanent confinement.

It is often necessary to adopt all these expedients in the boundaries and subdivisions of parks; but the disgust excited at seeing a fence may be indulged too far, if in all cases we are to endeavour at concealment; and therefore the various situations and purposes of different sorts of fences deserve consideration.

Howerer we may admire natural beanties, we ought always to recollect, that, without some degree of art and management, 
it is impossible to prevent the injury which vegetation itself will occasion: the smooth bowling green may be covered by weeds in a month, while the pastured ground preserves its neatness throughout the year. There is no medium between the keeping of art and of nature, it must be either one or the other, art or nature, that is, either mowed or fed by cattle; and this practical part of the management of a place forms one of the most difficult points of the professors of art, because the line of fence, which separates the dressed ground from the pasture is too often objectionable; yet there is not less impropriety in admitting cattle to feed in a flower garden, than in excluding them from such a tract of land as might be fed with advantage.

At Sheffield Place, the beautiful and long meadow in Arno's Vale is a striking example of what I have mentioned; because, if it were possible, or on the principle of neconomy advisable, to keep all this ground as neatly rolled and moved as the lawn near the house, by which it would always appear as it does the first week after the hay is carried off; yet I contend that the want of animals and animation deprives it of half its real charms; and although many beauties must be relinquished by curtailing the number of walks, yet others may be obtained, and the whole will be more easily kept with proper neatness by judicious lines of demarcation, which shall separate the grounds to be fed, from the grounds to be mown; or rather by such fences as shall, on the one hand, protect the woods from the encroachments of cattle, and on the other, let the cattle protect the grass land from the encroachment of woods; for such is the power of vegetation at Sheffield PLace, that every berry soon becomes a bush, and every bush a tree. 
From this luxuriant vegetation the natural shape of the vale is obliterated, the gently-sloping banks are covered with wood, and the narrow glade in the bottom is choked with spreading larches. It is impossible to describe by words, and without a map, how this line of demarcation should be effected; but I am sure many acres might be given to cattle, and the scenery be improved, not only by such moving objects, but also by their use in cropping those vagrant branches which no art could watch with sufficient care and attention. It is to such accidental browsing of cattle that we are indebted for those magical effects of light and shade in forest scenery, which art in vain endeavours to imitate in pleasure grounds.

Perhaps the brook might be made the natural boundary of Arno's Vale, where a deep channel immediately at the foot of the hill, with or without posts and rails, would make an effectual fence. It will perhaps be objected that a walk by the side of such a fence would be intolerable; yet surely this watercourse, occasionally filled with a lively stream, is far preferable to a dry channel; and yet the only walk from the house at present is by the side of what may be so called: and far from considering this a defect, I know it derives much of its interest from this very circumstance. A gravel walk is an artificial convenience, and that it should be protected, is one of its first requisites: therefore, so long as good taste and good sense shall coincide, the eye will be pleased where the mind is satisfied. Indeed, in the rage for destroying all that appeared artificial in the ancient style of gardening, I have frequently regretted the destruction of those majestic terraces which marked the precise line betwixt nature and art. 
To describe the various sorts of fences suitable to various purposes, would exceed the limits and intentions of this work: every county has its peculiar mode of fencing, both in the construction of hedges and ditches, which belong rather to the farmer than the landscape gardener; and in the different forms and materials of pales, rails, hurdles, gates, \&c. my object is rather to describe such application of common expedients as may have some degree of use or novelty.

Among these I shall first mention, that instead of surrounding: a young plantation with a hedge and ditch, with live quick or thorns, I generally recommend as many, or even more, thorns than trees, to be intermixed in the plantation, and the whole to be fenced with posts and rails, more or less neat, according to the situation; but, except near the house, I never suppose this rail to continue after the trees (with the aid of such intermixed thorns) are able to protect themselves against cattle; and thus, instead of a hard marked outline, the woods will acquire those irregularities which we observe in forest scenery, where in some few instances the trees are choked by the thorns, though in many they are nursed and reared by their protection.

It often happens that a walk in a plantation or shrubbery is crossed by a road or a drift way; this has been ingeniously obviated (I believe originally by Mr. Brown) by making one pass over the other, and where the situation requires such expence, a subterraneous passage may either be made under the 
carriage road, as I have done at WELBECK, at GAy HuRST, and at other places, or a foot bridge may be carried over the road, as I have frequently advised: but a more simple expedient will often answer the purpose, which I shall describe with the help of the annexed sketch, representing the ground plan of the intersected roads.

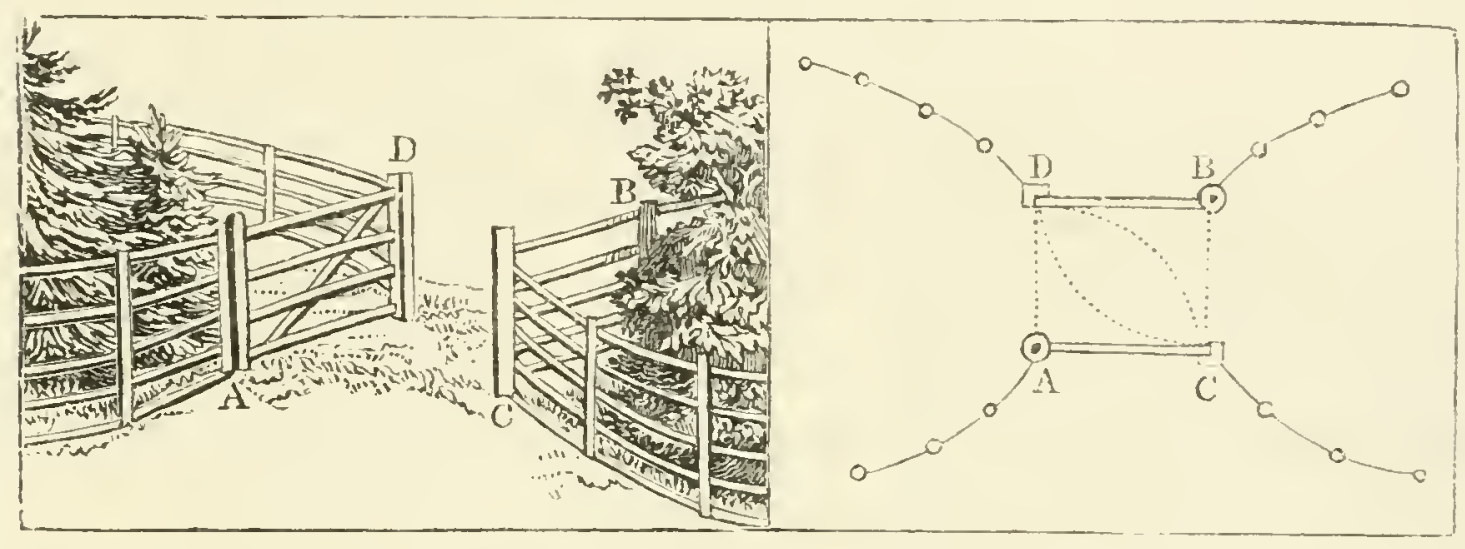

Two light gates, like the rail fence to the plantation, are so hung to the posts A. and B. that they will swing either to the posts D. or C. and thus they will either close the spaces D. B. and A. C. leaving open the walk, or they may be shut so as to close the spaces A. D. and B. C. leaving open the road or drift way; for this purpose the posts $A$. and B. to which the gates are hung, should be round, and the hinge turn on a pivot at the top; the other two posts may be square, or with a rebate to receive the gate.

In the course of this work I may have frequent occasion to mention the necessity of providing a fence near the house, to 
separate the dressed lawn from the park or feeding ground: various ingenious devices have been contrived to reconcile, with neatness and comfort, the practice introduced by Mr. Brown's followers, of setting a house in a grass field.

The sunk fence, or ha! ha! in some places, answers the purpose, in others a light fence of iron or wire, or even a wooden rail has been used with good effect, if not too high; but generally near all fences the cattle make a dirty path, which, immediately in view of the windows, is unsightly; and where the fence is higher than the eye, as it must be against deer, the landscape seen through its bars becomes intolerable. After various attempts to remedy these defects by any expedient that might appear natural, I have at length boldly had recourse to artificial management, by raising the ground near the house about three feet, and by supporting it with a wall of the same materials as the house. In addition to this, an iron rail on the top only three feet high, becomes a sufficient fence, and forms a sort of terrace in front of the house, making an avowed separation between grass kept by the scythe. and the park fed by deer or other cattle, while at a little distance it forms a base line or deep plinth, which gives height and consequence to the house.

This will I know be objected to by those who fancy that every thing without the walls of a house should be natural; but a house is an artificial object, and to a certain distance around the house, art may be avowed: the only difference of opinion will be, where shall this line of utility, separating art from nature, commence? Mr. Brown said at the threshold of the door: yet he contradicted himself when he made, as he always 
did, another invisible line beyond it. On the contrary, I advise that it be near the house, though not quite so near: and that the line should be artificially and visibly marked.c

When Mr. Brown marked the outline of a great wood sweeping across hill and valley, he might indulge his partiality for a serpentine or graceful curve, which had been then newly introduced by Hogarth's idea respecting the line of beauty: but it may be observed that a perfectly straight line, drawn across a valley diagonally, appears to the eye the same as this line of fancied beauty, and therefore, in many cases, the line should be straight. I have already hinted in this Chapter that the fence of a wood or plantation should be considered as merely temporary, that is, till the thorns planted among the trees can supersede its use. Wherefore, it is of little consequence in what manner a hurdle, or rough posts and rails, without any hedge or ditch, may be placed: a straight line is ever the shortest, and I have often preferred it, especially as I know that a few trees or bushes at each end of such a line will prevent the eye from looking along its course.

Sometimes it happens, from the intermixture of property or other causes, that the fence is obliged to make a very acute angle; this may occasionally be remedied by another line of fence fitting to its greatest projection; and as this same principle may be extended to roads, walks, or rivers, I shall explain it.

- Examples of this may be seen at Burstrode, at Michel Grote, at Brextree HILL, \&c. 


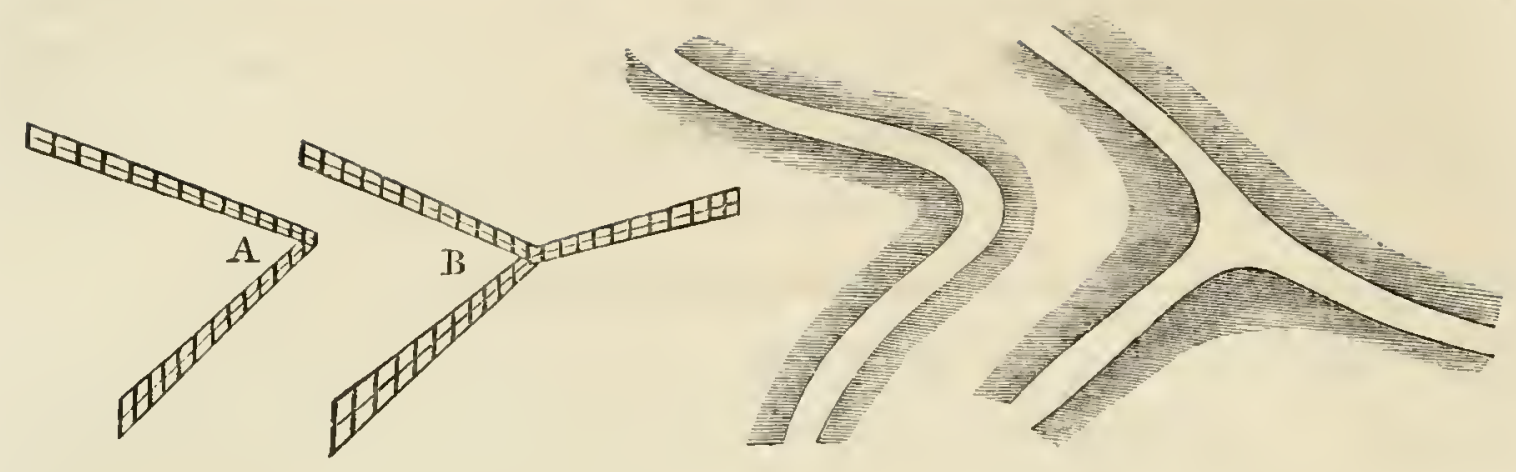

The sharp elbow or projection of the fence A. ceases to be offensive if another fence can be joined to it as at $B$. and the same with the line of road or walk; the branch obviates the defect.

It has been observed by the adversaries of the art, that exactly the same line will serve either for a road or a river, as it may be filled with gravel or with water. This ridicule may perhaps be deserved by those engineers who are in the habits of making navigable canals only, but the nice observer will see this material difference.

The banks of a natural river are never equidistant, the water in some places will spread to more than twice the breadth it does in others; this pleasing irregularity depends on the shape of the ground through which it flows; a river seldom proceeds far along the middle of a valley, but generally keeps on one side, or boldly stretches across to the other, as the high ground resists, or the low ground invites its course: these circumstances in natural rivers should be carefully imitated in those of art, 
and not only the effects, but even the causes, if possible, should be counterfeited, especially in the form of the shores: thus the convex side of the river at $\mathrm{A}$. should have its shores convex, or steep; and the concave side of the river at $B$. should have its shores concave, or flat; because by this means the course of the river is accounted for.

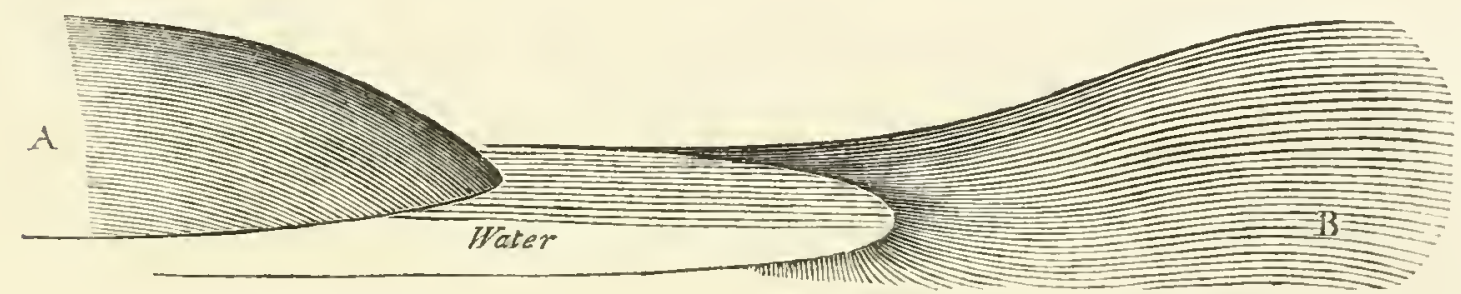

There is another circumstance, with respect to lines, deserving attention. The course of a river may frequently shew two or more different bends, which do not so intersect each other as to impede the view along it; and these may be increased in proportion to the breadth of the river: but in a road, or a walk, especially if it passes through a wood or plantation, a second bend should never be visible.
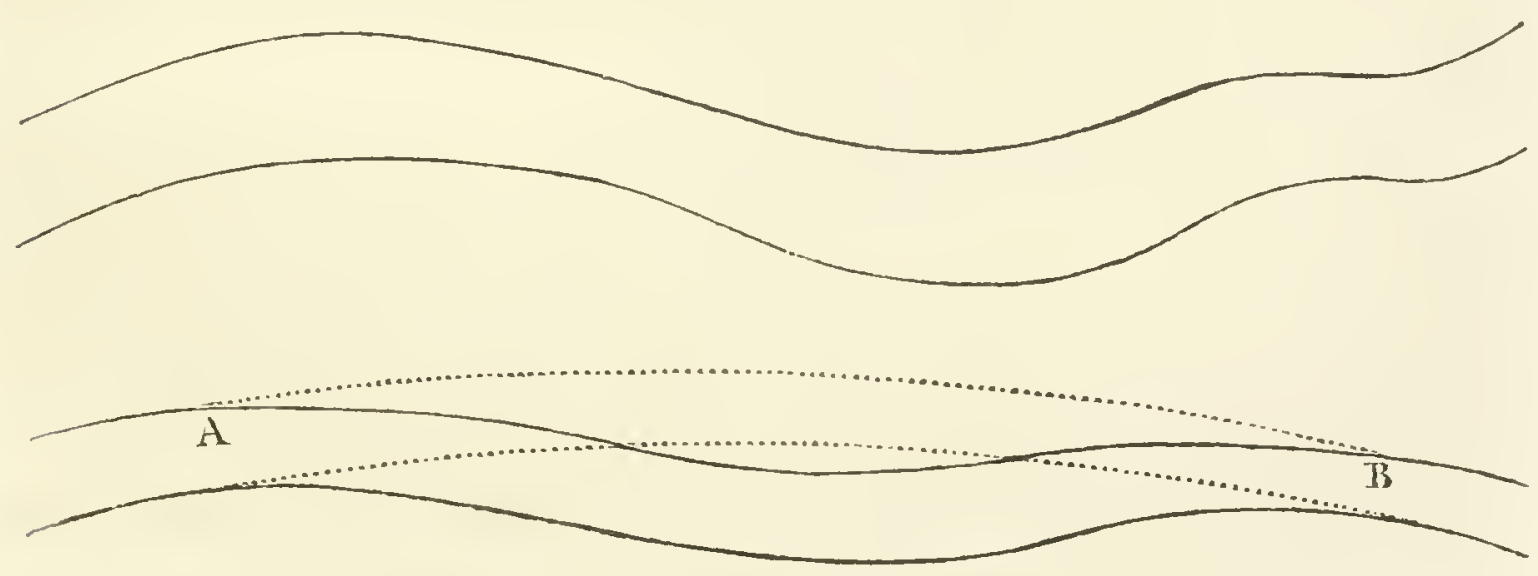
The degree of curve in a walk, or road, will therefore depend on its width; thus looking along the narrow line of walk, you will not see the second bend: but in the same curve, if the road be broader, we should naturally wish to make the curve bolder by breaking from it according to the dotted line from $A$. to $B$. in the diagram of the preceding page.

When two walks separate from each other, it is always desirable to have them diverge in different directions as at $A$. rather than give the idea of re-uniting, as at $B$.

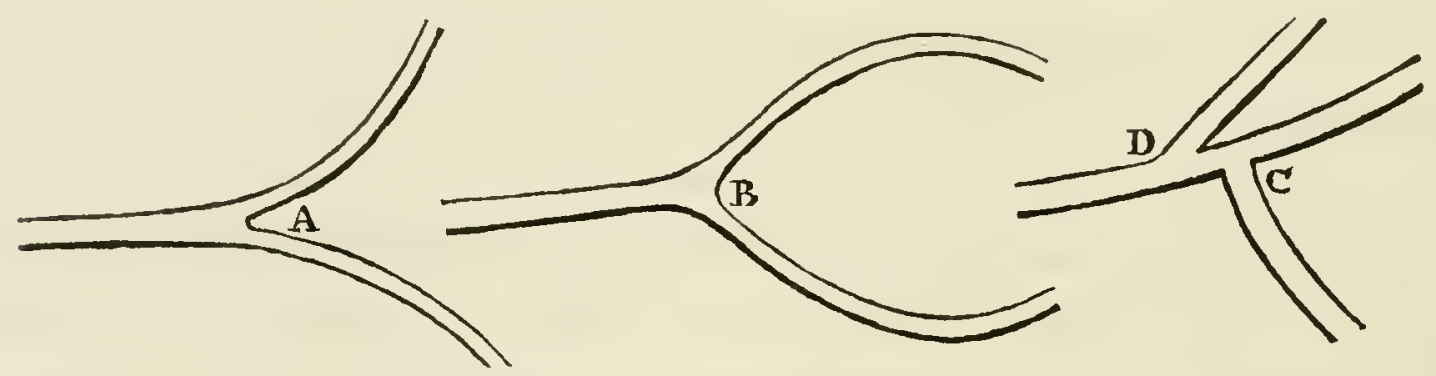

Where two walks join each other, it is generally better that they should meet at right angles, as at $\mathrm{C}$. than to leave the sharp point as in the acute angle at $D$.

The most natural course for a road, or walk, is along the banks of a lake or river; yet I have occasionally observed great beanty in the separation of these two lines; as where the water sweeps to the left, and the road to the right, or vice versâ: the true effect of this circumstance I have often attempted to represent on paper, but it is one of the many instances in which the reality and the picture excite different sensations. 


\section{1}

This Chapter might have included every necessary remark relative to fences, whether attached to parks or farms; but as I wish to enlarge upon the distinction between the improvements designed for ornament, and those for profit or gain, I shall endeavour to explain these different objects as they appear to me opposite in their views, and distinct in their characteristics. Both are, indeed, subjects of cultivation, but the cultivation in the one is husbandry, and in the other decoration. 


\section{CHAPTER VII.}

Ferme ornée, a Contradiction-Farm and Park distinct ObjectsEaperimental, or useful Farm - Beauty and Profit seldom compatible.

The French term Ferme ornée, was, 1 believe, invented by Mr. Shenstone, who was conscious that the English word Farm would not convey the idea which he attempted to realize in the scenery of the Leasowes. That much celebrated spot, in his time, consisted of many beautiful small fields, connected with each other by walks and gates, but bearing no resemblance to a farm as a subject of profit. I have never walked through these grounds without lamenting not only the misapplication of good taste, but that constant disappointment which the benevolent Shenstone must have experienced in attempting to unite two objects so incompatible as ornament and profit. Instead of surrounding his house with such a quantity of ornamental lawn or park only, as might be consistent with the size of the mansion, or the extent of the property; his taste, rather than his ambition, led him to ornament the whole of his estate; vainly hoping that he might retain all the advantages of a farm, blended with the scenery of a park. Thus he lived under the continual mortification of disappointed hope, and with a mind exquisitely sensible, he felt equally the sneer of the great man, at the magnificence of his 
attempt, and the ridicule of the farmer, at the misapplication of his paternal acres.

Since the removal of court yards and lofty garden walls from the front of a house, the true substitute for the ancient magnificence destroyed, is the more cheerful landscape of modern park scencry; and although its boundary ought in no case to be conspicuous, yet its actual dimensions should bear some proportion to the command of property by which the mansion is supported. If the yeoman destroys his farm by making what is called a Ferme ornée, he will absurdly sacrifice his income to his pleasure: but the country gentleman can only ornament his place by separating the features of farm and park; they are so totally incongruous as not to admit of any union but at the expence either of beauty or profit. The following comparative view will tend to confirm this assertion.

The chief beauty of a park consists in uniform verdure; undulating ${ }^{c}$ lines contrasting with each other in variety of forms; trees so grouped as to produce light and shade to display the varied surface of the ground; and an undivided range of pasture. The animals fed in such a park appear free from confinement, at liberty to collect their food from the rich herbage of the valley, and to range uncontrouled to the drier soil of the hills.

The furm, on the contrary, is for ever changing the colour of its surface in motley and discordant hues; it is subdivided by straight lines of fences. The trees can only be ranged in formal

' I am aware that the word undulating is seldom applied to solid bodies, but I know no other word so cxpressive of that peculiar shape of ground consisting of alternate concave and convex lines flowing into each other. 
rows along the hedges; and these the farmer claims a right to cut, prune, and disfigure. Instead of cattle enlivening the scene by their peaceful attitudes or sportive gambols, animals are bending beneath the yoke, or closely confined to fatten within narrow enclosures, objects of profit, not of beauty.

This reasoning may be further exemplified by an extract from the Red Book of Antony.

The shape of the ground at Antony is naturally beautiful, but attention to the farmer's interest has ${ }^{\mathrm{d}}$ almost obliterated all traces of its original form; since the line of fence, which the farmer deems necessary to divide arable from pasture land, is unfortunately that which, of all others, tends to destroy the union of hill and valley. It is generally placed exactly at the point where the undulating surface changes from convex to concave, and of course is the most offensive of all intersecting lines; for it will be found, that a line of fence following the shape of the ground, or falling in any direction from the hill to the valley, although it may offend the eye as a boundary, yet it does not irjure, and in some instances may even improve the beautiful form of the surface. No great improvement therefore can be expected at Antony, until almost all the present fences be removed, although others may be placed in more suitable directions.

I am aware that in the prevailing rage for agriculture, it is unpopular to assert, that a farm and a park may not be united; but after various efforts to blend the two, without

\footnotetext{
'In this, as in many other cases, I transcribe from the Red Book, as if my plans were not yet executed.
} 


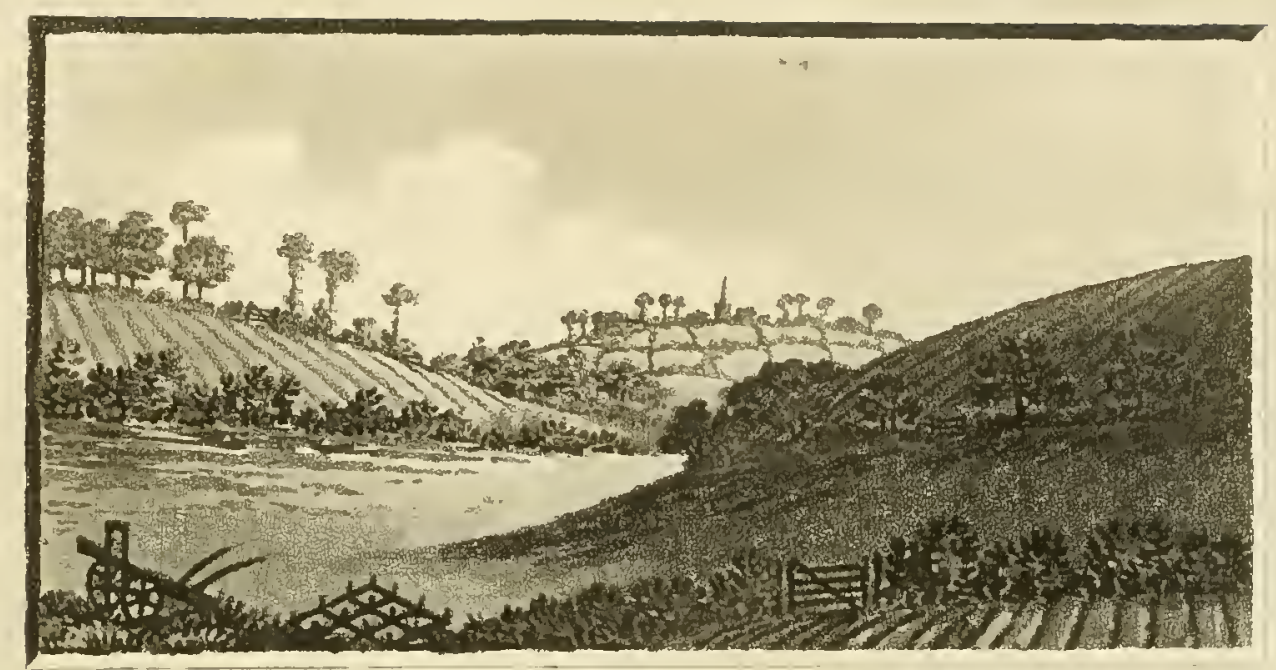

FARM and PARK

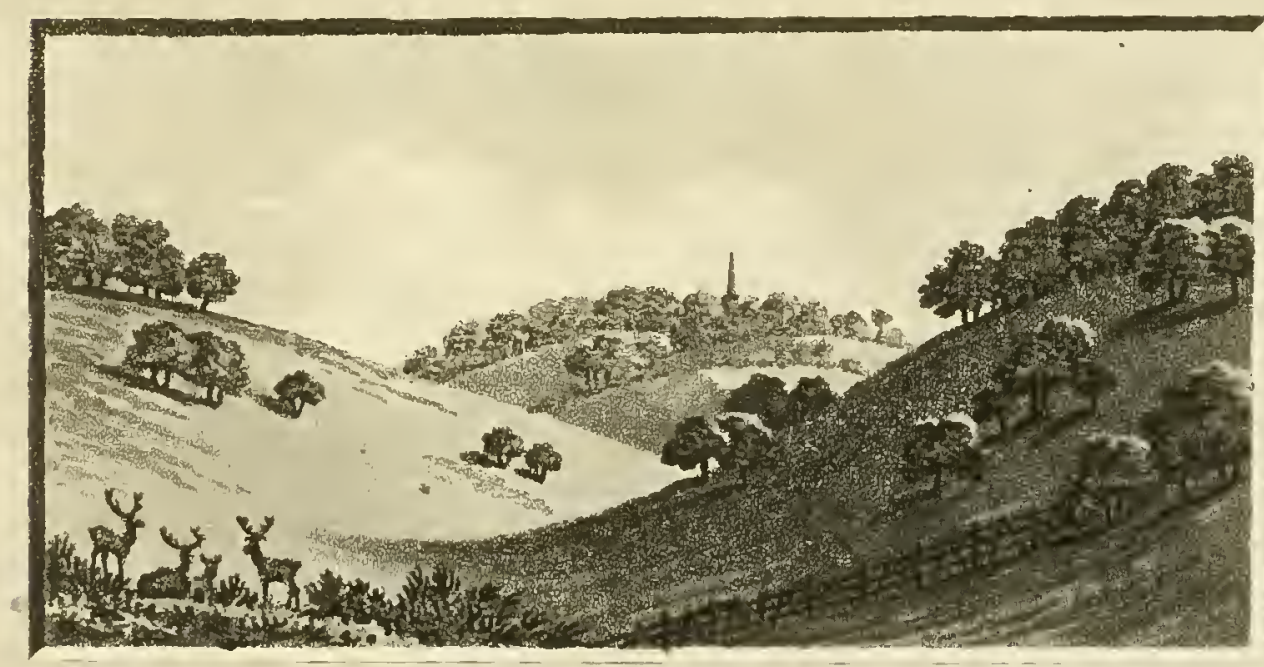

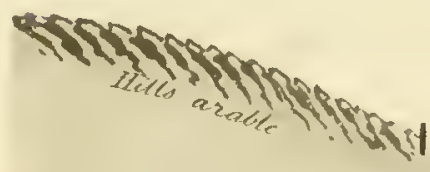

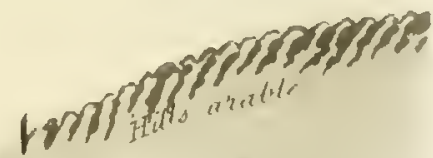



violation of good taste, I am convinced that they are, and must be distinct objects, and ought never to be brought together in the same point of view.

To guaid against misrepresentation, let me be allowed to say, each may fill its appropriate station in a gentleman's estate: we do not wish to banish the nectarine from our desserts, although we plant out the wall which protects it; nor would I expunge the common farm fiom the pleasures of the country, though I cannot encourage its motley hues, and domestic occupations, to disturb the repose of park scenery. It is the union, not the existence, of beanty and profit, of laborious exertion and pleasurable recreation, against which I would interpose the influence of my art; nor let the fastidious objector condemn the effort, till he can convince the judgment, that without violation of good taste he could introduce the dairy and the pigsty (those useful appendages of rural economy) into the recesses of the drawing room, or the area of the saloon.

The difficulty of uniting a park and a farm arises from this material circumstance, that the one is an object of beauty, the other of profit. The scenery of both consists of Ground, Trees, Water, and Cattle; but these are very differently arranged. And since a park is less profitable than arable land, the more we can diminish the quantity of the former, provided it still be in character with the style of the mansion, the less we shall regret the sacrifice of profit to beanty.

The shape and colour of corn fields, and the straight lines of fences, are so totally at variance with all ideas of picturesque beauty, that I shall not venture to suggest any hints on the 
subject of a farm, as an ornament; yet I think there might be a distinction made between the farm of a tenant, who must derive benefit from every part of his land, and that occupied by a gentleman for the purposes of amusement or experiment.

It is usual in Hampshire, and indeed in the neighbourhood of many forests, to divide the enclosures of a farm by rows of copse wood and timber, from ten to twenty yards wide; at a little distance these rows appear united, and become one rich mass of foliage. This kind of subdivision I should wish to be generally adopted on experimental farms. The advantages of such plantations will be,

Shady and pleasant walks through the farm - to afford shelter to corn, and protect the cattle which are grazed on the farm-to give the whole, at a distance, the appearance of one mass of wood - to make an admirable cover for game; and lastly, if it should ever hereafter be thought advisable to extend the lawn, such plantations will furnish ample choice of handsome trees to remain single or in groups, as taste or judgment shall direct.

In some counties the farms consist chiefly of grass land, but even a dairy farm must be subdivided into small enclosures; and although it is not necessary that the lawn near a mansion should be fed by deer, yet it is absolutely necessary that it should have the appearance of a park, and not that of a farm; because, in this consists the only difference betwixt the residence of a landlord and his tenant, the gentleman and the farmer: one considers how to make the greatest immediate advantage of his land; the other must, in some cases, give up the idea of profit for the sake of that beauty which is derived from an 
air of liberty totally inconsistent with those lines of confinemem and subdivision which are characteristic of husbandry.

Since the beauty of pleasure ground, and the profit of a farm, are incompatible, it is the business of taste and prudence so to disguise the latter and to limit the former, that park scenery may be obtained without much waste or extravagance; but I disclaim all idea of making that which is most beautiful also most profitable: a plowed field, and a field of grass, are as distinct objects as a flower garden and a potatoe ground. The difference between a farm and a park consists not only in the number of fences and subdivisions, but also in the management of the lines in which the fences of each should be conducted. The farmer, without any attention to the shape of the ground, puts his fences where they will divide the uplands from the meadows; and in subdividing the ground he aims only at square fields, and consequently straight lines, avoiding all angles or corners. This is the origin of planting those triangular recesses in a field, surrounded by wood, which the farmer deems useless; but which to the eye of taste produce effects of light and shade.

There is no mistake so common as that of filling up a recess in a venerable wood with a miserable patch of young plantation. The outline of a wood can never be too boldly indented or too irregular; to make it otherwise by cutting off the projections or filling up the hollows, shews a want of taste, and is as incongruous as it would be to smooth the furrowed bark of an aged oak.

In a park the fences cannot be too few, the trees too majestic, or the views too unconfned. In a farm small enclosures 
are often necessary; the mutilated pollard, or the yielding willow, in the farmer's eye, are often preferable to the lofty elm or spreading oak; whilst a full crop of grain, or a copious swath of clover, is a more gladdening prospect than all the splendid scenery of wood and lawn from the windows of a palace. Small detached farms adapted to useful and laborious life, unmixed with the splendours of opulence, but supporters of national wealth, are indeed objects of interest in every point of view; they want not the adventitious aid of picturesque effect to attract peculiar notice; to a benevolent mind they are more than objects of beauty; they are blessings to society; nor is it incompatible with the pursuit of pleasure, sometimes to leave the boundaries of the park, and watch the exertions of laudable industry, or visit the cottages

"Where cheerful tenants bless their yearly toil."

The monopolist only can contemplate with delight his hundred acres of wheat in a single enclosure; such expanded avarice may enrich the man, but will impoverish and distress, and (I had almost added) will ultimately starve mankind. 
Of Pleasure Grounds-Flower Gardens, Excomple BuxstrodeVAlley Field - Nunehan - Greenhouse and Conservatory belong to a Flower Garden-Various modes of attaching them to a House - Difficulty-Objection-Attempt to make them Gothic.

IN the execution of my profession I have often experienced great dificulty and opposition in attempting to correct the false and mistaken taste for placing a large house in a naked grass field, without any apparent line of separation between the ground exposed to cattle and the ground annexed to the house, which I consider as peculiarly under the management of art.

This line of separation being admitted, advantage may be easily taken to ornament the lawn with flowers and shrubs, and to attach to the mansion that scene of "embellished neatness," usually called a Pleasure Ground.

The quantity of this dressed ground was formerly very considerable. The royal gardens of Versailles, or those of Kensington palace, when filled with company, want no other animation; but a large extent of ground without moving objects, however neatly kept, is but a melancholy scene. If solitude delight, we seek it rather in the covert of a wood, or the sequestered alcove of a flower garden, than in the open lawn of an extensive pleasure ground. 
I have therefore frequently been the means of restoring acres of useless garden to the deer or sheep, to which they more properly belong:

This is now carrying on with admirable effect at BuLsTrope, where the gardens of every kind are on a great scale, and where from the choice and variety of the plants, the direction of the walks, the enrichment of art, and the attention to every circumstance of elegance and magnificence; the pleasure ground is perfect as a whole, while its several parts may furnish models of the following different characters of taste in gardening: the ancient garden, the American garden, the modern terrace walks, and the fower garden: the latter is, perhaps, one of the most varied and extensive of its kind, and therefore too large to be otherwise artificial, than in the choice of its flowers, and the embellishments of art in its ornaments.

Flower gardens on a small scale may, with propriety, be formal and artificial; but in all cases they require neatness and attention. On this subject I shall transcribe the following passage from the Red Book of VALLey Field. ${ }^{e}$

To common observers, the most obvious difference between Mr. Brown's style and that of ancient gardens, was the change

e "Although I have never seen VALLEY FiELD myself, yet it flatters me to learn, that under the direction of my two sons, by taking advantage of the deep romantic glen and wooded banks of the river which flows through the grounds, and falls into the Frith of Forth at a short distance from the house, an approach has been made, which, from variety, interest, and picturesque scenery, miay vie with any thing of the kind in England; while it remains a specimen of the powers of landscape gardening in that part of Scotland, where the art had been introduced only by those imitators of Mr. Brown's manner, who had travelted into the north. His own improvements were confined to England." 
from straight to waving or serpentine lines. Hence many of his followers had supposed good taste in gardening to consist in avoiding all lines that are straight or parallel, and in adopting forms which they deem more consonant to nature, without considering what objects were natural and what were artificial.

This explanation is necessary to justify the plan which I recommended for the canal in this flower garden: for while I shonld condemn a long straight line of water in an open park, where every thing else is natural; I should equally object to a meandering canal or walk, by the side of a long straight wall, where every thing else is artificial.

A flower garden should be an object detached and distinct from the general scenery of the place; and whether large or small, whether varied or formal, it ought to be protected from hares and smaller animals by an inner fence: within this enclosure rare plants of every description should be encouraged, and a provision made of soil, and aspect for every different class. Beds of bog earth should be prepared for the American plants: the aquatic plants, some of which are peculiarly beautiful, should grow on the surface or near the edges of water. The numerous class of rock plants should have beds of rugged stone provided for their reception, without the affectation of such stones being the natural production of the soil: but above all, there should be poles or hoops for those kind of creeping plants which spontaneously form themselves into graceful festoons, when encouraged and supported by art.

Yet with all these circumstances the flower garden, except where it is annexed to the house, should not be visible from the roads or general walks about the place. It may therefore be of 
a character totally different from the rest of the scenery, and its decorations should be as much those of art as of nature.

The flower garden at Nunemam, ${ }^{\text {f }}$ without being formal, is highly enriched, but not too much crowded, with seats, temples, statues, vases, or other ornaments, which being works of art, beantifully harmonize with that profusion of flowers and curious plants which distinguish the flower garden from natural landscape, although the walks are not in straight lines.

But at Valley Field, where the flower garden is in front of a long wall, the attempt to make the scene natural would be affected; and therefore as two great sources of interest in a place are variety and contrast, the only means by which these can be introduced, are in this flower garden, which, as a separate object, becomes a sort of episode to the general and mag-. nificent scenery.

The river being every where else a lively stream rattling and foaming over a shallow bed of rock or gravel, a greater contrast will arise from a smooth expanse of water in the flower garden : to produce this must be a work of art, and therefore, instead of leading an open channel from the river to supply it, or making it appear a natural branch of that river, I recommend that the water should pass under ground, with regulating sluices or shuttles to keep it always at the same height. Thus the canal will be totally detached from the river, and become a distinct

' Earl Harcourt, although possessing great good taste, gives the whole merit of this garden to Mason the poet, as he does of his pleasure grounds to Brown. Thus superior to that narrow jealousy which would deny the just tribute of praise to the professor, his lordship is satisfied with having been the liberal friend and patron of merit. 


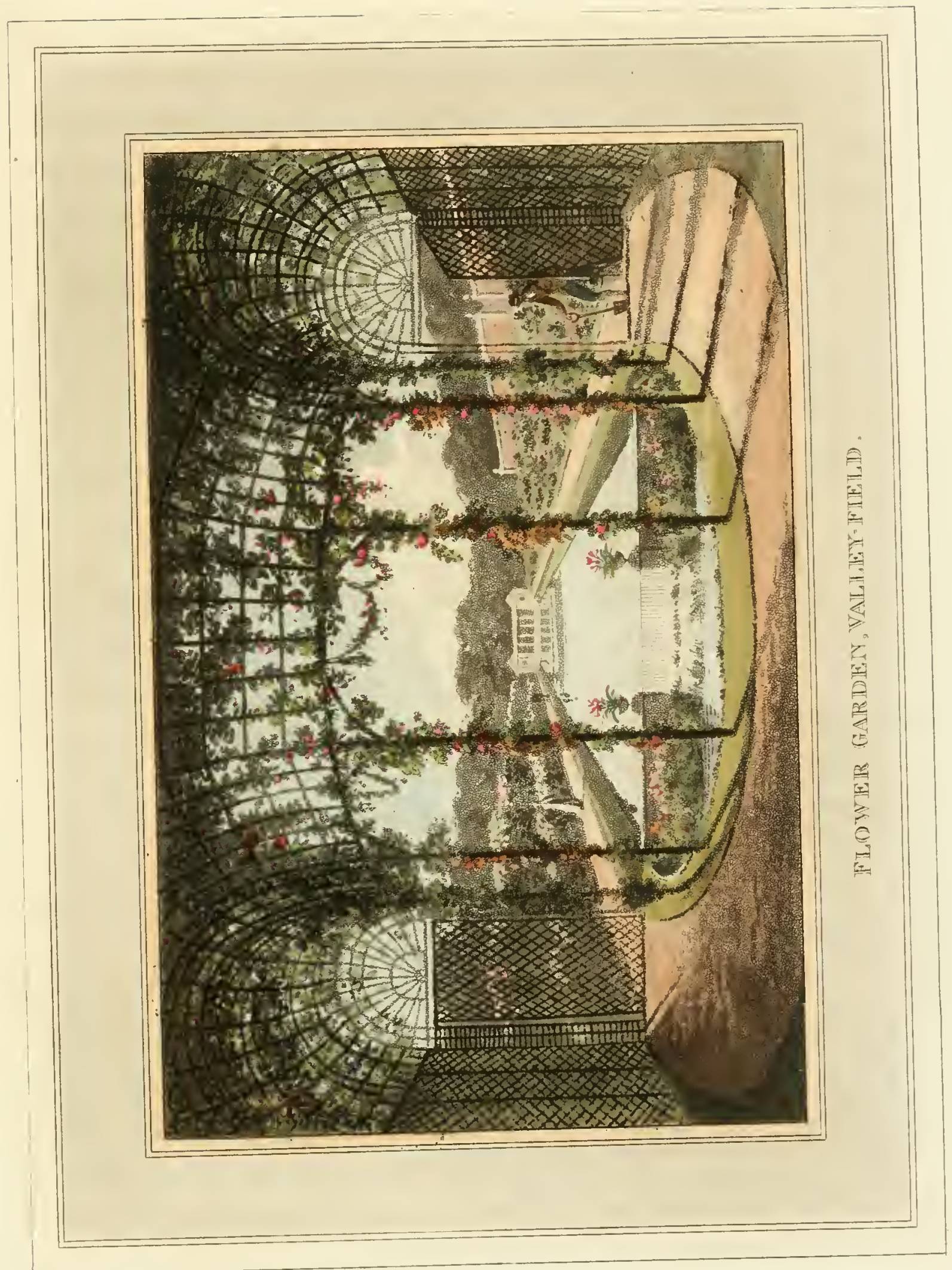



object, forming the leading feature of the scene to which it belongs; a scene purely artificial, where a serpentine canal would be as incongruous as a serpentine garden wall, or a serpentine bridge; and, strange as it may appear, I have seen such absurdities introduced to avoid nature's supposed abhorrence of a straight line.

The banks of this canal, or fish pond, may be enriched with borders of curious flowers, and a light fence of green laths will serve to train such as require support, while it gives to the whole an air of neatness and careful attention.

But as the ends of this water should also be marked by some building or covered seat, I have supposed the entrance to the flower garden to be under a covered passage of hoops, on which may be trained various sorts of creeping plants; and the farther end may be decorated by an architectural building, which I suppose to consist of a covered seat between two aviaries.

It will perhaps be objected that a long straight walk can have little variety: but the greatest source of variety in a flower garden is derived from the selection and diversity of its shrubs and flowers.

There is no ornament of a flower garden more appropriate than a conservatory or green-house, where the flower garden is not too far from the house; but amongst the refinements of modern luxury, may be reckoned that of attaching a greenhonse to some room in the mansion, a fashion with which I have so often been required to comply, that it may not be im- 
proper in this work, to make ample mention of the various methods by which it has been effected in different places.

At Bowood, at Wimpole, at Bulstrode, at Attingham, at Dyrham Park, at Cannood, at Thoresby, and some other large houses of the last century, green-houses were added to conceal offices behind them, and they either became a wing of the house, or were in the same style of architecture: but these were all built at a period when only orange trees and myrtles, or a very few other green-house plants, were introduced, and no light was required in the roof of such buildings. In many of them, indecd, the piers between each window are as large as the windows.

Since that period, the numerous tribe of geraniums, ericas, and other exotic plants, requiring more light, have caused a very material alteration in the construction of the green-house; and perhaps the more it resembles the shape of a nursery-man's stove, the better it will be adapted to the purposes of a modern green-house.

Yet such an appendage, however it may increase its interior comfort, will never add to the external ornament of a house of regular architecture: it is therefore generally more advisable to make the green-house in the flower garden, as near as possible to, without forming a part of the mansion; and in these situations great advantage may be taken of treillage ornaments to admit light, whilst it disguises the ugly shape of a slanting roof of glass.

There is one very material objection to a green-house immediately attached to a room constantly inhabited, viz. that the smell and damp from a large body of earth in the beds or pots, is 
often more powerful than the fragrance of the plants, therefore the conservatory should always be separated from the house by a lobby or small anti-room. But the greatest objection arises from its want of conformity to the neighbouring mansion, since it is difficult to make the glass roof of a conservatory arehitectural, whether Grecian or Gothic.

An arcade is ill adapted to the purpose, because by the form of an arch the light is excluded at the top, where it is most essential in a green-house, for this reason, the flat gothic arch of Henry the Eighth is less objectionable, yet in such buildings we must suppose the roof to have been taken away to make room for glass; of this kind is the conservatory in front of Rendesham House.

In the adaptation of ancient forms to modern uses and inventions, we are often under the necessity of deviating from the rules of true Gothic. Under such circumstances it is perhaps better to apply old expedients to new uses, than to invent a new and absurd stile of Gothic or Grecian arehitecture. At Plas-Newy d, where the house partakes of a Gothic character, I suggested the addition of a green-house, terminating a magnificent enfilade through a long line of principal apartments. The hint for this model is taken from the chapter rooms to some of our eathedrals, where an octagon roof is supported by a slender pillar in the middle, and if this were made of cast iron, supporting the ribs of a roof of the same maierials, there would be no great impropriety in filling the interstices with glass, while the side window frames might be removed entirely in summer, making a beautiful pavilion at that season when the plants being removed, a green-house is generally a 
deserted and unsightly object. The effect of this building by moonlight is shewn in the annexed sketch. And there are many summer evenings when such a pavilion would add new interest to the magnificent scenery of water and mountains with which Plas-Newyd every where abounds. ${ }^{g}$

z In a conversation I had the satisfaction to enjoy with the late Earl of Orford, at Strawberry Hill, he shewed me the gradual progress of his knowledge in gothic architecture by various specimens in that house, in which he had copied the forms of mouldings without always attending to the scale or comparative proportion; and his lordship's candour pointed ont to me the errors he had at first committed. This error, in the imitators of gothic, often arises from their not considering the difference of the materials with which they work: if in the mullions of a window, or the ribs of a ceiling, they copy in wood or plaster, ornaments originally of stone, they must preserve the same massive proportions, that were necessary in that material, or they must paint it like wood, and not like stone: but if the architects of former times had known the use we now make of cast iron, we should have seen many beautiful effects of lightness in their works; and surely in ours, we may be allowed to introduce this new material for buildings, in the same manner that we may fairly suppose they would have done, had the invention been known in their time: but whererer cast iron is used in the construction, it ought to be acknowledged as a support, either by gilding, or bronze, or any expedient that may shew it to be metal, and not zcood or stone, otherwise it will appear unequal to its office. 


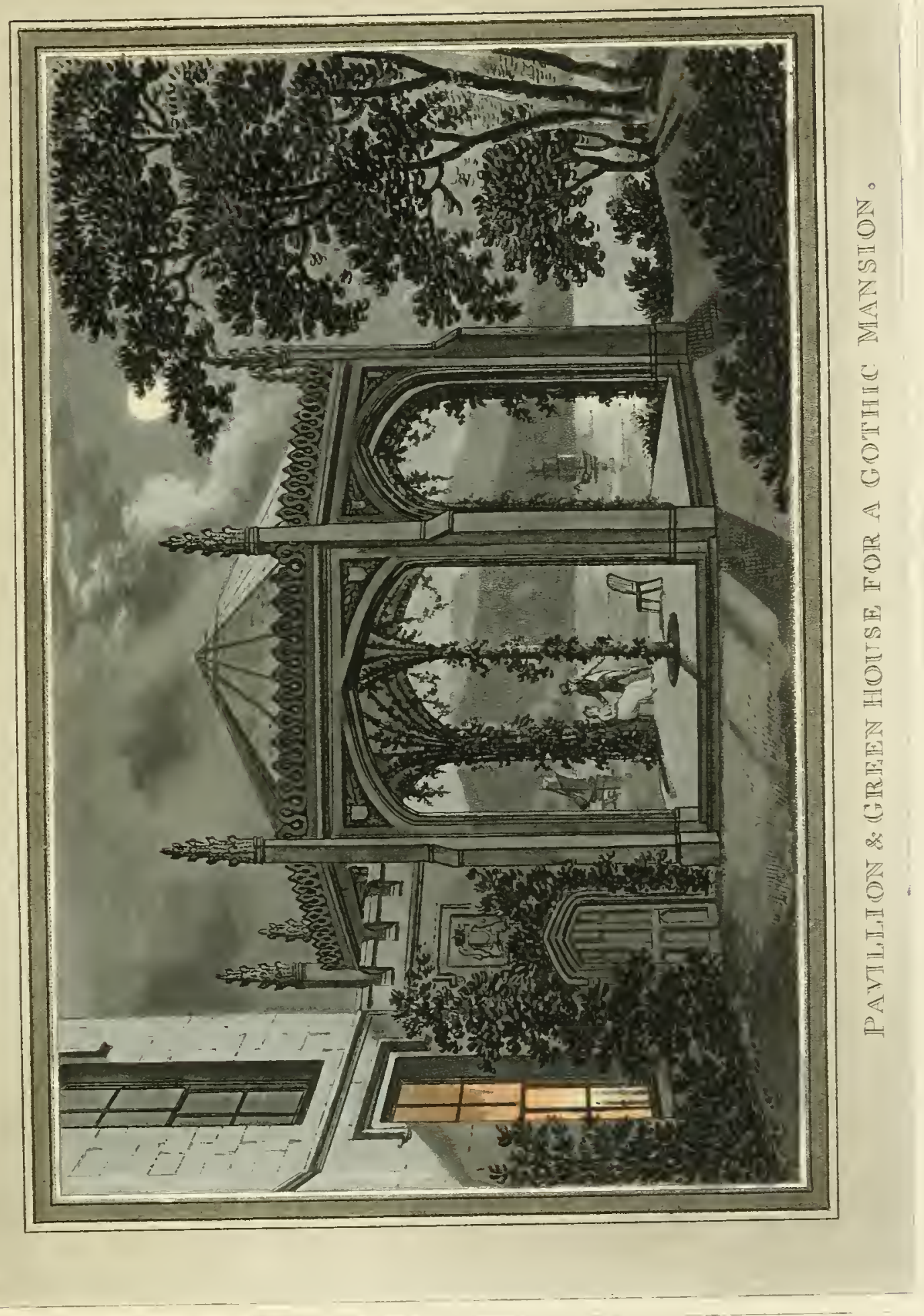





\section{CHAPTER IX.}

Defence of the Art-Difference between Landscape Gardening and Painting-Further Answer to Messrs. Price and KingutCursory Remarks on views from Rooms, Appropriation, Extent, \&c. - Example from Atringhaм - Pictures may imitate Nature, but Nature is not to copy Pictures.

A the time my former publication was in the press, the Art of Landscape Gardening was attacked by two gentlemen, $\mathrm{Mr}$. Knight, ${ }^{\text {h }}$ of Herefordshire, and Mr. Price, ${ }^{i}$ of Shropshire; and I retarded its publication till I could take some notice of the opinions of these formidable, because ingenious, opponents.

Having since been consulted on subjects of importance in those two counties, I willingly availed myself of opportunities to deliver my sentiments as particular circumstances occurred,

'Mr. Knight has endeavoured to ridicule all display of extent of property, which I consider one of the leading principles of the art. I contend that it is impossible to annex the same degree of importance to a modern house, however large, by the side of a high road, that may be justly given to one surrounded by an exteusive park. To this principle of improvement I have given the name of appropriation.

'Mr. Price builds a theory of improvement on the study of the best pictures, without considering how little affinity there is between the confined landscape exhibited on canvass, and the extensive range which the eye at once comprehends, and argues that, the best works of the painter should be models for the improver. 
and therefore, with permission of the respective proprietors, I insert the following observations from the Red Books of Sufton Court, in Herefordshire, and Attingham, in Shropshire.

"My opinion concerning the improvement of Sufton Court, involving many principles in the art of landscape gardening, I take this opportunity of justifying my practice, in opposition to the wild theory which has lately appeared: and shall therefore occasionally allude to this new system when it bears any relation to our objects at Sufton Court.

Having already published a volume on the subject of landscape gardening, it will be unnecessary to explain the motives which induced me to adopt this name for a profession, as distinct from the art of landscape painting, as it is from the art of planting cabbages, or pruning fruit trees. ${ }^{k}$ The slight, and often gaudy sketches, by which I have found it necessary to elucidate my opinions, are the strongest proofs that $I$ do not profess to be a landscape painter; but to represent the scenes of nature in her various hues of blue sky, purple mountains,

" "In the art of gardening, the great materials of the scene are provided by "nature herself, and the artist must satisfy himself with that degree of expression " which she has bestowed.

"In a landscape, on the contrary, the painter bas the choice of the circumstances "he is to represent, and can give whatever force or extent he pleases to the expression "he wishes to convey. In gardening the materials of the scene are few, and those "few unwieldy, and the artist must often content himself with the reflection that he "has given the best disposition in his power to the scanty and intractible materials " of nature. In a landscape, on the contrary, the whole range of scenery is before "the eye of the painter." 
green trees, \&c. which are often disgusting to the eye of a connoisseur in painting.

The best painters in landscape have studied in Italy, or France, where the verdure of England is unknown: hence arises the habit acquired by the connoisseur of admiring brown tints and arid foregrounds in the pictures of Clande and Poussin, and from this cause he prefers the bistre sketches to the green paintings of Gainsborough. One of our best landscape painters studied in Ireland, where the soil is not so yellow as in England; and his pictures, however beautiful in design and composition, are always cold and chalky.

Autumn is the favourite season of study for landscape painter's, when all nature verges towards decay, when the foliage changes its vivid green to brown and orange, and the lawns put on their russet hue. But the tints and verdant colouring of spring and summer will have superior charms to those who delight in the perfection of nature, without perhaps ever considering whether they are adlapted to the painter's landscape.

It is not from the colouring only, but the general composition of landscapes, that the painter and landscape gardener will feel the difference in their respective arts; and although each may occasionally assist the other, yet I should no more advise the latter, in laying ont the scenery of a place, to copy the confined field of vision, or affect the careless graces of Claude or Poussin, than I should recommend as a subject proper for a landscape painter the formal rows or quincunx position of trees in geometric gardening. It has been wittily observed, that "the works of nature are well executed, but in a bad taste;" this, I suppose, has arisen from the propensity of good taste, to display 
the works of nature to advantage; but it does not hence follow that art is to be the standard for nature's imitation; neither does it disgrace painting, to assert that nature may be rendered more pleasing than the finest picture; since the perfection of painting seldom aims at exact or individual representation of nature. A panor:mna gives a more natural idea of ships at sea, than the best picture of Vandervelde; but it has little merit as a painting, because it too nearly resembles the original, to please as an effort of imitative art. My sketches, if they were more highly finished, would be a sort of panorama, or fac simile, of the scenes they represent, in which little effect is attempted on the principle of composition in painting; but, like a profile shadow or sillouette, they may please as portraits, while they offend the connoisseur as paintings. The art I profess is of a higher nature than that of painting, and is thus very aptly described by a French author.

“ Il est à la poèsie et à la peinture ce que la realité est à la description et l'original à la copie."

The house at Sufton Court having been built long before I had the honour of being consulted, its aspects, situation, and general arrangement, do not properly come under my consideration. Yet as I shall suggest a hint for altering the windows in the drawing-room, I must consider the different landscapes in each direction.

The views towards the south and west are extensive, and under certain circumstances of light and weather, often wonderfully beautiful; but as distant prospects depend so much on the state of the atmosphere, I have frecuently asserted, that the views from a house, and particularly those from the drawingroom, ought rather to consist of objects which evidently belong 
to the place. To express this idea, I have used the word Appropriation, by which I mean, such a portion of wood and lawn, as may be supposed to belong to the proprietor of the mansion, occupied by himself, not so much for the purposes of gain as of pleasure and convenience: this, of course, should be grass, whether fed by deer, by sheep, or by other cattle, and its subdivisions, if there be any, ought not to be permanent. I am ready to allow that this part of modern gardening has often been egregiously mistaken and absurdly practised; I find no error so difficult to counteract as the general propensity for extent, without sufficient attention to the size, style, or character of the house, or of the surrounding estate.

Extent and beauty have ever appeared to me distinct objects; and a small place, in which the boundary is not obtrusive, may be more interesting, and more consonant to elegance and convenience, than a large tract of land, which has no other merit than that it consists of many hundred acres, or is encompassed by a pale of many miles in circuit, while, perhaps, within this area, half the land is ploughed in succession.

The drawing-room at present looks towards the south, but there appear to be several reasons for altering its aspect; 1 st. because the hall and dining-room command the same prospect, but more advantageously; 2d. becanse the windows being near the hall door, a carriage road, which must occasionally be dirty, becomes a bad foreground; and lastly, the view towards the east will not only be different from the others, but is of such a nature as to appear wholly appropriate to the place, and, therefore, in strict harmony with the quiet home scene of a country residence: it consists of a beautiful lawn 
or valley, having its opposite bank richly clothed with wood, which requires very little assistance to give it an irregular and pleasing outline; and is one of the many subjects, more capable of delighting the eye in nature, than in a picture. The sketch shews with accuracy the situation of the several trees which ought to be removed.

It has been laid down by a recent author before named, as a general rule for improvement, to plant largely and cut down sparingly: this is the cautious advice of timidity and inexperience; for in some situations improvement may be effected by the axe rather than by the spade, of which this sketch furnishes an instance: the trees in a straight line at the bottom of the hill have in vain been encumbered by young trees, planted with a view of breaking their formal row; while in reality they produce the contrary effect. I rather advise boldly taking away all the young trees and part of the old ones, but particularly an oak, which not only hides the forked stem of a tree behind, but from its situation depresses the other trees, and lessens the magnitude and importance both of the hill and of the grove, by which its brow is covered."

"The situation of ATT1NGHAM is at variance with its character; since it is impossible to annex ideas of grandeur and magnificence to a mansion, with little apparent domain. The flat lawn between the high road and the house, al though very extensive, 


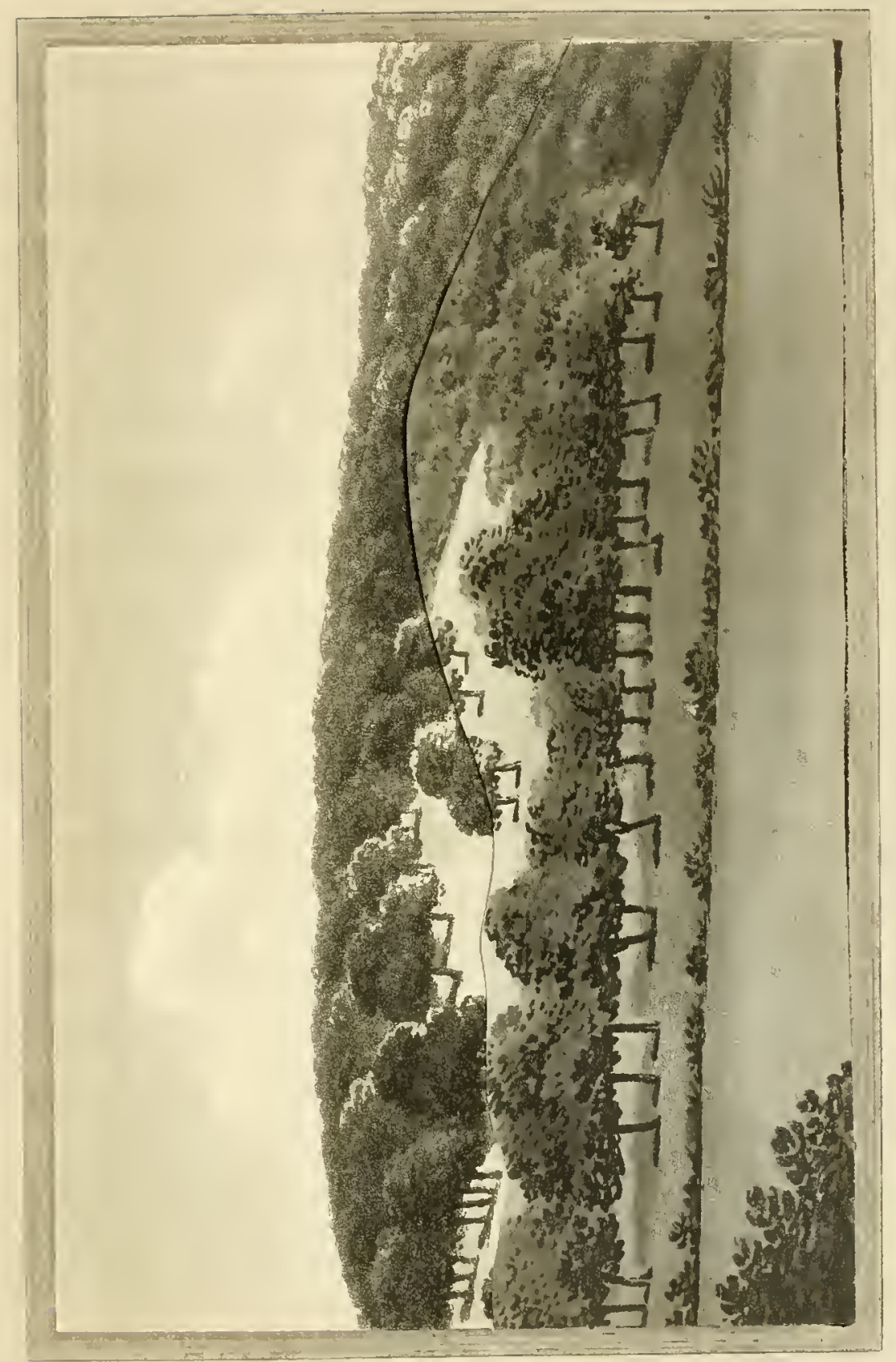



yet, possessing no variety in the size of the trees, and but little in the shape of ground, the eye is deceived in its real distance.

By the laws of perspective, the nearer any object is to the eye, the larger it will appear; also the larger any object is, the nearer it will appear to the eye: consequently the magnitude of the house makes it appear nearer than it really is, there being no intervening objects to divert the attention, or to act as a scale, and assist the eye in judging of the distance. For this reason, every stranger who sees this house from the turnpike road, would describe it as a large house with very little ground between it and the road. The first idea of improvement would be, either to remove the house or the road; but as neither of these expedients are practicable, we must have recourse to art to do away this false impression. This I shall consider as forming the basis of the alteration proposed at Atтingham.

In ancient gothic structures, where lofty walls and various courts intervened between the palace and the neighbouring village, there was sufficient dignity or seclusion without that apparent extent of domain which a modern mansion requires; but since the restraint of ancient grandeur has given place to modern elegance, which supposes greater ease and freedom, the situation of a house in the country is more or less defective in proportion as it is more or less bounded or incommoded by alien property. Thus a high road, a plowed field, a barn, or a cottage adjoining a large house, have a tendency to lessen its importance; and hence originates the idea of extending park, lawn, or pleasure grounds, in every direction from the house: hence also arises the disgust we feel at seeing the park pales, and grounds beyond, when they are so near or so conspicuous 
as to impress the mind with an idea of not belonging to the place.

Perhaps the love of mity may contribute to the pleasure we feel in viewing a park where the boundary is well concealed. This desire of hiding the boundary introduced the modern practice of surrounding almost every park with a narrow plantation or belt; which, if consisting of trees planted at the same time, becomes little better than a mere hedge row, and is deservedly rejected by every man of taste; yet there are many situations where a plantation becomes the natural boundary of a park: such is the skreen of wood on the highest ground to the east of Aтtringam, where it forms a pleasing ontline to the landscape, without exciting a wish to know whether it is the termination of the property.

In consequence of the apparent want of extent in the park or lawn at Atrivguan, it was suggested to add many hundred acres of land to the east, by removing the hedges of the adjoining fields. This would have increased the real, without extending the apparent magnitude of the park: but I contend, that oftentimes it is the appearance, and not the reality of extent, which is necessary to satisfy the mind; for the size of the park has little reference to that of the estate of the proprietor. 'The land at ached to a villa near a city may with propriety be surrounded by pales or a wall, for the sake of privacy and seclusion; but it is absurd to enclose more of a distant domain than is necessary for the beauty of the place: besides, if this park or lawn had been extended a mile firther to the east, the confinement to the south, which is in the front of the house, would not have been done arvay, and consequently to the traveller passing the 
road the apparent extent would not have been increased; and without some striking or beautiful feature, extent alone is seldom interesting.

If large trees, river scenery, or bold inequality of ground, can be included, by enlarging a park, they are sufficient motives; but views of distant mountains, which may be seen as well from the high road, are not features that justify extensive lawn over a flat surface.

To do away the impression of confinement at Atтingham, the park should be extended across the road, and thus the stranger will be induced to believe he passes through, and not at the extremity of the park. Secondly, some striking and interesting features should be brought into notice, such as the junction of the Severn and the Terne, which may be actually effected within the limits of the park; and particularly the great arch across the Terne, of which no adequate advantage is at present taken. There are also some large trees, and many interesting points of view, which well deserve attention in a plan professing to increase the number of beautiful circumstances, rather than the number of acres in the park.

In opposition to Mr. Price's idea, that all improvement of scenery should be derived from the works of great painters, I shall observe, that there are at present, very near the house, soine fragments of an old mill and brick arches, that make a charming study for a painter; the composition is not unlike a beantiful picture of Ruisdale's, at AттікGнам, which every

'One great error in Mr. Brown's followers has been the unnecessary extent of parks. It is my opinion, that, provided the boundary can be properly disguised, the largest parks need not exceed two or three hundred acres, else they are apt to become farms within a pale, or they are forests rather than parks. 
Inan of taste must admire: of this scene, as it now exists, I have endeavoured to give a faint idea. Among the trees is seen part of the colonade that joins the east wing to the body of the house: from the general character of this scenery, we cannot but suppose this to be a fragment of some ruined Grecian temple, and no part of a modern inhabited palace. Hence it is evident that the mind cannot associate the ideas of elegance with neglect, or perfect repair and neatness with ruin and decay: such objects, therefore, however picturesque in themselves, are incongruous and misplaced, if near such a palace as Attringham.

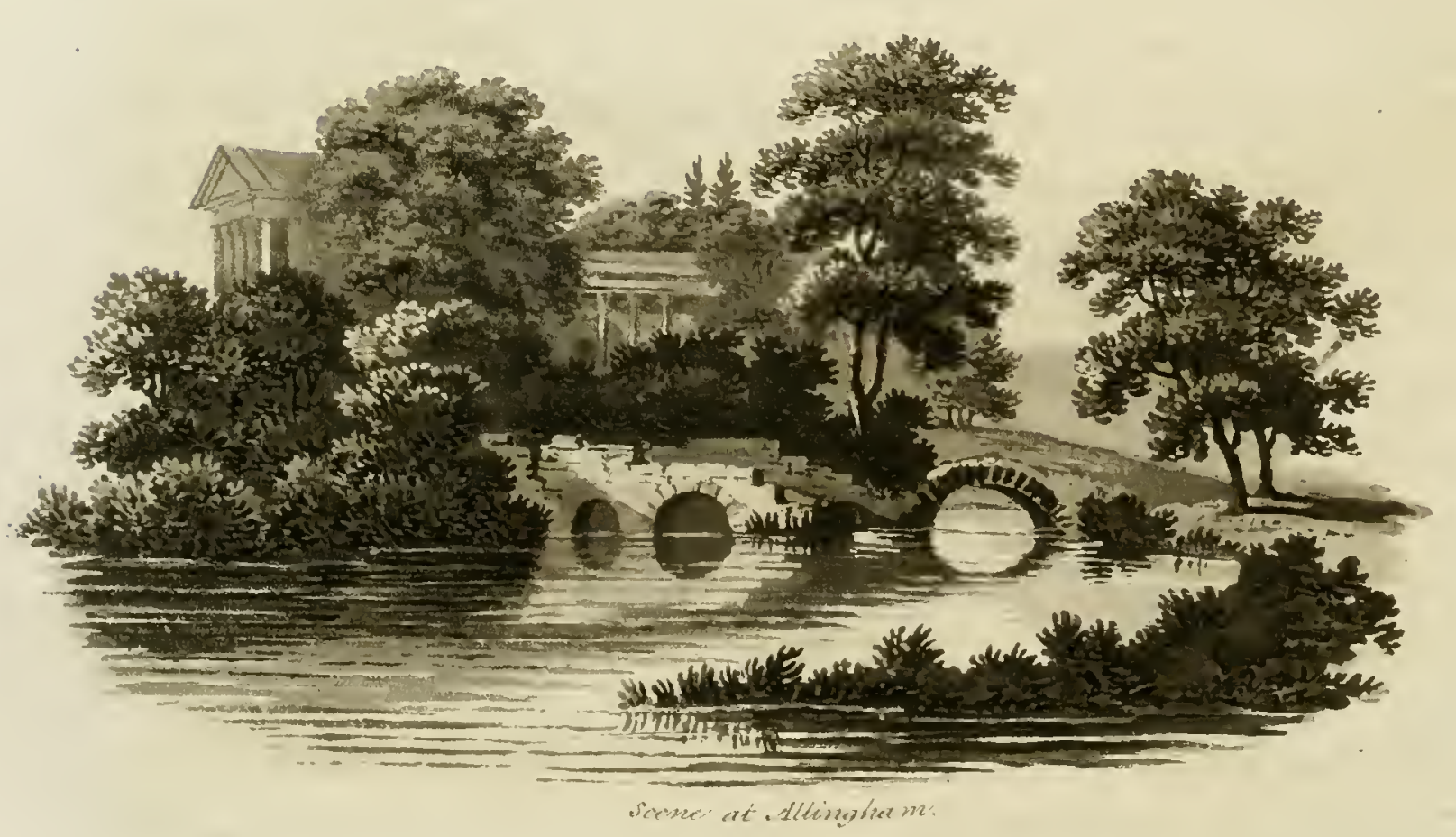


Another mistake of the admirers of painters' landscape is, the difference in the quantity of a uatural and an artificial composition: the finest pictures of Claude (and here again I may refer to a picture at $A$ Ttivgham) seldom consist of more than one-fifth of that field of vision which the eye can with ease behold without any motion of the head, viz. about 20 degrees out of 90 ; and we may farther add, that without moving the body, our field of vision is extended to 180 degrees.

Now it is obvious that the picture of Claude already mentioned, which is between four and five feet long, if it had been extended to 20 or 30 feet, would not have been so pleasing a composition; because, instead of a picture, it would have resembled a panorama. This I may further instance in the view from the breakfast room, consisting of a distant range of mountains, by far too long for any picture. Yet a small part of this view might furnish a subject for the painter, by supposing a tree to form the foreground of the landscape. Are we then to plant such a tree? or a succession of such trees, to divide the whole field of vision into separate landscapes? and would not such an attempt at improvement be like placing five or six pictures of Claude in one long frame? The absurdity of the idea proves the futility of making pictures our models for natural improvements: however I may respect the works of the great masters in painting, and delight to look at nature with a painter's eye; yet I shall never be induced to believe that " the best land"scape painter would be the best landscape gardener."m

" Since I began these remarks on Attingham, Mr. Price has published a second volume of Essays on the Picturesque, the whole of which is founded on his cnthusiasm for pictures; and he very justly observes, (page 20\%), "Enthusiasm always leads to 
The river Terne being liable to floods from every heavy shower of rain which falls upon the neighbouring hills, has formed a number of different channels and islands: some of these channels are dry when the water is low, and some of the islands are covered when the water is high. These irriguous appearances have charms in the eye of a landscape painter, who, from some detached parts, might select a study for a foreground at a happy moment when the water is neither too high nor too low; but the landscape gardener has a different object to effect,

the verge of ridicule, and selrlom keeps totally within it." Thus not content with making the works of great painters the standard for laying out grounds, they are also to furnish plans and elerations for all our buildings, from the palace to the cottage: and since we cannot be quite reconciled to their being in a state of ruin, which would certainly be most picturesque, we must build them in such irregular forms that trees may be introduced in various hollows and recesses, to be left for this purpose: these will, indeed, very soon contribute to produce those weather stains, and harmonious tints, which are more grateful to the painter's eye than polished marble; as the green rust on copper coins, is more interesting to the antiquarian, than the bright surface of gold or silver. Mr. Price confesses, that two small difficulties occur in putting these projects fully in practice, viz. that "he sees no examples of chimneys, and very few of slanting roofs," but where fine pictures can be transferred from the canvass to the real residence of man. How void of taste must that man be, who could desire a chimney, or roof to his country-house, when we are told that Poussin, and Panl Veronese, built whole cities without a single chinney, and with only one or two slanting roofs! This idea of deriving all our instruction from the works of great painters, is so ingenious and useful, that it ought not to be confined to gardening. and building. In our markets, for instance, instead of that formal trim custom of displaying poultry, fish, and fruit, for sale on different stalls, why should we not rather copy the picturesque jumble of Schnyders and Rubens? Our kitchens may be furnished after the designs of Teniers and Ostade, our stables after Woovermans, and we may learn to dince from Watteau or Zuccarelli; in short, there is no individual from the emperor to the cobbler, who may not find a model for his imitation in the works of painters, if he will but consult the whole series from Guido to Teniers. 
he must secure a constant and permanent display of water, which may be seen at a distance, and which shall add brilliancy and grandeur to the character of the scenery: it is not an occasionally meandering brook that such a palace or such a bridge requires, but it is an ample river majestically flowing through the park, and spreading cheerfulness on all around it.

Mr. Price has written an Essay to describe the practical manner of finishing the banks of artificial water: but I confess, after reading it with much attention, I despair of making any practitioner comprehend his meaning; indeed, he confesses that no workman can be trusted to execute his plans. It is very true that large pieces of water may be made too trim and neat about the edges, and that often in Mr. Brown's works, the plantations are not brought near enough to the water; but if the banks are finished smoothly at first, the treading of cattle will soon give them all the irregularity they require: and with respect to plantations, we must always recollect, that no young trees can be planted without fences, and every fence near the water is doubled by reflexion; consequently all rules for creating. bushes to enrich the banks are nugatory, except where cattle are excluded.

The difficulty of clothing the banks of artificial water has been a source of complaint made against Mr. Brown, for having left them bare and bald: but the river at ATtixghAm will be sufficiently enriched by the few trees already growing on its margin, and by the plantations proposed, on the island, \&c.

There is a part of the river Terne above the house where both its banks are richly clothed with alders, and every person of discernment must admire the beauty of this scene; but if the 
same were continued quite to the bridge, the river would be invisible from the house and from every part of the park: how then is it possible that the banks of water should every where be covered with wood? I contend that a broad ample channel, in proportion to the bridge, will be far more in character with the style of the house and the bridge, than the more intricate, which, on paper, is perhaps more picturesque.

If it be ridiculous to imitate nature badly in a picture, how much more ridiculous will it appear to imitate a picture badly in nature; an imitation which, after all, must be left for half a century to be finished by the slow process of " neglect and accident."

The water at Atringham having been completed, and a new channel made to connect the river Terne with the Severn, the improvement is obvious to every person who travels the great road to Shrewsbury: it is therefore needless to elucidate these observations by any views of the place, especially as painting can give but an imperfect idea of the situation commanding that extensive range of hills which separates England from Wales. 
121

CHAPTER $\mathrm{X}$.

Of ancient and modern Gardening-Authors-Change of StyleWimpole-Terraces - at the Haselus - at Cовнам - Art and Nature considered-Example BurLey on the HiLL.

IT is not my intention to enter into a minute history of gardening, or pursuing the course of some other writers, to trace back the gradual progress of the art from Brown to Kent, from Kent to Le Nôtre, from him to the Italians, the Romans, the Grecians, and ultimately to Adam, who was " the first gardener," but I shall confine myself to a few observations on the change in the fashion of gardens, to shew how much of each different style may be preserved or rejected with advantage: and lest it should appear to some readers that my allusions are too frequent to the late theoretical writers on landscape gardening, it is necessary to observe, that many of the MSS. whence I now transcribe, were written long before Mr. Knight's and Mr. Price's works appeared; of course the allusions relate to other authors on the subject, whose sentiments these gentlemen seem to have taken up without acknowledging that they had ever read them.

It may not be uninteresting here to mention a few of the authors, who have written on gardening, especially as the works of some are become scarce and are not generally known. 
I scarcely need mention the late Horace Walpole, who, in his lively and ingenious manner, has given both the history and the rules of the art, better than any other theorist.

The History of Gardening is very learnedly discussed, in a brief inquiry into the knowledge the ancients possessed of the art, by Dr. Fuulkner; and the same subject is more lightly, but not less correctly or elegantly, treated by my late ingenious friend Daniel Malthus, Esq. in a preface to his translation of "D'Emenonville de la Composition des paysages."

"From this gentleman I received a letter in 1795, written in so playful a style, and so much connected witl the subject of this volume, that I will venture to insert it, even though I should incur the imputation of vanity.

" DEAR SIR,

I $1 \mathrm{AVE}$ been lately very much pleased with a letter of yours to Mr. Price, which is so easy, friendly, and gentleman-like, that it defeats at once the pertuess of your antagonists before you enter into the question; at the same time, I think it is as perfect an answer as if it were more laboured, and that you have put your finger on the very pith and marrow of the question. Even in the little snatch of acquaintance we have had together, you may have perceived that $I$ am rather too much inclined to the Price and Knight party, and yet I own to you that I have been often so much disgusted by the affected and technical language of connoisseurship, that I have been sick of pictures for a month, and almost of nature, when the same jargon was applied to her. I know the abilities of the two gentlemen, and am sorry they have made themselves such pupils of the Warburtonian school, as to appear more like Luther and Calvin, than a couple of west country gentlemen, talking of gravel walks and syringas. To be sure one would imagine they would have broiled poor Brown, but I hope not. I suppose you know Mr. Knight's place, his clegant house, and the enchanting valley which lies under it: no man wants to dot himself about with firs, who has such woods as those. He has done nothing to spoil it, and every thing that he could have done chastely to adorn it. He has three bridges that are admirable in their way. I was diverted with one of the revicwers, who took him for a poor Grub-Street poet, who had never seen any more gardening than the pot of mint at his windows." 
Every person the least interested in this study, must have read the beautiful "Poems of Mason," and "De Lille," the "Oriental Gardening of Sir William Chambers," and the "Observations on Modern Gardening by Mr. Whately;" but, perhaps, few have seen that elaborate performance, in five volumes quarto, published in German, and also in French, under the title of "Theorie de l'Art des Jardins par M. Hirschfeld," a .work in which are collected extracts from almost every hook in every European language, that has any reference to the scenery of nature or to the art of landscape gardening. ${ }^{\circ}$

When gardening was conducted by the geometric principles of the school of Le Notre, the perfection of planting was deemed to consist in straight lines of trees, or regular corresponding forms of plantation, and as the effect of this style of gardening greatly depended on a level surface of ground, we often find that prodigious labour was employed to remove those inequalities which nature opposed to this ill-judging taste.

At Wrmpole the natural shape of the surface seemed to invite this fashion for geometric forms, the ground was covered in every direction with trees in straight lines, circles, squares, triangles, and in almost every mathematical figure. These had acquired the growth of a century, when the taste

- If I were to enumerate all those who have occasionally mentioned gardening as a relative subject of taste, I should hardly omit the name of any author, either ancient or modern. Some of the most ingenious hints, and even some just principles in the art, are to be found in the works of Theocritus, Homer, Virgil, Petrarch, Rousseau, Voltaire, Temple, Bacon, Addison, Home, Gilpin, Allison, \&c. 
of gardening changed; and as every absurd fashion is apt to run from one extreme to another, the world was then told, that " nature ablıorred a straight line," that perfection in gardening consisted in waving lines, and that it was necessary to obliterate every trace of artificial interference. And now many a lofty tree, the pride and glory of our ancient palaces, was rooted up, because it stood on the same line with its fellows and contemporaries: and because these ranks of sturdy veterans could not, ${ }^{p}$ like a regiment of soldiers, be marched into new shapes, according to the new system of tactics, they were unmercifully cut down; not to display beantiful scenery behind them, but merely to break their ranks: while a few were spared which could be formed into platoons, this was called clumping an avenue.

The position of all the large trees on the plain near the house at Wimpole, shervs the influence of fashion in these different styles; the original lines may be easily traced by the trees which remain, and the later formed clumps are scattered about like the ghosts of former avenues, or monstrous shapes which could not be subdued.

One great advantage of WIMPOLE arises from its comparative beauty, or the contrast between the place and its environs. The counties of Cambridge and Huntingdon consist generally

p That this simile may not appear ludicrous, I should observe, that the ancient gardenș were often made with a refcrence to military dispositions; or trees were sometimes planted in conformity to the order of certain battles; thus at Blenheim, the square clumps planted before Brown saw the place, were in imitation of the famous battle from whence the place was named. And in an old map of a place in Suffolk, Which I believe was planned by Le Notre, the names of regiments were given to square clumps or platoons of trees, which on paper resembled the positions of an army. 
of tlat ground, while the hills are open corn fields thinly intersected by hedges. But WIMPoLE abounds in beautiful shapes of ground, and is richly clothed with wood; it is therefore like a flower in the desert, beantiful in itself, but more beantiful by its situation. Yet no idea of this beanty can be formed from the approach to the house; because the plain is every where covered with lofty trees, which hide not only the inequalities of the ground, but also the depth of wood in every direction; and although the original straight lines of the trees have been partially broken, the intervals shew none of the varied scenery beyond. I do not therefore hesitate to say, that by judiciously removing some hundred trees the place would be made to appear more wooded: for it frequently happens, that a branch near the eye may hide a groupe of twenty trees, or a single tree conceal a whole grove.

In thus recommending the liberal use of the axe I hope I shall not be deemed an advocate for that bare and bald system of gardening which has been so justly ridiculed. I do not profess to follow either Le Nôtre or Brown, but selecting beanties from the style of each, to adopt so much of the grandemr of the former as may accord with a palace, and so much of the grace of the latter as may call forth the charms of natural landscape. Each has its proper situation; and good taste will make fashion subservient to goorl sense.

"The modern rage for natural landscape has frequently carried its admirers beyond the true limits of improvement, the 
first object of which ought to be comvenience, and the next picturesque beauty.

My taste may perhaps be arraigned for asserting that the straight terrace at the Haselus, ${ }^{9}$ ought not to be disturbed: although it is a remnant of geometric gardening of the last century, yet it is an object of such comfort and convenience, that it would be unpardonable to destroy it, for no other reason than because a straight walk is out of fashion, this would be acknowledging (what I protest against) that the art of landscape gardening ought to be under the dominion of fashion.

If this terrace were constantly an object of view, or very materially offensive to the general scenery of the place, its linear direction might cut the composition, and destroy its effect as a natural landscape: in its present situation it is merely a foreground or frame to a pleasing picture, and the view from hence is so fine, so varied, and so interesting, that the spectator must be fastidious indeed, who could turn away disgusted because it is seen over a clipt hedge, or with a broad flat walk in its foreground. A beautiful scene will always be beautiful, whether we view it from an alcove, a window, or a formal terrace; and the latter, in the height of summer, may sometimes answer the purpose of an additional room or gallery, when there is much company, who delight to saunter on such an esplanade; while the intricacies of a winding path are better calculated for a solitary walk."

"The ancient dignity of character in the house at Совнам

"The Red Books of the Hasells and Совнан, from whence these observations were transcribed, were written in the year 1790, before Mr. Price published his Essays. 
would be violated by the too near intrusion of that gay prettimess which generally accompanies a garden walk; yet convenience and comfort require such a walk at no great distance from the house. ${ }^{\mathrm{r}} \quad$ I shall perhaps astonish some of the improvers in modern serpentine gardening by declaring, that as an appendage to this ancient mansion, I would prefer the broad and stately mall along a straight line of terrace, to their too frequently repeated waving line of beauty.

This sort of walk may, I think, be still farther encouraged, where it already in some degree exists, to the north of the kitchen garden, which falling from the eye, might easily be concealed from the park by a shrubbery kept low; not to intercept the view towards the opposite bank in the park, while it wonld give an imaginary increase of depth to the vale beneath. And to remove the objection of returning by the same walk, a second terrace might be carried still higher on the bank, and by the style and accompaniment of its plantation, all sameness wonld easily be obviated, perhaps by making one of them a winter walk, planted chiefly with evergrcens and shrubs.

To justify my opinion, it is necessary to guard against a misconstruction of what I have advanced, lest I may be arcused of reviving the old taste of gardening.

I do not recommend the terrace as an object of beauty in all cases, but of convenience; for the same reason that $I$ advise the

Twelve years ago, when I first delivered these opinions, they were decmed so contrary to modern practice, that I was cautious in defending them. I have since more boldly supported my original opinion, and rejoice that the gnod sense of the country admits their propriety. 
proximity of a kitchen garden, provided the principal apartments do not look upon either.

Our ancestors were so apt to be guided by utility, that they at length imagined it was in all cases a substitute for beanty; and thus we frequently see ancient houses surrounded not only by terraces, avenues, and fish ponds, but even the stables, and the meanest offices, formed a part of the view from the windows of their principal rooms. I am far from recommending a return to these absurdities; yet in the rage for picturesque beauty let us remember that the landscape holds an inferior rank to the historical picture; one represents nature, the other relates to man in a state of society; if we banish winter comforts from the country seats of our nobility, we shall also banish their inhabitants, who generally reside there more in winter than in summer, and there is surely no object of greater comfort and utility belonging to a garden, and a country mansion, than a dry spacious walk for winter, sheltered by such trees as preserve their clothing while all other plants are destitute of foliage.

"Vernantesque comas tristis ademit hyems." s

- "In the summer season the whole country blooms, and is a kind of garden, for which reason we are not so sensible of those beauties, that at this time may be every where met with; but when nature is in her desolation, and presents us with nothing but bleak and barren prospects, there is something unspeakably cheerful in a spot of ground which is covered with trees, that smile amidst all the rigours of winter, and give us a view of the most gay season in the midst of that which is the most dead and melancholy." Spectator, No. 477.

Aud the great Lord Bacon says,

"In the royal ordering of gardens there ought to be gardens for every month in the year." 
I will add the opinion of a very able commentator, who, mentioning " this self-evident proposition, that a rural scene in "reality, and a rural scene on canvass, are not precisely one and " the same thing. But," he says, "that point in which they differ " here, is not itself without a guiding principle: Utruity sets up " her claim, and declares, that however concurrent the genuine "beauty of nature and picture may be, the garden scene is hers, " and must be rendered conformable to the purposes of human "life; if to these every consonant charm of painting be added, " she is pleased, but by no means satisfied, if that which is con"vertible to use be given absolutely to wildness." Elements of Criticisu.

'The natural situation of Bulicer differs from that of every other large place which has fallen under my consideration. To say that the house stands on a lofty hill, would be giving a very imperfect idea of its situation, on the contrary, it ought rather to be described as a magnificent palace, built at the extremity of a vast plain, or what is called by geographers a Table Mountain, from the brow of which it boldly commands an assemblage of wood, water, lawn, and distant country, spread magnificently at its base.

The view from the principal suite of apartments, however rich and varied in itself, becomes much more interesting by the power of contrast, because the great plain to the north affords no promise of such views, and therefore the surprise occasioned 
by this mexpected scenery, is a subject worthy the attention of the improver: the effects of surprise are seldom to be produced by Art, and those who attempt to excite it by novelty or contrast, are in danger of falling into puerile conceits. ${ }^{t}$ But where, as in the present instance, much of the natural sublime exists, this effect should be increased by every means, which does not betray the insignificance of art, when compared with the works of nature.

For this reason, if the approach were brought along the straight line of avenue, gradually ascending, the situation of BURLEY would lose much of its sublimity by anticipation.

The prevalence of fashion, in all subjects of taste, will at times have its influence, but as fashion is more the effect of whim and caprice, than of reason and argument, it has been my great object to rescue landscape gardening from its fascinating' power; and while accommodating myself to the wishes of those who consult me, to the customs of the times, or to the peculiarity of various situations and characters: I hope never to lose sight of the great and essential object of my profession, the elegance, the magnificence, and the convenience of rural scenes, appropriated to the uses of a "gentleman's habitation.

This may be equally effected, whether we revert to the formal fashion of straight walled gardening, or adopt the serpen-

"Like those rlescribed by Sir William Chambers in his Chinese Gardening.

"By this term I mean to express sccnery, less rude and neglected, than the forest lraunts of wild animals, and less artificial than the farmer's field, laid out for gain, and not for appearance: or in the words of a celebrated anthor, to "crcate a scencry more pure, more harmonious, and more expressive, than any that is to be found in nature itself." 
tine lines of modern improvers, under the pretended notion of imitating nature. But there is a certain dignity of style in BurLey, which, like the cumbrous robes of our nobility, neither can nor ought to be sacrificed to the innovation of fashion or the affectation of ease and simplicity.

Mr. Burke justly observes, that "A true artist should put a "generous deceit on the spectators, and effect the noblest designs " by easy methods. Designs that are vast, only by their dimen" sions, are always the sign of a common and low imagination. "Nowork of art can be great but as it deceives; to be otherwise " is the prerogative of nature only." This precept seems to have been overlooked in the attempts to modemize BurLeY: the spacions court, surrounded by a colonade, has been frequently quoted as a wonderful effort of art: and when the distant country was excluded by a wall, by the village, and by trees beyond it, this ample area was nudonbtedly one of the most striking appendages of a palace. $\quad$ But the moment one side of the quadrangle is opened to the adjacent country, it shrinks from the comparison, and the long fronts of opposite offices seem extended into the vast expanse, without any line of connexion. This comparative insignificancy of art is no where more strongly exemplified than in the large wet docks of Liverpool and Hull: while the margins of the river are left dry by the ebbing tides; we look with astonishment at the capacious basons, filled with a vast body of water; but when the tide flows to the same level,

Lest this slould look like an inplied censure on the person by whose adrice the wall was removed, I must acknowledge that till I had seen the effect, I might have adopted the same error, in compliance with the prevailing fashion of opening lawns. 
and the flood-gates are thrown open, the extent and importance of the river convert these artificial basons into creeks or mere pools. It is therefore only by avoiding a comparison with the works of nature, that we can produce the effect of greatness in artificial objects; and a large court, surrounded by buildings, can have no pretensions to be deemed a natural object.

After removing the wall, which formed the front of the court, a doubt arose whether the present gate and porter's lodge should or should not remain, and how to approach the house to the greatest advantage.

There is a certain point ${ }^{2}$ of distance from whence every object appears at its greatest magnitude: but in cases where symmetry prevails, the distance may be rather greater, because exact correspondence of parts assists the mind in forming an idea of the whole. I shonld therefore conceive that the effect of surprise, of magnificence, and of the sublime, in this effort of art, is greatly injured by seeing the interior of this ample court, before we arrive at the entrance gate; because that is nearly the spot where the eye is completely filled and gratified by the surrounding objects. But as this view should not be momentary, I suppose the road to continue from the gate in a straight line, till it falls into a circle with the colonade; and here the broad road may be intercepted with posts and chains, to direct carriages into that course which displays the whole area to the greatest advantage, passing nearer to the side colonade; shewing that in perspective, and presenting the house at the angle to shew its depth. The manner in which this is effected by sweeping 



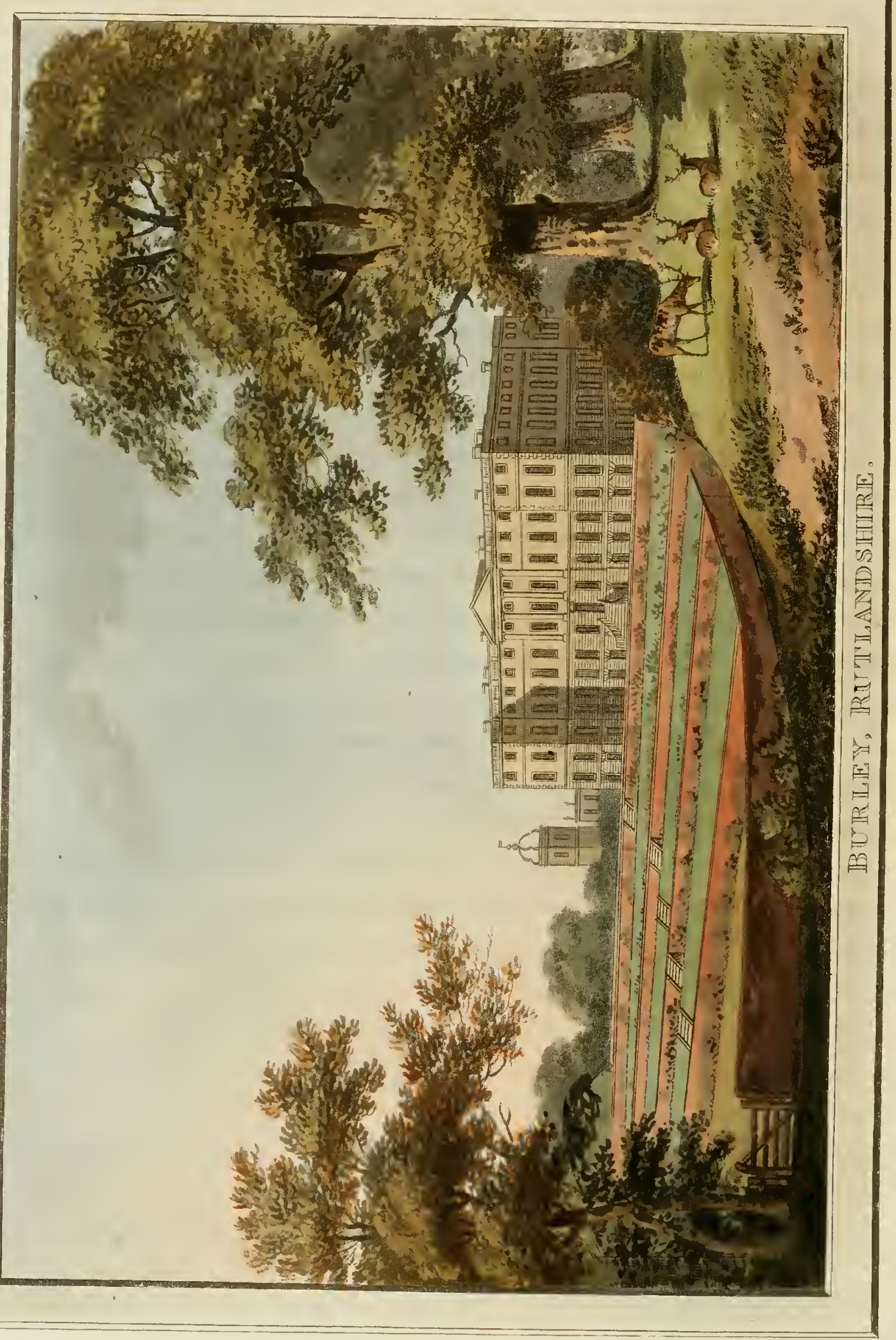


round the court, is not to be described by painting; because every step varies the position of the several parts as they advance or recede perspectively.

Hitherto I have spoken of the north or entrance front and court-yard of BurLey, the whole of which I would treat only as a work of art, and, if possible, exclude all view of the country. But to the south the prospect, or natural landscape, is the leading feature for our consideration.

The steep descent from the house has been cut into a number of terraces, each supported by a red brick wall; and if these several walls had been of stone, or architecturally finished like the old costly hanging gardens of France and Italy, they might perhaps have added more magnificence to the house, than any improvement which modern gardening could suggest, but they are mean in their forms, diminutive in their height, and out of harmony in their colour. Yet the style of the house and the steepness of the declivity will not admit of their being all taken away to slope the ground in the manner too often practised by modern improvers.

I therefore make a compromise between ancient and modern gardening, between art and nature, and by increasing the height, or rather the depth, from the upper terrace to the lower level of the ground, I make that the line of demarkation between the dressed ground and the park, in the manner explained by the view of Burler; and happy would it be for the magnificence of English scenery, if many such stately terraces near a palace, had been thus preserved. 


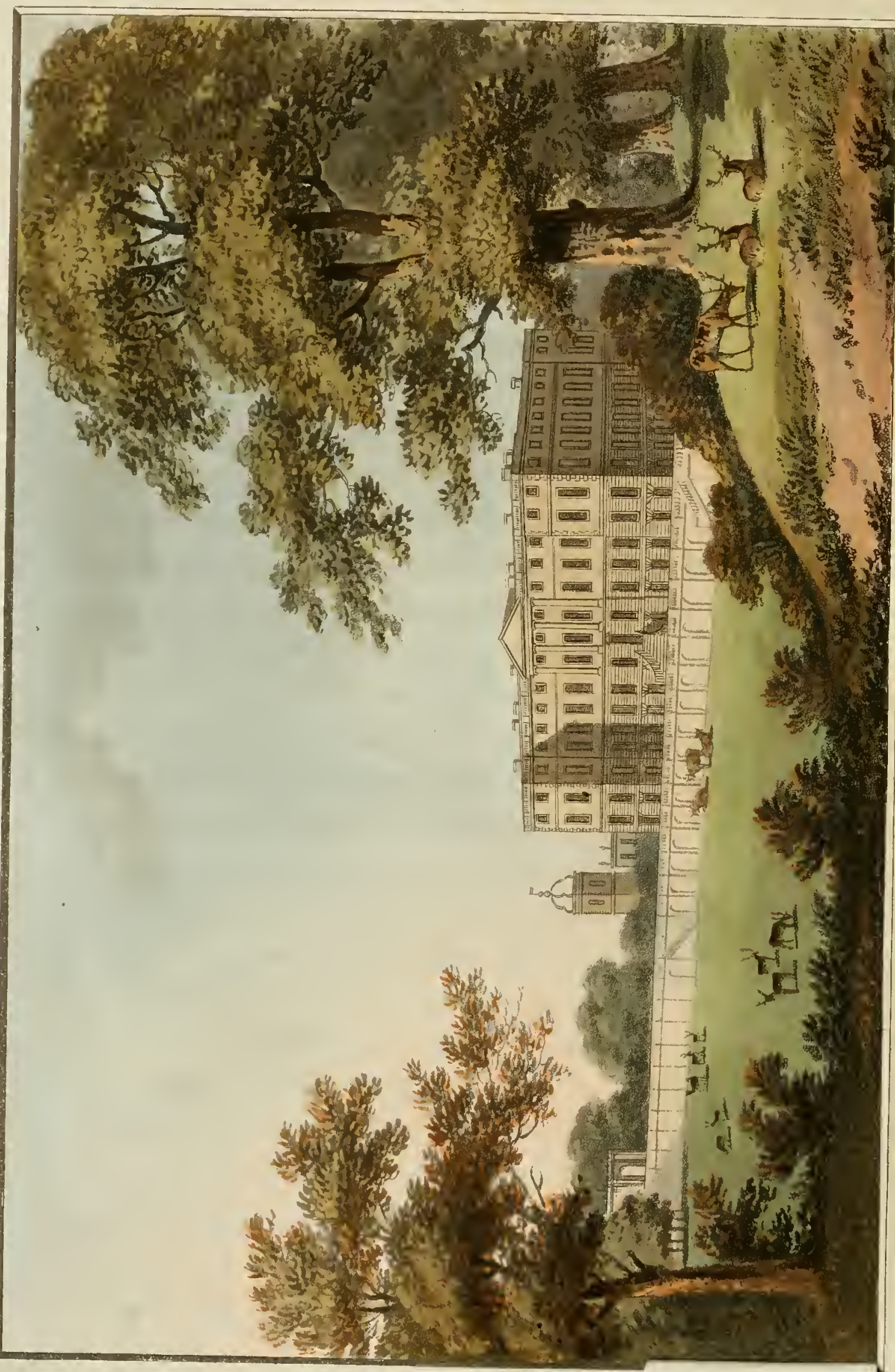

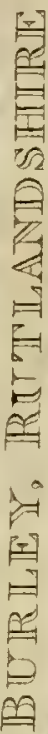



round the court, is not to be described by painting; because every step varies the position of the several parts as they advance or recede perspectively.

Hitherto I have spoken of the north or entrance front and court-yard of BurLey, the whole of which I would treat only as a work of art, and, if possible, exclude all view of the country. But to the south the prospect, or natural landscape, is the leading feature for our consideration.

The steep descent from the house has been cut into a number of terraces, each supported by a red brick wall; and if these several walls had been of stone, or architecturally finished like the old costly hanging gardens of France and Italy, they might perhaps have added more magnificence to the house, than any improvement which modem gardening could suggest, but they are mean in their forms, diminutive in their height, and out of harmony in their colour. Yet the style of the house and the steepness of the declivity will not admit of their being all taken away to slope the ground in the manner too often practised by modern improvers.

I therefore make a compromise between ancient and modern gardening, between art and nature, and by increasing the height, or rather the depth, from the upper terrace to the lower level of the ground, I make that the line of demarkation between the dressed ground and the park, in the manner explained by the view of Burler; and happy would it be for the magnificence of English scenery, if many such stately terraces near a palace, had been thus preserved. 


\section{CHAP'TER XI.}

Miscellaneous-Endless Variety of Situation and Character-Finst Impressions - Roads - Excomple Sтоке PaRK - Scenery in Wales - Example R $\mathrm{R}_{\mathrm{e}}^{\mathrm{e}}-$ Ornaments - Entrances - $\mathrm{H}_{\mathrm{AR}} \mathrm{E}-$ wood - Blatze Castle-Adaptation of omamental Buildings-Ornaments - Decorations-Colours-Metuls.

I HAVE occasionally been asked, when visiting a beautiful spot, "which of all the places I had seen was the most beautiful?" It is impossible to define those circumstances which on different persons make different impressions at first sight; perfection is no more to be found in the works of nature than in those of art. Such is the equal providence of the great Author of nature, that every place has its beauties and its deformities, and whether situated among the mountains of Wates, or on the margin of Clapham Common, it will not only be endeared to its proprietor, but to the discerning stranger, by some peculiar features of beanty.

The materials of natural landscape are ground, wood, and water, to which man adds buildings, and adapts them to the scene. It is therefore from the artificial considerations of utility, convenience, and propriety, that a place derives its real value in the eyes of a man of taste: he will discover graces and defects in every situation; he will be as much delighted with a 
bed of flowers as with a forest thicket, and he will be as much disgusted by the fanciful affectation of rude nature in tame scenery, as by the trimness of spruce art in that which is wild: the thatched hovel in a flower-garden, or the treillis bocrge in a forest, are equally misplaced.

General principles, or general designs, which may be applicable to all situations, would be alike impossible. The painter copies in their respective places, the eyes, the nose, and mouth, of the individual, but without adding character his picture will not be interesting. The landscape gardener finds ground, wood, and water, but with little more power than the painter, of changing their relative position; he adds character by the point of riew in which he displays them, or by the ornaments of art with which they are embellished. To describe by words the various characters and situations of all the places in which I have been consulted, would be tedious, and to give views of each would alter the design of this work: I shall therefore dedicate this chapter to a miscellaneous assemblage of extracts from different Red Books, withont aiming at connection or arrangement. 'These may furnish examples of variety in the treatment of various subjects; while the reasons on which their treatment is fonnded will, I hope, be deemed so far conclusive, that some general principles may be drawn from them, tending to prove that, There are Rules for good taste. 
There is no principle of the art so necessary to be studied as the effects produced on the mind by the first view of certain objects, or rather that general disposition of the human mind, by which it is capable of strongly receiving first impressions. We frequently decide on the character of places, as well as of persons, with no other knowledge of either, than what is acquired by the first glance of their most striking features; and it is with difficulty, or with surprise, that the mind is afterwards constrained to adopt a contrary opinion.

Thus if the approach to a house be over a flat plain, we shall pronounce the situation to be flat also, although the ground immediately near the house be varied and uneven; whilst, on the contrary, if the road winds its course over gentle hills and dales, and at length ascends a steep bank to the house, we shall always consider it as standing on an eminence, although the views from the house may be perfectly flat.

I have therefore watched with nice attention the first ideas which have occurred to me in visiting any new subject; and if a more intimate knowledge of it induces me afterwards to alter my opinion, I then inquire into the causes which influenced my former false judgment, that I may by this means increase or diminish them accordingly. ${ }^{\mathrm{a}}$

"The situation of the HaSelds, of BURLEY, and of SToneaston, on the extremity of table land, may serve as examples. 
One of the first objects of improvement should be to adapt the character of the grounds to that of the house; and both should bear some proportion to the extent of property by which they are surrounded.

"At Sтоке, in Herefordshire, the house and park are as perfectly separated from each other by a turmpike road as if they were the property of different persons; and both are seen from that road in the most unfavourable points of view. Of the house little is visible except the roof and chimnies, and with respect to the park, which naturally abounds with the most pleasing shapes of ground, richly clothed with wood, the road passes so immediately at the foot of the declivity, that the whole appears fore-shortened, and all its beauties are entirely lost. To divert the course of this road, therefore, becomes the first object of improvement."'b

I have, on several occasions, ventured to condemn as false taste, that fatal rage for destroying villages, or depopulating a country, under the idea of its being necessary to the importance of a mansion: from the same Red Book the following extract is taken.

"As a number of labourers constitutes one of the requisites of

- This has been done, and the improvement to the place is equally felt by the proprietor, and conspicuous to every stranger who travels fron Ledbury to Hereford. It seldom happens that both the public and the individual are benefited by altering the course of a high road, but their nutual advantage ought to be studied. It often happens that the basis of all improvement depends on removing a public road, of which examples occurred in the following places; Abington HaLl, AdLestrop, Baymam, Kexwood, Panshanger, Garnons, Haselds: these I mention in preference to many others, because the improvement is obvious to the public. 
grandeur, comfortable habitations for its poor dependants ought to be provided. It is no more necessary that these habitations should be seen immediately near the palace, than that their inhabitants should dine at the same table; but if their humble dwellings can be made a subordinate part of the general scenery, they will, so far from disgracing it, add to the dignity that wealth can derive from the exercise of benevolence. Under such impressions, and with such sentiments, I am peculiarly happy in being called upon to mark a spot for new cottages, instead of those which it is necessary to remove, not absolutely because they are too near the house, for that is hardly the case with those cottages in the dell, but becanse the turupike road being removed, there will be no access for the inhabitants but through a part of the park, which cannot then be private. I must advise, however, that some one or more of the houses in this dell be left, and inhabited either as a keeper's house, a dairy, or a menagerie, that the occasional smoke from the chimnies may animate the scene. The picturesque and pleasing effect of smoke ascending, when relieved by a dark hanging wood in the deep recess of a beautiful glen like this, is a circumstance by no means to be neglected."

As an example of a place in a mountainous country, the following extract from the Red Book of $\mathrm{RU}_{\mathrm{G}}$, in North Wales, is subjoined. "At a period when the ancient family honours of a neighbouring country are rooted out with savage barbarity, I 
rejoice in an opportunity of contributing my assistance to preserve in this, every vestige of ancient or hereditary dignity; and I shonld feel it a kind of sacrilege in taste, to destroy an atom of that old, ruinous, and almost uniuhabitable mansion at Rug, if it were to be replaced by one of those gaudy scarlet houses, which we see spring up like mushrooms, in the neighbourhood of large manufacturing towns. I am, however, restrained from indulging to its full extent my veneration for antiquity, by reflecting that modern comfort and convenience are the first objects to be consulted in the improvement of a modern residence; and therefore I trust I shall neither incur the censure of those who know and feel the comforts of the age we live in, nor offend the genius of the place, by "calling from the vasty deep "the angry spirits" of Owen Glendwr of Burgontum, who formerly inhabited this domain.

"In a country like that of North Wales, abounding in magnificent scenery, the views from the house should rather aim at comfort and appropriation of landscape, than extensive prospect; because the latter may be had from every field or public road on the mountains; and the attempt to make a large park or domain would be fruitless, where a lawn of a thousand acres would appear but a small spot; compared with the wide expanse of country seen from the neighbouring hills. I should therefore advise the lawn to be confined within the compass of forty or fifty acres; yet from the variety of its surface, and the diversity of objects it contains, there will be more real beanty, and even magnificence, within this small inclosure, than in other parks of many hundred acres. 
However partial we may be to grand and extensive prospects, they are never advisable for the situation of a house, in which convenience and comfort should doubtless take the lead of every other consideration. The frequent rains and violent storms of wind, to which all mountainous countries are exposed, have taught the inhabitants not only to choose warm valleys for their houses, but have also introduced a style of architecture peculiarly suited to those situations: the small towns of Llangollen and Corwen, as well as those in the mountains of Switzerland, have all low sheds or pent-houses, under which the inhabitants may take shelter from occasional driving storms. The arcade of gothic architecture is infinitely more applicable to such situations than the lofty portico of Greece, which is rather calculated for those warm regions where man wants protection from the vertical beams of a burning sun. I hope, therefore, that both the character and situation of $R_{U G}$, will justify a c design for a new house, which may possess a degree of grandeur and magnificence not incompatible with modern convenience."

' This Red Book having been written in 1793, it was before I had the advantage of my son's architectural assistance; and the design here mentioned was that of my ingenious friend Mr. Wilkins, who built one of the best houses in England for Earl Moira, at Donsington, in a correct gothic style, and under whom my son was at that time studying: for reasons, which I had no right to inquire into, the plan for the house was not adopted; in every other respect, howcrer, my plans have there been followed in the most gratifying manner. 
There is no circumstance in which bad taste is so conspicuous as in the misuse of ornaments and decorations; an observation equally applicable to all the polite arts, and not less true with respect to eloquence, poetry, music, and painting, than to architecture and gardening.

Thus, for instance, a rural scene may be delightful ivithout any building or work of art, yet, if judicionsly embellished by artificial objects in character with the scene, the landscape will be more perfect; on the contrary, if incumbered by buildings in a bad taste, or crowded by such as are too large, too small, or in any respect inapplicable, however correct they may be as works of art, the scene will be injured, and thus a thatched hovel may be deemed an ornament, where a Corinthian temple would be misplaced, or vice versâ.

In this miscellaneous chapter may properly be inserted some specimens of various buildings to elucidate the truth of an observation, which hardly seems to require enforcing; yet the frequent introduction of ornamental buildings, copied from books, without reference to the character and situation of the scenery, is not less fatal to the good taste of the country; than it would be to the life of individuals to use medical prescriptions withont inquiring into the nature and cause of diseases.

The facility with which a country carpenter can erect small buildings intended for ornament, may perhaps account for their frequency; but I am not ashamed to confess that I have often experienced more difficulty in determining the form and size of a hovel, or a park entrance, than in arranging the several apartments of a large mansion; indeed there is no subject on which I 
have so seldom satisfied my own judgment, as in that of an entrance to a park.

The custom of placing a gate between two square boxes, or, as it is called, a "pair of lodges," has always appeared to me absurd, because it is an attempt to give consequence to that which in itself is mean; the habitation of a single labourer, or perhaps of a solitary old woman, to open the gate, is split into two houses for the sake of childish symmetry; and very often the most squalid misery is found in the person thus banished from society, who inhabits a dirty room of a few feet square.

It is the gate, and not the dwelling of the person who opens it, that ought to partake of the character of the house, where architectural display is necessary; and this principle seems to point out the true mode of marking the entrance to a place. Instead of depopulating villages, and destroying hamlets in the neighbourhood of a palace, I should rather wish to mark the importance of the mansion, and the wealth of its domain, by the appearance of proper provision for its poor dependants; the frequent instances I have witnessed where the industrious labourer had many miles to walk from his daily task, have strongly inforced the necessity, not to say the humanity, of providing comfortable and convenient residences for those who may have employment about the grounds. It is thus that the real importance of a place might be distinguished by the number of its cottages, or rather substantial houses,

d As this absurd fashion of a pair of lodges deserves to be treated with ridicule, I cannot help mentioning the witty comment of a celebrated lady; who, because they looked like tea-caddies, wrote on two such lodges in large letters, Green and Bohea. 
appropriated to the residence of those belonging to the place; this would truly emich the scenery of a country by creating a village at the entrance of every park; it is not by their number only, but by the attention to the neatness, comforl, and simple omament of such buildings, that we should then judge of the style of the neighbouring palace; and whether the houses were of clay and thatched, or embellished with the ornaments of architecture, there would be equal opportunity for the display of good taste.

The entrance to Harewood Park, from a large town of the same name, may serve as a magnificent specimen of this kind of importance; and although in this instance the character and peculiar circumstances of this splendid palace are properly supported by the regularity and substantial manner in which the town is built and ornamented; yet in more humble situations, the same attention to the repair and neatness of the adjoining cottages, would confer adequate propriety to this mode of entrance. Various specimens of this attention may be seen in the roads near the following places: B в воотт, Bетсншовтн, Buckininter, Catton, Livermere, Panshanger, Prestwood, Stoke Park, Suttons, Scarisiric, Tendring, \&c. 


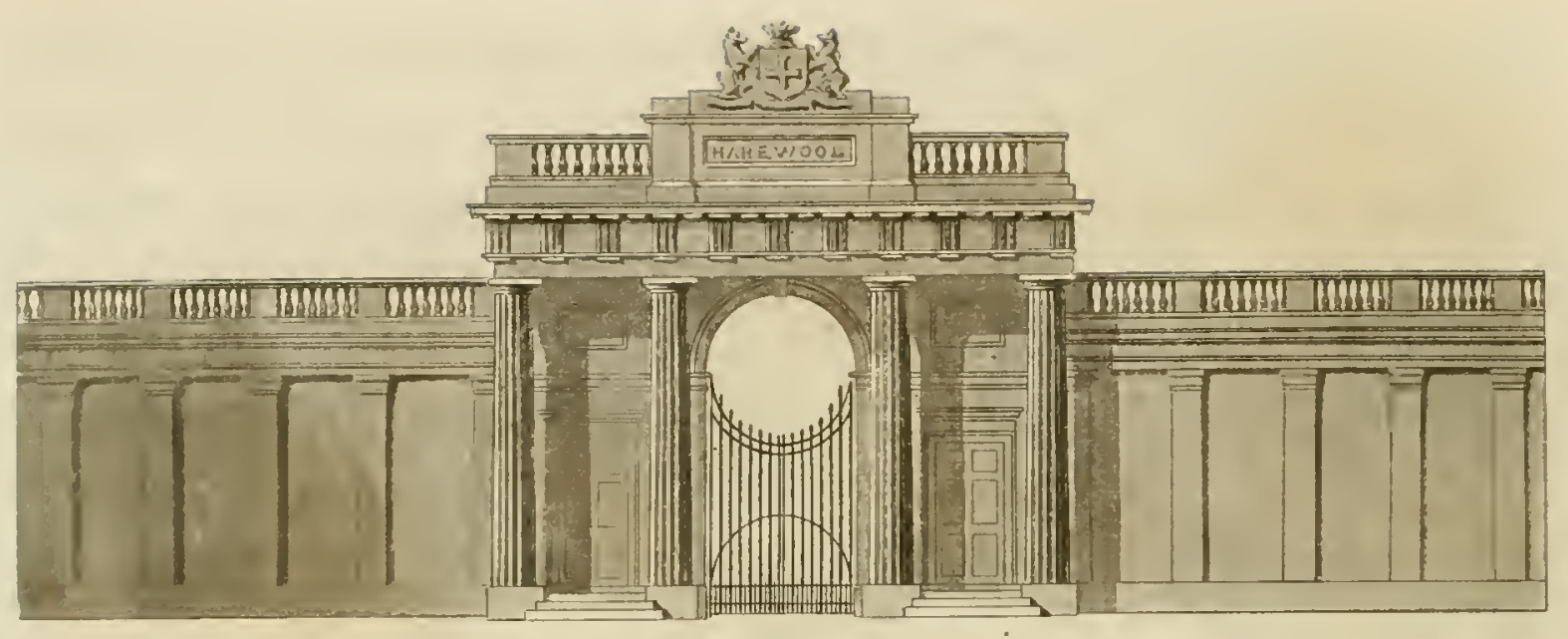

If the entrance to a park be made from a town or village, the gate may with great propriety be distinguished by an arch, as in that of HAREwOoD, where the approach from Weatherby, after passing along a straight road intended to be planted on each side, is terminated by a town regularly built of the most beautiful stone, at the end of which an arched gateway forms the entrance to one of the finest palaces in England.

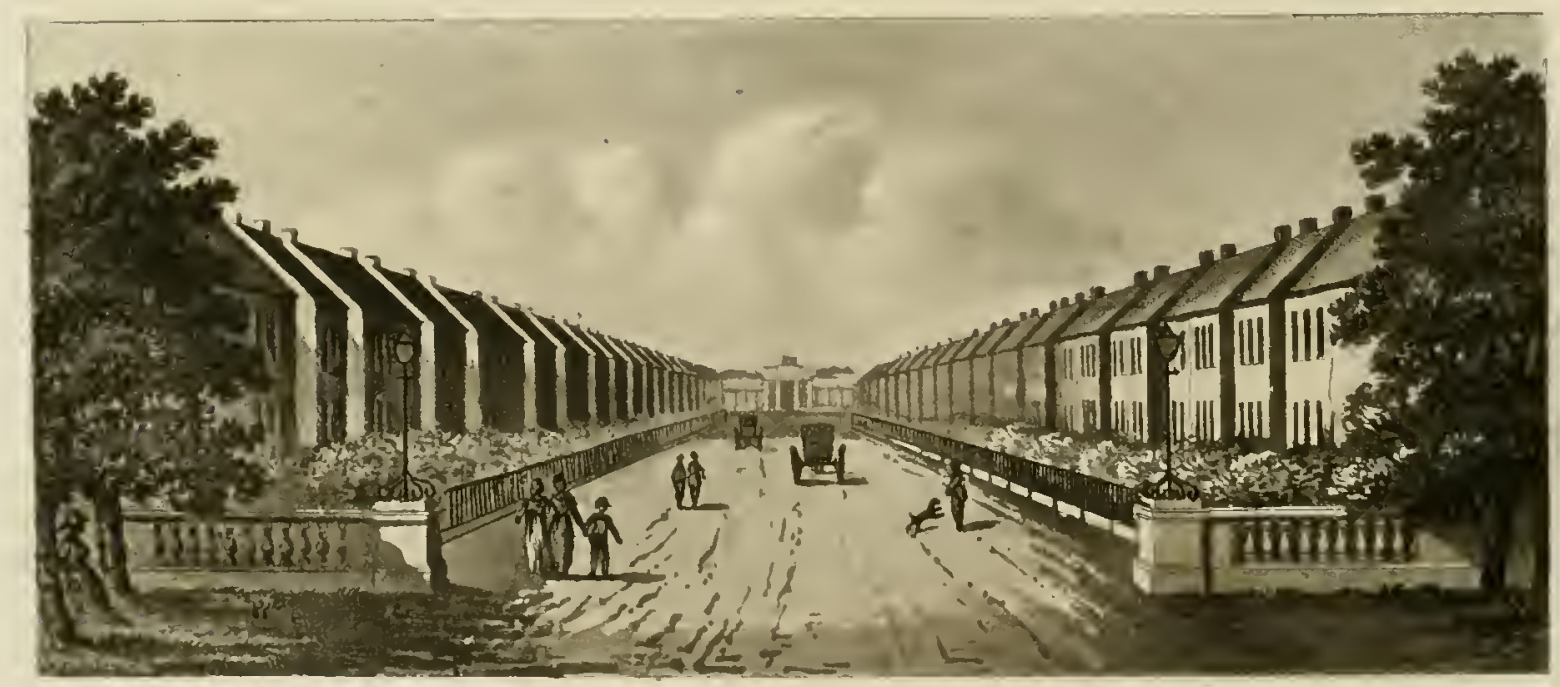





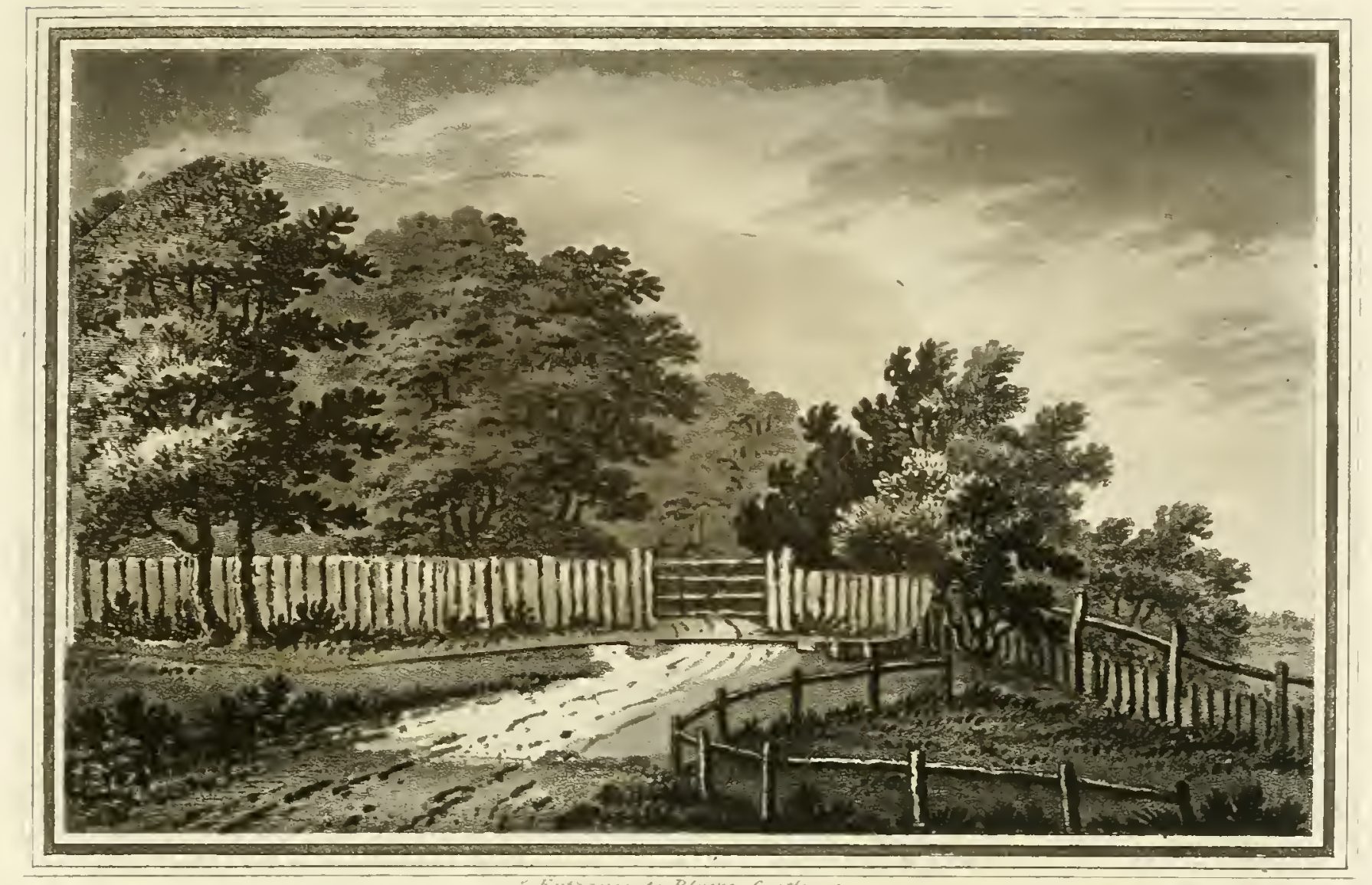

In determining the sort of entrance proper for BLaIzE CAstLe, the name of the place caused some difficulty; the house to which the castle belongs, neither does nor ought to partake of any Gothic character, yet there appeared some incongruity in making the entrance in the Grecian style of architecture, to accord with the house, which is no where seen from the road, while the castle is a conspicuous feature, and gives a name to the place; I therefore recommended the above design as a proper object to attract notice in the approach, which is one of the most interesting and romantic. ${ }^{\mathrm{e}}$

- After passing through a wood, the road arrives at a cottage on the side of a hill, from whence the house appears across a deep wooded glen, which was deemed impassable. However by cutting away the face of the rock in some places, and building lofty walls in others to support the road, and by taking advantage of the natural 



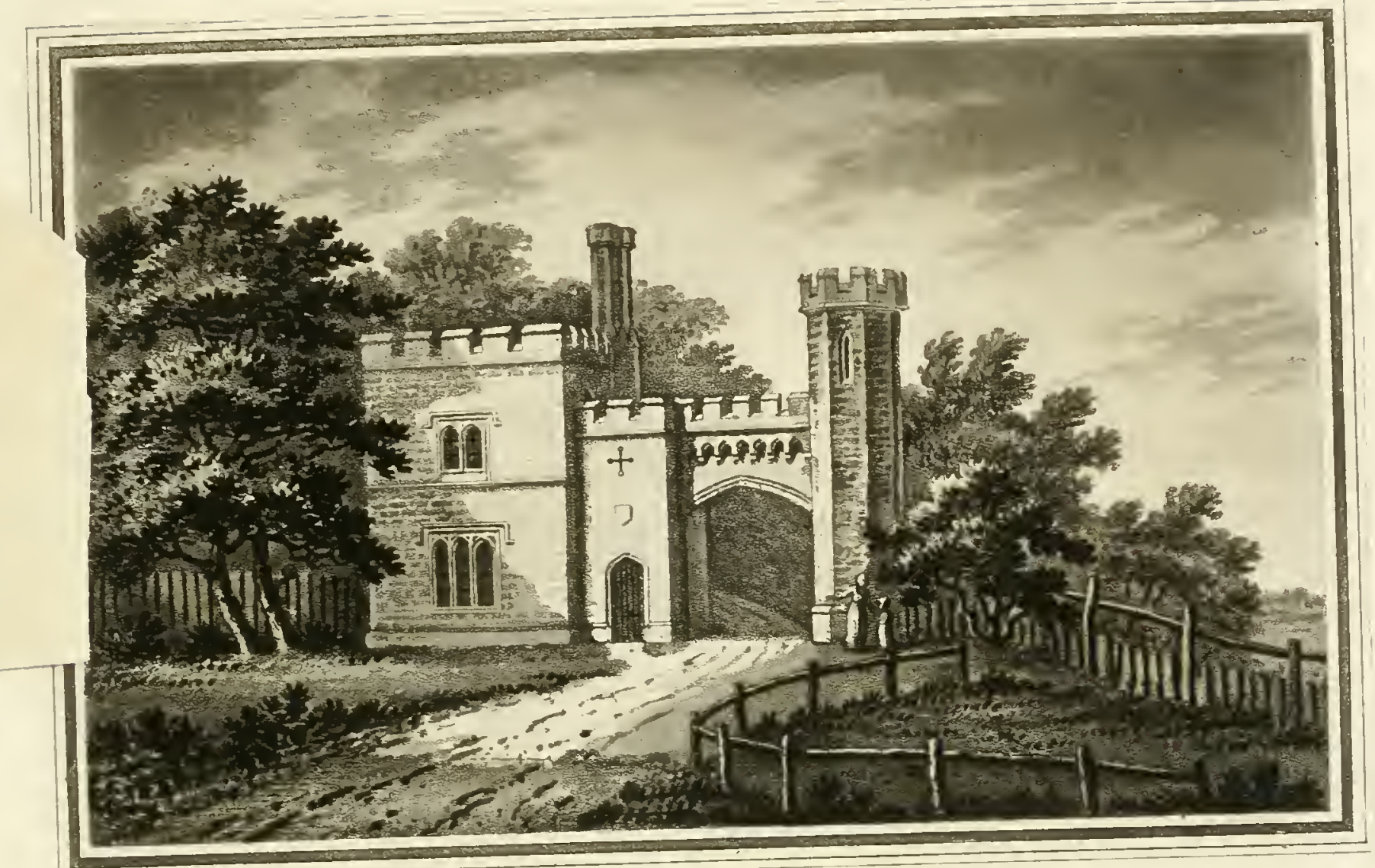

In determining the sort of entrance proper for BLAIzE CastuE, the name of the place caused some difficulty; the house to which the castle belongs, neither does nor ought to partake of any Gothic character, yet there appeared some incongruity in making the entrance in the Grecian style of architecture, to accord with the house, which is no where seen from the road, while the castle is a conspicuous feature, and gives a name to the place; I therefore recommended the above design as a proper object to attract notice in the approach, which is one of the most interesting and romantic.e

e After passing through a wood, the road arrives at a cottage on the side of a hill, from whence the house appears across a deep wooded glen, which was deemed impassable. However by cutting away the face of the rock in some places, and building lofty walls in others to support the road, and by taking advantage of the natural 
An arehed gateway at the entrance of a place is never used with so much apparent propriety as when it forms a part of a town or village, at least it should be so flanked by lofty walls as to mark the separation between the public and the park, and increase the contrast; but when seen in contact with a low parkpale, or even an iron pallisade, it appears to want connexion, it looks too ostentatious for its utility, and I doubt whether it wonld not lessen the pleasure we derive from viewing the magnificent Grecian arches at Burlington House and at Blenheim, if the side walls were lower. ${ }^{f}$

In recommending the use of an arch I must graard against being misunderstood, by mentioning several circumstances which I deem objectionable. 1 st. The arch should not be a mere aperture in a single wall, but it should have depth in proportion to its breadth.

2d. It should have some visible and marked connexion either with a wall, or with the town to which it belongs, and not appear insulated.

3d. It should not be placed in so low a situation that we may rather see over it than through it.

4 th. Its architecture should correspond with that of the house, in style if not in order, that is, the Grecian and Gothic should be kept separate, although the design may not be copied from projections and recesses to make the necessary curratures, carriages now pass this tremendous cliasm with perfect ease and safety.

Where man resides nature must be conquered by art: it is only the ostentation of her triumph, and not her victory, that ought to nffend the eye of taste.

"This remark is less applicable to a Gothic entrance, because if it is correct, it may bc supposed a fragment of some more extensive building; but a Grecian arch, in this country, must be modern, and cannot properly be a ruin, except by desigu. 


\section{7}

the house; and lastly, neither the house should be visible from the entrance, nor the entrance from the house, if there be sufficient distance between them to make the approach through a park, and not immediately into a court yard; the two last general rules are equally applicable to every sort of entrance, as well as that through an arch; yet there are certain situations where the latter cannot be avoided; of this an instance occurred in STоке Park, Herefordshire, where the gate and the cottage near it were disguised by the portico, represented in the following sketch; which forms a pavilion, or covered seat, adjoining to the walk in the shrubbery.

In varions situations, various expedients have been adopted; thus at Antony I recommended, near the gate, a cottage, over which is a room to command the fine view of the harbour, \&c. At St. Joun's, in the Isle of Wight, two cottages, covered with flowering creepers, attract the notice of all who visit the island; and while one is a comfortable residence for a family, the other consists of a room near the road side, from whence the mind derives peculiar satisfaction in seeing the constant succession of visitors who leave their homes in search of happiness. In some places the cottage is more conspicuous by dividing the road to the house from the public road, as at Mrton; but in most cases I have endeavoured to conceal the cottage when it is quite solitary among the trees, only shewing the gate of entrance.

Concerning gates, it may not be improper to mention my opinion, with reasons for it. 
1st. As an entrance near a town, I prefer close wooden gates, for the sake of privacy, except where the view is only into a wood, and not into the open lawn.

2d. The gates should be of iron, or close boards, if hanging to piers of stone or brick work; otherwise an open or common field gate of wood appears mean, or as if only a temporary expedient.

3d. If the gates are of iron, the posts or piers ought to be conspicuous, because an iron gate hanging to an iron pier of the same colour, is almost invisible; and the principal entrance to a park should be so marked that no one may mistake it.

4th. If the entrance gate be wood, it should for the same reason be painted white, and its form should rather tend to shew its construction, than aim at fanciful ornament of Chinese, or Gothic, ${ }^{g}$ for reasons to be explained, in speaking of decorations.

g That I may not appear too severe in my comments upon those fanciful forms called Gothic, I am not ashamed to acknowledge that when I first retired into the country, I began the improvements to my own residence in Norfolk, by putting a sharp pointed window in a cottage seen from my house; and in my former work, a design was inserted for a wooden gate, which I then deemed applicable to the Gothic character, before I became better acquainted with subjects of antiquity. 


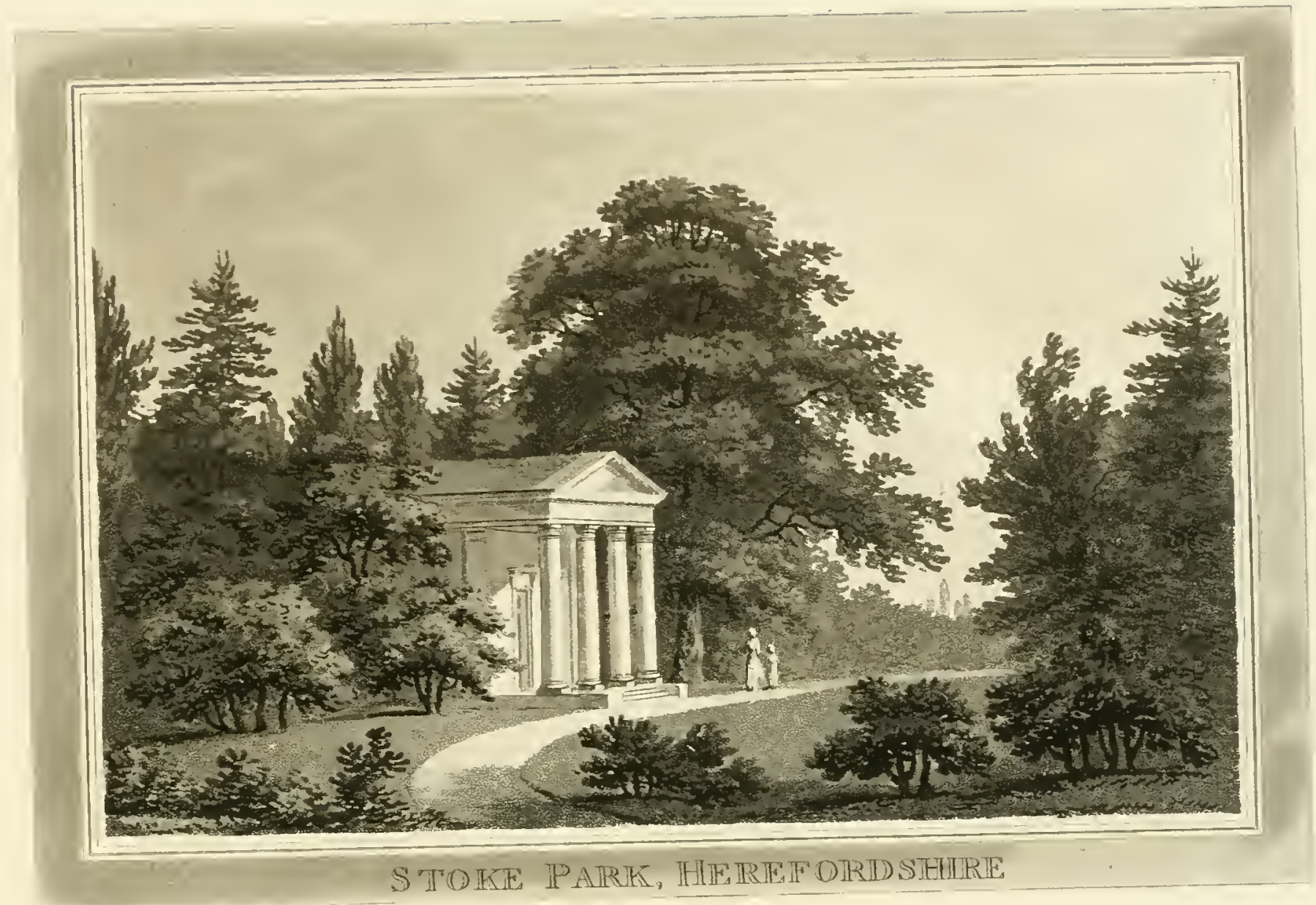

It is not sufficieni that a building should be in just proportions with itself, it shonld bear some relative proportion to the objects near it. The example here given is the Doric portico at Sтоке Park, in Herefordshire, where the size of the building was regulated by a large oak and a young plantation near it: had this building been more lofty, it would have overpowered the young trees, by which it is surrounded, and a smaller building would have appeared diminutive so near to the neighbouring large oak; I therefore judged, that the best rule for the dimensions of the columns was rather less than the diameter of the oak, and this of course determined the whole proportion of the Doric portico. 



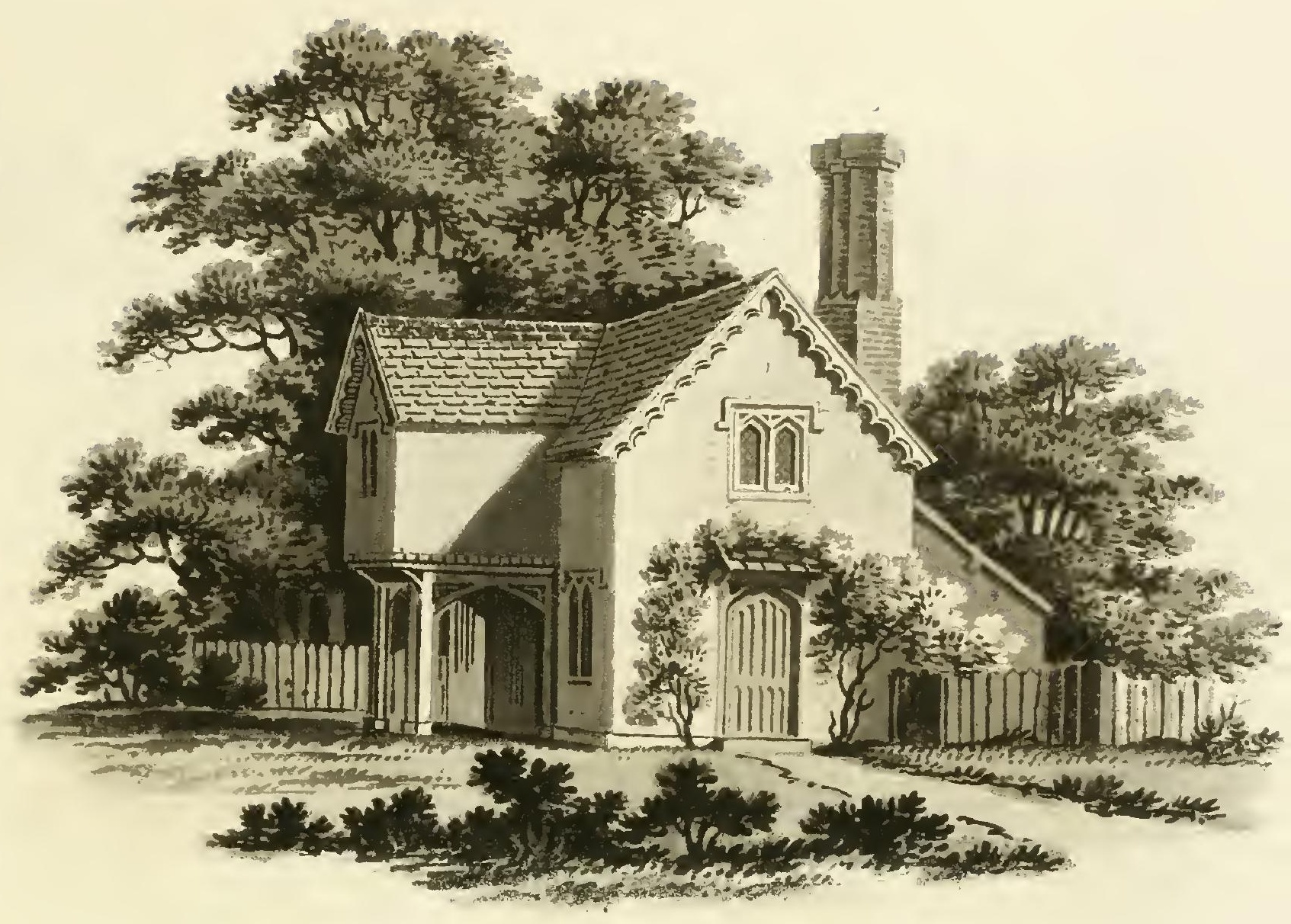

So prevalent is the taste for what is called Gothic, in the neighbourhood of great cities, that we see buildings of every description, from the villa to the pigstye, with little pointed arches, or battlements, to look like Gothic; and a Gothic dairy is now become as common an appendage to a place, as were formerly the hermitage, the grotto, or the Chinese pavilion. Why the dairy should be Gothic, when the house is not so, I cannot understand, unless it arises from that great source of bad taste, to introduce what is called a pretty thing, without any reference to its character, situation, or uses. Even in old Gothic cottages, we never see the sharp pointed arch, but often the flat arch of Henry VIII, and perhaps there is no form more picturesque for a cottage than buildings of that date, especially as their lofty perforated chimneys not only contribute to the beauty of the outline, but tend to remedy the curse of the poor man's fire-side, a smoky house. 



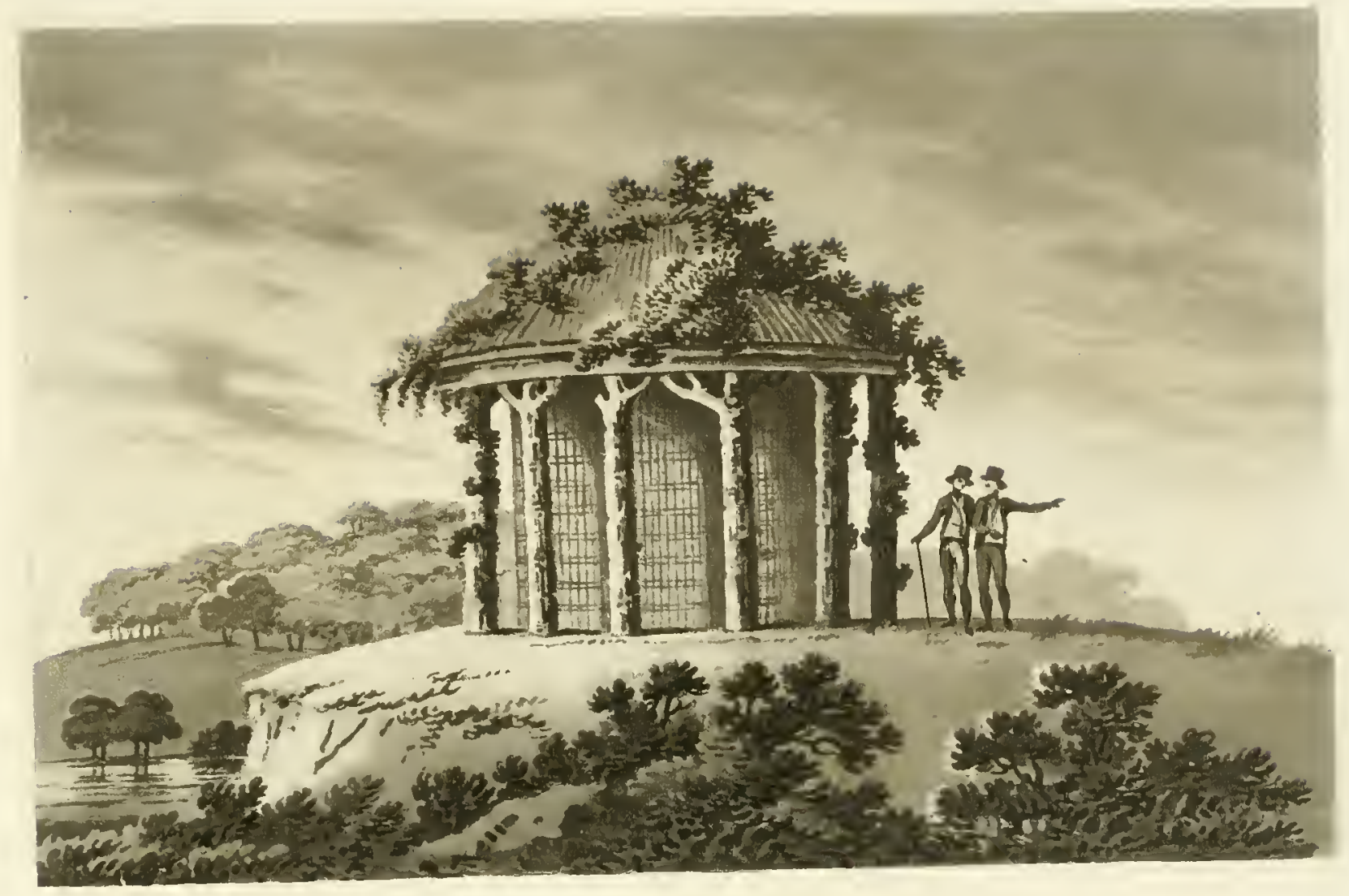

There are few situations in which any building, whether of rude materials or highly finished architecture, can be properly introduced without some trees near it. Yet the summit of a naked brow, commanding views in every direction, may require a covered seat or pavilion; for such a situation, where an architectural building is proper, a circular temple with a dome, such as the temple of the Sybils, or that of Tivoli, is best calculated; but in rude scenery, as on a knoll or promontory in a forest, the same idea may be preserved in a thatched hovel supported by rude trunks of trees; yet as the beauty of such an object will greatly depend on the vegetation, it should be planted with ivy, or vines, and other creeping plants should be encouraged to spread their foliage over the thatch. 



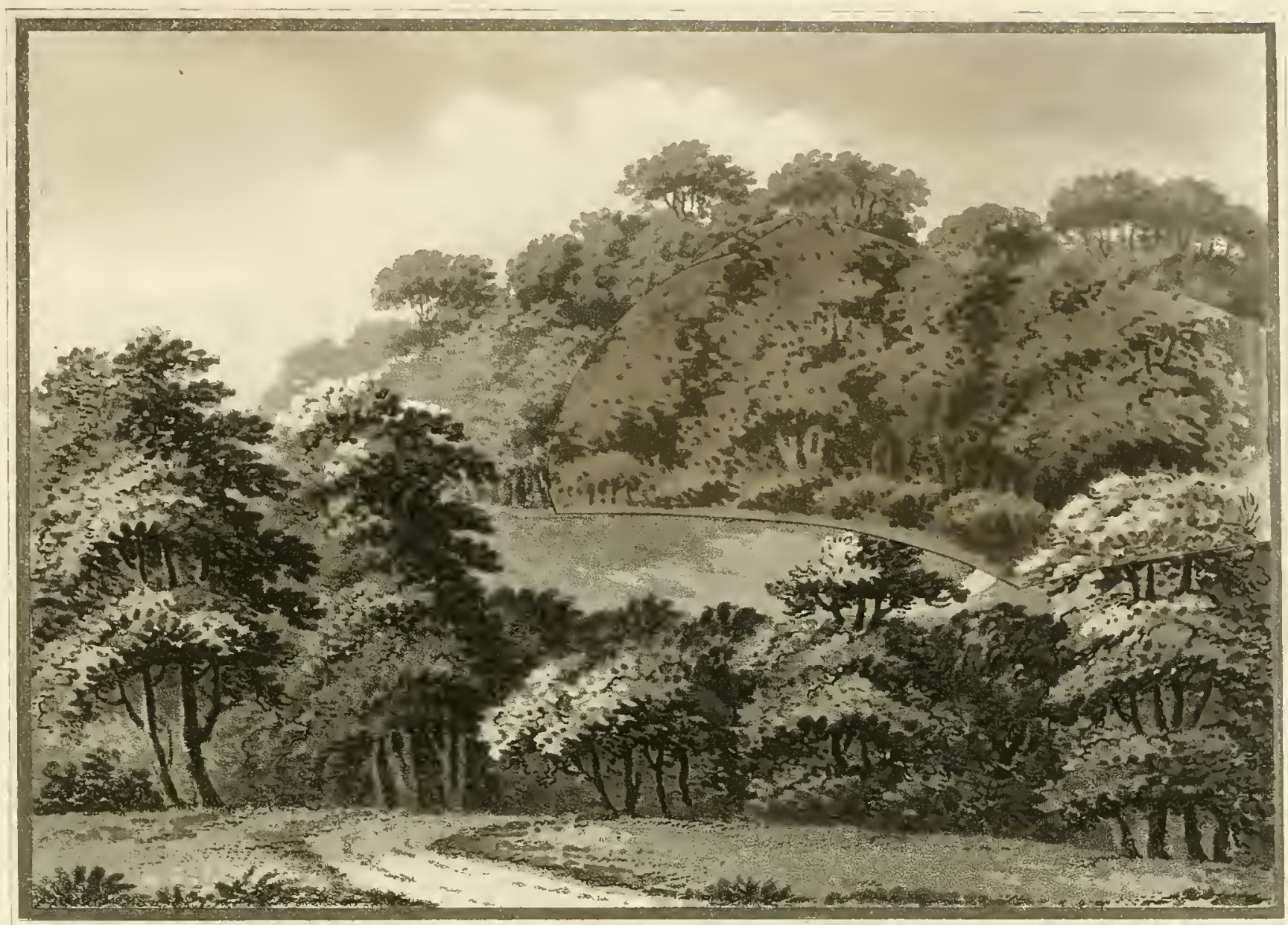

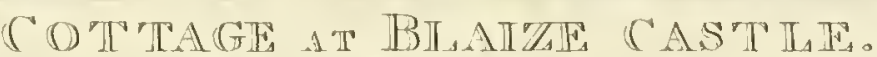

The principal view from the house at Blaize Castle, is along that rich glen of wood through which the approach has been made as already described: in this view the castle, although perfectly in harmony with the solemn dignity of the surrounding woods, increases rather than relieves that apparent solitude which is too sombre for the character of a villa. ${ }^{\mathrm{h}}$

"Sone object was wanting to enliven the scenery; a temple, or a pavilion, in this situation, would have reflected light, and formed a contrast with the dark woods; but such a building would not have appeared to be inhabited, this cottage therefore derives its chief beauty from that which cannot easily be expressed by painting; the ideas of motion, animation, and inluabitancy, contrasted with those of stillness and solitude. Its form is meant to be humble, without meanness; it is; and appears the labitation of a labourer who has the care of the neighbouring woods; its simplicity is the effect of art, not of neglect or accident; it seems to belong to the mansion, and to the more conspicuous tower, without affecting to imitate the character of eithcr. 



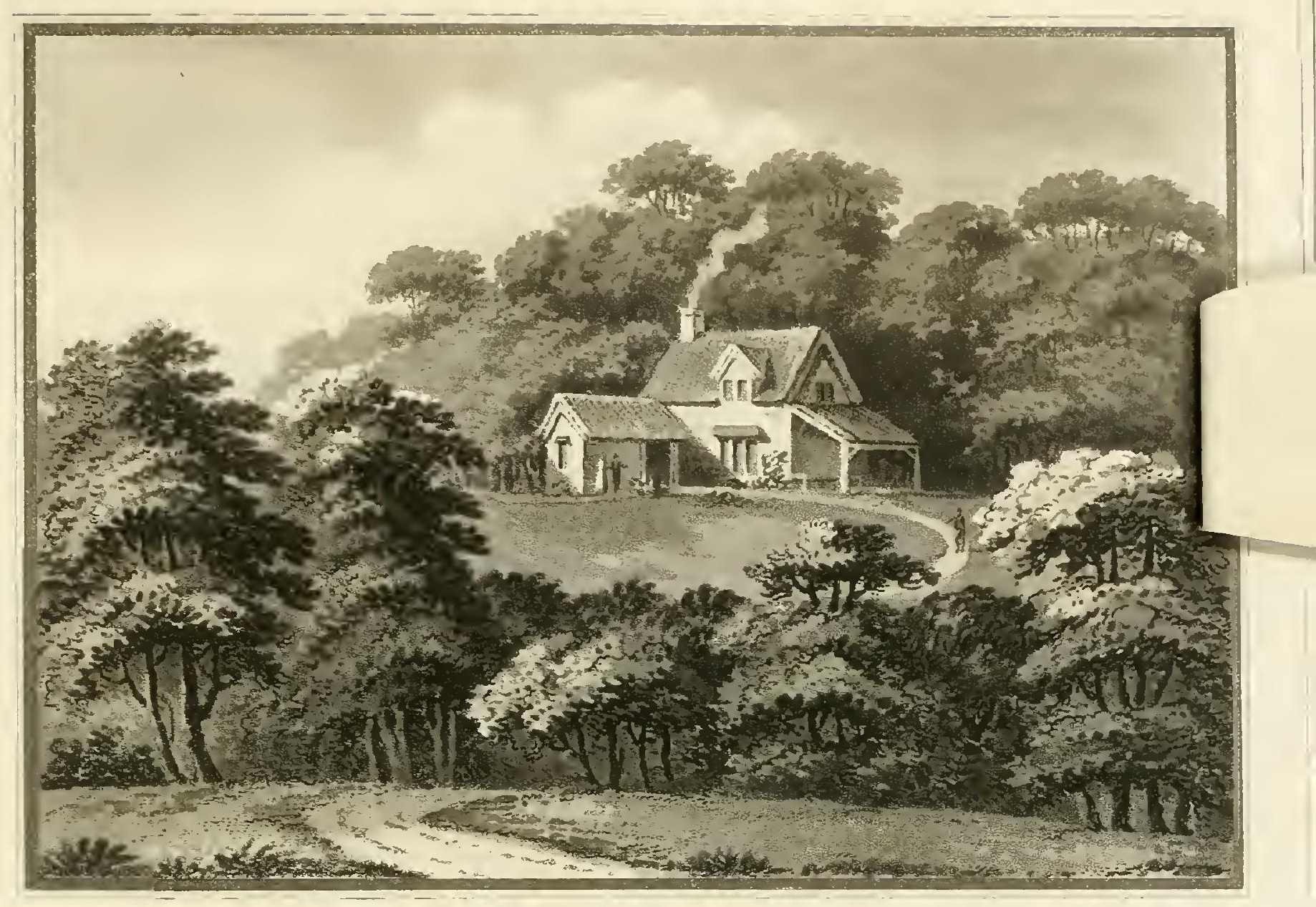

SO'TRTAGE - AT BIAAIZE CASTLE。

The principal view from the house at Blaize Castle, is along that rich glen of wood through which the approach has been made as already described: in this view the castle, although perfectly in harmony with the solemn dignity of the surrounding woods, increases rather than relieves that apparent solitude which is too sombre for the character of a villa. ${ }^{\mathrm{h}}$

'Some object was wanting to enliven the scenery; a temple, or a pavilion, in this situation, would have reflected light, and formed a contrast with the dark woods; but such a building would not have appeared to be inhabited, this cottage thcrefore derives its chief beauty from that which camnot easily be expressed by painting; the ideas of motion, animation, and inhabitancy, contrasted with those of stillncss and solitude. Its form is meant to be humble, without meanness; it is; and appears the habitation of a labourer who has the care of the neighbouring woods; its simplicity is the effect of art, not of neglect or accident; it seems to belong to the mansion, and to the more conspicuous tower, without affecting to initate the character of either. 



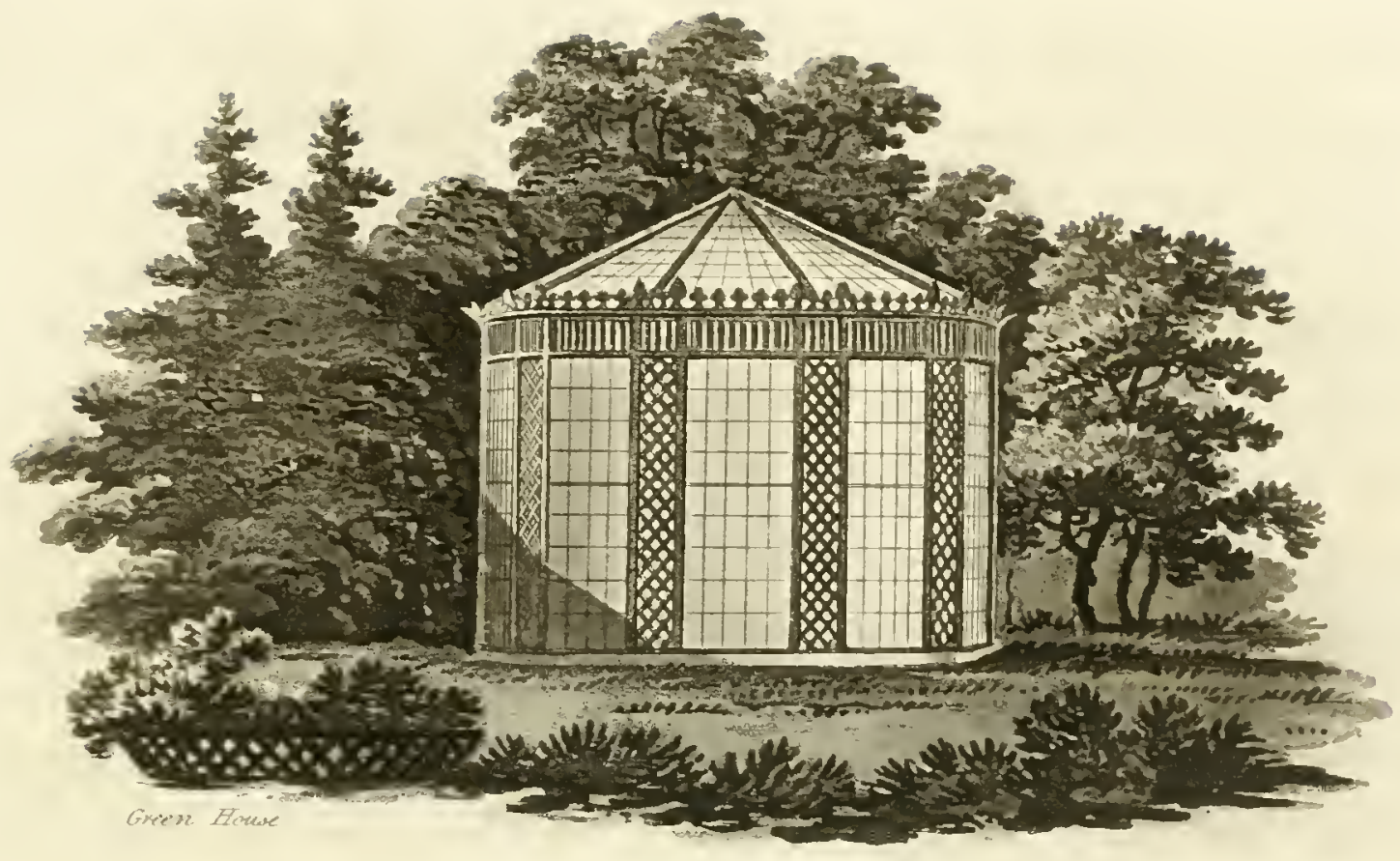

The propensity for imitation, especially where no great trouble or expence is incurred, has made treillage ornaments so common, that some observations concerning them may be expected in this work, especially as I believe I may have con-

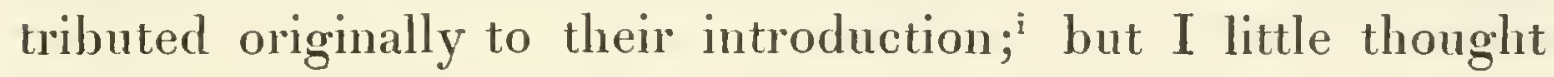
how far this flimsy ornament might be misapplied.

The treillages of Versailles and Fontainbleau were of substantial carpentry, preserving architectural proportions, in which plants were confined and clipped to form a sort of vegetable and

i To conceal a house near the entrance of a flower-garden at TAPLOW, I covered the whole with treillage many years ago. 
architectural berceau, or cabinet de verdure; these being made of strong wood and painted, were more costly and more durable; and as they only formed a frame for the plants, they might perish, without injuring the forms of these leafy buildings; but the English treillage is made of such slight materials, and so slightly put together, that they can hardly outlive the season for which they are erected; this, however, is no objection where they are used in flower-gardens, or where they are merely to be considered as garden sticks supporting plants, but when added to architectural houses, and made the supporters of a heavy roof, or even a canvass awning, it looks as if the taste of the country were verging to its decline; since shade might be obtained by the same awning supported by iron, if architectural forms and projections are to be despised ${ }^{k}$ or discarded.

I should therefore suppose that no treillage ought to be introduced, except in situations where creeping plants may be fastened to the framing, which should be stout in proportion to its height, or its intentions : it is a common mistake to suppose a thing will look light by being slender; if it be not equal to its office by its apparent substance, it will look weak not light; but the lattice work is supposed to support nothing, and may therefore be of any dimensions, and being always painted, it will be invisible at a distance.

${ }^{k}$ This observation is the result of having lately seen some houses containing rooms of admirable proportion, and well connected together, but which externally appear to be built of lath, and paper or canvass; perhaps the late frequency of living in camps, or at watering-places, may have introduced this unsubstantial mode of builling, which looks as if it were only intended for the present generation, or rather for the present year. 


\section{Architectural Ornaments and Decorations.}

I could wish, in speaking of architecture, if the use of language would admit of such distinction, to make a difference between the words Omament and Decoration. The former should include every emrichment bearing the semblance of utility; the latter is supposed to have no relation whatever to the uses or construction of the building; thus for instance, a house may answer all the purposes of habitation without a column, a pilaster, an entablature, a pediment, a dome, an arcade, or a balustrade, which I call the external ornaments of Grecian architecture. ${ }^{1}$

I include under the word Decorations-statues, vases, bassorelievos, sculpture, \&c. which have no use, but as additional enrichments to the orvaments of architecture; on the contrary,

That these ormaments, although not absolutely necessary, should appear to be useful, is evident from the disgust we feel at seeing them improperly applied; as in a column, without an entablature, or an arch supporting nothing, or a pediment without a roof; but I da not consider columns, or pilasters, as ornamients, when used, as we often see them, to the doors of houses; they may then more properly be called decorations in a bad taste. A column is the most sumptuous ornament of Grecian architecture, and should never be subordinate to any other part of the edifice; it should either belong to the entablature and cornice of the building, or it should be wholly omitted.

If the door requires a projecting covering, it is far better to support it by consoles, or cautlivres, or even small cast iron pillars, without architectural pretensions, than by two dininutive columns which bear no proportion to the buildings against which they are attached.

This observation, however, does not include those porticos to churches or public buildings, which form a colonnale on so extended a scale, that they become in a manner detached and principal; of this kind are the magnificent and useful colonnade at Sтоке Pogies, and that added by the same architect to the garden front of Frogmore. 
where these decorations are applied to plain buildings without ornaments, they are marks of bad taste. ${ }^{\mathrm{m}}$

The ornaments of architecture must be correct in design, since no degree of costliness in their materials or their workmanship, can compensate for any defect in proportion, order, or disposition. The eye of good taste will be equally offended with columns too large or too small, too near or too far apart; in short, with every deviation from the established rules of the respective orders, whether such column be composed of marble, of stone, or of plastered brickwork; the costliness of the material makes no difference in the design; but this is not the case with decorations. The cheapness and facility with which good designs may be multiplied in papier maché, or putty composition, have encouraged bad taste in the lavish profusion of tawdry embellishment.

This consideration leads me to assert, that every species of enrichment or decoration ought to be costly, either in its materials or in its workmanship: and if we attend to the common opinion of all, except children and savages, we shall find that no real value is attached to any decoration, except upon this principle; on the contrary, it becomes contemptible in proportion as it affects to seem what it is not. ${ }^{\mathrm{n}}$

"Instances of this often occur in the neighbourhood of large citics and towns, where the taste of a carpenter, and not of an architect, puts balustrades to houses without any entablatures, or perhaps places them in a garret window, while the plain parapet wall is loaded with Mercuries, vases, pine-apples, eagles, acorns, and round balls.

"If a lady of high rank were to decorate her person with gauze and gilt paper, with glass beads, and the feathers of common English birds, instead of muslins and gold lace, diamonds, and the feathers of an ostrich, or a bird of paradise; although she might be equally brilliant, and even dispose her clress with grace and fancied tiste, we slould pronounce it tromperie, as affecting to seem what it is not. 
The idea of costliness in ornament is increased by its rarity, or rather by its being used only where it is most conspicuous, and this sort of oconomy is observable even in the works of nature; for instance, the most beautiful coloured feathers of birds are on the surface, while those for use, rather than for shew, are generally of a dirty brown; it may also be observed, that those butterflies, or moths, whose wings are ornamented on the under side, generally bear them erect; while those which have the upper side most beautiful generally spread them flat. The same remark may be extended to all the vegetable tribe, every flower, and every leaf, has one side more ornamented, more glossy, more vivid, or more highly finished than the other, and this is always the side presented to the eye. Hence we are taught by the example of nature, not to lavish decorations where they cannot generally be seen. ${ }^{\circ}$

While treating on the subject of ornaments and decorations, I must not omit to mention colours; since improper colouring may destroy the intended effect of the most correct design, and render ridiculous what would otherwise be beautiful. ${ }^{p}$

- Good taste can only be acquired by leisure and observation; it is not therefore to be expected in men whose time is fully employed in the more important acquirement of wealth or fame; while on certain subjects of taste the most elegant women often excel the most learned inen; and although they may not have investigated the causes of the pleasure, they either derive or communicate, yet they are more exquisitely sensible to both. This, if it were necessary, might be used as an apology for occasionally introducing allusions more familiar than the philosophic reader may deem conformable to the nature of a didactic work.

P I cannot help mentioning, that, from the obstinacy and bad taste of the Bristol mason who executed the design, page 145, I was mortified to find that Gothic entrance built of a dark blue stone, with clressings of white Bath stone; and in another 
Both the form and the colour of a small house in LANGLEY $P_{A R K}$ rendered it an object unworthy of its situation; yet, from peculiar circumstances, it was not deemed advisable, either to remove it, or to hide it by plantations. I therefore recommended a Doric portico to cover the front; and thus a building formerly unsightly, because out of character with the park, became its brightest ornament, doing honour to the taste and feelings of the noble proprietor, who preserved the house for having been a favourite retreat of his mother, and which, thus ornamented, may be considered as a temple sacred to filial piety.

In the following instances there is something more than harmony of colours, there is an association from habit, which causes part of our pleasure or disgust.

A compact red house displeases from the meanness of its materials, because we suppose it to be of common red bricks, although it may perhaps be of the red stone of Herefordshire.

On the contrary, a large pile of red buildings is not so displeasing; witness the houses of Совнам, Glemнам, \&c. and the royal palaces of St. James's, Hampton Court, Kensington, \&c.; but perhaps the weather stains of time may have contributed more than the quantity to reconcile us to the colour of these large masses.

Lime-whited houses offend the eye, partly from the violent glare, and partly from the associated meamness of a lath and

place, the intention of the design, page 1.50, was totally destroyed, by painting all the wood work of this cottage of a bright pea green. Such, alas! is the mortifying difference betwixt the design of the artist, and the execution of the artificer. 


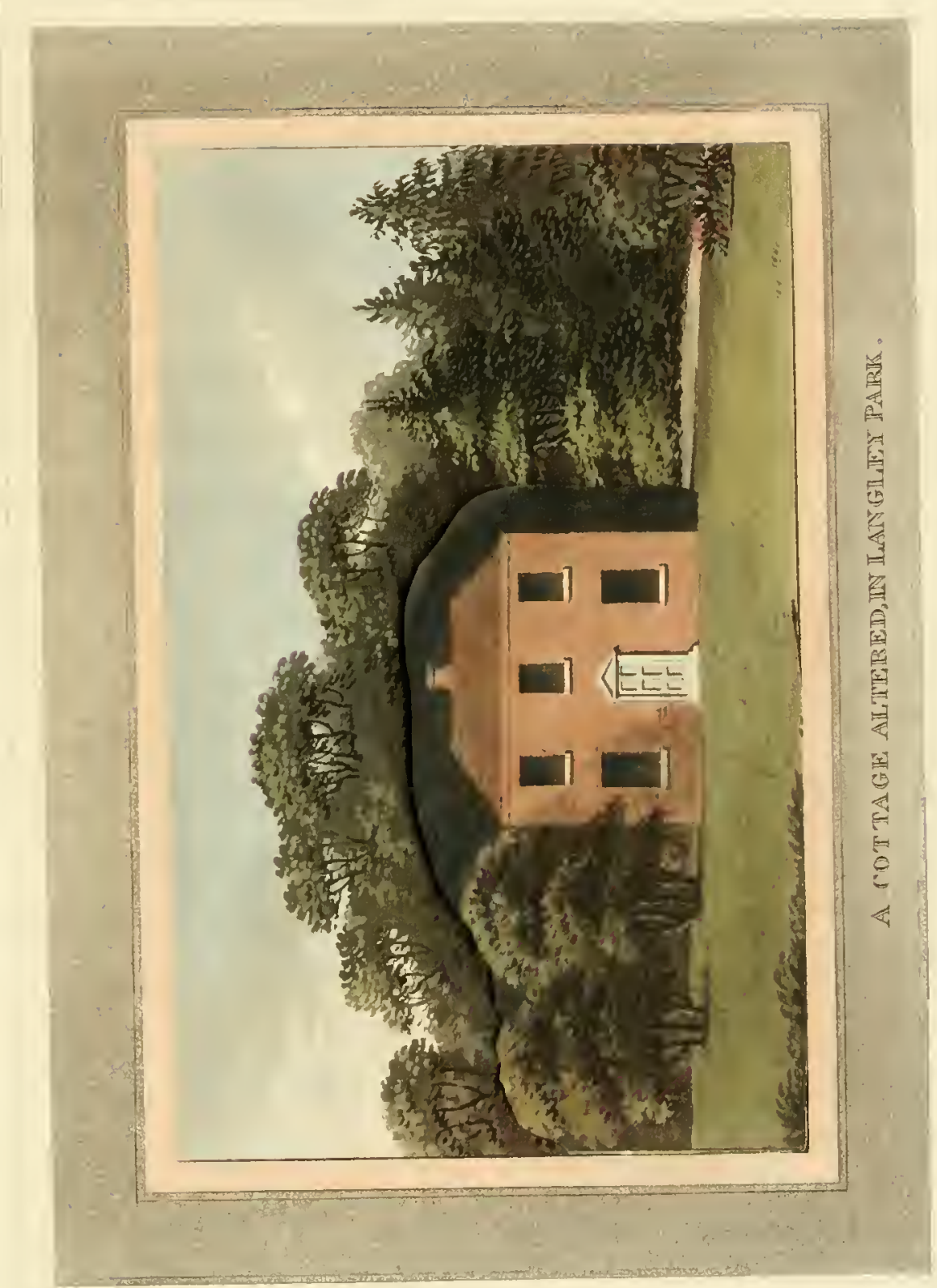





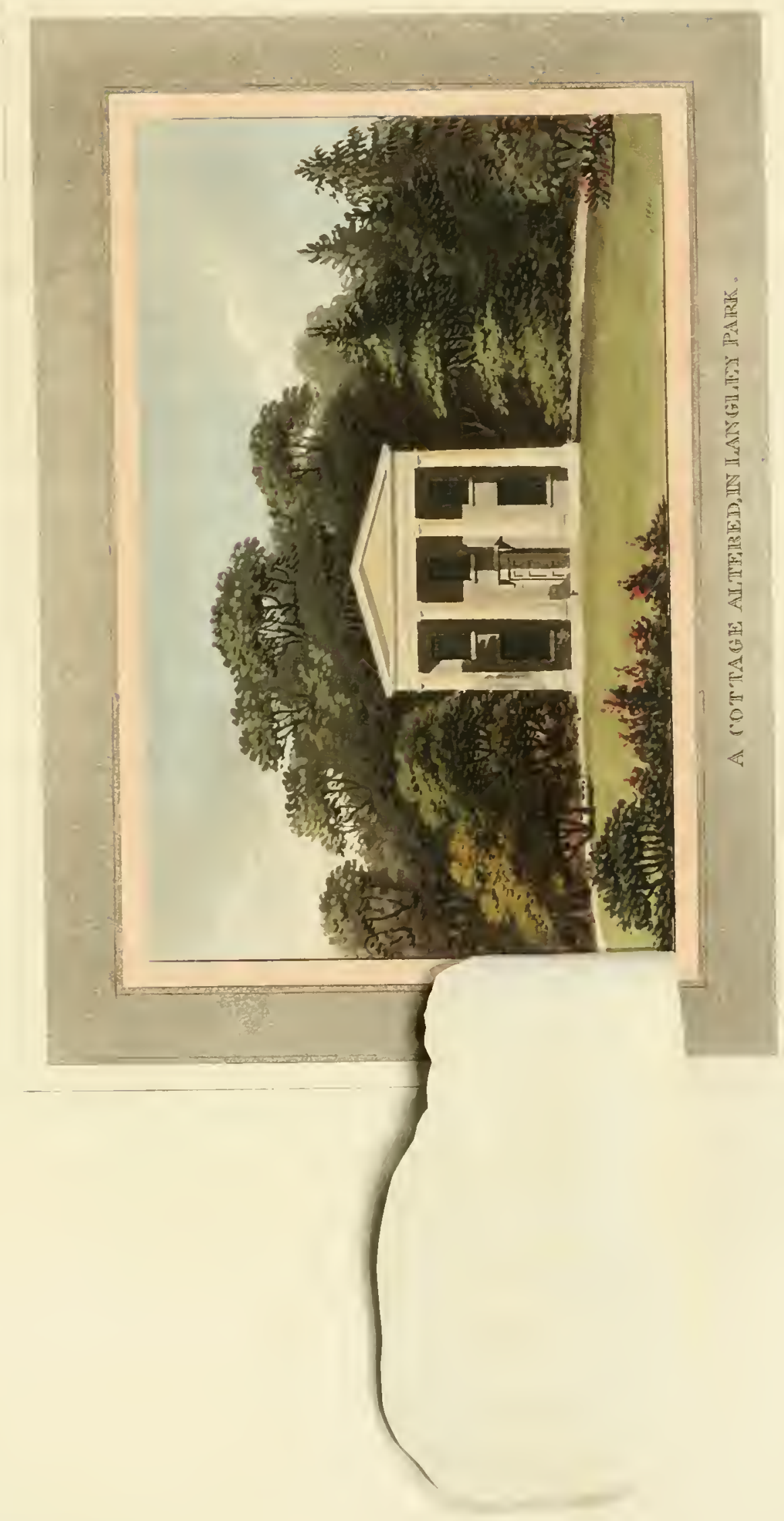



plaster building; but if a little black and yellow be mixed with the lime, the resemblance to the colour of stone satisfies the eye almost as much as if it were built of the most costly materials, witness Woodley, Babworth, Taplow, \&c.

To produce effect by difference of colour in buildings, such as red and yellow bricks, black and white flints, or even edging brick-work with dressings of stone, is the poor expedient of the mere bricklayer; the same may be observed of that paltry taste for pointing the joints of brick-work to render them more conspicuous, and of course more offensive.

As a general principle I should assert, that no external effect of light or shade on a building ought to be attempted, except by such projections or recesses, as will naturally produce them, since every effect produced by colour is a trick, or sham expedient; and on the same principle a recess in the wall is preferable to a painted window, unless it is actually glazed.

With respect to the colour of sashes and window frames, I think they may be thus determined with propriety, first observing that, from the inside of the room, the landscape looks better through bars of a dark colour; but on the outside, in small cottages, they may be green, because it is a degree of ornament not incompatible with the circumstances of the persons supposed to inhabit thent, and even in such small houses as may be deemed cottages, the same colour may be proper; but in proportion as it approaches to a mansion, it should not derive its decoration from so insignificant an expedient as colour, and therefore to a gentleman's house the outside of the sashes should be white, whether they be of mahogany, of oak, or of deal, because externally the glass is fastened by a substance which 
must be painted, and the modern sash-frames are so light, that unless we see the bars, the houses appear at a distance unfinished, and as having no windows. In palaces or houses of the highest description, the sash-frames should be gilt, as at HoLkнам, Wentwort t, \&c. The effect of gold in such situations can hardly be imagined by those who have never observed it; and even at Thoresby, where the house is of red brick, the gilding of the sashes has wonderfully improved its importance.

There is a circumstance with respect to gold and gilding of which few are aware who have not studied the subject. The colour of gold, like its material, seems to remove all difficulties, and makes every thing pleasing; this is evident on viewing a finely coloured picture on a crimson hanging, with or without a gold frame; two discordant colours may be rendered more harmonious by the intervention of gilding, it is never tawdry or glaring, the yellow light catches on a very small part of its surface, while the brown shadows melt into the adjoining colours, and form a quiet tint, never offensive: gold ornament may be applied to every colour, and every shade, and is equally britliant, whether in contact with black or white.

All ornaments of gold should be more plain and simple than those of silver; not only because the costliness of the material renders the costliness of workmanship less necessary, but because the carved or enriched parts reflect very little light or brilliancy, compared with those that are plain.

On the contrary, in silver ornaments, if the surface be too plain, we annex the ideas of tin or pewter, and it is only by the richness or the embossing, that its intrinsic value becomes apparent. 
These remarks are applicable to gold and silver plate, ${ }^{9}$ as well as to every species of ornament in which those metals can be used.

Since the improvement in the manufactory of cast iron has brought that material into more frequent use, it may not be improper to mention something concerning the colour it ought to be painted. Its natural colour, after it is exposed to wet, is that of rusty iron, and the colour of rust indicates decay; when painted of a slate colour it resembles lead, which is an inferior metal to iron; and if white or green, it resembles wood: but if we wish it to resemble metal, and not appear of an inferior kind, a powdering of copper or gold dust on a green ground makes a bronze, and perhaps it is the best colour for all ornamental rails of iron. In a cast-iron bridge at Whiтton, the effect of this bronze colour, mixed with gilding, ${ }^{\mathrm{r}}$ is admirable; and for the hand-rails of staircases it is peculiarly appropriate.

q Lest it should be objected that I am going beyond the precise boundaries of my profession, either as a Landscape Gardener or as an Architect, I shall observe that the professor of taste in those arts must necessarily have a competent knowledge of every art in which taste may be exercised. I have frequently given designs for furniture to the upholsterer, for monuments to the statuary, and to the goldsmith I gave a design for one of the most sumptuous presents of gold plate, which was ever exccuted in this country: it consisted of a bason in the form of a broad flat vase, and pedestal, round which were the figures of Faith, Hope, and Charity; the former spreading her hand orer the water, as in the act of benediction; and the two latter supporting the vase, which resembled a baptismal font: the whole was executerl in gold, and was the present of a noble duke to his son on the birth of his first child.

" Those who have seen the gilded domes of Constantinople, mention them with admiration; and from the observations I have made on the effect of external gilding in large masses, I have often considered gilding the dome of St. Paul's as a subject worthy of this nation's wealth and glory. This idea will, I doubt not, excite ridicule from those who have never observed or studied the wonderful, the pleasing, the unexpected, and harmonious effect of gilding on smooth surfaces. 
With respect to wooden fences or rails, it is hardly necessary to say, that the less they are seen the better; and therefore a dark, or as it is called, an invisible green, for those intended to be concealed, is the proper colour; perhaps there can hardly be produced a more striking example of the truth " that whatever is cheap, is improper for decorations," than the garish ostentation of white paint, with which, for a few shillings, a whole country may be disfigured, by milk white gates, posts, and rails. 


\section{CHAPTER XII.}

Architecture and Gardening inseparable - Some Inquiry into the Forms and Arrangements of different Eras - Situation and Arrangement of $\mathrm{M}_{\mathrm{Iche}} \mathrm{G}$ Gove-Singular Character of the House-Change in Customs and Manners alters Uses of Rooms - An extended Plan - Example Garnons - A contracted Plan-Example Brentry Hill, \&c.

IT has been objected to my predecessor Mr. Brown, that he fancied himself an architect. The many good houses built under his direction, prove him to have been no mean proficient in an art, the practice of which he found, from experience, to be inseparable from landscape gardening: he had not early studied those necessary, but inferior branches of architecture, better known perhaps to the practical carpenter than to Palladio himself : yet from his access to the principal palaces of this country, and his intercourse with men of genius and science, added to his natural quickness of perception, and his habitual correctness of observation, he became acquainted with the higher requisites of the art, relating to form, to proportion, to character, and, above all, to arrangement. ${ }^{\mathrm{s}}$

- Mrr. Brown's fame as an architect seems to have been eclipsed by his celebrity as a landscape gardener, he being the only professor of one art, while he had many jealous competitors in the other. But when I consider the number of excellent work: 


\section{These branches of architecture are attainable without much early practice, as we have seen exemplified in the designs of}

in architecture designed and executed by him, it becomes an act of justice to his memory to record, that if he was superior to all in what related to his own peculiar profession, he was infcrior to none in what related to the comfort, convenience, taste, and propriety of design in the several mansions and other buildings, which he planned. Having occasionally visited and admired nany of them, I was induced to make some inquiries concerning his works as an architect, and with the permission of Mr. Holland, to whom at his decease he left his drawings, I insert the following list:

For the Earl of Coventry. Croome, house, offices, lodges, church, \&c. 1751.

The same. Spring Hill, a new place.

Earl of Donegal. Fisherwick, house, offices, and bridge.

Earl of Exeter. Burleigh, addition to the house, new oftices, \&c.

Ralph Allen, Esq near Bath, additional buildings, 1765.

Lord Viscount Palmerston. Broadland, considerable additions.

Lord Craven. Benham, a new house.

Robert Drummond, Esq. Cadlands, a new house, offices, farm buildings, \&c.

Earl of Bute. Christ Church, a bathing-place.

Paul Methuen, Esq. Corsham, the picture gallery, \&c.

Marquis of Stafford. Trentham Hall, considerable alterations.

Earl of Newbury. House, offices, \&c. 176\%.

Rowland Holt, Esq. Redgrave, large new house, 1765.

Lord Willoughby de Broke. Compton, a new chapel.

Marquis of Bute. Cardiff Castle, large additions.

Earl Harcourt. Nuneham, alterations and new offices.

Lord Clive. Clermont, a large new house.

Earl of Warwick. Warwick Castle, added to the entrance.

Lord Cobhan. Stowe, several of the buildings in the garden.

Lord Clifford. Ugbrooke, a new house.

To this list Mr. Holland added: "I cannot be indifferent to the fame and character "of so great a genius, and am only afraid lest in giving the annexed account I should " not do him justice. No man that I ever met with understood so well what was " necessary for the habitation of all ranks and degrees of society; no one disposed his "offices so well, set his buildings on such good levels, designed such good roons, or "so well provided for the approach, for the drainage, and for the comfort and con- 
certain noblemen, who, like Lord Burlington, had given their attention to this study. A knowledge of arrangement or disposition is, of all others, the most useful: and this must extend to external appendages as well as to internal accommodation.

This knowledge cannot be acquired without observing and comparing various houses under various circumstances; not occasionally only, but the architect must be in the habit of living much in the country, and with the persons for whom he is to build; by which alone he can know their various wants with respect to comfort as well as to appearance, otherwise he will, like an ordinary builder, be satisfied in shewing his skill by compressing the whole of his house and offices under one

"veniences of every part of a place he was concerned in. This he did withont ever " having had one single difference or dispute with any of his employers. He left them "pleased, and they remained so as long as he lived; and when he died his friend, "Lord Coventry, for whom he had done so much, raised a monument at Croome to "his memory."

Such is the testimony of one of the most cminent and experienced architects of the present time; and in a letter to me from the Earl of Coventry, written at Spring Hill, his Lordship thus mentions Mr. Brown:

"I certainly held him very high as an artist, and esteemed him as a most sincere "friend. In spite of detraction his works will ever speak for him. I write from a "house which he built for me, which, without any pretension to architecture, is "perhaps a model for every internal and domestic convenience. I may be partial to "my place at Croome, which was entirely his creation, and I believe originally as "hopeless a spot as any in the island."

I will conclude this tribute to the memory of my predecessor, by transcribing the last stanza of his cpitaph, written by Mr. Mason, and which records with more truth than most epitaphs, the private character of this truly great man.

But know that more than Genius slumbers here, Virtues were his which $A$ rt's best powers transcend;

Come ye superior train, who these revere, And weep thc Christian, Ilusband, Father, Friend. 
compact roof; without considering aspect, views, approaches, gardens, or even the shape of the ground, on which the house is to be built.

It is impossible to fix or describe the situation applicable to a house, without at the same time describing the sort of house applicable to the situation.

This is so evident that it seareely requires to be pointed out, yet I have often witnessed the absurdity of designs for a house where the builder had never seen the situation; I have therefore long been compelled to make architecture a branch of my own profession. ${ }^{t}$

Having occasionally observed the various modes by which large houses and their appendages have been connected at various periods, it may not be uninteresting if $I$ attempt to describe them by reference to the annexed plate."

No. 1. The earliest form of houses, or rather of palaces, in the country, prior to the reign of Elizabeth, consisted of apartments built round a large square court. These were formerly either castles or abbeys, and often received all their light from the inner courts; but when afterwards converted into habitations,

' Before I had the advantage of my eldest son's assistance in this department, I met with continual difficulties. I will mention one instance only which occurred to me some years ago. Having been consulted respecting the situation for a villa to be built near the metropolis, I fixed the precise spot, and marked the four corners of the house with stakes upon the ground, proposing that the best rooms should command the best views and most suitable aspects; but not having any consultation with the architect, I was afterwards surprised to find my position of the four corners of the house strictly observed; but to accommodate the site to his previously settled plan on paper, the chimneys were placed where I had supposed the windows should be to command the finest views, and the windows, alas! looked into a stable court.

"By an error on the plate, No. 2. should be No. 3. 



\section{HOUSES OT VARTOUS DATES.}
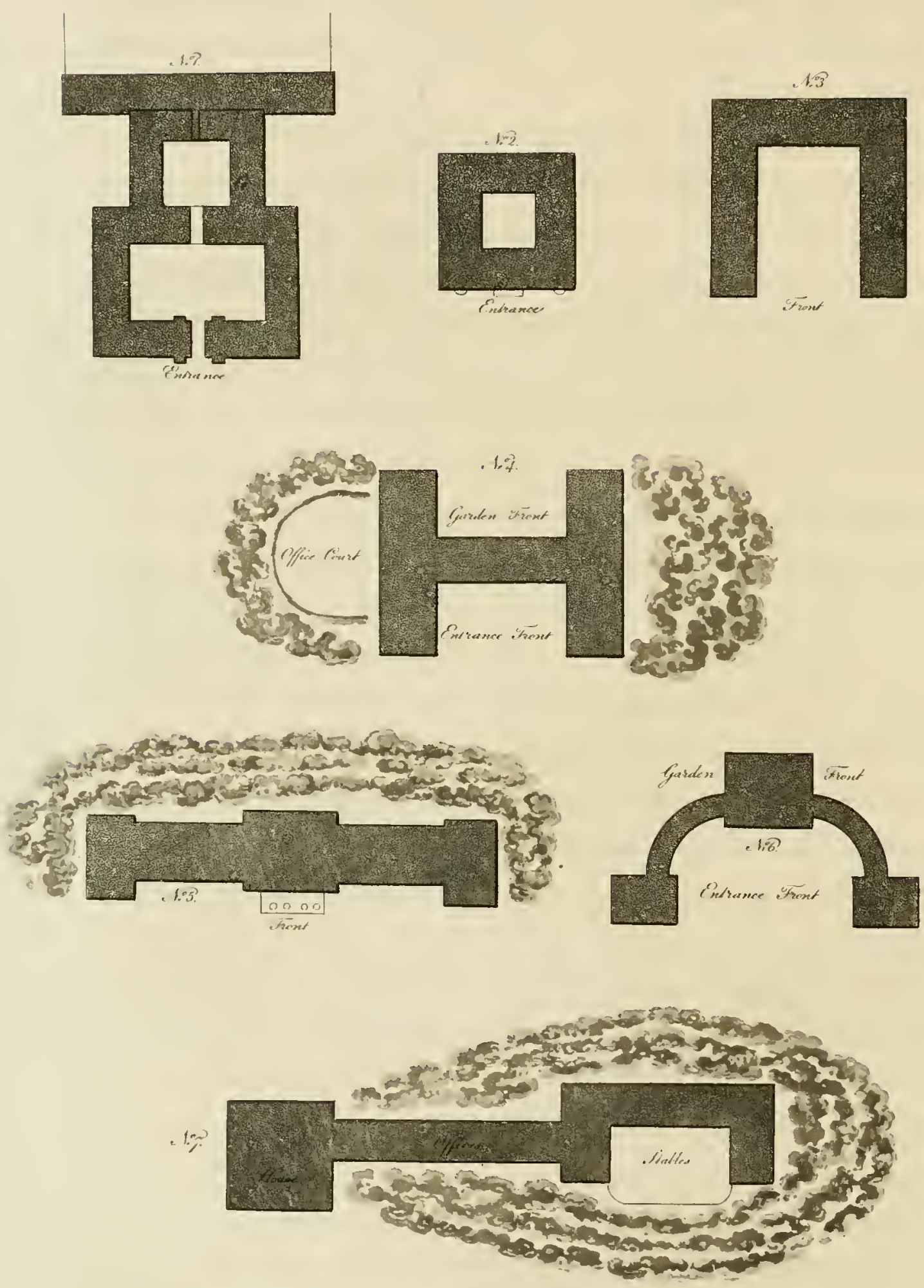
windows were opened on the outside of the building. The views from a window were of little consequence at a time when glass was hardly transparent, and in many of the ancient castles the small lozenge panes were glazed with coloured glass, or painted with the armorial bearings, which admitted light without any prospect. Perhaps there is no form better calculated for convenience of habitation, than a house consisting of one or more of these courts, provided the dimensions are such as to admit free circulation of air, because in such a house the apartments are all easily comnected with each other, and may have a passage of communication for servants from every part. Of this kind are the old palaces at Hampton Court and St. James's, of Penshurst and Knowle, in Kent, Warwick Castle, and various other ancient mansions.

No. 2. Houses of the next form I consider as of later date, although from the various subsequent alterations it is difficult to define their original shapes: they seem to have had one side of the quadrangle opened, and thus the line of communication being cut off, this sort of house becomes less commodious in proportion to the length of its projecting sides. Of this description were Совнам HALL and Cashiobury, to both which have been judiciously added square courts of offices, under the direction of Mr. James Wyatt.

No. 3. is a form introduced in the reign of James $I$, with the quadrangle so small, that it is often damp and dark; of this kind are Crewe, Hill Hall, Gayhurst, and Culford; although the latter has been modernised and changed to the form No.7. Houses of this shape may sometimes be greatly improved by covering the inner court entirely, and converting 
it into a hall of communication; this I advised at SARsDen, a house of later date. The offices are generally attached to the side of these houses. In mansions of the foregoing three descriptions, a mixture of Grecian with Gothic is often observed, particularly in those repaired by Inigo Jones.

No. 4, the form next in succession, was of the date of William III, and George I, and has been commonly called an $\mathrm{H}$ or half $H$. This kind of house is often rendered very inconvenient by the centre being one great hall, which breaks the connexion of apartments above stairs. It is also further objectionable, because it is a mere single house in the centre, and must have offices attached on one side: of this description are $\mathrm{S}_{\text {ток }} \mathrm{P}_{\mathrm{A}} \mathrm{K}$, Langleys, Glenham Hali, Dullingham, and Condover.

No.5. When the Italian or Grecian architecture became more general, a greater display of fasçade was introduced than the body of the house required; the offices and appendages were therefore made in wings to extend the design, as at WENTwort н House, Wimpole, Attingham, Drrham Park, and numerous others.

A house on this plan, if it commands only one view, may be less objectionable; but when applied to situations where the windows are to look in opposite directions, it becomes very inconvenient, because the oflices want that uninterrupted communication which is absolutely necessary to the comfort of a dwelling. After the views from the windows became an object of consideration, it was not deemed sufficient to preserve the views to the north and to the south, but even the views to the east and to the west were attempted to be preserved, and this introduced the plan No. 6 . 
No.6. has wings not in the same line with the house, but receding from it, which of course destroy the symmetry proposed by wings, unless the whole be viewed from one particular point in the centre; of this form are Merieg, Newton Park, Normanton, Latrom House, \&c. The houses built by Paine and Leadbeter are frequent instances of want of comfort in the two latter forms.

No. 7. is a form so generally adopted in modem houses that I will not mention any particular instances, especially as they are the works of living architects; yet I hope I shall be pardoned in also making some observations on their construction.

This last invented form consists in a compact square house with three fronts, and to the back are attached oflices, forming a very long range of buildings, courts, walls, \&c. supposed to be hid by plantation. These ${ }^{x}$ I have been often required to hide by planting, while, in fact, during the lives of the architect and the proprietor, the buildings can never be concealed, and in the lives of their successors the trees must be cut down to give a free circulation of air to the buildings.

Notwithstanding the danger of giving offence when I an obliged to speak of the works of living artists, I shall venture to point ont some objections to the compact form No. 7, as applied to a large mansion, which have not an equal weight when applied to a villa or a house near a city, where land is valued by the foot and not by the acre; for howerer ingenious it may be in such

* Such is the horror of sceing any building belonging to the oftices, that, in one instance, I was desired by the architect to plant a wood of trees on the earth which had been laid orer the copper roofs of the kitchen offices, and which extended 300 feet in length from the house. 
places to compress a large house within a small compass, or to cover under the same roof a great number of rooms; yet a mansion in a park does not require such management, or warrant such œeconomy of space.

Of all the forms which can be adopted, there is none so insignificant as a cube; because, however large it may be, the eye can never be struck with its length, its depth, or its height, these being all equal; and the same quantity of building which is often sunk under ground, raised in the air, or concealed in plantation, might have been extended to appear four times as large, with less expence and more internal convenience.

A house in the country is so different from a house in town that I never could see any good reason for disposing the living rooms above stairs: it may perhaps be said, that the views are more perfect from the higher level; but the same degree of elevation may be obtained by building the cellars above ground, and afterwards raising the earth over them, as I advised at Donnington and Blaize Castle; and surely the inconvenience of an external staircase can scarcely be compensated by any improvement of the views. To comteract this error in modern houses, I have in some instances, raised the earth to the principal floor; and in others, where the architecture would not allow this expedient, I have advised a gallery to be added, as at Hooton and Higham Hicl. 
Few subjects having occurred in which I have so fully discussed the proper situation for a house, and all its appendages, as that of Michel Grove, ${ }^{y}$ I shall subjoin the following extract from that Red Book.

"There is no circumstance connected with my profession, in which I find more error of judgment, than in selecting the situation for a house, yet it is a subject every one fancies easy to determine. Not only visitors and men of taste fall into this error, but the carpenter, the land-steward, or the nurseryman, feels himself equally competent to pronounce on this subject. No sooner has he discovered a spot commanding an extensive prospect, than he immediately pronounces that spot the true situation for a house; as if the only use of a mansion, like that of a prospect-tower, was to look out of the windows. ${ }^{2}$

After long experiencing the many inconveniencies to which

Y The plate of Micnec Grove House had been engraved when the death of its late possessor put a stop for the present, to these extensire plans of improvement, which from his perfect approbation and decisive rapidity, would probably by this time have been completed. Whaterer disappointment I may feel from this melancholy interruption in my most farourite plan, I must still more keenly regret the loss of a valuable friend, and a man of true taste; for he had more celerity of conception, more method in clecision, and more punctuality and liberality in execution, than any person I ever knew.

z The want of confort, inseparable from a house in an exposed situation, even in the climate of Italy, is well illustrated by Catullus.

"Furi! villula nostra, non arl Austri

"Flatus opposita est, nec ad Faroni,

"Nec særi Boreæ, aut Apeliotæ;

"Verum ad millia quindecim et ducentos.

"Oh ventım horribilem! atque pestilentem!"

Catullus, Ode 24. 
lofty siluations are exposed: after frequently witnessing the repentance and vexation of those who have hastily made choice of such situations, under the flattering circumstances of a clear atmosphere and brilliant sky; after observing how willingly they would exchange prospect for shade and shelter, and after vainly looking forward to the effect of future groves, I' an convinced that it is better to decide the situation of a house when the weather is unfavourable to distant prospects, and when the judgment may be able to give its due weight to every circumstance which ought to be considered in so material an object: that the comforts of habitation may not be sacrificed to the fascinating glare of a summer's day.

From these considerations I do not hesitate to assert, that if no house existed at Miches Grove, the sheltered situation of the present magnificent and singular mansion is greatly to be preferred to any spot that could be found on the hill, every part of which is more or less exposed to the force of the winds from the south west. I shall therefore inquire into the character of the present house, and consider how far the old mansion may be rendered convenient and adapted to modern comforts.

There are few old mansions in England which have not been either castles or monasteries altered into houses, but there is no trace of this house ever having been either; and indeed its situation in a dry valley is unlike that of any abbey, and it is so immediately commanded by the surrounding hills, that it never conld have been a castle or place of defence.

The proposed addition of a drawing-room, an anti-room, and an eating-room of large dimensions, will alter those relative proportions, now so pleasing. It is not therefore with a view of 
improving, but with that of doing as little injury as possible to its appearance, that I venture to suggest the additions in the annexed sketch; because the terrace will tend to preserve the apparent height, which the additions to the east tend to destroy.

The present style of living in the country is so different from that of former times, that there are few houses of ancient date which would be habitable without great alterations and additions. Such indeed is the constant fluctuation in the habits and customs of mankind, and so great the change in the luxuries, the comforts, and even the wants of a more refined people, that it is in these times impossible to live in the baronial castle, the secularized abbey, or even in the more modern palaces, built in the reign of Queen Elizabeth, preserving all the apartments to their original uses.

The chief rooms formerly required in a house of that date were,

The Hall, for the entertainment of friends and vassals; a large and lofty room, having the floor at one end raised above the common level, as at present in the halls of onr colleges; this was to mark some distinction in the different ranks of the guests.

The next large room required was a Gallery, for the reception of company in a morning, for dancing in the evening, and for the exercise of the family within doors. Very few books were then in use; and instead of the newspapers and pamphlets of the present day, the general information was collected in conver-

a This house is said to have been built by a Knight of Malta in the Reign of Henry VIII, in initation of a Morisco palace which he had seen in Spain; if this be true, it accounts for the singular style of architecture.

$2 \mathrm{~A}$ 
sations held in those long galleries, which had large recesses or bays, sometimes called bowre windows, and now bow windows; into which some of the company would occasionally withdraw for conversation of a more private nature, as we frequently read in the Memoires de Sully, \&c.

But the apartment of all others, which was deemed indispensable in former times, and in which the magnificence of the proprietor was greatly displayed, was the Chapel.

The other apartments were one or more small parlours, for the use of the ladies and their female attendants, in which they carried on their various works of embroidery, \&c. and instead of the present dressing-room, and sitting-rooms, which are added to each modern bed-room, there was generally

A small closet to each, with perhaps an oriel window for private moruing devotions.

After thus mentioning the uses of ancient apartments, it is necessary to enumerate those additions which modern life requires. 1st. The Eating-room, which does not exactly correspond with the ancient hall, because it is no longer the fashion to dine in public. 2d. The Library, into which the gallery may somelimes be changed with propriety. 3d. 'The Drawing-room,

" "If this law hold in Vienna ten years, I'll rent the fairest louse in it after three"pence a bay."

Measure for Measure, Act II. Sc. I.

"The fashion of building in our author's time, was to have two or three juttings out " in front, which we still see in old houses, where the windows were placed, and these "projections were called bays, as the windows were from thence called bay windows."

ThEOBALD, ibid.

These projections answer to the Exhedra of the Greeks and Romans. 



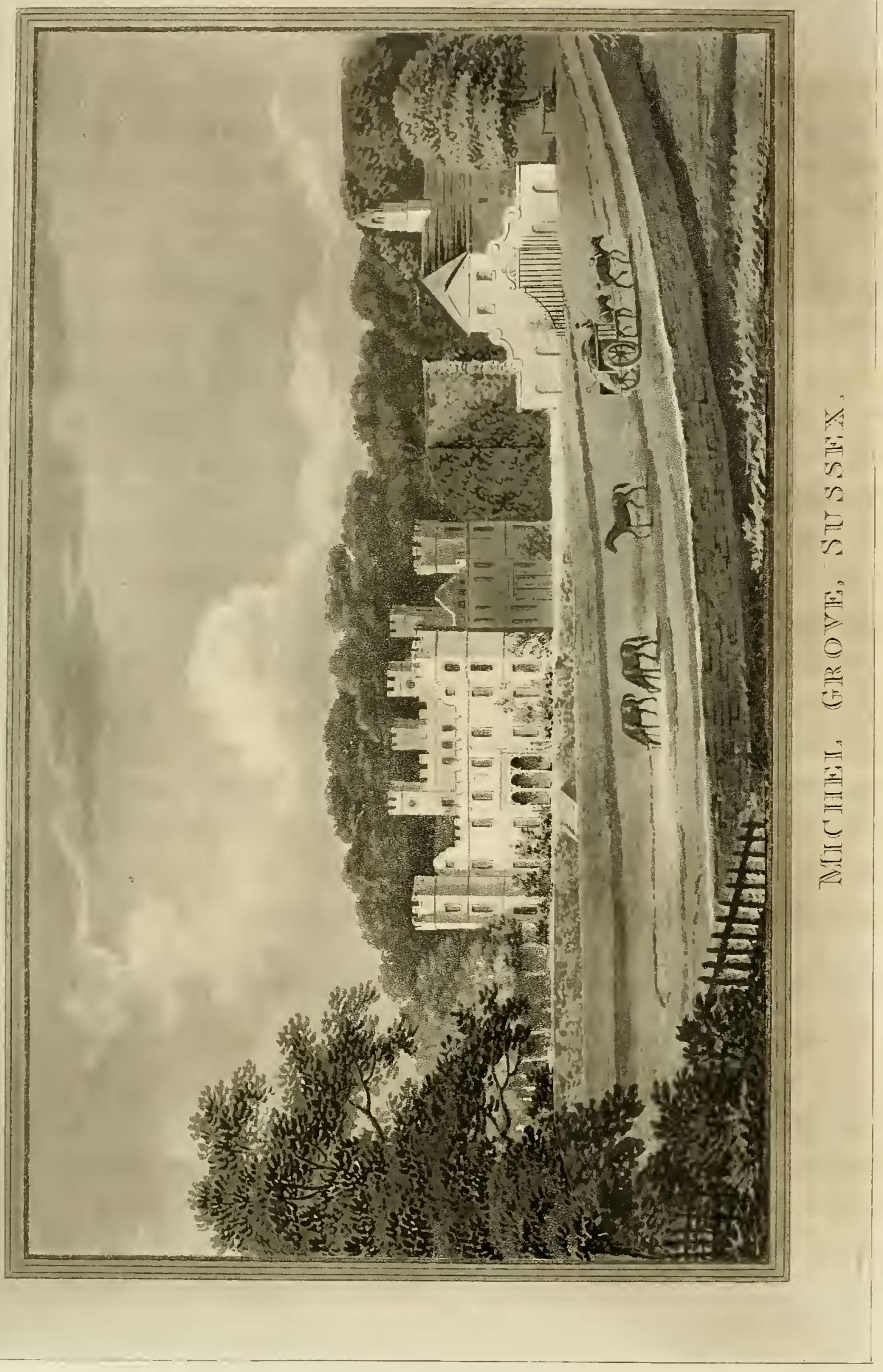


or saloon. 4th. The Music-room. 5th. The Billiard-room. 6th. The Conservatory attached to the house; and lastly, the Boudoirs, wardrobes, hot and cold baths, \&c. which are all modern appendages unknown in Queen Elizabeth's days. Under these circumstances, it is difficult to preserve the ancient style of a mansion without considerable additions. For this reason we see few specimens of Gothic buildings which have not been mixed and corrupted with the architecture of various dates; and whilst every casual observer may be struck with the incongruity of mixing the Grecian with the Gothic styles, yet the nice antiquarian alone discovers by the contour of a moulding, or the shape of a battlement, that mixture of the castle and abbey Gothic, which is equally incorrect with respect to their different dates and purposes.

The annexed view of this house will, I hope, justify my anxiety to preserve it as far as may be consistent with modern habitation: for although it can neither be deemed a castle, an abbey, or a house of any Gothic character with which we are acquainted, yet its form is singularly picturesque, and the slide shews the effect of removing the present road, walls, and stables, which would obstruct the view from the new apartments.

In determining the situation for a large house in the country, there are other circumstances to be considered besides the offices and appendages immediately contiguous. These have so often occurred, that I have established in imagination certain positions for each, which I have never found so capable of being realized as at Michel Grove. 
I would place the house with its principal front towards the south or south-east.

I would build the offices behind the house, but as they occupy much more space, they will of course spread wider than the front.

I would place the stables near the offices.

I would place the kitchen garden near the stables.

I would put the home furm buildings at rather a greater distance from the house; but these several objects should be so connected by back roads as to be easily accessible.

I would bring the park to the very front of the house.

I would keep the farm, or land in tillage, whether for use or for experiment, behind the house.

I would make the dressed pleasure ground to the right and left of the house, in plantations, which would skreen the unsightly appendages, and form the natural division between the park and the farm, with walks communicating to the garden and the farm.

It will be found that these are exactly the positions of all the appendages at Mrehel Grove. But in support of my opinion, it may be proper to give some reasons for the choice of these general positions.

1. The aspect of a house requires the first consideration, since no beauty of prospect can compensate for the cold exposure to the north, the glaring blaze of a setting sun, or the frequent boisterous winds and rains from the west and southwest; while in a southern aspect, the sun is too high to be troublesome in summer, and during the winter, it is seldom an unwelcome visitant in the climate of Eugland. 
2, 3. It can hardly be necessary to enumerate the advantages of placing the oflices near, and stables at no great distance from the house.

4. The many interesting circumstances that lead us into a kitchen garden, the many inconveniencies which I have witnessed from the removal of old gardens to a distance, and the many instances in which I have been desired to bring them back to their original situations, have led me to conclude that a kitchen garden cannot be too near, if it be not seen from the house.

5. So much of the comfort of a conntry residence depends on the produce of its home farm, that even if the proprietor of the mansion should have no pleasure in the fashionable experiments in husbandry, yet a farm, with all its appendages, is indispensable: but when this is considered as an object of profit, the gentleman-farmer commonly mistakes his aim; and as an object of ornament, I hope the good taste of the country will never confound the character of a park with that of a farm.

To every dwelling there must belong certain unsightly premises, which can never be properly oruamental; such as yards for coal, wood, linen, \&c. and these are more than doubled when the farm house is contiguous; for this reason I am of opinion, that the farming premises should be at a greater distance than the kitchen garden or the stables, which have a more natural connexion with each other.

The small pool in front of the house has been purposely left; not as an object of beauty in itself, but as the source of great beauty to the scenery; for in the dry valleys of Sussex, such a pond, however small, will invite the deer and cattle to frequent 
the lawn in front of the house, and add to the view, motion and animation.

'Those who only remember the former approaches to this house over lofty downs, with a dangerous road to descend, will hardly believe, that this venerable mansion is not situated in the bottom, but at the extremity of a valley; for, in reality, the house is on the side of a hill, and by the proposed line of approach it will appear that it actually stands on a considerable eminence, the road ascending along the whole course of the valley for more than a mile."

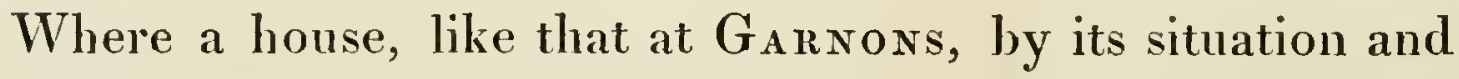
southern aspect, will constantly be a marked feature from the surrounding country, presenting only one front embosomed in wood, that front should be so extended as to distinguish the site of the mansion with adequate importance.

In such a situation it would be difficult to produce the same greatness of character by a regular Grecian edifice, that will be effected by the irregularity of outline in the proposed house, offices, and stables; and in defence of this picturesque style, I shall take the liberty to transcribe in a note ${ }^{c}$ the following very judicious remarks of R. L. Girardin Viscomte d'Ermenonville.

- "C'est par une suite de cet usage de voir et d'entendre par les yeux et les oreilles " de l'habitude, sans se rendre raison de rien, que s'est etablie cette manière de couper "sur le méme patron la droite et la gauche d'un bâtiment. On appelle cela de la " symetrie; le Nôtre l'a introduite daus les jardins, et Mansard dans les bâtiments, et 


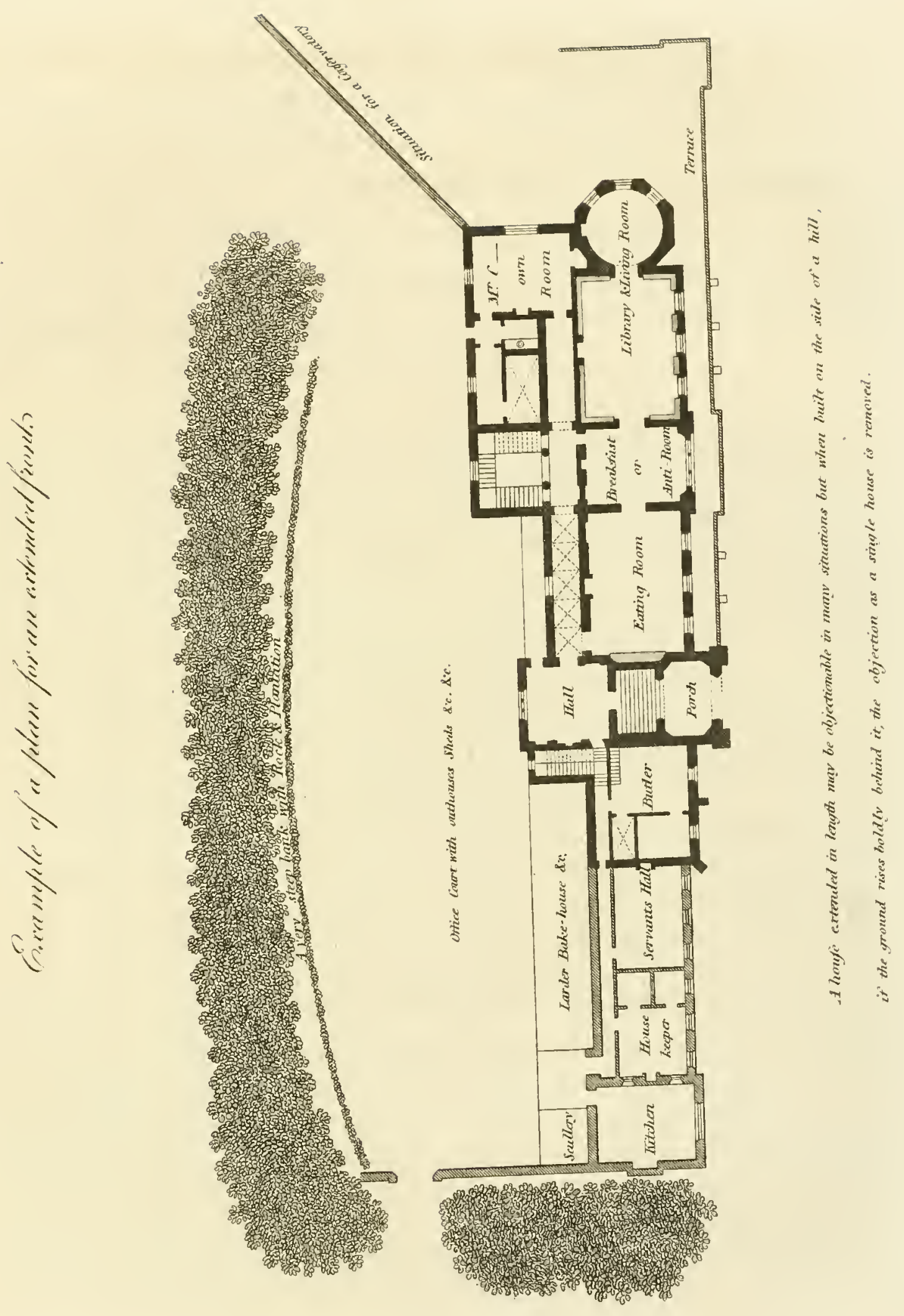



A plan of the house proposed for this situation is added to shew how conveniently the comforts of modern habitations may be adapted to ancient magnificence; and I rejoice in observing. that many large houses are at this time building, or altering, in this irregular style, under the direction of one of our most eminent architects. I may mention those of CAsino Bury and Wickнam MARKet, which disdain the spruce affectation of symmetry so fatal to the Gothic character.

" cequ'il y a de curieux, c'est que lorsqu'on demande à quoi bon? aucun expert Juré, " ne peut le dire; car cette sacrée symetrie ne contribue en rien à la solidité, ni à la " commodité des bâtiments, et loin qu'elle contribue à leur agrément, il n'y a si " habile Peintre, qui puisse rendre supportable dans un tableau un bîtiment tout plat" tement symetrique. Or, il est plus que vraisemblable que si la copie est ressemblante "et mauvaise, l'original ne vaut gueres mieux, d'autant qu'en general tous les desseins "de fabriqucs font plus d'effet en peinture qu'en nature."

"C'est donc l'effet pittoresque qu'il faut principalement chercher, pour donner aux "bâtiments le charme par lequel ils peuvent séduire et fixer les yeux. Pour y par"venir, il faut d'abord choisir le meilleur point de vue pour developper les objets; et "tacher, autant quil est possible, d"en presenter plusieurs faces."

"C'est à donner de la saillie, et du relief à toutes les formes, par l'opposition des "renfoncemens, et par un beau contraste d'ombre et de luniere, c'est dans un juste " rapport des proportions, et de la convenance avec tous les objects environnans, qui " doivent se presenter sous le même coup d'œil ; c'est a bien disposer tous les objets "sur différens plans, de nanière que l'effet de la perspective semble clonner du move" ment aux differentes parties dont les une paroissent eclairées, les autres dans l'ombre; " dont les unes paroissent venir en avant, tandis que les autres semblent fuir; enfin "c'est à la composer de belles nasses dont les orméments et les details ne combattent " janmais l'effet principal, que doit s'attacher essentiellenent l'architecture."

"Les anciens l'avoient si bien senti, qüils ne se sont jamais occupées dans leur "constructions, que de la grande masse, de manière que les plus precieux ornements "sembloient se confondre dans l'effet general, et ne contrarioient jamais l'objet prin"cipal de l'ensemble, qui annoncoit toujours au premier coup d'ail, par son genre et "ses proportions, le caractere et la destination de leur edifices." 
When a house, as in the foregoing instance, is to be built on the side of a hill, or on an inclined plane, it is hardly possible to dispose it in any other form than that of an extended front: but this supposes a certain degree of property to belong to the house, or it is apt to appear too large for the annexed estate: this objection is however less forcible in a villa than in a mansion; yet even a villa, which covers too much of its own field or lawn, partakes more of ostentation than good taste.

A field of a few acres called Brestry Hill, near Bristol, commands a most pleasing and extensive view. In the foreground are the rich woods of King's Weston, and Blaize Castle, with the picturesque assemblage of gardens and villas in Henbury and Westbury; beyond which are the Severn and Bristol Channel, and the prospect is bounded by the mountains of South Wales. This view is towards the west, and I have generally observed, that the finest prospects in England are all towards this point. ${ }^{\mathrm{d}}$ Yet this, of all aspects, is the most unpleasant for a house; it was not therefore advisable to give an extended front in this direction, yet it would have been unpardonable not to have taken advantage of so fine a prospect.

A compact plan often demands more trouble and contrivance, than a design for a palace, in which the rooms may be so numerous, that different apartments may be provided for summer and

d This remark concerning our finest prospects being towards the west, has been so often confirmed by repeated observations, that I have endeavoured to discover some natural cause for its general prevalence; and perhaps it may, in some degree, be accounted for from the general position of the strata in all rocky countries, which appear to dip towards the east and rise towards the west; in one direction the view is along an inclined plane, in the other, it is taken from the edge of a cliff, or some bold promontory overlooking the comntry towards the west. 
for winter use; lout where compactness and oeconomy are studied. some contrivance is necessary to avail ourselves of views and aspects, without sacrificing convenience and relative fitness to the beauty of the prospect.

Under this restraint perhaps few houses have been built wilb more attention to the situation and circumstances of the place, than the villa at Brentry. The eating-room is to the north, with one window towards the prospect, which may be opened or shut out by Venetian blinds at pleasure. The breakfast roon is towards the south, and the drawing-room towards the prospect.

Modern habits have altered the uses of a drawing-room: formerly the best room in the house was opened only a few days in each year, where the guests sat in a formal circle, but now the largest and best room in a gentleman's house is that most frequented and inhabited: it is filled with books, musical instruments, tables of every description, and whatever can contribute to the comfort or anusement of the guests, who form themselves into groups, at different parts of the room; and in winter, by the help of two fire-places, the restraint and formality of the circle is done away.

This has been often happily effected in old houses by laying two rooms together, preserving the fire-places in their original situations, without regard to correspondence in size or place; but two fires not being wanted in summer, a provision is made in this villa to preserve an additional window towards the fine prospect at that season of the year; and the pannel, which ornaments the end of the room, may be removed in winter, when the window will be less desirable than a fire-place; thus the same room will preserve, in every season, its advantages of 


\section{aspects and of views, while its elegance may be retained without increasing the number of rooms for different purposes.}

- This attention to the wants of different seasons has been too little studied in this country, whilst in France almost every large house has its Garçon tapessier, whose business it is to change the furniture of the apartments for summer and winter. Those who have compared the fitting up of rooms in France, with that of any other country of Europe, must doubtless give the preference to French taste, as far as it relates to the union of internal magnificence and comfort; but those architects who copy both the inside and outsidc of Italian houses, should at least provide for such occasional alterations as our climate may require.

Another circumstance may be mentioned, in which oconomy has been consulted at this small villa. More rooms are generally required on the chamber than on the ground floor; yet, exccpt the kitchen, there is no part of a house which ought properly to be so lofty as the principal rooms; instead, therefore, of increasing the quantity of offices, by what a witty author calls, "turning the kitchen out of cloors for "smelling of victuals," this offence is here avoided by the external passage of communication.

The operations of landscape gardening have often been classed under the general term of improcement; hut there are three distinct species. The first relates to places where the grounds are altered, and aclapted to a house already existing; the second to those where the houses, by additions, having changed their original character or aspect, renders it necessary to make alterations in the ground also; the third includes those places where no house previously exists, and where the entire plan of the house appendages and grounds has sometimes been called a Creation. Of the first kind it is needless to enumerate examples. Among the second may be mentioned those, in which the eutrance of the house being changed, new rooms added, or barns, stables, and kitchen gardens removed, new arrangements have taken place, as at Abingtonilall, Clayberry, Wallitall, West-Coker, Betchworth, Highlands, Brandsury, Holwood, \&c. Of those places which may be called Creations, the number is necessarily small, yet I may refer to the following examples. In some, where new houses were built, I was consulted by the respective arehitects on the situation and appenlages; as at Braconale, Milton House, Donnington, Buckanster, Courteen Hall, Bank Farm, Chilton Lodge, Dulwich Casina, Holme Park, Stre八tham, The Grove, Southgate, Luscombe, \&c. In others I gave general plans for the whole, with the assistance of my Son only in the architectural department, as at Brentry Hill, Cotilam Bank, Organ Hall, Stapleton, Stratton Park, Scarrisbick, Pansilanger, Bayham, \&c. 

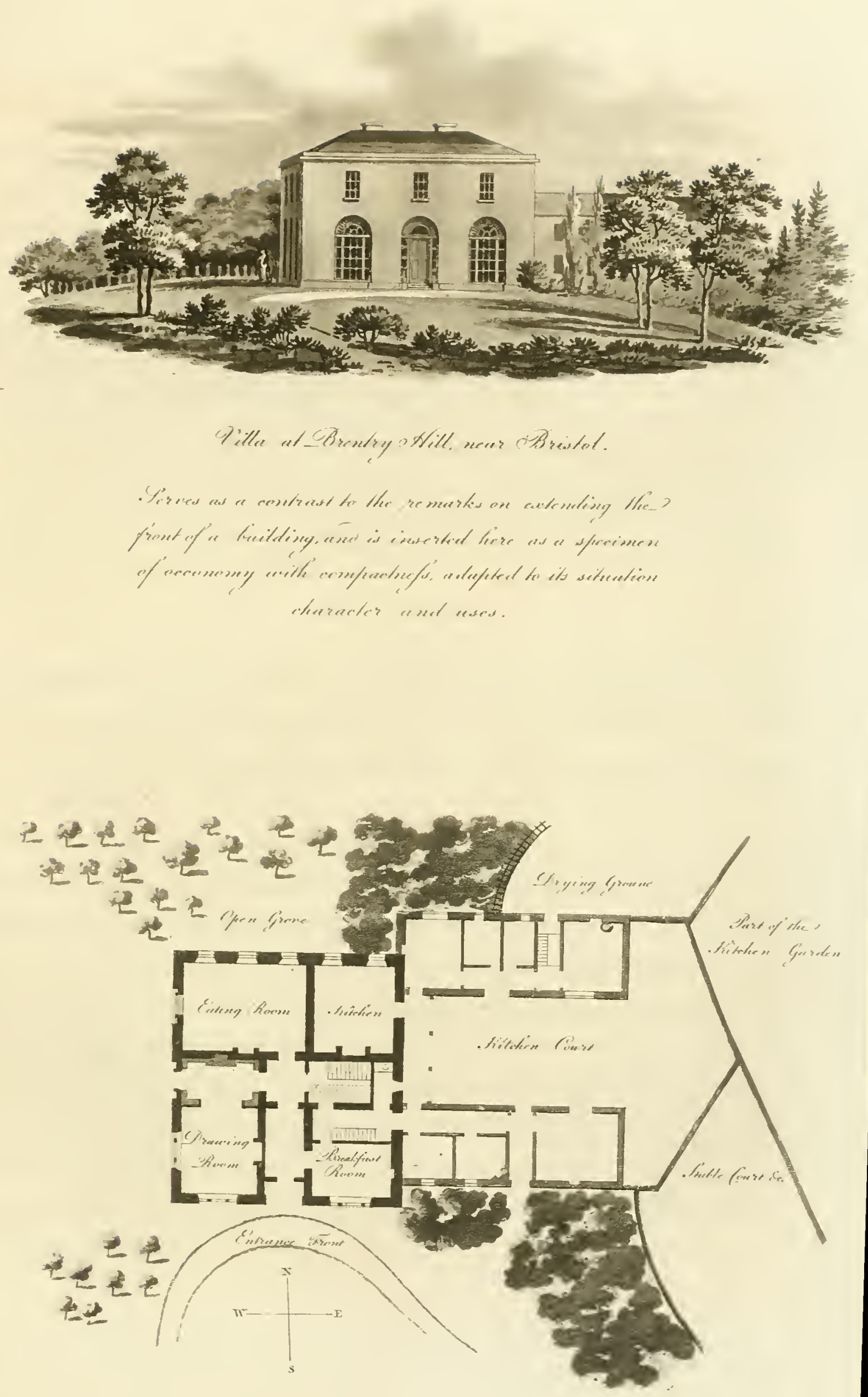



\section{CHAPTER XIII.}

Ancient Mansions - Danger of modemizing - Three characters of Gothic Architecture - for Castlos, Churches, and HousesCorshan House - Mixing Characters, how far allowablePort Eliot - Remarks on Grecian and Gothic Architecture, extracted from the Red Book in the Library of MAGDALEN College, Orford-Example of Additions to the Gothic Mansion of Ashton Court.

The following extract from the Red Book of Corsham, may serve to exemplify the impropriety of improving the grounds. without previous attention to the style, character, and situation of the house.

At the time Corshan House was erected, instead of the modern houses now placed in the centre of parks, distant from every other habitation, it was the glory and pride of an English baron to live in or near the town or village which conferred its title on his palace, and often on himself. Nor was the proximity of the village attended with any inconvenience so long as the house was disjoined from it by ample court yards, or massive gates; some of its fronts might look into a garden, lawn, or park, where the neighbours could not intrude. Yet even these views, in some instances, were confined, formal, and clull, by lofty walls and clipped hedges. 
In determining the situation for a new house, it may often be advisable to place it at a distance from other habitations, that the modern taste for freedom and extent may be gratified; but in accommodating plans of improvement to houses already built, it requires due consideration how far such taste should be indulged, otherwise we may be involved in difficulties and absurdities; for it is not uncommon to begin by removing walls which conceal objects far more offensive than themselves.

When additions or alterations are made to an old house; intemal convenience and improvement should certainly be the first objects of consideration; yet the external appearance and character must not be neglected. This is a circumstance which our ancestors seem to have little regarded, for we frequently distinguish the dates of additions to buildings by the different styles of architecture; and hence it often happens, that a large old house consists of discordant parts mixed together, without any attempt at unity either in date or character of building.

This was of less consequence, when each front, surrounded by its court or parterre, became a separate and entire object; but since modern gardening, by removing those separations, has cnabled us to view a house at the angle, and at once to see two frouts in perspective, we become disgusted by any want of unity in the design.

The south front of Corsham is of the style called Queen Elizabeth's Gothic, although rather of the date of King James. The north front is of Grecian architecture.

The east front is in a correct, but heavy style of regular architecture; and to alter the old south front in conformity to it, wonld not only require the whole to be entirely rebuilt, but 

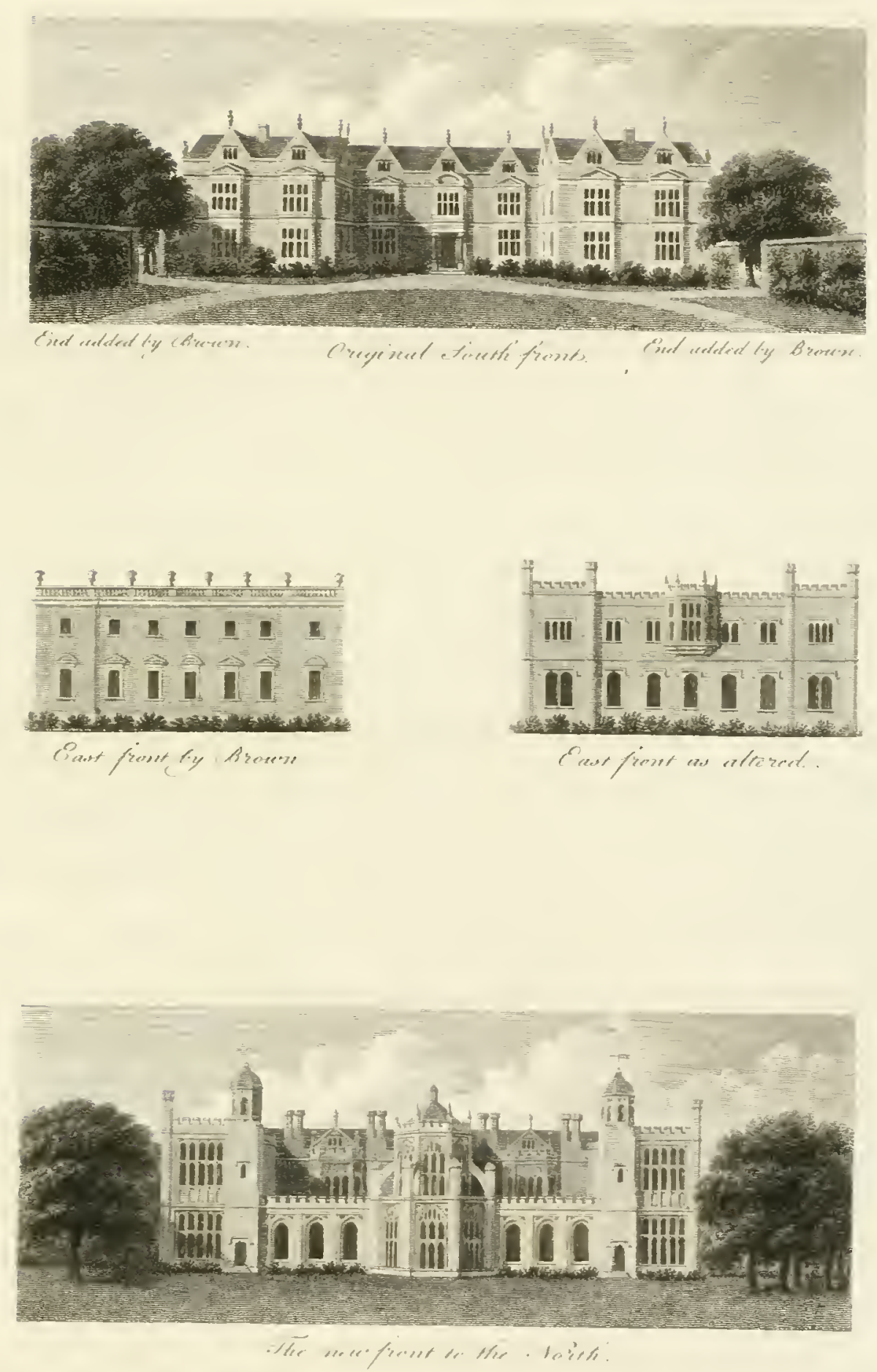
make an alteration of every room in that part of the house unavoidable. This not according with the intention of the proprietor of Consmam House, the original south front becomes the most proper object for imitation.

A house of Grecian architecture, built in a town, and separated from it only by a court-yard, always implies the want of landed property; because being evidently of recent erection, the taste of the present day would have placed the house in the midst of a lawn or park, if there had been sufficient land adjoining: while the mansions built in the Gothic character of Henry VIII, Elizabeth, and James, being generally annexed to towns or villages, far from impressing the mind with the rant of territory, their size and grandeur, compared with other honses in the town, imply that the owner is not only the lord of the surrounding country, but of the town also.

The valuable and celebrated collection of pictures, at Corsu A M House, in a modern Grecian edifice, might appear recent, and not the old inhabitants of an ancient mansion, belonging to a still more ancient family: and although Grecian architecture may be more regular, there is a stateliness and grandeur in the Jofty towers, the rich and splendid assemblage of turrets, battlements, and pinnacles, the bold depth of shadow produced by projecting buttresses, and the irregularity of outline in a large Gothic building, unknown to the most perfect Grecian edifice. 
Gothic structures may be classed under three heads, viz. The Castle Gothic, the. Church Gothic, or the House Gothic: let us consider which is the best adapted to the purposes of a dwelling.

'The Castle Gothic, with few small apertures and large masses of wall, might be well calculated for defence, but the apartments are rendered so gloomy, that it can only be made habitable by enlarging and increasing these apertures, and, in some degree, sacrificing the original character to modern comfort.

The more elegant Church Gothic consists in very large apertures with small masses or piers: here the too great quantity of light requires to be subdued by painted glass; and however beantiful this may be in churches, or the chapels and halls of colleges, it is seldom applicable to a house, without such violence and mutilation, as to destroy its general character: therefore a Gothic house of this style would have too much the appearance of a church; for, I believe, there are no large houses extant of earlier date than Henry VIII, or Elizabeth, all others being either the remains of baronial castles or conventual edifices.

At the dissolution of the monasteries by Henry VIII, a new species of architecture was adopted, and most of the old mansions now remaining in England were either built or repaired, about the end of that reign, or in the reign of Queen Elizabeth: hence it has acquired in our days the name of Elizabeth's Gothic; and although in the latter part of that reign, and in the unsettled times which followed, bad taste had corrupted the original purity of its character, by introducing fragments of Grecian architecture in its ornaments, yet the general character and effect of those houses is perfectly Gothic; and the bold projections, the broad 
masses, the richness of their windows, and the irregular outline of their roofs, turrets, and tall chimnies, produce a play of light and shadow wonderfully picturesque, and in a painter's eye, amply compensating for those occasional inaccuracies urged against them as specimens of regular architecture.

Although the old south front should be the standard of character for the new elevations of Corsham House, yet I hold it not only justifiable, but judicious, in the imitation of any building, to omit whatever is spurious and foreign to its character, and supply the places of such incongruities from the purest examples of the same age. For this reason, in the plans delivered, the Grecian mouldings are omitted, which the corrupt taste of King James's time had introduced, and the true Gothic mouldings of Elizabeth's reign are introduced.

The turrets, chimney shafts, and oriels, will be found in the examples of Burleigh, Blickling, Hampton Court, Hatfield, \&c. or in most of the buildings of Henry VIII, and Elizabeth. The centre of the north front, although of the same character, being in imitation of a building somewhat earlier than Elizabeth, together with the peculiarity of its form, it is necessary to describe why it has been adopted. Here another principle arises, viz. that in designing any Gothic building, it is presumed that some fragments exist of the style we propose to imitate; otherwise it ceases to be an imitation.

In pursuance of this principle, we ${ }^{\mathrm{f}}$ looked for an instance of

'In speaking of this house I use the plural number, because the plans wcre the joint effort of a connexion and confidence which then so intimately existed between me and another professional person, that it is hardly possible to ascertain to whom belongs the chief merit of the design. Yet I claim to myself all that relates to the 
an octangular room projecting beyond the general line of the wall, in some building of that date. The chapel of Henry VII, at Westminster, though not an octagon, was the only projecting regular polygon: this therefore became our model for the centre room of the north front, and this example not only furnished a precedent for a projecting room, but other parts of its composition peculiarly suited our situation.

In the modern rage for removing to a distance all those objects which were deemed appendages to the ancient style of gardening, such as terraces, lofty walls, almshouses, quadrangular courts, \&c. a mistaken idea has prevailed, that the house should stand detached from every surrounding object: this injudicious taste has, in many parts of the kingdom, destroyed towns and villages, to give solitary importance to the insulated mausion.

"The situation of Port Eliot is apparently oppressed by its vicinity to St. Germain's and its stupendous cathedral, whose magnitude and lofty situation forbid its being made subordinate to the mansion. Under such circumstances, instead of shrinking

reasoning and principles on which the character of the house was adopted: to my Son's knowledge and early study of the antiquitics of England, may justly be attributed a full share of the general effect and proportions of the buildings; but as we did not direct the execution of the work, the annexed elevations are on so small a scale, as to describe only the general outline proposed, without copying the detail of what has beell executed. 


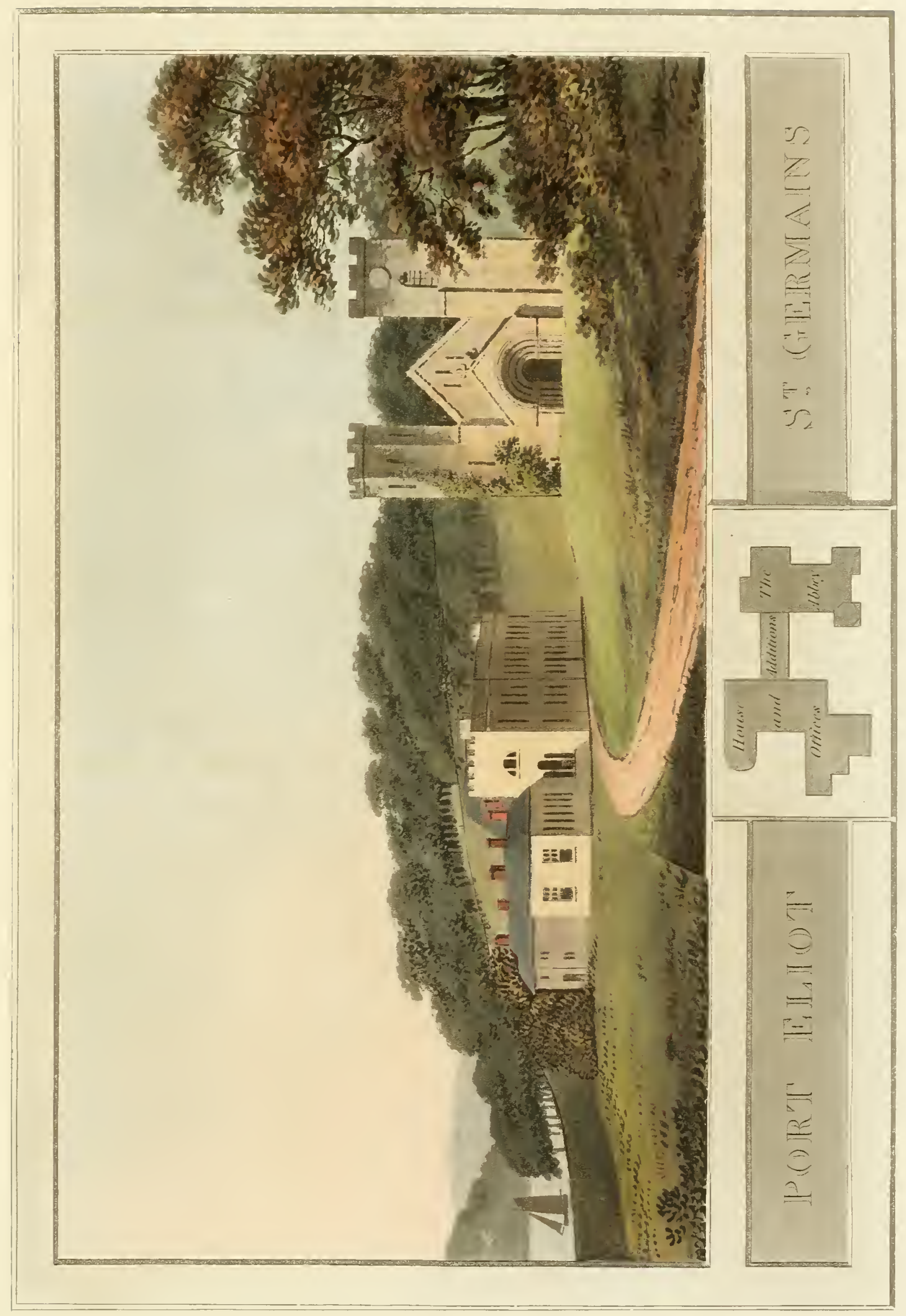





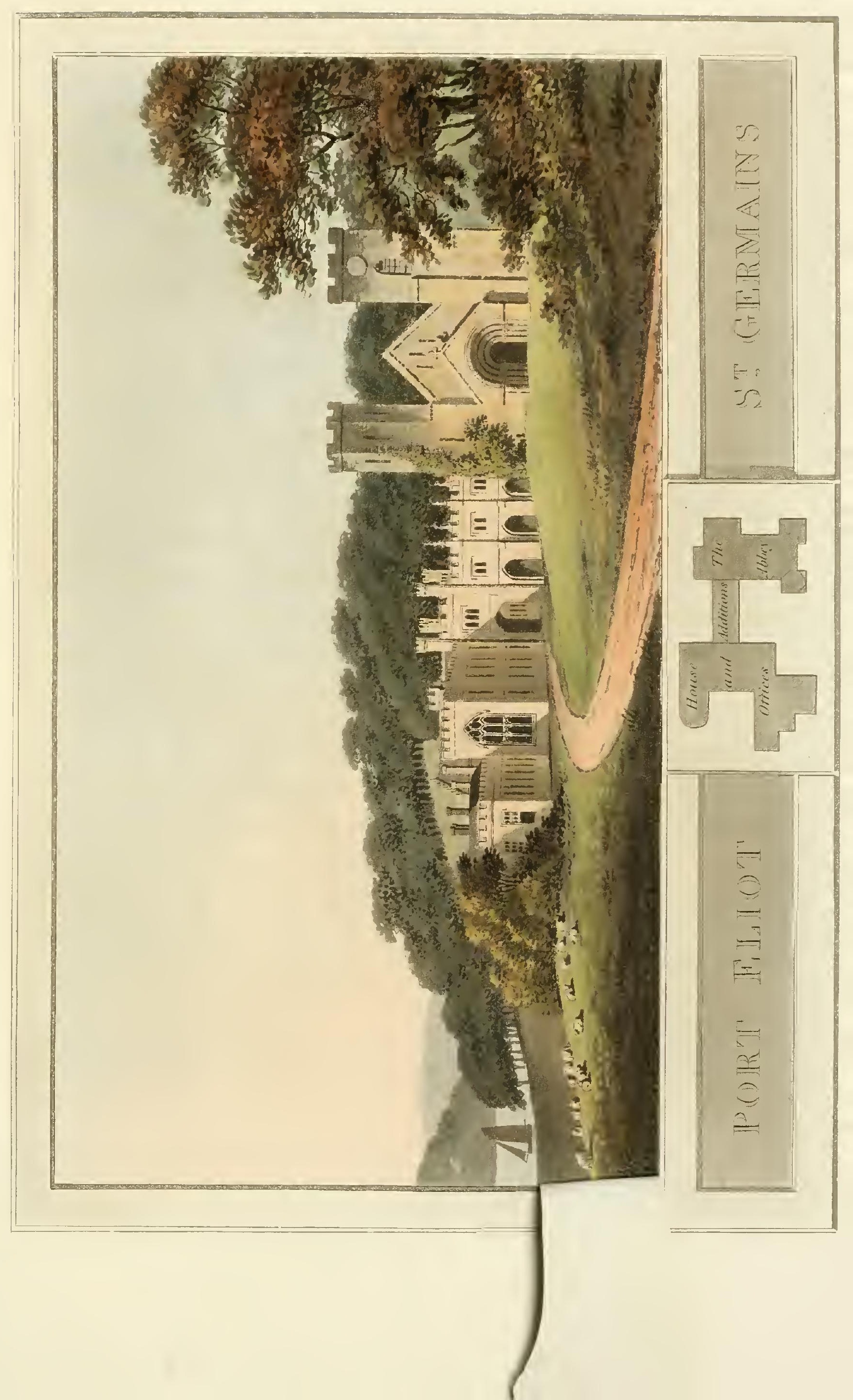



from this powerful neighbour, it will rather be advisable to attempt such an union as may extend the influence of this venerable pile to every part of the mansion.

This I purpose to effect by a narrow building, or cloister, to connect the house with the abbey, as described in the annexed view, in which the plan is purposely introduced to shew how inconsiderable in proportion to the present buildings would be such addition, although it appears to be a work of great magnitude; and this being a deception arising from perspective, I shall explain its cause.

The south front of the house being only about fourscore feet distant from the abbey, it is impossible to view it, except in such perspective as must shew it very much foreshortened. For this reason, as it appears by the drawing, the west end of the house, though containing only two windows, is more conspicuous than the whole south front, in which there are twentysix; it is therefore the more necessary that this small part of the building which faces the west should be enriched by such ornaments as may be in harmony with the Gothic character of the abbey: the Venetian window, and the paladian window over it, may be externally united into one Gothic window, which, by its size and character, will extend the importance of the abbey to the whole of the mansion..$^{g}$

A large window is necessary, because a number of small parts will never constitute one great whole; but if a few large parts, such as the window here mentioned, the gateway, and

${ }^{8}$ A beautiful specimen of thus uniting two floors by one window, may be seen at Sheffield Place, where, I believe, it was first introduced by Mr. James Wyatt.

$2 \mathrm{c}$ 
another large window in the cloister, be properly introduced, they will extend the impression of greatness, and overpower all the lesser parts of the building in the same manner that the great west entrance of the abbey takes off the attention from the smaller windows in the same massive pile.

It may perhaps be observed, that in the cloister proposed, J have not strictly followed the architecture of the abbey, which is either Saxon or Norman, (a distinction in which very learned antiquarians have differed in opinion). It is certainly of a style anterior to the kind of Gothic distinguished by pointed arches and pinnacles. But I conceive there is no incongruity in mixing these different species of Gothic, because we see it done in every cathedral in the kingdom; indeed the greatest part of this abbey itself is of the date and style which I have adopted.

The following remarks on the improvement of MAGDALEN College, Oxford, were accompanied with many drawings, on a scale too large for this work; but as the book is in the library of that college, I suppose such of my readers as are interested in these observations concerning Grecian and Gothic architecture, may have access to the original designs, if they wish farther to consider the subject; at the same time their enquiries will be facilitated by having previously perused the following extract from that manuscript. 


\section{5}

"The love of novelty and variety, natural to man, is alone sufficient to account for the various styles of building with which our universities abound.

When Grecian architecture was first introduced into this country, it was natural to adopt the new style, without considering how far its uses or general character might accord with the buildings to which it was applied; and, without recollecting the elimate from whence it was imported, every other consideration was sacrificed, or made subservient to the external ornaments of Greece and Rome. ${ }^{\mathrm{h}}$ On a more exact enquiry, we shall find, it was not the habitable buildings of ancient Greece or Rome which formed our models: the splendid and magnificent remains of Athens, of Palmira, of Balbec, of Pæstum, or of Rome herself, supply only temples with columns, entablatures, and porticos, but without windows or chimneys, or internal subdivisions by floors for apartments, indispensable in our English habitations, and even to our public buildings.

In this climate we should seldom visit a hall, or a chapel, where all the light admitted was from the entrance, or from an uneovered aperture in the roof; and on such plans were eonstructed all the temples of the ancients.

Our students in architeeture, who have visited southern climates, were therefore obliged to copy the works of more

${ }^{b}$ Among the conveniencies olservable in Gothic colleges, may be mentioned the uninterrupted communication; this was formerly provided for by cloisters, that each member of the society might at all times, in all weather, walls under cover from his respective apartment to the hall, the chapel, the library, or to the apartment of any other member. Such cloisters also yielded a dry and airy walk when the uncertainty of our climate would otherwise have prevented that sort of moderate exercise necessary to the sedentary occupations of the lcarned. 
modern artists, who, by various expedients, had endeavoured to make their buildings habitable; and from the modem Italian, rather than from the buildings of ancient Rome, have been introduced, floors intersecting the shaft of a lofty column, or, what is still more offensive, columns of various orders, built over cach other; while the whole face of the building is cut into minute parts by ranges of square apertures. Having at length discovered how seldom a very lofty portico ${ }^{i}$ can be useful in this climate, where we have little perpendicular sun, the portico itself is filled up with building, and the columns are nearly half buried in the walls: this is the origin of that unmeaning ornament called a three quarter column.

By degrees these columns were discovered to be totally useless, and were at length entirely omitted: yet the skeleton of the portico and its architectural proportions still remain, as we frequently observe in the entablature and pediment of what is called a Grecian building.

This is all that remains of Grecian architecture in the present new building at Magdalen College; yet from its simplicity we are still pleased with it, and more from its utility, because it evidently appears to be a succession of similar apartments for the separate habitations of a number of members of the same

'I have frequently smiled at the incongruity of Grecian architecture applied to buildings in this country, whenever I have passed the beautiful Corinthian portico to the north of the Mansion House, and observed, that on all public occasions it becomes necessary to erect a temporary awning of wood and canvas to guard against the iuclemency of the weather. In southern climates, this portico, if placed towards the soutli, would have afforded shade from the vertical rays of the sun; but in our cold and rainy atmosphere, such a portico towards the north, is a striking instance of the false application of a beautiful model. 
society, equal in their rank and in their accommodations, and only claiming that choice of aspect or situation which seniority or priority confers.

It has been observed, that the age of every manuscript is as well known to the learned antiquarian from the letters or characters, as if the actual date were aflixed. The same rule obtains in architecture. And even while we profess to copy the models of a certain æra, we add those improvements or conveniencies which modern wants suggest; and thus in after ages the dates will never be confounded.

In Gothic, which is the style of architecture most congenial to the uses and to the character of a college, we are to study first, the general and leading principles, and afterwards that detail, of which we can collect the best specimens from buildings of the date we mean to imitate.

The leading principles of all Gothic buildings were these:

1. The Uses of a building were considered before its Ornaments.

This principle is obvious in the staircases of towers, which were generally made in a turret at one corner, larger than the other three, and often carried up higher to give access to the roof of the building. Small turrets and pinnacles, or fineals, will be considered only as ornaments by the careless observer, but the mathematician discovers that such projections above the roof, form part of its construction; because they add weight and solidity to those abutments which support the Gothic arch.

2. The ornaments prevailed most where they would be inost conspicuous.

The richest ornaments of Gothic architecture are the turrets, pimacles, or open battlements on the top of the building. These were seen from all parts, and in the 
beautiful tower at Magdalen, it may be observed, that the enrichment ceases below, where it would not be so much seen. The gates and entrances are highly ornamented, because they are immediately subject to the eye; but the walls are frequently without any decoration. This cconomy in ornaments is confirmed by the laws of nature. See page 161.

3. The several principal parts of the building were marked by some conspicuous and distinguishing character.

As the chapel, the hall, the chapter-room, and the bishop's, abbot's, or president's habitation, \&c. The dormitories were not less distinguished as a suite of similar apartments. But where, in conformity to the modern habits of symmetry, it is necessary to build two parts cxactly similar, it is dificult for a stranger to distinguish their separate uses.

4. Some degree of symmetry, or correspondence of parts, was preserved, without actually confining the design to such regularity as involved unnecessary or useless buildings.

This irregularity, which has been already noticed in speaking of the towers for staircases, is carried still farther in those projections, by which an apparent centre is marked: for if any ancient (iothic building be attentively examined, it will be found that the apparent centre is seldom in the middle. Thus in the beautiful cloister of Magdalen, the gateway is not in the centre of the west, nor the large window of the hall in the centre of the south side of the quadrangle; yet the general symmetry is not injured, and the dimensions are perhaps enlarged by this irregularity.

5. This degree of irregularity seems often to have been studied in order to produce increased grandeur by an intricacy and variety of parts. A perfect correspondence of two sides assists the mind in grasping the whole of a design on viewing only one-half; it therefore, in fact, lessens the apparent magnitude, while the difficulty with which dissimilar parts are viewed at once, increases the apparent dimensions, provided the eye be not distracted by too much variety. 
The frequency of Gothic towers having been placed at a different angle with the walls of the chapel, must have been more than accident. The position of the tower at Magdalen, with respect to the chapel, is a circumstance of great beauty when seen from the centre of the cloisters, because two sides are shewn in perspective. And upon actual measurement it will be discovcred that few quadrangular areas are correctly at right angles.

And lastly, The effect of perspective, and of viewing the parts of a building in succession, was either studied, or chance has given it a degree of interest, that makes it worthy to be studied: since every part of a building is best seen from certain points of view, and under certain relative circumstances of light, of aspect, of distance, or of comparative size.

The great scale on which Gothic architecture was generally executed, is one source of the grand impression it makes on the mind, since the most correct modcl of a cathedral would convey no idea of its grandeur. The false Gothic attempts of our modern villas, offend as much by their littleness as by the general incorrectness of detail.

The Red Book in Magdalen College contains such examples and remarks, concerning the detail of Gothic architecture, as might be curious to the antiquarian; but which can only be understood by the numerous drawings with which the subject was elucidated.

Having assigned as a reason for writing in the plural number in the Red Book of Consham, that a third person was there consulted, it may perhaps be proper to mention, that in the architectural part of the plans for Magdalen College, and all the other buildings described in this volume, I lave been assisted by my son only. 
The annexed plate of Asnton Court fumishes an example of making considerable additions to a very ancient mansion, without neglecting the comforts of modern life, and without mutilating its original style and character.

This house was built about the reign of Henry VI, and originally consisted of many different courts, surrounded by building, of which three are still remaining; in all these the Gothic windows, battlements, and projecting buttresses, have been preserved; but the front towards the south, 150 feet in length, was built by Inigo Jones, in a heavy Grecian style; this front was designed to form one side of a large quadrangle, but from the unsettled state of public affairs, the other three sides were never added, and the present long front was never intended to be seen from a distance: this building consists of a very fine gallery, which has been shortened to make such rooms as modern habits require; but it is now proposed to restore this gallery to its original character, and to add in the new part, a library, drawing-room, eating-room, billiard-room, with bedrooms, dressing-rooms, and a family apartment, for which there is no provision in the old part of the mansion. It is also proposed to take down all the ruinous offices, and rebuild them with the appearance of antiquity, and the conveniencies of modern improvement.

If, in conformity to buildings of this date, the courts were all to be preserved, and surrounded with buildings, or lofty walls, the damp and gloom, as well as the grandeur of former times, would be recalled; but by opening the side of these courts to the park with an iron rail, cheerful landscapes will be admitted; and by keeping the buildings in some parts low, 



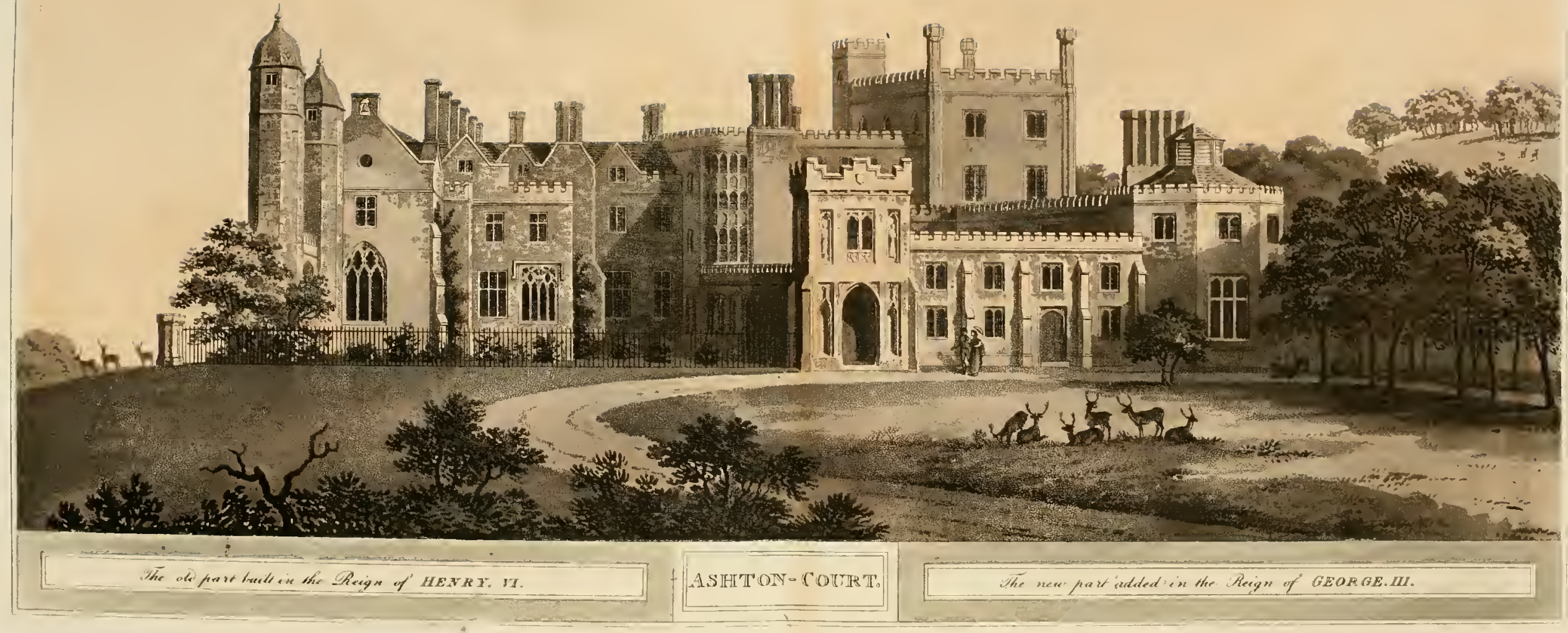


a free circulation of air will be encouraged, and the more lofty buildings rising above these subordinate ones, will produce that degree of grandeur and intricacy exemplified in the east view of Ashton Court.

The old part (as distinguished in the plate) consists of the hall, the chapel, and the two turrets; but no part of the gallery added by Inigo Jones is visible, except the chimneys in perspective. The new part consists of the entrance porch, and cloister, which supplies a covered way to the great hall, and forms one side of a quadrangle. ${ }^{k}$

Over this low range of offices the more lofty range of new building appears, consisting of a large square torver, which will also be seen rising above the long south front. In that part which joins the new to the old buildings, are a dressing-room and boudoir, lighted by a bow window, placed at the angle in such direction as to command an interesting view of Bristol, and the river Avon, with its busy scene of shipping. To take advantage of this view from a house in the country, may appear objectionable to some; but I consider it among the most interesting circumstances belonging to the situation of Ashtor Court. To the wealthy mechanic, or the more opulent merchant perhaps, the view of a great city may recall ideas of labour, of business, of difficulty and dangers, which he would wish to

${ }^{k}$ The idea of an octagon kitchen is taken from that still remaining among the ruins of Glastonbury Abbey: I mentioned it to the architect engaged at KENWOOD many years ago, and I have since observed it is introduced at CASHIOBURY, with admirable effect, by Mr. James Wyatt, under whose direction that ancient abbey has been lately altered with such good taste and contrivance, that I shall beg leave to refer to it as a specimen of adapting ancient buildings to modern purposes. 
forget in the serenity of the country; but the country gentleman, who never visits the city but to partake in its amusements, has very different sensations from the distant view of a place which by its neighbourhood increases the value and the enjoyment of his estate.

A general idea prevails, that in most cases it is better to rebuild than repair a very old house, and the architect often finds less difficulty in making an entire new plan, than in adapting judicious alterations; but if a single fragment remains of the grandeur of former times, whether of a castle, an abbey, or even a house of the date of Queen Elizabeth, I cannot too strongly inforce the propriety of preserving the original character of such antiquity, lest every hereditary mansion in the kingdom should dwindle into the insignificance of a ${ }^{1}$ modern villa.

${ }^{1}$ There is not more false taste in adding pointed arches, and wooden battlements, to a modern building, than in cutting off the projections, filling up the recesscs, and mutilating thic picturesque appendages of a true Gothic structure. 



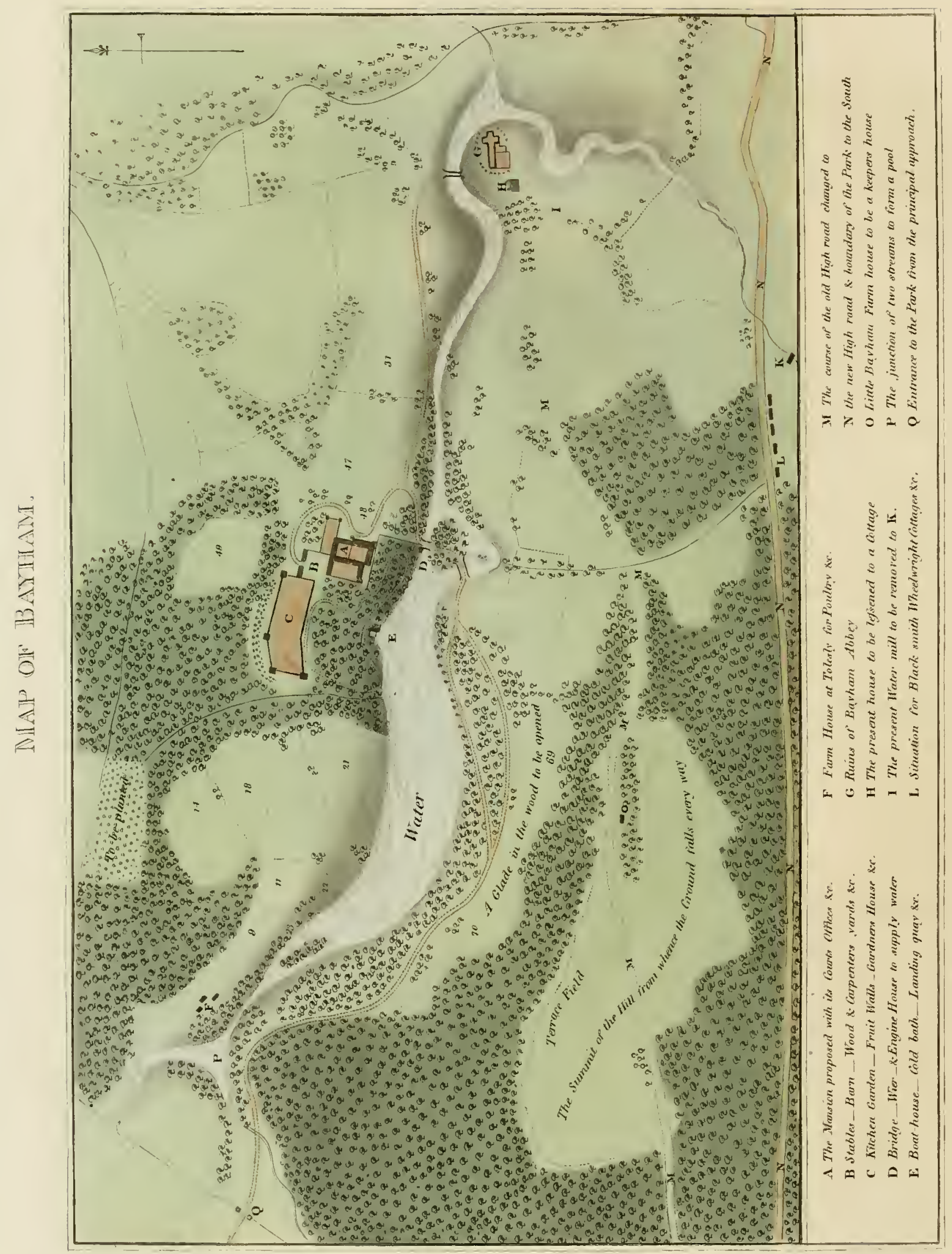




\section{CHAPTER XIV.}

Application of Gardening and Architecture united in the Formation of a new Place-Example from $\mathrm{B}_{\mathrm{A} \text { Y }}$ - E $\mathrm{A}$ - River-LakeThe House-Charater-Observations on Grecian Houses Characteristic Architecture-External Gothic not incompatible with Comfort-How far it should prevail internally.

The necessity of uniting architecture and landscape-gardening, is so strongly elucidated in the Red Book of BAyHAM, that I gladly avail myself of the permission of its noble possessor to insert the following observations: but as the ruins of Bayham Abbey are generally known to those who frequent Tunbridge Wells, it is necessary to premise that the situation proposed for a new house, is very different from that of the abbey.

"No place concerning which I have had the honour to be consulted, possesses greater variety of water, with such difference of character as seldom oceurs within the limits of the same estate.

The water near the abbey, now intersecting the meadow in various ehannels, should be brought together into one river, winding through the valley in a natural course: this may be so managed as to drain the land while it improves the scenery; and I suppose the whole of this valley to be a more highly dressed lawn, fed by sheep and cattle, but without deer. 
Above this natural division the water will assume a bolder character; that of a lake, or a broad river, filling the entire bottom of the valley between two wooded shores, and dashing the foot of that steep bank on which the mansion is proposed to be erected. This valley is so formed by nature, that an inconsiderable dam will canse a lake, or rather broad river, of great apparent extent: for when I describe water, I never estimate its effects by the number of acres it may cover; but by its form, its continuity, and the facility with which its termination is concealed.

Where a place is rather to be formed, than improved, that is, where no mansion already exists, the choice of situation for the house will, in some measure, depend on the purpose for which it is intended, and the character it ought to assume: thus a mansion, a villa, and a sporting seat, require very different adaptation of the same principles, if not a variation in the principles themselves. The purpose for which the house at BAYHAM is intended must decide its characier: it is not to be considered as a small villa, liable to change its proprietor, as good or ill success prevails; but as the established mansion of an English nobleman's family. Its character, therefore, should be that of greatness and of durability. The park should be a forest, the estate a domain, the house a palace. Now, since magnificence and compactness are as diametrically opposite to each other as extension and contraction, so neither the extended scale of the comtry, nor the style, nor the character of the place, will admit of a compact house.

In determining effects it is not sufficient to consider merely the size of the building; but as all objects appear great or small 
only by comparison, it is also necessary to consider the sizc and character of those by which this mansion will be accompanied.

The surrounding scenery of $\mathrm{B}_{\text {AYнам }}$ must influence the character of the house, we must therefore consider what style of architecture will here be most appropriate. There has ever. appeared to me something wrong, or misunderstood, in the manner of adapting Grecian architecture to our large mansions in the country: our professors having studied from models in a different climate, often forget the difference of circumstances, and shew their classic taste, like those who correctly quote the words, but misapply the sense of an author. The most striking feature of Grecian architecture is a portico, and this, when it forms part of a temple or a church, may be applied with propriety and grandeur; but when added to a large house, and intersected by two or three rows of windows, it is evidently what in French is called in Appliqué, something added, an after thought; and it has but too often the appearance of a Grecian temple aficed to an English cotton mill.

There is also another circumstance belonging to Grecian architecture, viz. symmetiy, or an exact correspondence of the sides with each other. Symmetry appears to constitute a part of that love of order so natural to man; the first idea of a child in drawing a house, is to make the windows correspond, and, perhaps, to add two correspondent wings.

There are, however, some situations where great magnificence and convenience are the result of a building of this description; yet it can only be the anse where the house is so large, that one of the wings may contain a complete suite of 
private apartments comnected with the house by a gallery or library, while the other may consist of a conservatory, \&c.

Every one who has observed the symmetrical elevations scattered round the metropolis, and the small houses with wings, in the neighbourhood of manufacturing towns, will allow that symmetry so applied, is apt to degenerate into spruceness; and of the inconvenience of a house separated from its offices by a long passage (however dignified by the name of colonnade) there cannot surely be a question. There is yet another principle which applies materially to $\mathrm{B}_{A}$ Y HAM, viz. that symmetry makes an extensive building look small, while irregularity will, on the contrary, make a small building appear large: a symmetrical house would therefore ill accord with the character of the surrounding country.

Having expressed these objections against the application of Grecian architecture, before I describe any other style of house I shall introduce some remarks on a subject which has much engaged my attention, viz. the adaptation of buildings not only to the situation, character, and circumstances of the scenery, but also to the purposes for which they are intended; this I shall call Characteristic Architecture.

Although it is obvious that every building ought "to tell its own tale," and not to look like any thing else; yet this principle appears to have been lately too often violated: our hospitals resemble palaces, and our palaces may be mistaken for hospitals; our modern churches look like theatres, and our theatres appear like warehouses. In surveying the public buildings of the metropolis we admire St. Luke's Hospital as a mad-house, and 
Newgate as a prison, because they both announce their purposes by their appropriate appearance, and no stranger has occasion to enquire for what uses they are intended.

From the palace to the cottage this principle should be observed. Whether we take our models from a Grecian temple, or from a Gothic abbey, from a castle, or from a college, if the building does not look like a house, and the residence of a nobleman, it will be ont of character at BAYInм. It may perhaps be objected, that we must exactly follow the models of the style or date we mean to imitate, or else we make a pasticcio, or coufusion of discordant parts. Shall we imitate the thing, and forget its application? No! let us rather observe how in Warwick Castle, and in other great mansions of the sane character, the proud baronial retreat " of the limes of old," has been adapted to the purposes of modern habitation. Let us preserve the massive strength and durability of the castle, and discard the gloom which former tyranny and cruelty inspired; let us preserve the light elegance of Gothic abbeys in our chapels, but not in our houses, where such large and lofty windows are inadmissible; let us, in short, never forget that we are building a house, whether we admire and imitate the bold irregular outline of an ancient eastle, the elegant tracery in the windows of a Gothic church, or the hamony of proportions, and the symmetrical beauty of a Grecian temple.

Of the three distinct characters, the Castle, the Abbey, and the House-Gothic, the former of thesc appears best calculated for Baymam. Yet as the object is not to build a castle, but al house, it is surely allowable to blend with the magnificence of this character the advantages of the other two, as well as the 
elegance, the comfort, and the convenience of modern habitation. It may be urged, that the first purpose of a castle is, defence; that of a house, habitation; but it will surely be allowed, that something more is required than the mere purposes of habitation. An ordinary carpenter may build a good room; a mechanic rather more ingenious may connect a suite of rooms together, and so arrange their several offices and appendages as to make a good house; that is, a house sufficient for all the purposes of habitation. But an architect will aim at something higher; he will add to the internal convenience, not merely external beauty, but external propriety and character; he will aim not only to make a design perfect in itself, but perfect in its application.

Where the lawn, the woods, the water, the whole place, and the general face of the surrounding country, are on so extensive a scale, the only means of preserving the same character is, by extending the plan of the house also. How can this be effected unless we adopt the Gothic style of architecture? In Grecian or modern buildings, it has been considered an essential part of the plan to conceal all the subordinate appendages of the mansion, such as the stables, the offices, the garden walls, \&c, and why? Because they neither do, nor can partake of the character of the house; and the only method by which this extension of site is usually acquired in a Grecian building, is, by adding wings to the house. Thus the same mistaken principle obtains, and is considered material, for it is a part of the duty of these wings to conceal the offices. But if continuity be an essential cause of the sublime, if extension be an essential cause of magnificence, whatever destroys continuity weakens 



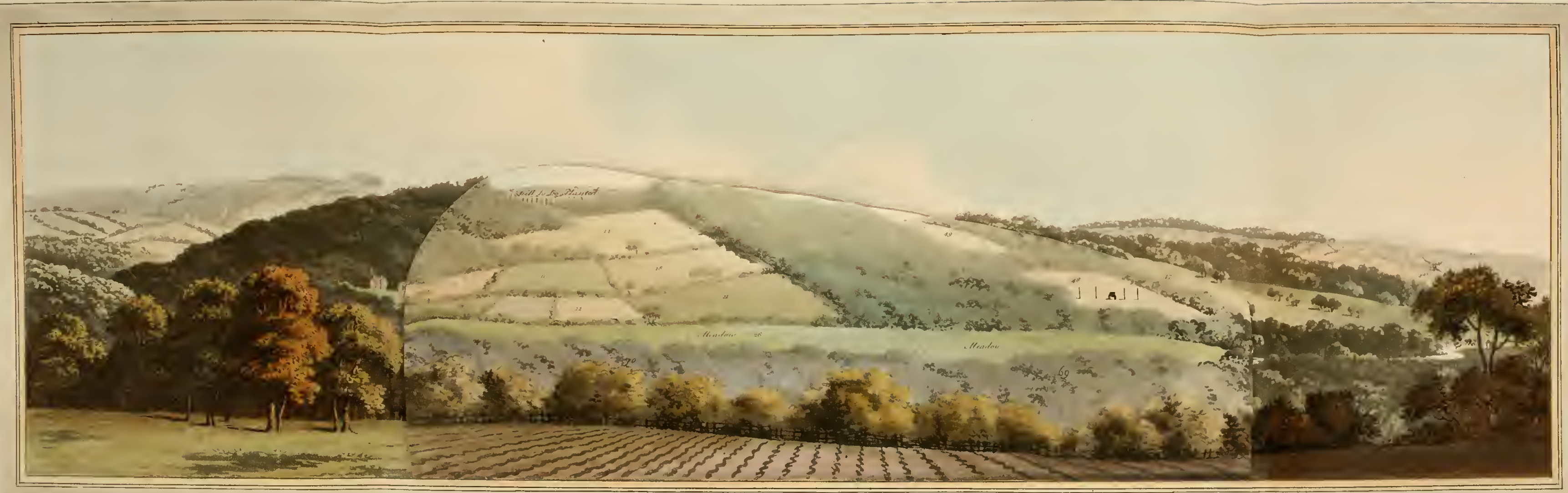

GENERAL TIEW OF BAYHATI 


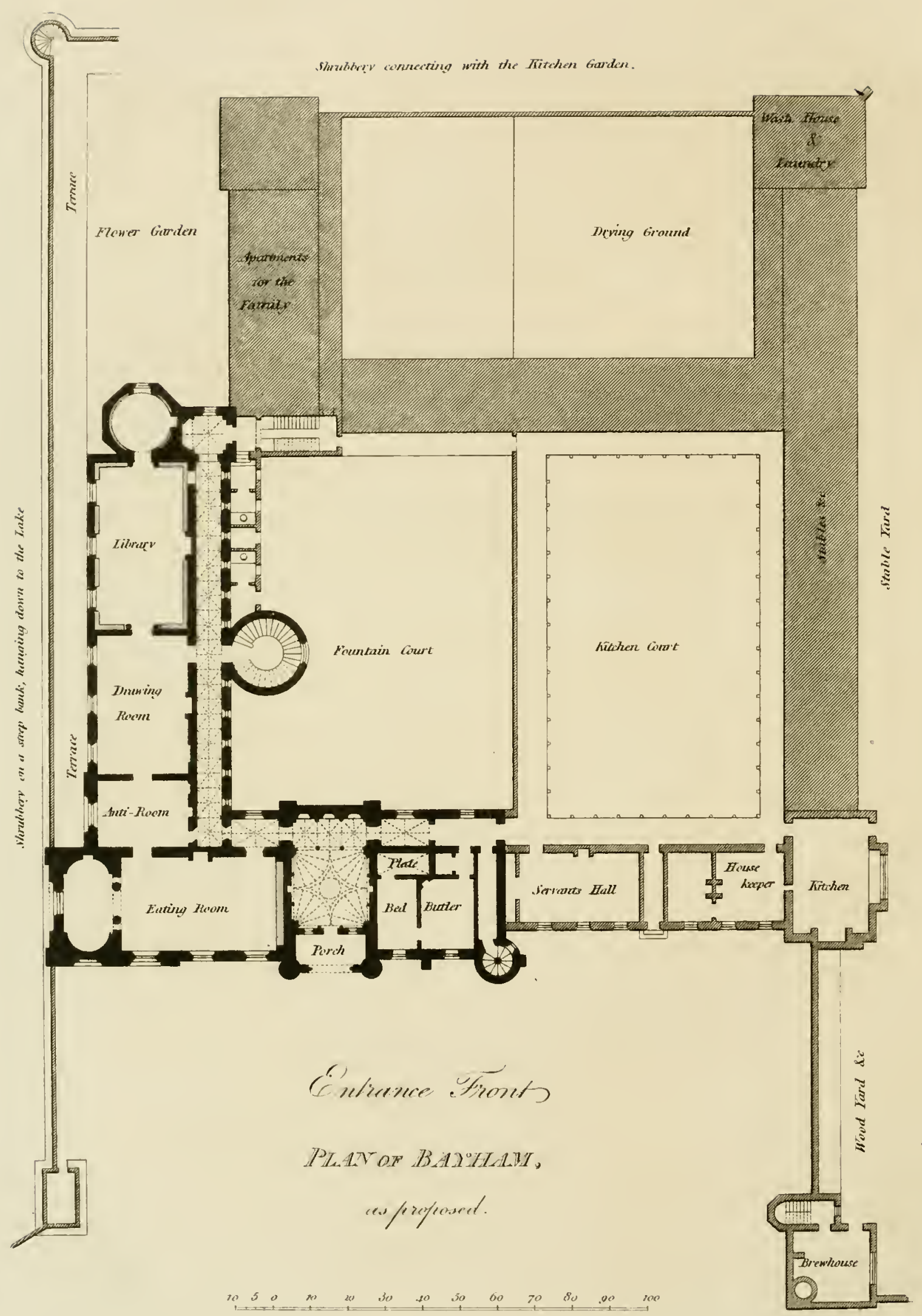


the sublime, and whatever destroys extension lessens magnificence; therefore as the oflices and court-yards attached to a honse, are generally five times more extensive than the honse itself: where magnificence is the object, why neglect the most effectual means of creating it? viz. continnity and extension, blended with unity of design and character: or, in other words, when it is desirable to take advantage of every part of the buildings, why conceal five parts in six of them?

If the truth of this principle be allowed, I trust the propriety of its application will be obvions, and for its effect I appeal to the following sketch, where both the actual size of the honse, and its comparative proportion to the surrounding scenery, are correctly ascertained.

However pleasing these representations may appear, I should consider myself as having planned a "castle in the air," unless it should be proved that this design is not only practicable, but that it actually contains no more building than is absolutely necessary for the purposes of modem habitation. By the plan it appears to contain,

1. A Gothic hall, for the sake of ancient grandeur, but leading through a passage lower than the roons, for the sake of not depressing their comparative height. The hall and passages should be rather dimly lighted by painted glass, to impress a degree of gloom essential to granderr, and to render the entrance into the rooms more brilliant and cheerful.

This, it may be objected, is in character with those houses which Gray describes as having

"Winclows that exclude the light,

"And passages that lead to nothing." 
Yet I trust these passages will be found no less useful than magnificent; they lead to the several rooms, which form a complete suite of apartments, consisting of eating-room, breakfast-room, draving-room, and library. The rooms all open by windows to the floor on a terrace, which may be enriched with orange trees and odoriferous flowers, and will form one of the greatest luxuries of modern, as well as one of the most magnificent features of ancient habitation.

It now remains for me to shew that I have not suggested a design more expensive, than a house of any other character, containing the same number of apartments. The chief difficulty of building arises from the want of materials. A house of Portland stone would be very expensive. A red brick house, as Mr. Brown used to say, "puts the whole valley in a fever." A house of yellow brick is little better. And the great Lord Mansfield often declared, that had the front of Kenwood been originally covered with Parian marble, he should have found it less expensive than stucco. Yet one of these must be used in any building except a castle; but for this the rude stone of the country, lined with bricks or faced with battens, will answer every purpose; because the enrichments are few, except to the battlements and the entrance tower, which are surely far less expensive than a Grecian portico.

The attached offices, forming a part of the front, are so disposed as to lie perfectly convenient to the principal floor and to the private apartments, while the detached offices, the courtyards, and eren the garden-ivalls, may be so constructed and arranged, as to increase in dimensions the extent of the castle. This unity of design will be extended from the house to the 
water, by the boat-house, the cold-bath, and the walls with steps leading to a bridge, near which the engine-house may form a barbican, and contribute to the magnificent effect of the picture, as well as to the general congruity of character.

When we look back a few centuries, and compare the habits of former times with those of the present, we shall be apt to wonder at the presumption of any person who shall propose to build a house that may suit the next generation. Who, in the reign of Queen Elizabeth, would have planned a library, a music-room, a billiard-room, or a conservatory? Yet these are now deemed essential to comfort and magnificence: perhaps, in future ages, new rooms for new purposes will be deemed equally necessary. But to a house of perfect symmetry these can never be added: yet it is principally to these additions during a long succession of years, that we are indebted for the magnificent irregularity, and splendid intricacy, observable in the neighbouring palaces of Knowle and Penshurst. Under these circumstances, that plan cannot be good which will admit of no alteration.

"Malum consilium est, quod non mutari potest."

But in a house of this irregular character every subsequent addition will increase the importance: and if I have endeavoured to adopt some of the cumbrous magnificence of former times, I trust that no modern conveniences or elegances will be unprovided for. 
It has been doubted how far a house, externally ${ }^{m}$ Gothic, should internally preserve the same character, and the most ridiculous fancies have been occasionally introduced in libraries and eating-rooms, to make them appear of the same date with the towers and battlements of a castle, without considering that such rooms are of modern invention, and consequently the attempt becomes an anachronism: perhaps the only rooms of a house, which can with propriety be Gothic, are the hall, the chapel, and those long passages which lead to the several apartments; and in these the most correct detail should be observed. As a specimen of internal Gothic, my son has inserted a design for a Gothic hall, which is supposed to occupy two stories: yet the comparative loftiness will not depress the height of the rooms, because the gallery which preserves the connexion in the chamber floor, marks a decided division in the height; and as this hall ought not to open into any room without an intermediate, and lower passage, the several apartments will appear more lofty and magnificent.

It has occasionally been ohjected to Gothic houses, that the old form of windows is less comfortable than modem sliding sashes; not considering that the square top to. a window is as much a Gothic form as a pointed arch, and that to introduce sash frames, as at Donnington, we have only to suppose the mullions may have been taken out without injuring the general effect of the building; while, in some rooms, the ancient form of window with large mullions may be preserved. Those who have noticed the cheerfulness and magnificence of plate glass in the large Gothic windows of Cashiobury and Cobmas, will not regret the want of modern sashes in an ancient palace. 


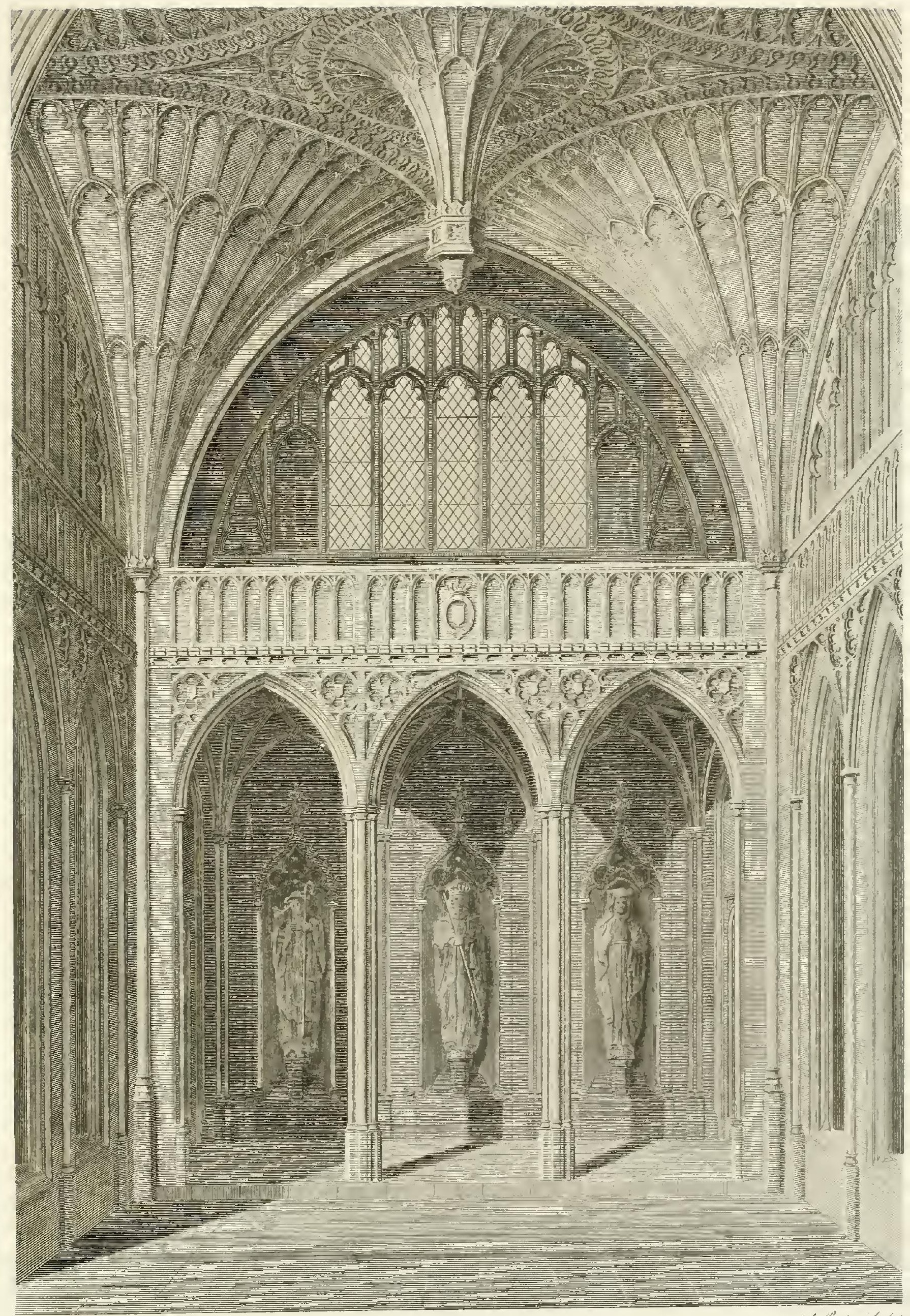

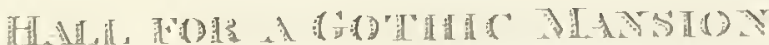





\section{CHAPTER XV.}

Conchusion-Concerning Colou-New Thenry of Colours and Shadows, by Dr. Milner-Application of the sameHarmony-Discord-Contrast-Diffculty of Comparisons between Art and Nature.

THE Arl of Painting has been usually treated under four distinct heads, viz.

Composition. Design, or Drawing. Expression, and Colouring. Each of which may, in some measure, be applied to Landscape Gardening, as it has been treated in this work.

Composition, includes those observations on utility, scale, perspective, \&c. contained in Chap. I, and II.

Design, may be considered as belonging to the remarks on water, wood, fences, lines, \&c. contained in Chap. III, IV, V, VI, and VII.

Expression, includes all that relates to character, situation, arrangement, and the adaptation of works of art to the scenery of nature, which have been discussed in the remaining chapters of this work; and lastly, Colouring, so far as it relates to certain artificial objects, has been mentioned in Chap. XI. 
Having since been led to consider this subject more attentively, in consequence of a conversation with Mr. Wilberforce concerning a new theory of colours and shadows, I have, through his intervention, obtained permission to emrich my work with the following curious remarks: and as Mr. Wilberforce, in his letter which inclosed them, observes of their reverend and learned author, that "He is a man unequalled for the store of knowledge " he possesses, for the clearness with which he views, and the " happy perspicuity with which he communicates his concep" tions," so I shall give this theory in his own words.

\section{THEORY OF COLOURS AND SHADOWS,}

By the Rer. Dr. MILNER, F.R.S.

DRAN OF CARLISLE, AND PRESIDENT OF QUEEN'S COLLEGE, CAMBRIDGE.

Sect. 1. Several years ago some curious questions, concerning the colours of the shadows of bodies, were proposed to me by an ingenious and philosophical friend, who himself can paint very well, and is an excellent judge of colours. He first mentioned the following facts.

2. Supposing a piece of writing paper to be weakly illumined by zohite light, and at the same time to have a strong red light thrown upon it by any contrivance, the shadow upon the paper, of a body placed in the said red light, will be green.

3. Or, vice versâ, if a strong green liglit be thrown upon the same paper, the sliadow of a body placed in the green light will be red.

4. Under similar circumstances, the shadow of a body intercepting orangecoloured light will be blue, purple, or almost violet, according as the orange light contains more or less red; and vice versâ.

5. And lastly, the shadow of a body which intercepts yellow light will be purple, and vice versî.

6. The phænomena just mentioned may be cxhibited in several ways. The weak white light may always be had in a dark room, either by admitting a small portion of claylight, or by means of a small lamp or wax taper, the light of which is sufficiently 
white for the purpose; and in regard to the strong coloured lights, they are also easily procured, either by using transmitted or reflected light of the particular colour wanted. As candles and lamps are always at hand, and solar rays not so, I will here briefly describe the method of shewing any one, and conseguently all, of these beautiful experiments by candle light.

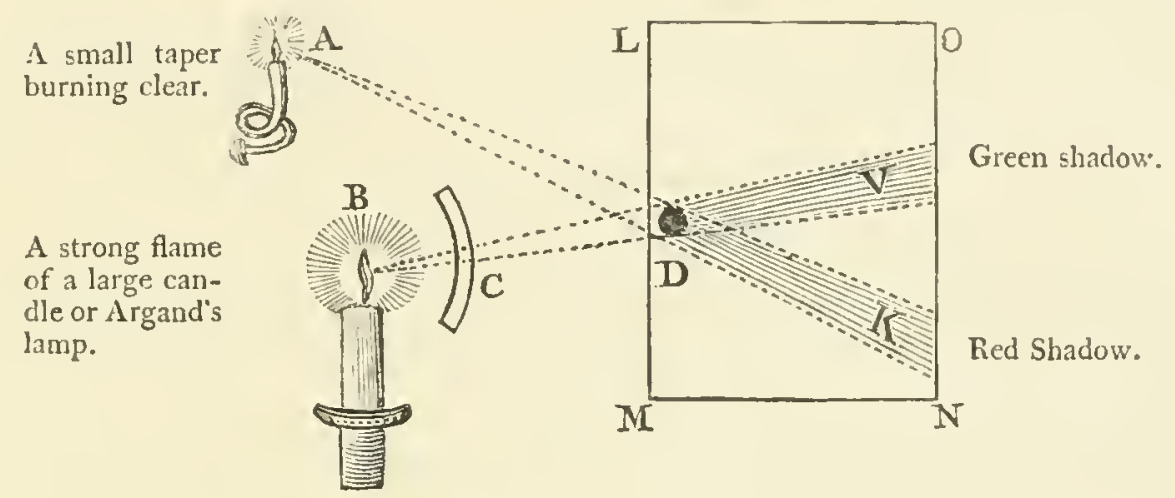

7. L. M. N. O. is a piece of white paper, illumined as in the figure; D. is a small cylinder of wood, as a black lead pencil, or even one's finger, in such a manner, as to produce the respective shadows D.V. and D. K.-C C. being a piece of red glass in this experiment.

S. If instead of red glass, a piece of green glass be placed at C. then the shadow D. V. will no longer be green but of a reddish cast; and so of the rest as mentioned above at Sect. 3.

9. My friend was very desirous that I should endeavour to account for these beautiful and most extraordinary appearances; with this view I first observe, that the burning lights $A$. and $B$. when the experiments are made without daylight, may be reckoned nearly white, particularly if they are made to burn without smoke, though, in reality, they are yellowish, or even orange-coloured sometimes, as is very plain when they are compared with strong daylightit.

10. Secondly, white light is well known to consist of several other colours, as red, orange, yellow, green, blue, purple, and violet: and further, as violets and purples, with all their varieties, may be imitated by miving blue and red in different proportions; and as green also may be compounded in a similar way by mixing blue and yellow; and oranges by mixing red and yellow; we need not attend to more than the three primary colours, red, yellow, and blue; for, in fact, it is found that by mixing these threc colours in certain proportions, a sort of white, or any colour may be 
formed, and there is reason to believe, that if we had colours equal in brilliancy to the prismatic colours, the white so formed would be perfect.

11. This last observation shews us, that white may be considered as made up even of two colours only, and we shall find it very convenient in the cxplanation of the phienomena in question, to consider white as so made up, namely, of red and green, of yellow and purple, or of blue and orange. These colours are called contrasts to each other respectively: their apparent brillianey, when they are placed contiguous to each other, is promoted in a remarkable manner, but they cannot be mixed together without mutual clestruction of their natural properties, and an approach to a white or a grey colour.

12. To understand the experiment above represented on the paper, we are first to consider the nature of the shadow D. V. green as it is in appearance; that is, we are to consider what kind of light or lights can possibly come to this portion of the paper which we call the shadow D. V.; and here it is plain, that this space D. V. is illumined only by the ${ }^{a}$ zohite light (I will call it) which comes from the small taper $A$. directly, and also by a small quantity of white light from B. not directly, but by reflection from the sides of the room, or from other objects. The direct red light coming from B. through the red glass C. is intercepted by D.; and the small quantity of this red light, which can arrive at the spacc DV. by reflection, is not worth mentioning; the green shadow D. V. therefore is illumined by a small quantity of white light, and our business is to explain why it should appear green to the eye.

13. Keep in mind that the idea of a perfect shadow excludes all light, and that the space D. V. is an imperfect shadow, illumined as we have seen with a small portion of white light. Let this small portion of white light be considered as made up of red light and green light, according to what has been stated above in Sect. 12, and the reason of the phænomenon will be readily understood.

For we must now attend to the strong red light which passes through the glass $\mathrm{C}$. and covers the paper every where except in the space D. V. where it is intercepted: the effect of this strong light coning up to the very boundaries of the shadow D. V. is such as to inçapacitate the eye from seeing at the same time the weaker red light contained in the shadow D. V. which we have proved to be really of a weak dull white colour, but which, because its red light cannot be seen, appears green to the eye.

14. This effect of rendering the organs of perception insensible to weaker excitations, by strongly exciting those organs, is analogous to the constitution of the

2 I call it white light because it is nearly so, and because it answers all the purposes of perfectly white light; in such an experiment supposed to be made in a room without daylight. When actually compared with daylight, it is found to be yellowish, or even orange coloured. 
human frame in many instances. Accustom the eye either to much light, or to intense colours, and for a time it will hardly discern any thing by a dull light, or by feeble colours, provided the feeble colours be of the same kind with the previous strong ones. Thus, after it has been excited by an intense red, for example, it will for a time be insensible to weak red colours, yet it will still easily perceive a weak green, or blue, \&c. as in the instance before us respecting the shatow D. V. where the green part of the compound still affects the eye, after the red has ceased to produce any effect, owing to the previous excitation of a stronger red. ${ }^{b}$

15. Nor is this the case only witls the eye, it is the same with every other sense; precise instances of this kind in regard to the taste, the smell, the touch, \&c. will occur plentifully to every one.

16. I consider this solution of the appearances of the colours as perfectly satisfactory. Here it is applied only to one instance, but it is equally applicable to all the rest; and it appears to me to account for all the difficulties which seem to have embarrassed Count Rumford, in his very ingenious and entertaining paper, Phil. Trans. 1794, p. 107. Also in Dr. Priestley's History of Optics, p. 436, there is a curious Chapter, containing the observations of philosophers on blue and green shadows; the true cause of these shadows is not, I think, there mentioned; and it may be entertainhng to read that Chapter with these principles in the mincl.

17. When the sun has been near setting in a summer eveniug, I have often observed most beautiful blue shadows upon a white marble chimney-piece. In this casc, the weak white light of the evening which illumines the shaded part of the marble, is to be considered as compounded of two colours, orange and blue. The direct orange rays of the sun at this time, render the orange part invisible, and leave the blue in perfection.

18. And in the same way is to be explained that beautiful and easy experiment mentioned by Count liumford, p. 103. Phil. Traus. 179t, where a burning candle in

b This distinction should always be kept in mind, for unless the eye has been absolutely injured or weakened by excessive excitation, there is reason to believe that strong excitations of it, whether immediately preceding weaker ones, or contemporaneous with them, much improve its sensibility in regard to those weaker ones, provided only that they be of a different class. If the eye has been excited by a lively red colour, it will scarcely perceive a weak red, but it will perceive a weak green much better on account of the previous excitation by the strong red; and the reason may be, that in looking at a red colour, the eye wastes none of that nervous sensibility which is necessary for its seeing a green colour; and the same reasoning holds in all other cases where the colours are contrasts to each other. For such colours seem incapable of mixing with each other, in the proper sense of the word, as when red and yellow are mixed together, and produce a compound evidently partaking of the obvious properiles of the two ingredients. When contrasts are mixed together, as red and green, these colours seem destructive of each other, and effect a compound approaching to whiteness. Similar observations may be made on the other senses. 
the day-time produces two shadows, and one of them of a most beautiful blue colour. The experinent is the more valuable, as it may be made at any time of the day with a burning candle. Amost darken a room, and then by means of a lighted eandle and a little day-light, produce two shadows of any small object, as of a pencil, \&c. one from the candle, and another from the day-light received at a small opening of one of the window-shutters; the light of the candle will appear orange-coloured in the day-time, and so will that shadow of the body which belongs to, or is unade by the day-light; but the shadow of the body made by the candle, will surprise any person, by being of a fine blue.

19. More than once I have becn agreeably struck with this appearance produced unintentionally when I have been writing by candle-light in a winter's morning; upon the day-light being let in, the shadow of my pen and fingers in the orange-light of the candle, were beautifully bluc.

20. I suppose there is such a thing as the harmony of colours, of which painters speak so much; according to the explanation here given, our key to the solution of every case of harmony and of contrast, is to consider what is the other colour, simple or compound, which, joined to a given one simple or compound, will constitute white. Thus red, requires green; yellow, purple; blue, orange; and vice versâ, the mixtures in proper proportions will be white.

21. Sir Isaac Newton (Prop. 6. part. 2. of book i. Opties.) has given a methorl for judging of the colour of the compound in any known mixture of primary colours, but it is not easy, even for mathematicians, to put his rules in practice. The gentleman who consulted me on this sulject of shadows, has becn accustomed, for a long time, to assist his memory when he is painting by the use of the following simple diagram. Let R.Y.B. represent the three uncompounded colours, red, yellow, blue; and let O.G. P. represent the compounds, orange, green, purple. It is evident, that to make a deeper orange, we must add more red; and to make a bluer green, we must add more blue; and to make the purple redler, we must add more red, and vice rersâ: but besides this, the diagram puts us in mind that $\mathrm{G}$. is the contrast to $\mathrm{R}$. and that therefore those two colours cannot be mixed withont approaching to a dull whiteness or greyness; and the same may be said of $Y$. and $P$. and of $B$. and $O$.; these colours are also contrasts to each other, by nixture they destroy each other, and produce a whiteness, or greyness, according as they are more or less perfect, but when kept distinct, they are found to make each other look more brilliant by being brought elose together, and all this is agreeable to what is said in sect. 11. and in the Note to Sect. 14.

22. Sir Isac Newton observes, that he had never been able to produce a perfect white by the mixture of only two primary colours, and seems to doubt whether sueh a white can be compounded even of three. IIe tells us, that one part of red lead, 
and five parts of verdigris, composed a dun colour like that of a mouse; but there is nothing in all this which militates against the explanation here given of the cause of the coloured shadows of bodies; for even supposing that there did not exist in nature any two bodies of such colours as to form perfect whiteness by their mixture; or, to go still further, supposing that no two prismatic colours of the sun could form a compound perfectly white; still the facts and reasonings here stated respecting the mixtures of such colours as are called contrasts, are so near the truth, that they furnish a satisfactory account of the appearances of the colours of the shadows which we have been considering. The terms by which we are accustomed to denominate colours, have not a very accurate or precise meaning, and particularly those terms which denote colours that are known to be mixtures of others, as green, purple, and orange: neither the prismatic green, nor the colour of any known green body, may, perlaps, combine with red so as to make actually an accurate white, and yet the existence or composition of such a green may not be impossible. The philosophical reader will clearly perceive, that no argument of any weight can be drawn from considerations of this sort against this theory of coloured shadows.

23. Every one knows that red colours and yellow colours mixed together, in different proportions, produce orange colours of various kinds; also that reds and blues produce purples and violets; and, lastly, that blues and yellows produce greens in great variety; but it is not so generally known that green, purple, and orange colours, are as it were almost annihilated by mixture, and much improved by contiguity with red, yellow, and blue colours respectively.

The little diagram suggests all these things to the memory, and a great many more of the same kind, and, therefore, must be extremely useful to the artist who is endeavouring to produce certain cffects by contrast, harmony, \&c. but it should always be carefully remembered, that it contributes nothing to the proof of any of the truths here advanced; the proof rests upon the reasons given for each of them respectively."

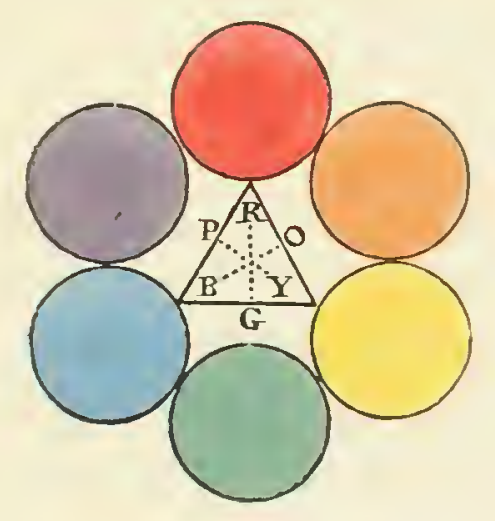


This curious and satisfactory theory demonstrates that the choice of colours which so often distinguishes good from bad taste in manufactures, furniture, dress, and in every circumstance where colour may be artificially introduced, is not the effect of chance, or fancy, but guided by certain general laws of NATURE.

Sir Isaac Newton discovered a wonderful coincidence between sound and colours, and proves mathematically, that the spaces occupied by the colours in the prismatic spectrum correspond with the parts of a musical chord, when it is so divided as to sound the notes of an octave. So this resemblance may now be considered as extending further, for as in music, so likewise in colours, it will be found that harmony consists in distance and contrast, not in similitude or approximation. Two notes near each other, are grating to the ear, and called discords; in like manner, two colours very near each other, are unpleasing to the sight, and may be called discordant; this maybe proved by covering all the colours in the preceding diagram except the two adjoining, which, in every part of the scale, will appear discordant; while, on the contrary, if the two sides be covered in any direction so as only to shew the two opposite colours, they will appear in perfect harmony with each other; and this experiment confirms the good taste of those who, in the choice of colours, oppose reds to greens, yellows to purples, and blues to oranges, \&c. But if instead of contrasting these colours, they are mixed, or so blended, as not to appear each distinctly, as in silks or linens where the stripes are too narrow; when seen at a little distance instead of relieving, they will destroy each other. In the application of this theory to some familiar instances, particularly in the furniture of rooms, I have observed that two colours here deemed 
discordant, may be used without offending the eye, as green and blue, or green and yellow; but I have alvays considered such assortment intolerable, unless one were very dark, and the other very light; and thus the effect is again produced by contrast, although on a different principle; it is the contrast, not between colours, but between light and darliness.

So far this theory is perfectly satisfactory with respect to works of Art, but when carried to those of Nature, I confess my inability to reconcile a conviction of its truth, with certain appearances which seem to contradict it.

By the mniversal consent of all who have considered the harmony of colours, it is allowed that in works of art, the juxta position of bright blues and greens is discordant to the eye, and the reason of this discordance has been shewn by the foregoing remarks. Yet these are the two prevailing colours in nature; and no person ever objected to the want of harmony in a natural landscape, because the sky was blue, and the surface of the earth covered with greens, except he viewed it with a painter's eye, and considered the dificulty, or even impossibility, of exciting the same pleasurable sensations by transfering these colours to his canvass; the only way in which I can solve this seeming paradox, is by observing, that the works of nature, and those of art, must ever be placed at an immeasurable distance, from the different scale of their proportions; and whether we compare the greater efforts of man, with the system in which the world he inhabits forms but an inconsiderable speck; or the most exquisite miniature of mechanism with the organs of sense and motion in an insect, we must equally feel the deficiency of comparison, the incompetency of imitation, 
and the imperfection of all human system. Yet while lost in wonder and anazement, the man of taste, and the true philosopher, will feel such agreement existing in the laws of nature as can only be the consequence of Infinite Wisdom and Design; while to the sceptic, whether in moral or in natural philosophy, the best answer will be in the words of the poet:

"All nature is but art, unknown to thee;

"All chance, direction which thou canst not see;

"All discord, harmony not understood;

"All partial evil, universal good." 


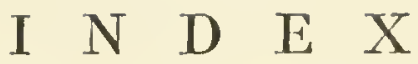

OF THE

\section{SUBJECTS CONTAINED IN EACI CHAPTER.}

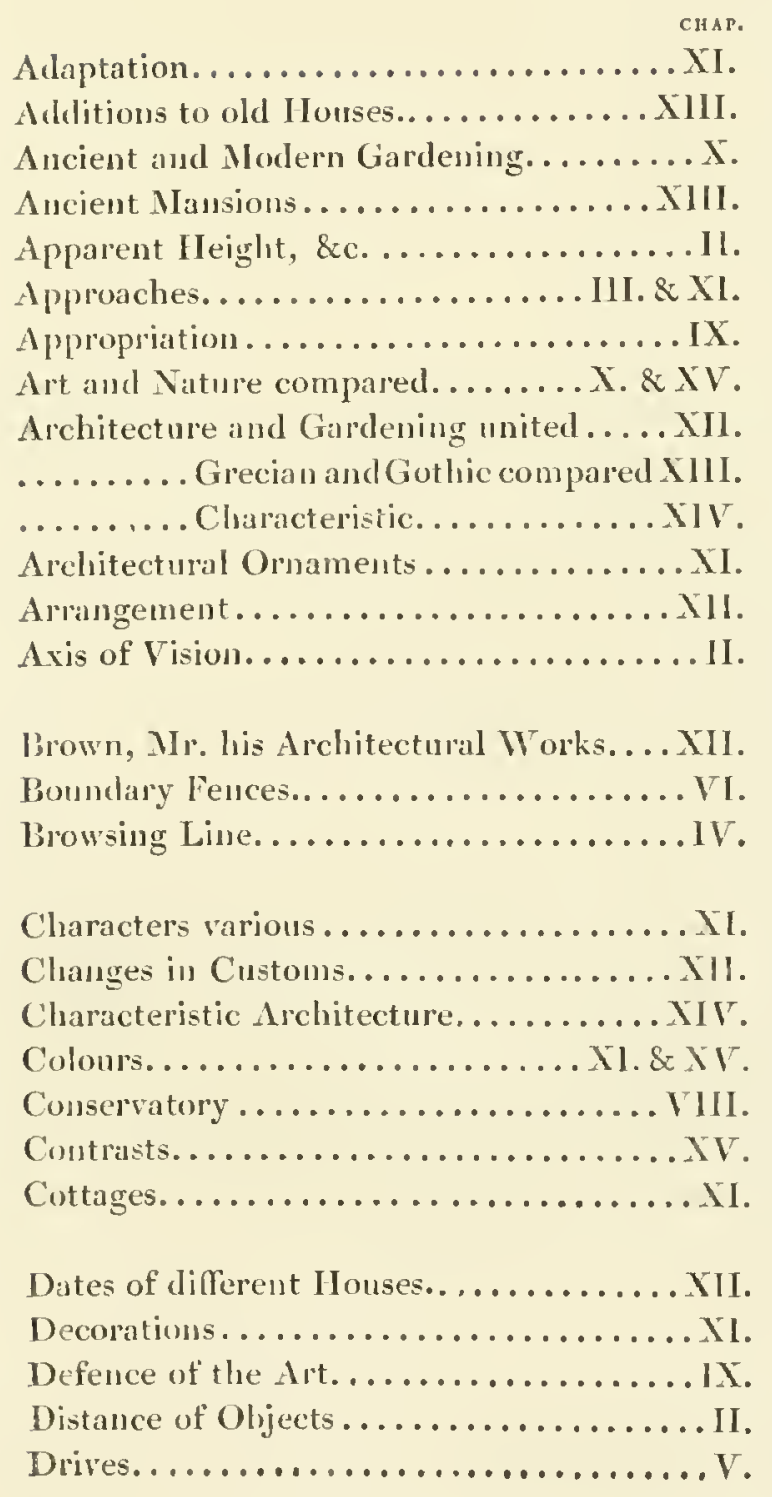

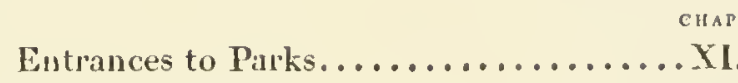

Extent of Ground..................

Estent of Building................ $1 \mathrm{~V}$.

Farms................. VII. \& XII.

Ferry Boat....................

Fences......................... VI.

First Impressions ..............

Field of Vision ..................

Flower Gardens................ VIll.

Formation of new Place............ XIV.

Gates.............................

Gothic Buildings............ XI. \& XIll!.

Grecian Houses.................. XIT.

Green Houses.................. VIII.

Ground....................... \& \& II.

Harmony of Colours............... XV.

Height of Objects................... II.

Home Farm...................

Interior, how far Gothic...........XIV.

Kitchen Garden................. XII.

Light different................... II.

Lines......................... VI.

Metals...................... XI.

Motion of Water.................. 
Oruamental Buildings..............

Ornanents and Decorations...........XI.

Park and Farm distinct.

Perspective Elfects............. \& \& XIII.

Pictures and Painting.................

Plans of extended or contracted Houses. . XII.

Planting...

Pleasure Ground................. VIII.

Reflexions from Water...............II.

Removing Earth......................

Roads altered......................

Rock Scenery....................III.
Scale of Proportions................ Symmetry................... XIV.

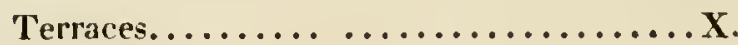

Thimning Woods.................. Treillage, or 'Trellis ................

Utility.....................

Variety of Situations ..............XI.

Vision, or Optics................. II.

Water....................... III,

Woods.........................

\section{LIST OF PLATES.}

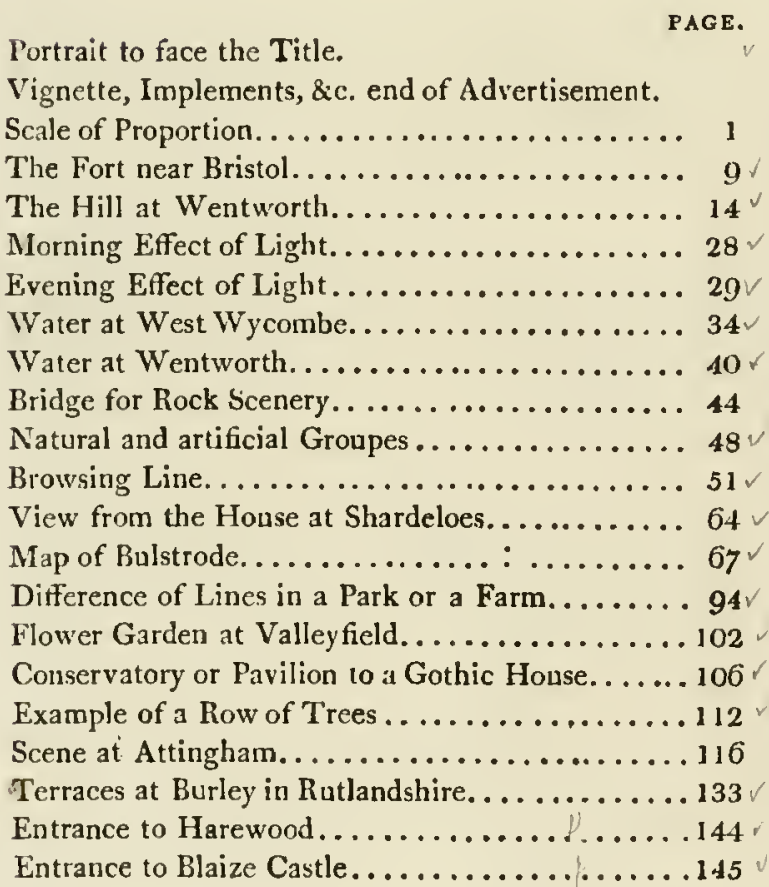

Doric Portico at Stoke Park.

Doric Portico at Stoke Park... ............. 149

Gothic Cottage....................... 151

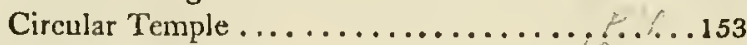

Cottage at Blaize Castle . . . . . . . . . . . 155

Treillage Greenhouse.................. 157

Cottage at Langley Park. ............... 162

Plans of Houses of various Dates ............ 171

Michel Grove. ....................... 179

Plan of an extended House............... 182

Plan of a compact House. . . . . . . . . . . . 186

Corsham House. . . . . . . . . . . . . . . . . 188

Port Eliot........................ 192

Asbton Court. This Plate was finished with the approbation of the Proprietor before $I{ }_{200}$ learned that the alterations here shewn will not 200 immediately be carried into execution. .......

Map of Bayham. . . . . . . . . . . . . . . 1 . . 203

General View of Bayham ...............208

Ground Plan proposed for a Gothic Mansion.... . .209

A Gothic Hall of Entrance...............212

Diagram to explain the Harmony of Colours.... . 219 



